\title{
Synthesis of Tetra-ortho-Substituted, Phosphorus- Containing and Carbonyl-Containing Biaryls Utilizing a Diels-Alder Approach
}

\author{
Bradley O. Ashburn and Rich G. Carter* and Lev N. Zakharov \\ Department of Chemistry, Oregon State University, Corvallis, OR 97331.
}

Electronic Supplementary Information: Spectral Data 
Table of Contents

\begin{tabular}{|c|c|}
\hline $\begin{array}{c}\text { Compound } \\
\#\end{array}$ & $\begin{array}{c}\text { Page } \\
\text { Number }\end{array}$ \\
\hline 1 & S3 \\
\hline $2 \mathrm{a}$ & $\mathrm{S} 5$ \\
\hline $2 \mathrm{~b}$ & $\mathrm{~S} 7$ \\
\hline $5 \mathrm{a}$ & $\mathrm{S} 9$ \\
\hline $5 \mathrm{~b}$ & $\mathrm{~S} 11$ \\
\hline 6 & $\mathrm{~S} 13$ \\
\hline 10 & $\mathrm{~S} 15$ \\
\hline 12 & $\mathrm{~S} 17$ \\
\hline $13 \mathrm{a}$ & $\mathrm{S} 19$ \\
\hline $13 \mathrm{~b}$ & $\mathrm{~S} 21$ \\
\hline $13 \mathrm{c}$ & $\mathrm{S} 23$ \\
\hline $54 \mathrm{a}$ & $\mathrm{S} 25$ \\
\hline $54 \mathrm{~b}$ & $\mathrm{~S} 27$ \\
\hline $54 \mathrm{c}$ & $\mathrm{S} 29$ \\
\hline $14 \mathrm{a}$ & $\mathrm{S} 31$ \\
\hline $14 \mathrm{~b}$ & $\mathrm{~S} 33$ \\
\hline $14 \mathrm{c}$ & $\mathrm{S} 35$ \\
\hline $16 \mathrm{a}$ & $\mathrm{S} 37$ \\
\hline $16 \mathrm{~b}$ & $\mathrm{~S} 39$ \\
\hline $16 \mathrm{c}$ & $\mathrm{S} 41$ \\
\hline $18 \mathrm{a}$ & $\mathrm{S} 43$ \\
\hline $18 \mathrm{~b}$ & $\mathrm{~S} 45$ \\
\hline $18 \mathrm{c}$ & $\mathrm{S} 47$ \\
\hline $20 \mathrm{a}$ & $\mathrm{S} 49$ \\
\hline $20 \mathrm{~b}$ & $\mathrm{~S} 51$ \\
\hline $20 \mathrm{c}$ & $\mathrm{S} 53$ \\
\hline 21 & $\mathrm{~S} 55$ \\
\hline $27 \mathrm{a}$ & $\mathrm{S} 57$ \\
\hline $27 \mathrm{~b}$ & $\mathrm{~S} 59$ \\
\hline $27 \mathrm{c}$ & $\mathrm{S} 61$ \\
\hline $28 \mathrm{a}$ & $\mathrm{S} 63$ \\
\hline $28 \mathrm{~b}$ & $\mathrm{~S} 65$ \\
\hline $28 \mathrm{~d}$ & $\mathrm{~S} 67$ \\
\hline $28 \mathrm{e}$ & $\mathrm{S} 69$ \\
\hline $28 \mathrm{f}$ & $\mathrm{S} 71$ \\
\hline 29 & $\mathrm{~S} 73$ \\
\hline 30 & $\mathrm{~S} 75$ \\
\hline & \\
\hline & \\
\hline & \\
\hline & \\
\hline & \\
\hline & \\
\hline & \\
\hline
\end{tabular}

\begin{tabular}{|c|c|}
\hline $\begin{array}{c}\text { Compound } \\
\#\end{array}$ & $\begin{array}{c}\text { Page } \\
\text { Number }\end{array}$ \\
\hline 32 & S77 \\
\hline 34 & S79 \\
\hline 37 & S81 \\
\hline 42 & S83 \\
\hline 44 & S85 \\
\hline $45 \mathrm{a}$ & S87 \\
\hline $45 b$ & S89 \\
\hline $45 \mathrm{c}$ & S91 \\
\hline $45 \mathrm{~d}$ & S93 \\
\hline $45 \mathrm{e}$ & S95 \\
\hline $45 \mathrm{f}$ & S97 \\
\hline $45 \mathrm{~g}$ & S99 \\
\hline $45 \mathrm{~h}$ & S101 \\
\hline $45 \mathrm{i}$ & S103 \\
\hline $45 \mathrm{j}$ & S105 \\
\hline $45 \mathrm{k}$ & S107 \\
\hline 451 & S109 \\
\hline $47 \mathrm{a}$ & S111 \\
\hline $47 \mathrm{~b}$ & S113 \\
\hline $47 \mathrm{c}$ & S115 \\
\hline $47 \mathrm{~d}$ & S117 \\
\hline $47 \mathrm{e}$ & S119 \\
\hline $47 \mathrm{f}$ & S121 \\
\hline $47 \mathrm{~h}$ & S123 \\
\hline $47 \mathrm{i}$ & S125 \\
\hline $47 j$ & S127 \\
\hline 49 & S129 \\
\hline 50 & S131 \\
\hline 52 & S133 \\
\hline 53 & S135 \\
\hline 54-(aS) & S137 \\
\hline 54-(aR) & S139 \\
\hline 55 & S141 \\
\hline 56 & S143 \\
\hline 57 & S145 \\
\hline 58 & S147 \\
\hline
\end{tabular}




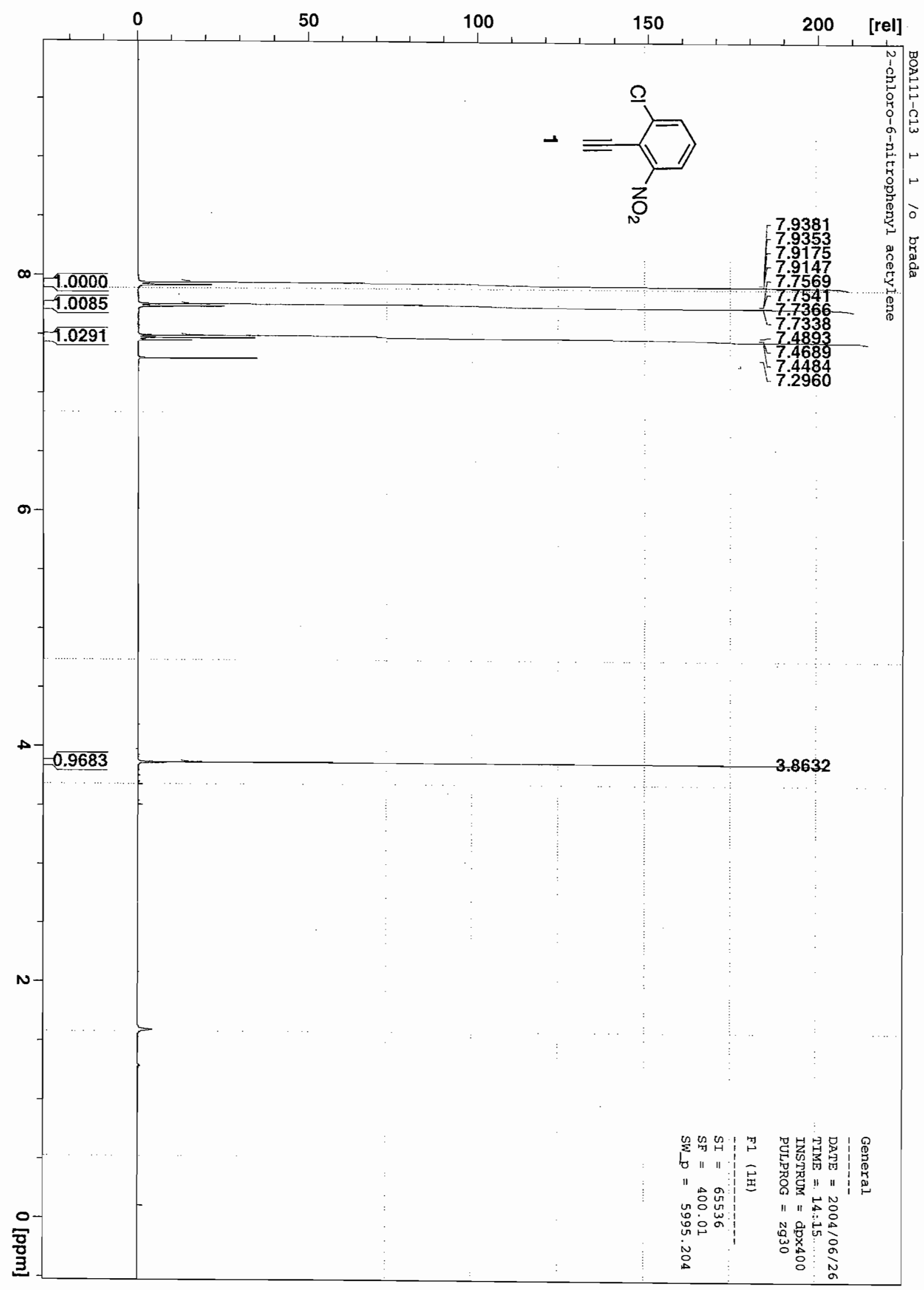




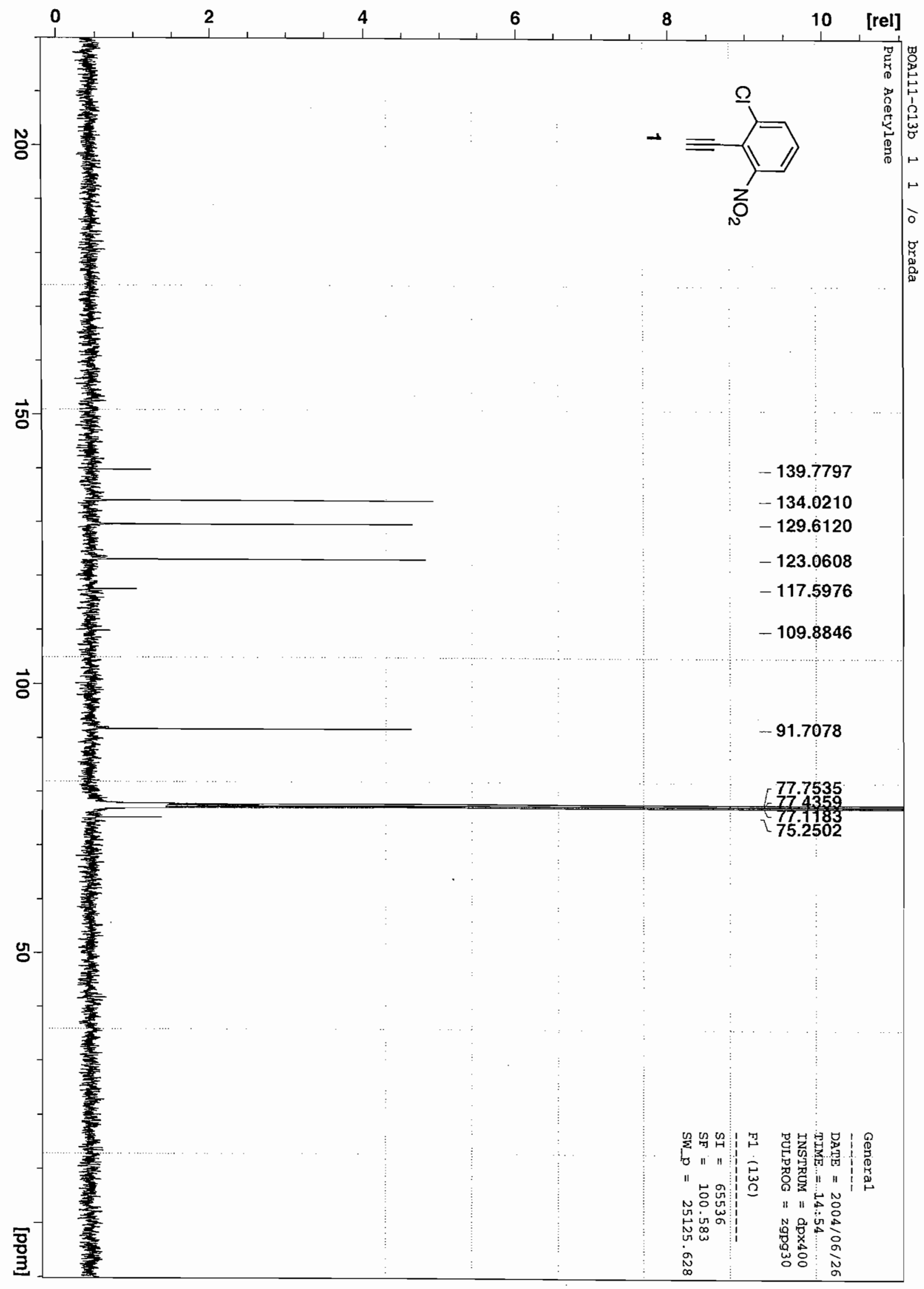



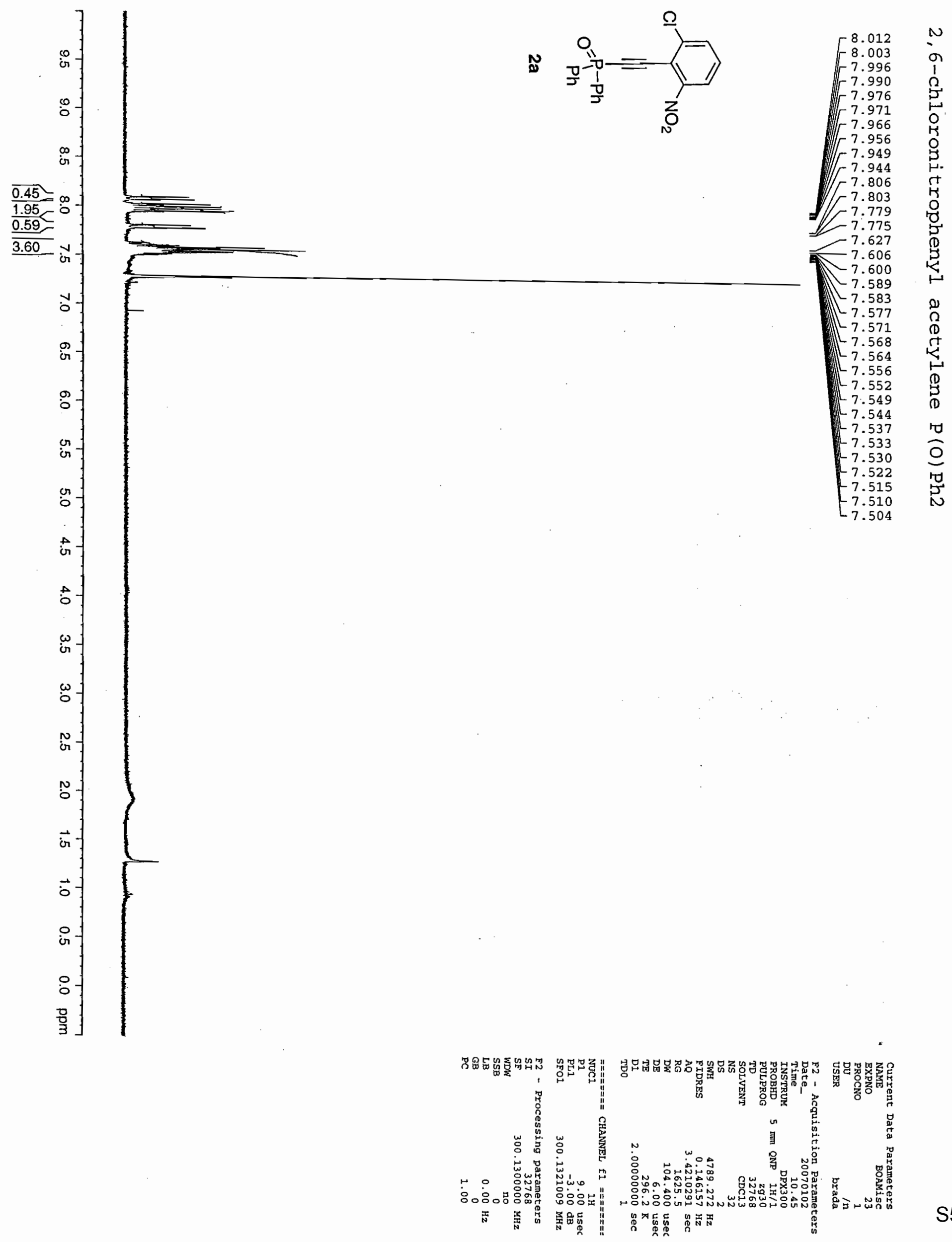


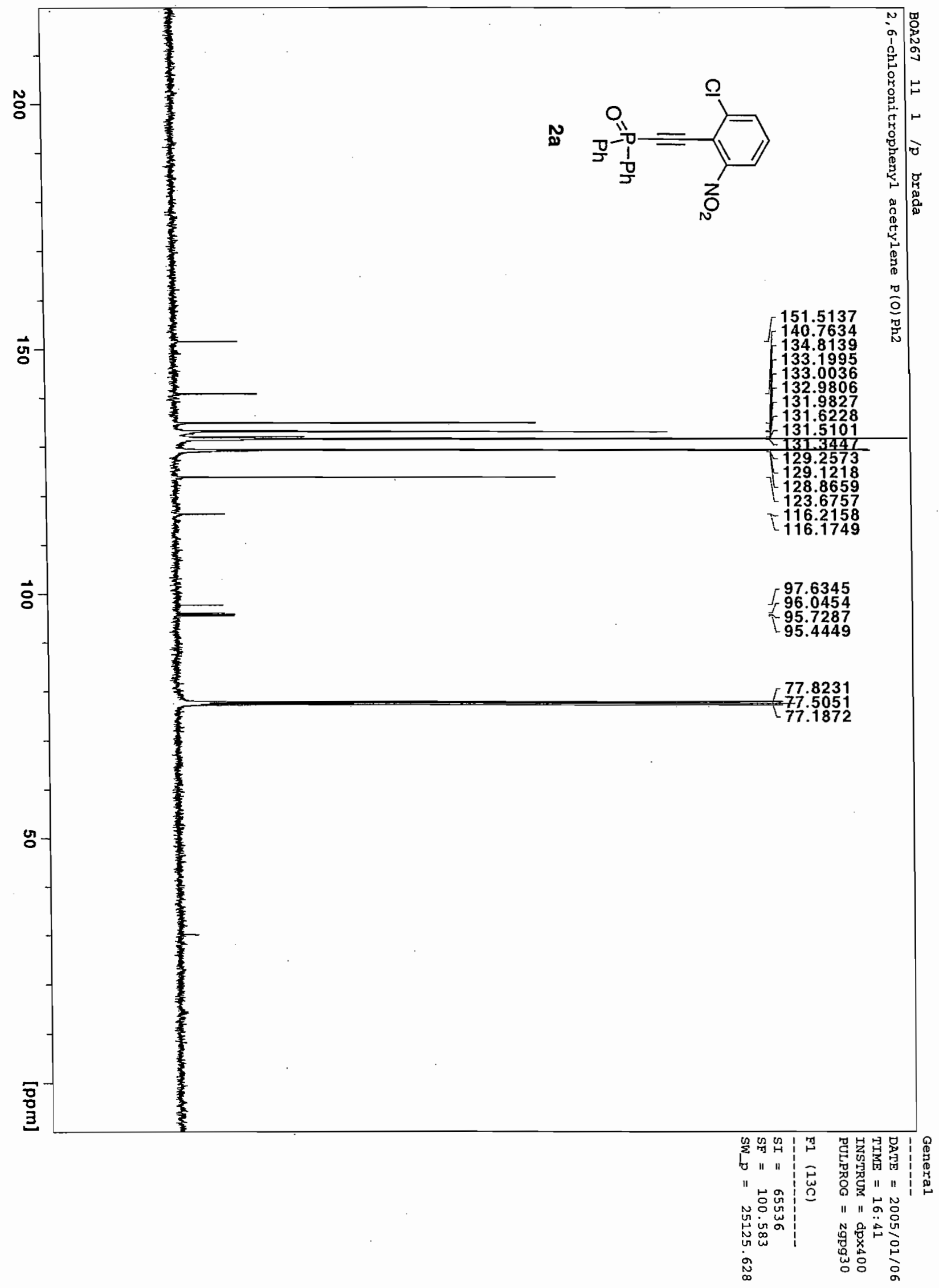



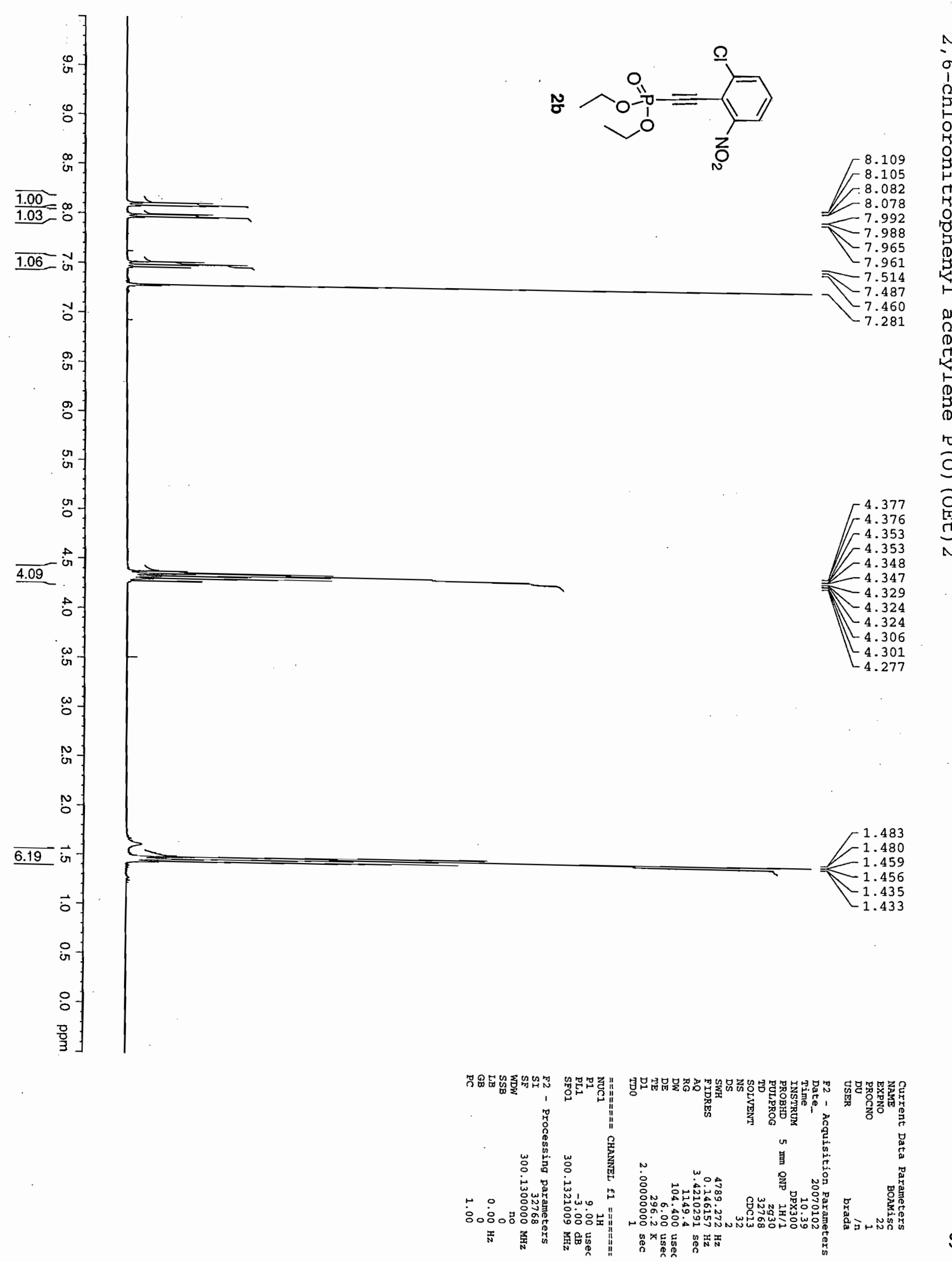


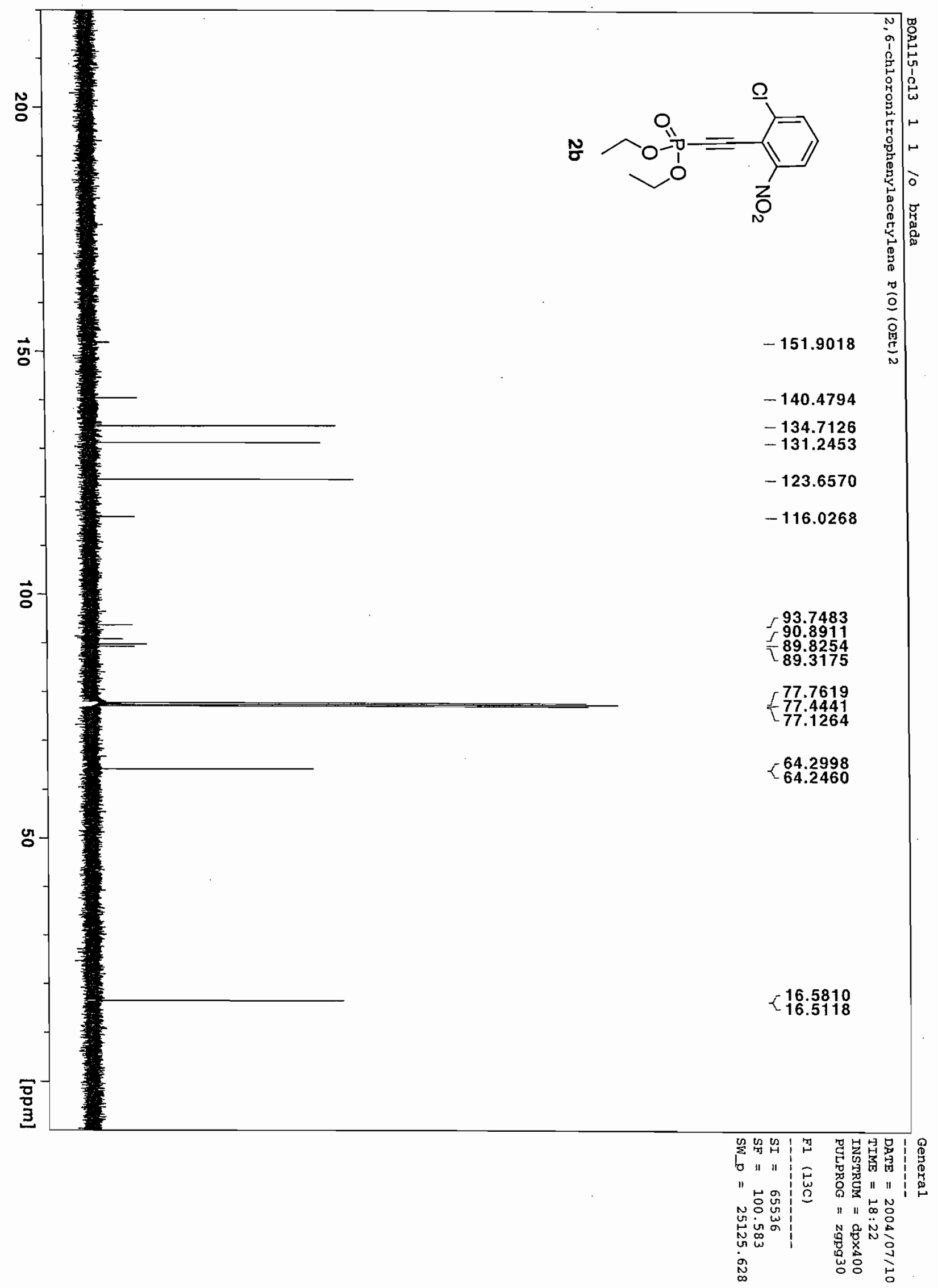



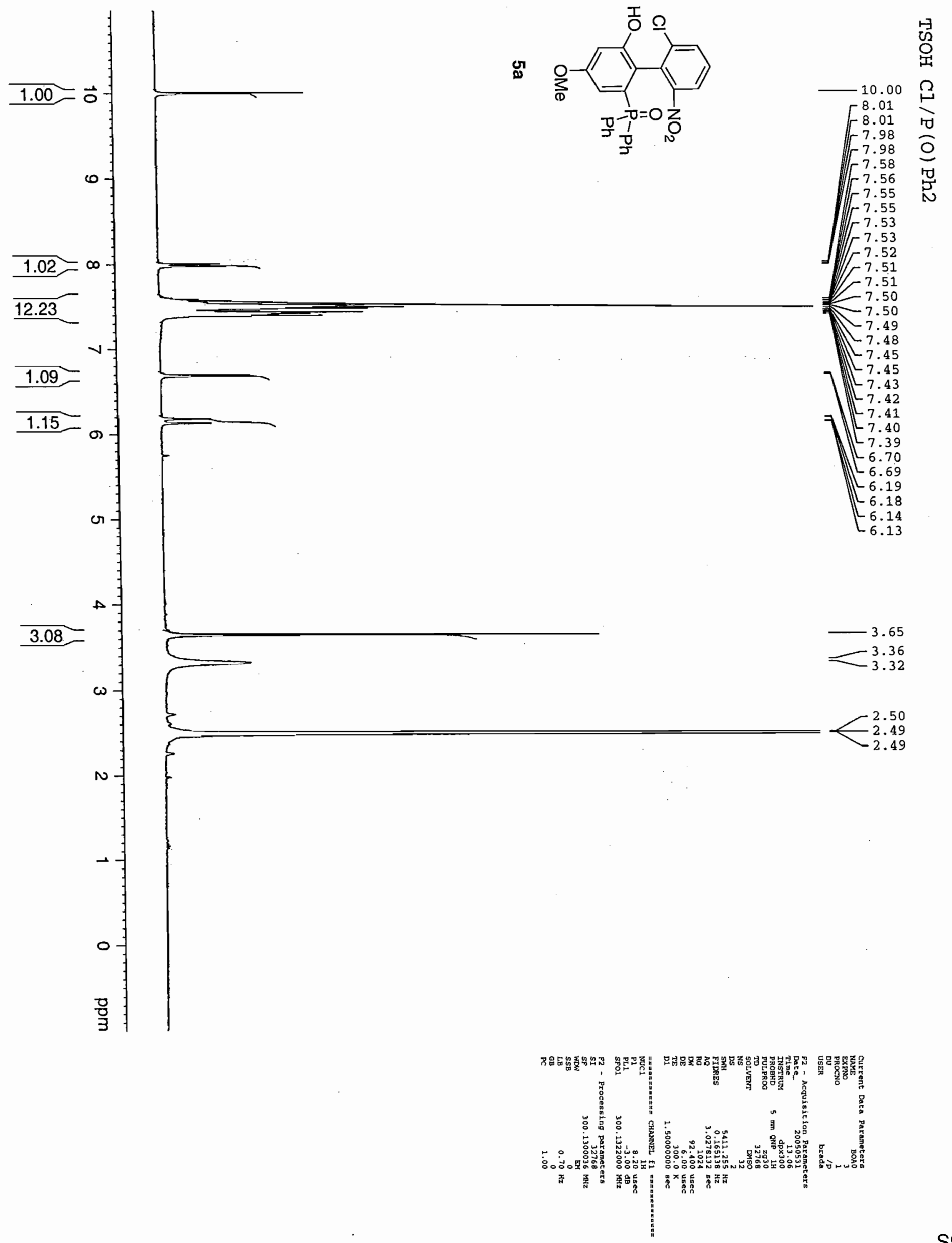


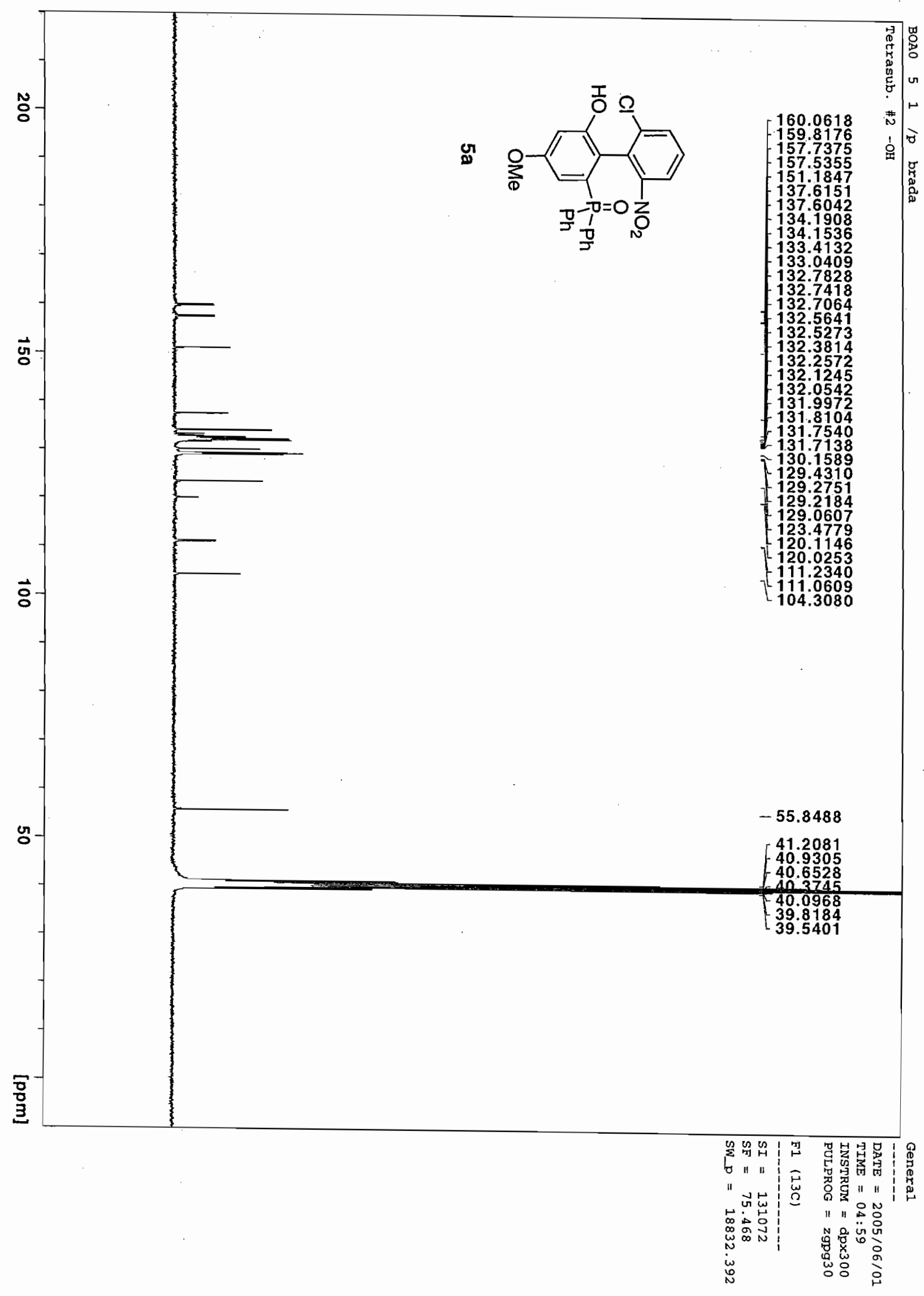



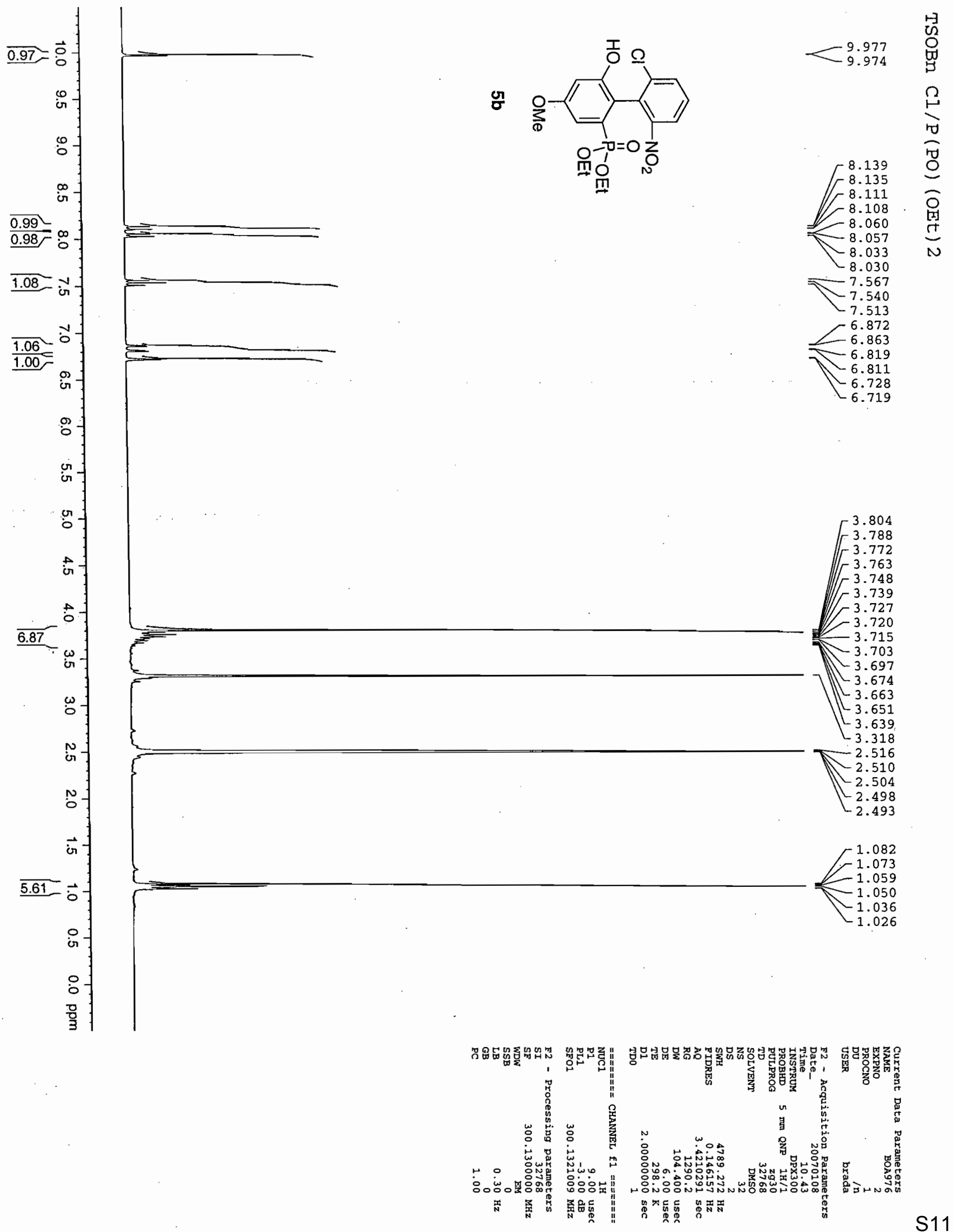


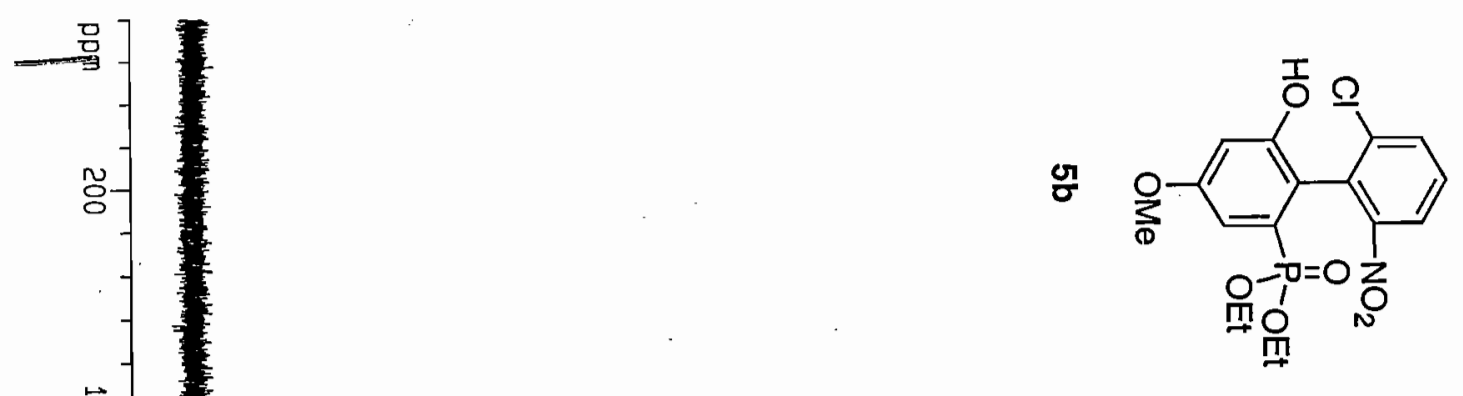

ข

ㅂ.

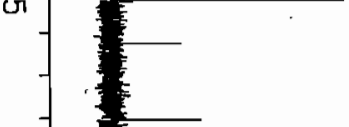

s

ज-
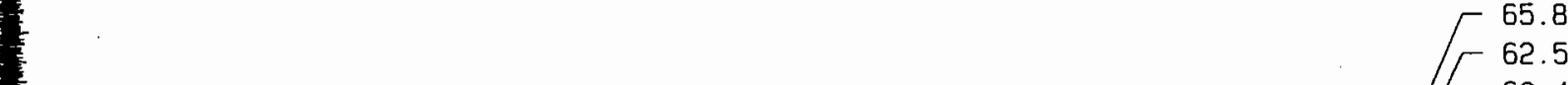

r 62.5

$-62.4$

- 62.4

- 62.4

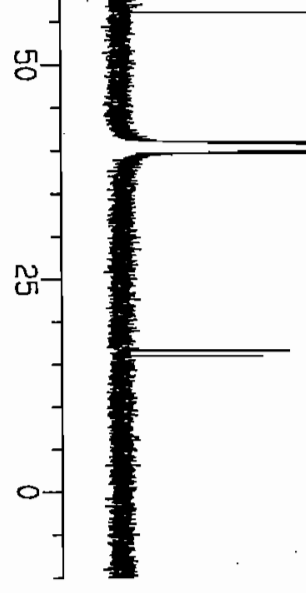

56.1

$-41.0$

$-40.8$

$-40.6$

40.4

$-40.2$

$-40.0$

$-39.8$

16.8

16.7

$-16.7$

16.7

$-16.1$

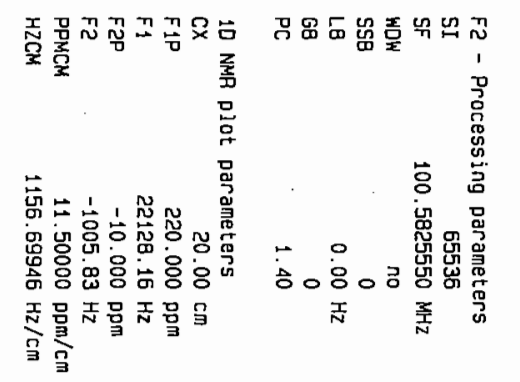

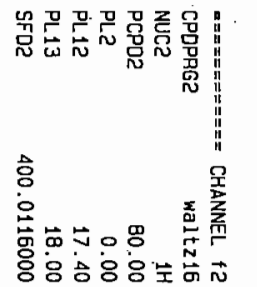

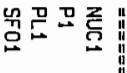

品品

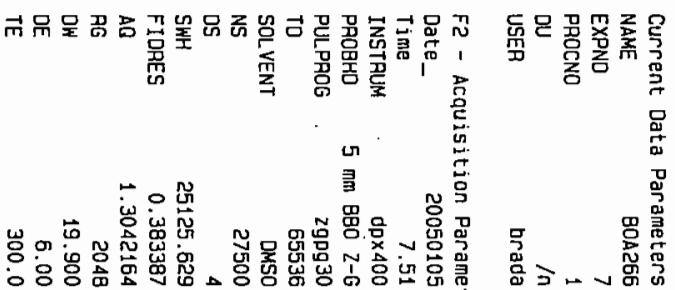

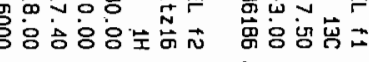

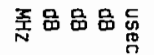

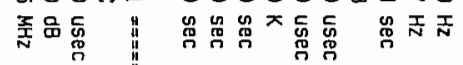




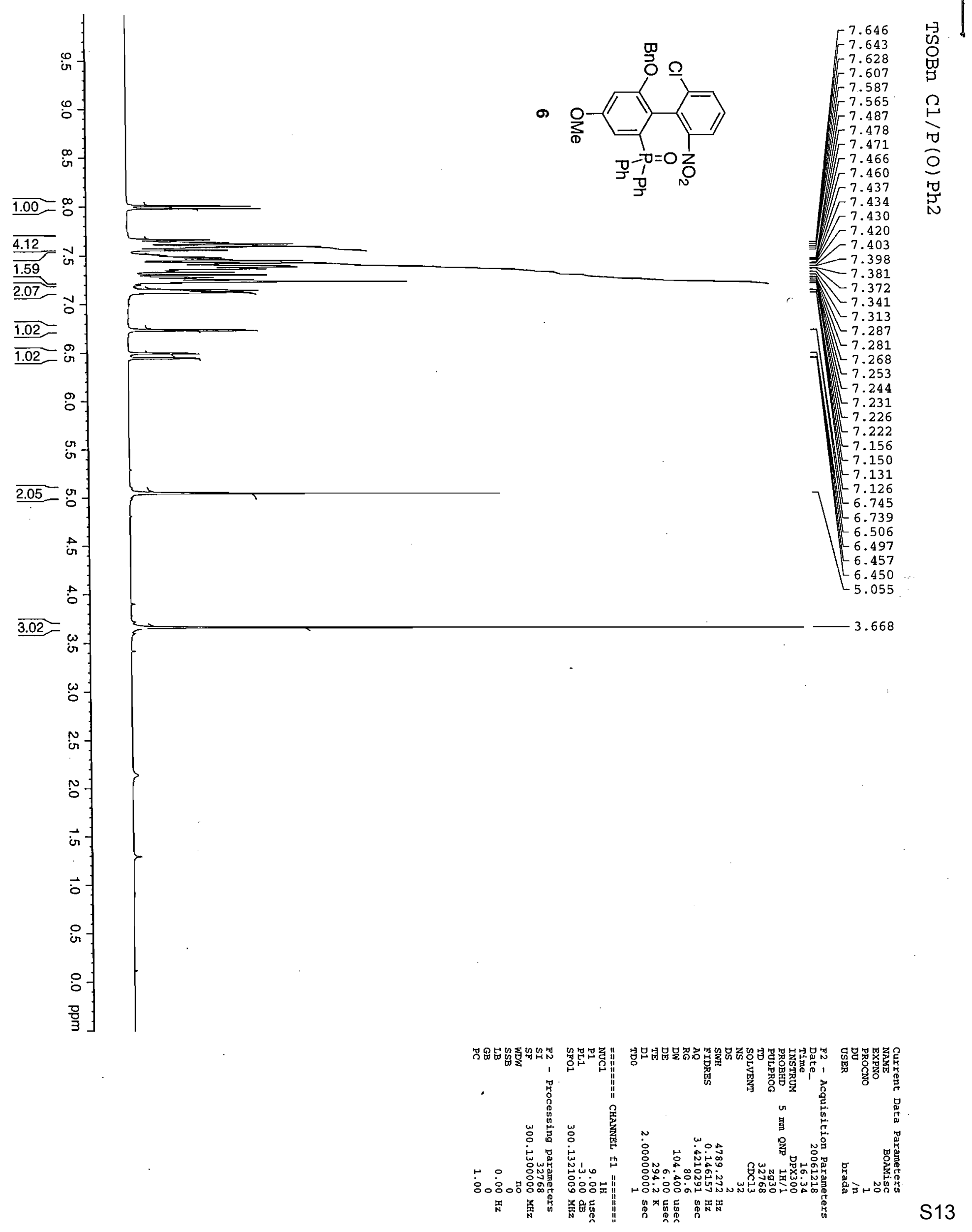



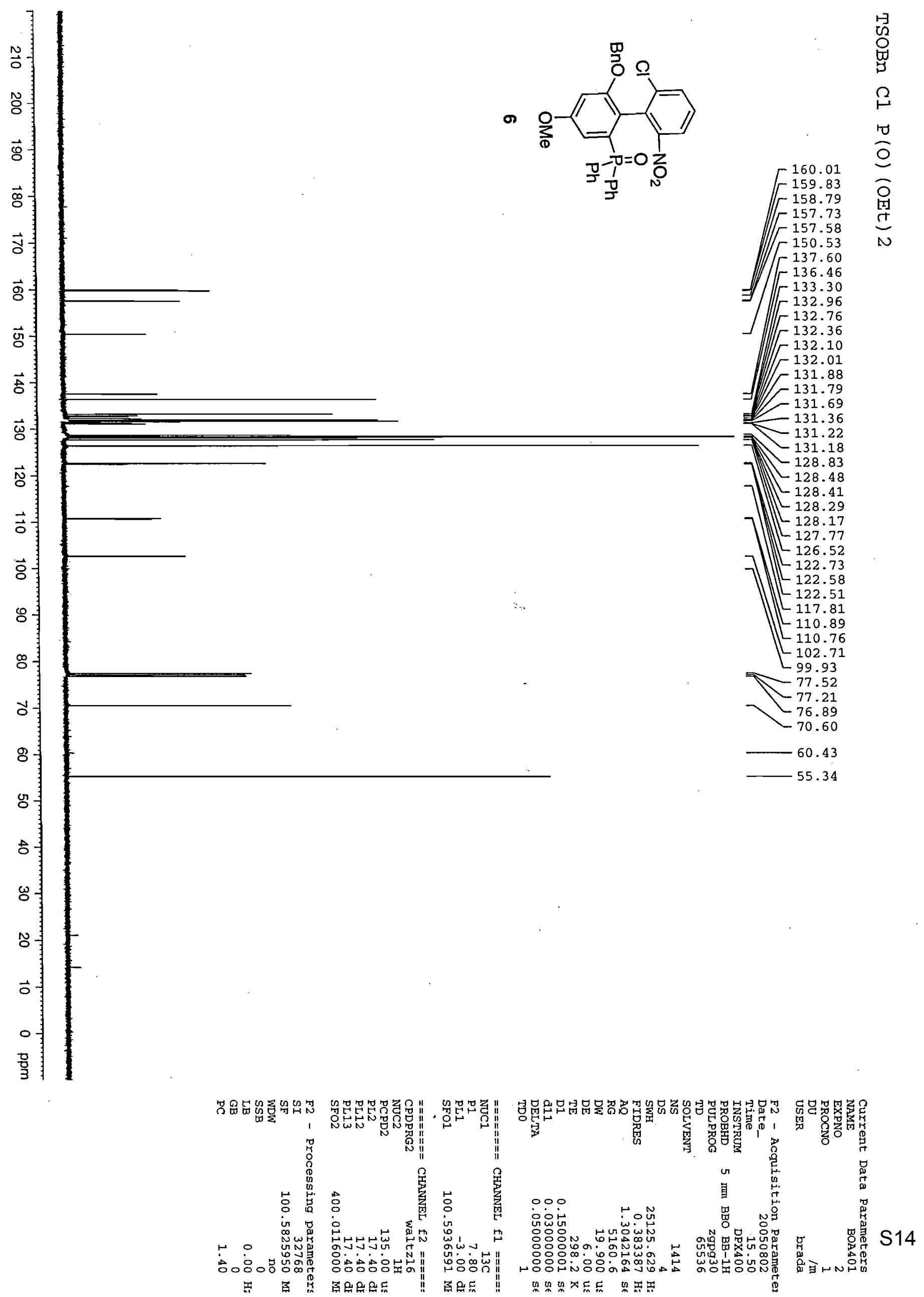

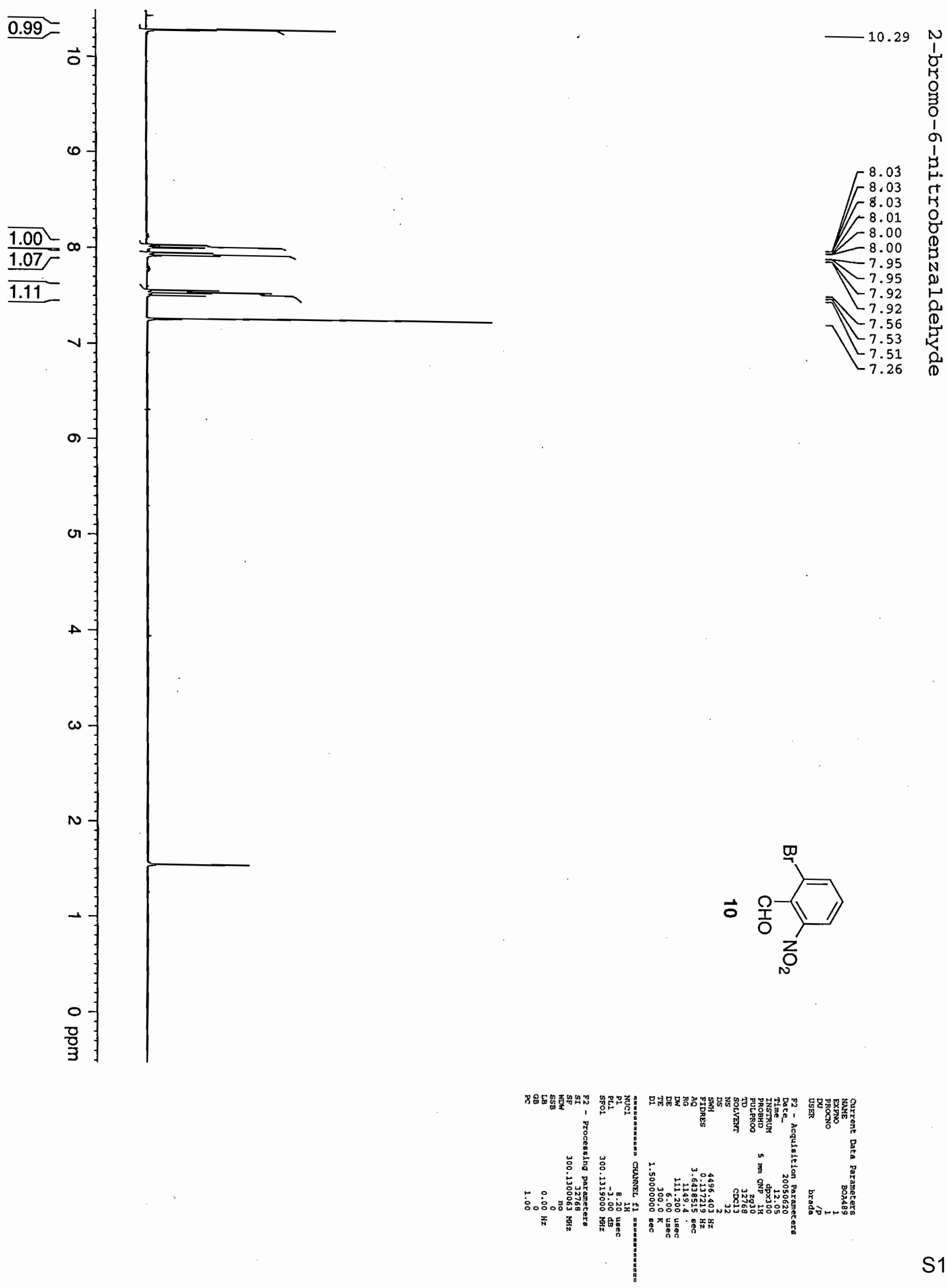


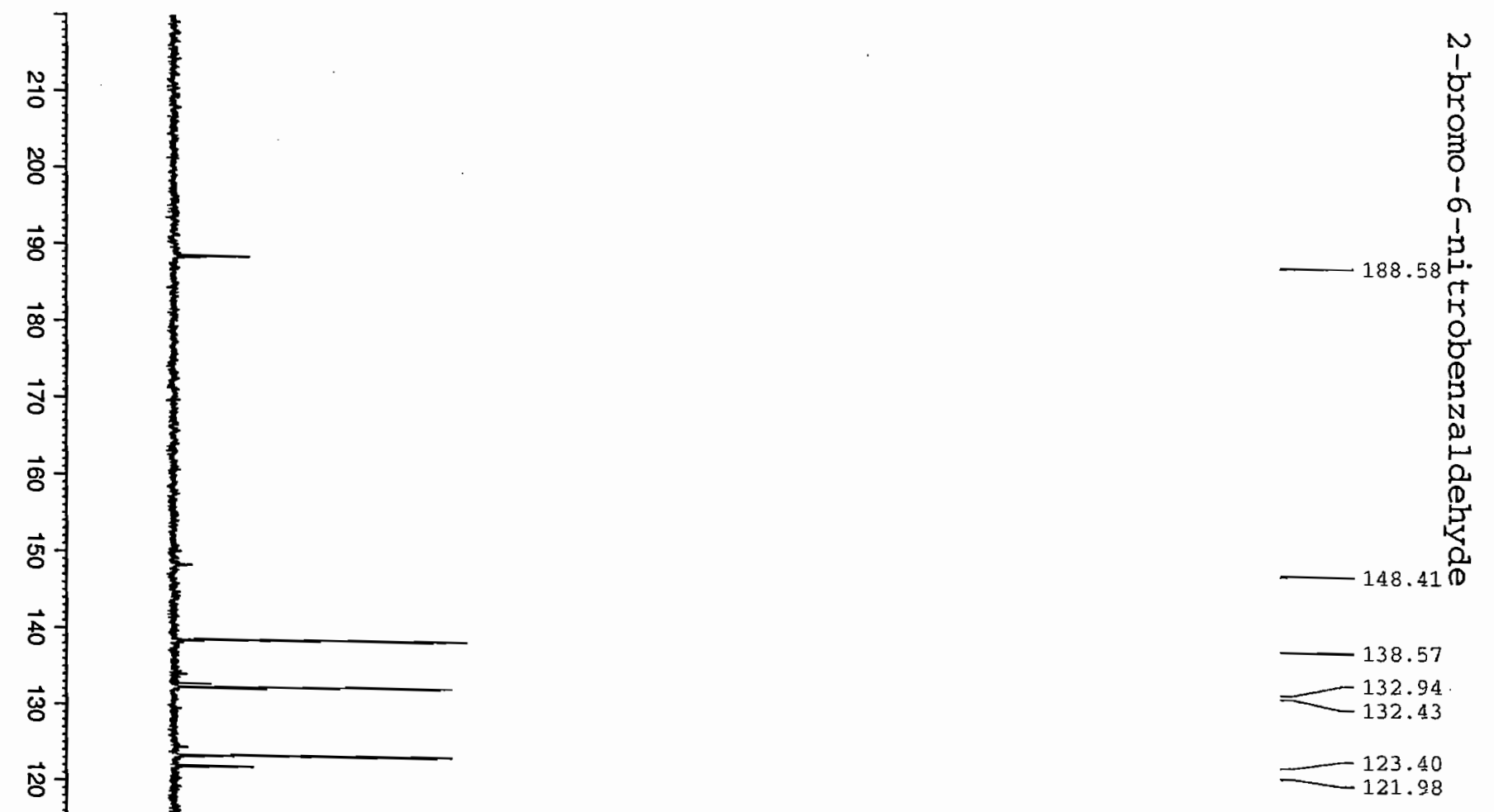

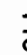

홍

$\mathscr{8}$

8

ช

8

on

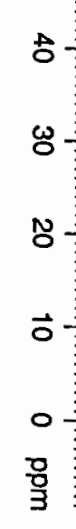
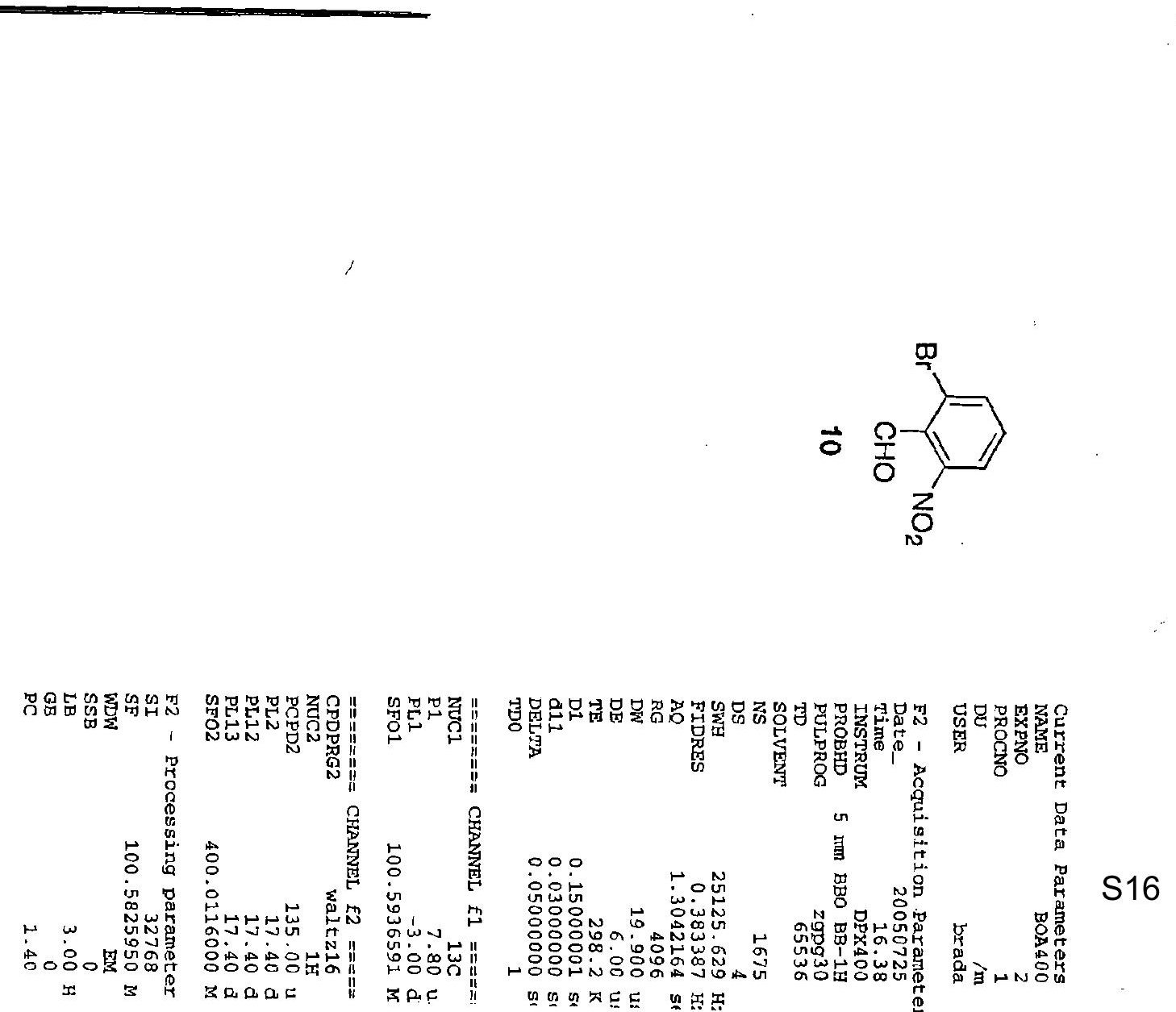

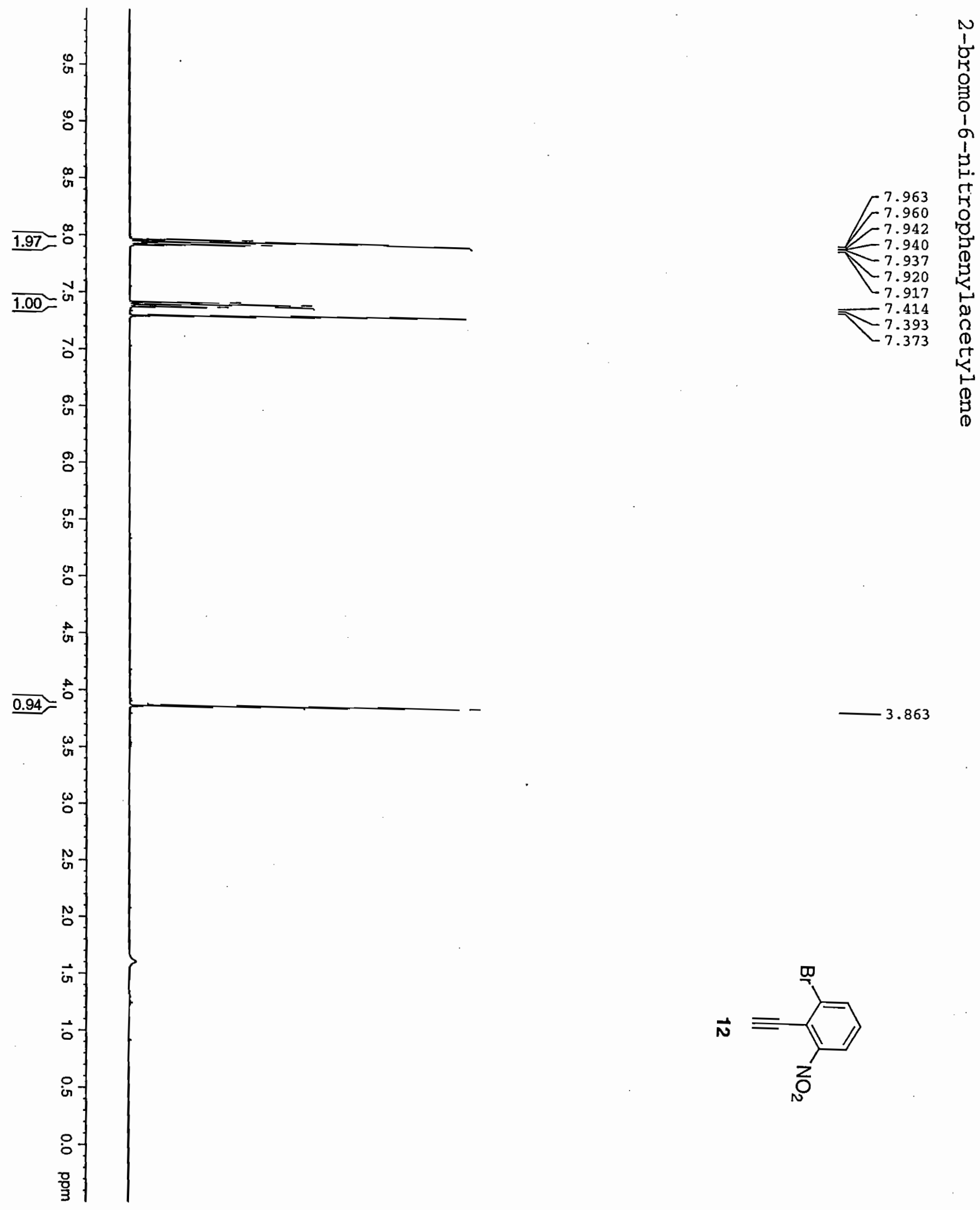

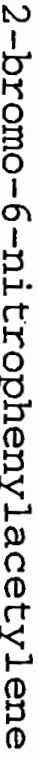
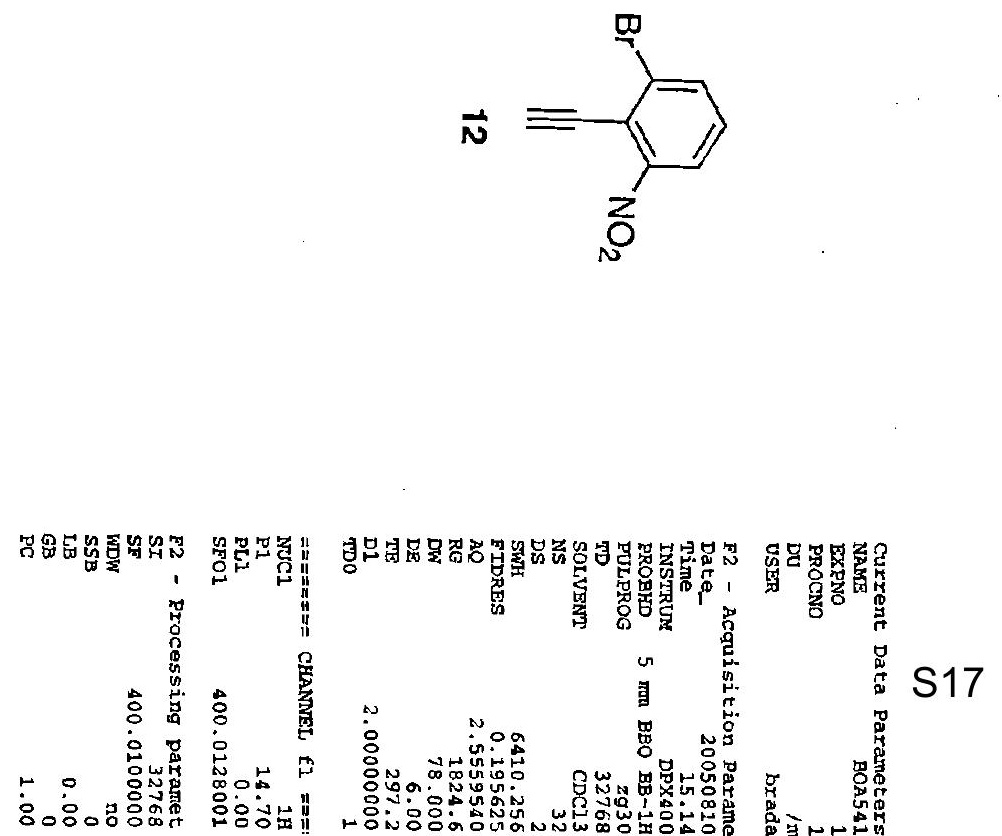


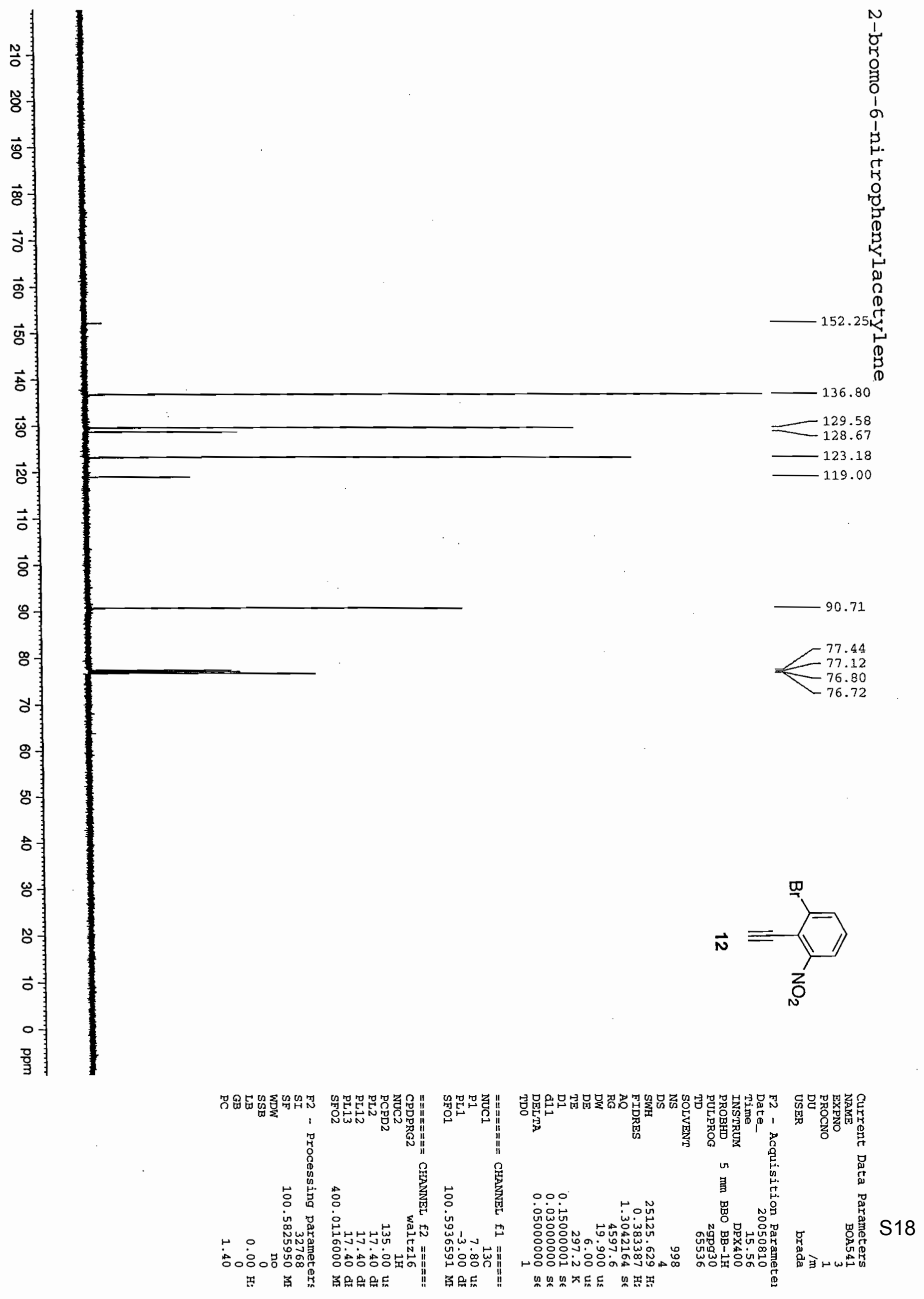



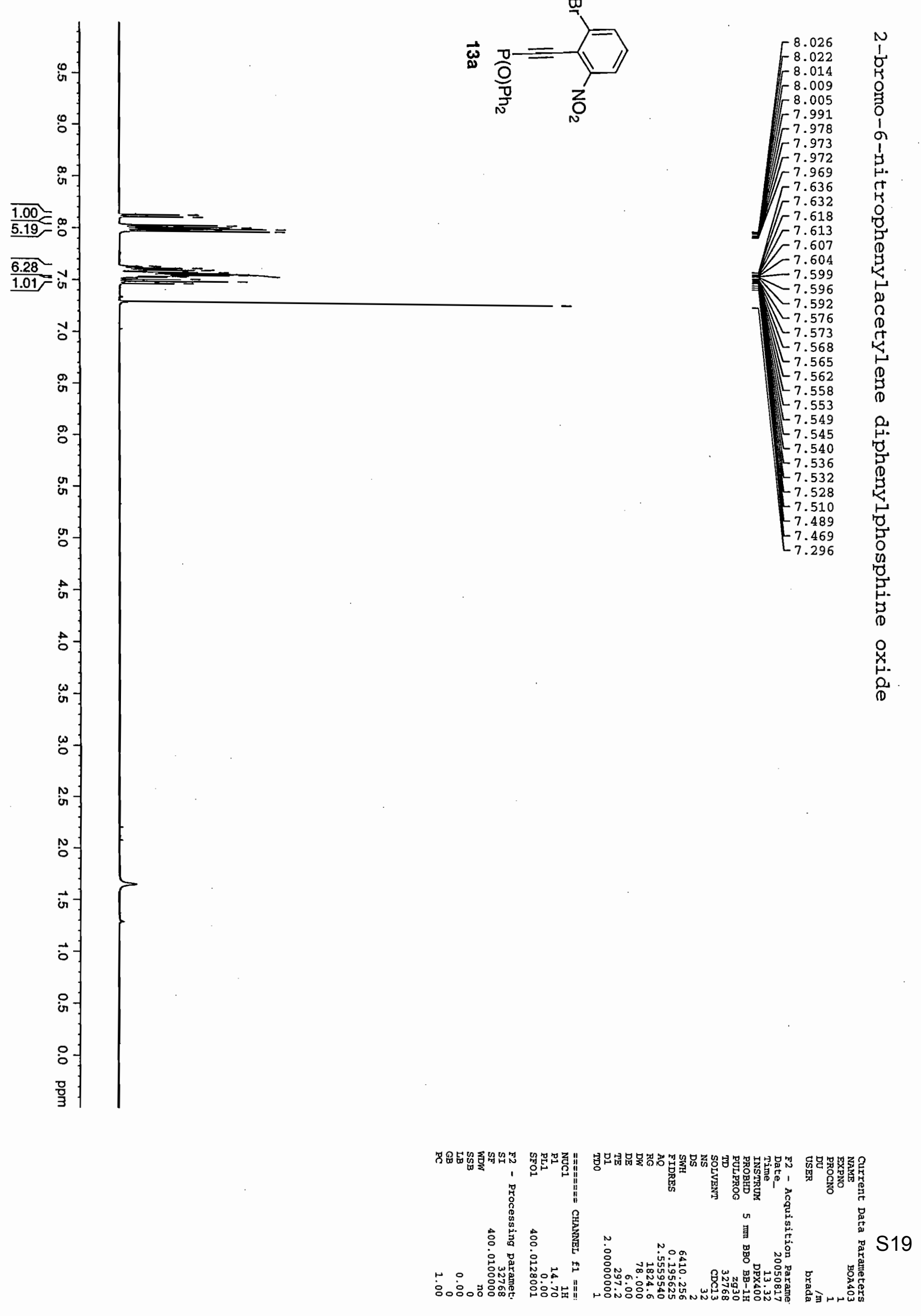

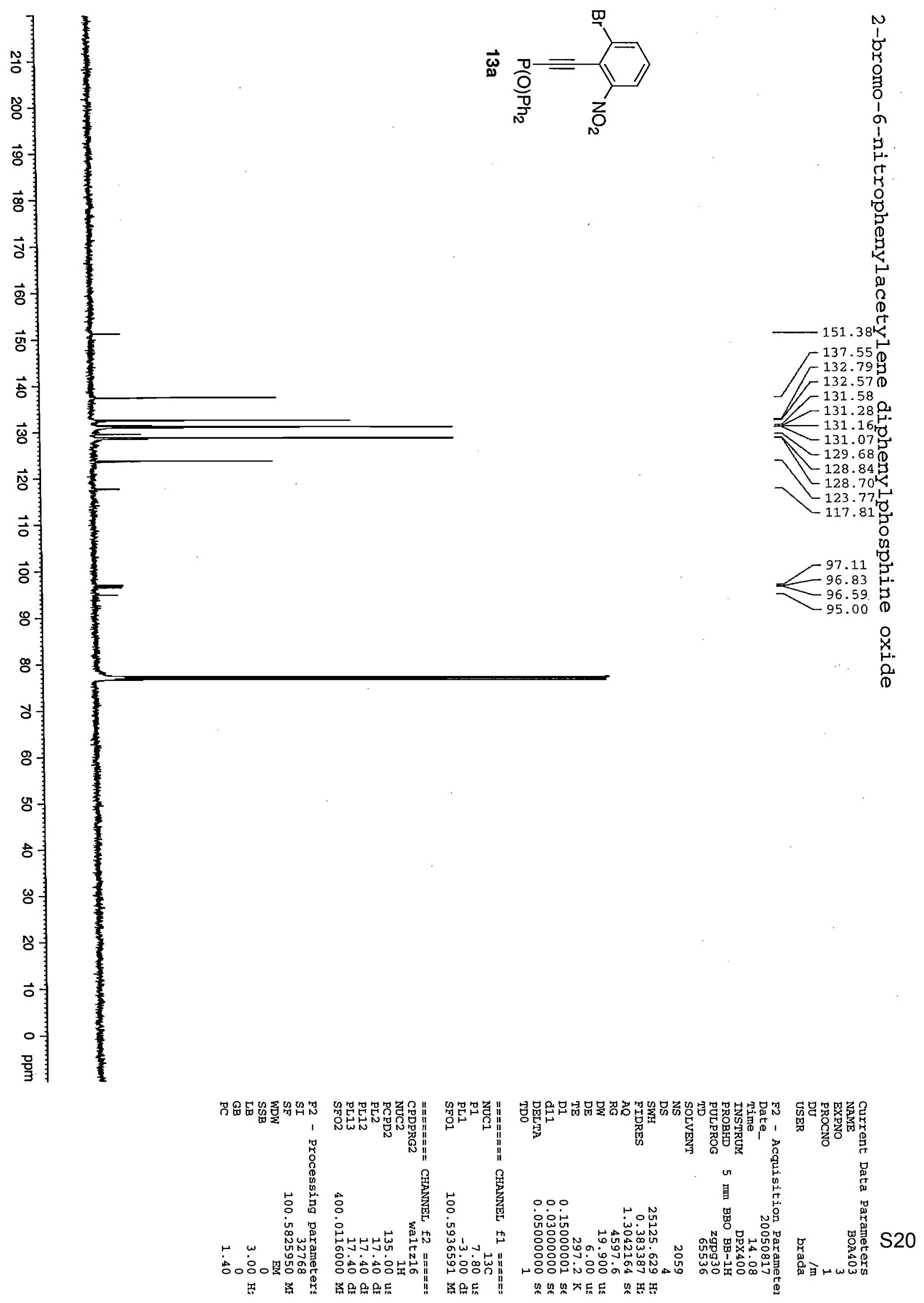


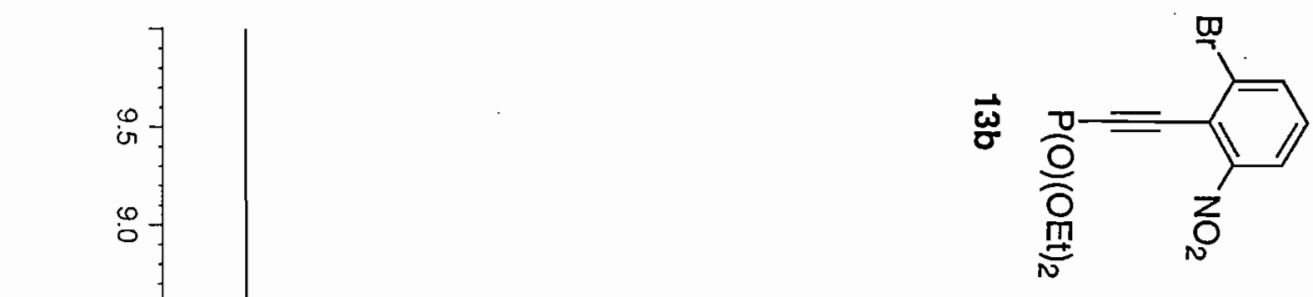

$\Gamma^{8.074}$ r8.071 $-8.047$ $-8.043$ $\overline{1.00}-\infty$ $\underline{1.07}$

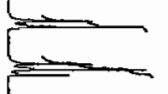
$-7.807$ $-7.804$ - 7.780 气 $\quad 7.777$ $-7.592$

$-7.564$

$\lcm{-7.537}$

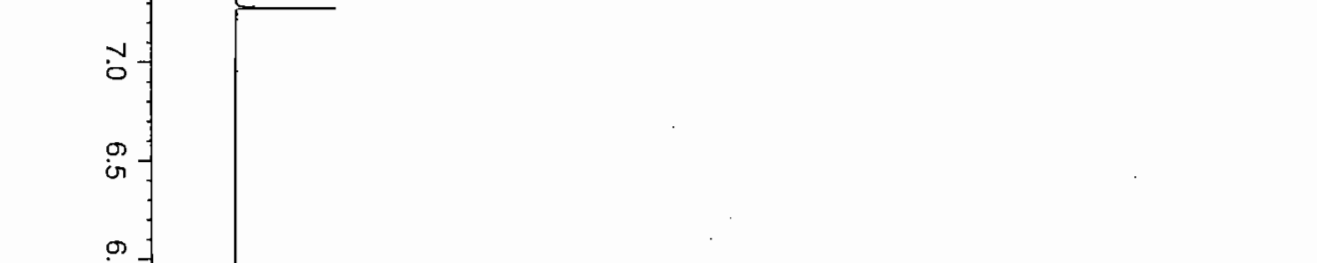

4.363

$-4.339$

$-4.316$

4.02

$-4.310$

-4.292
4.287

4.263
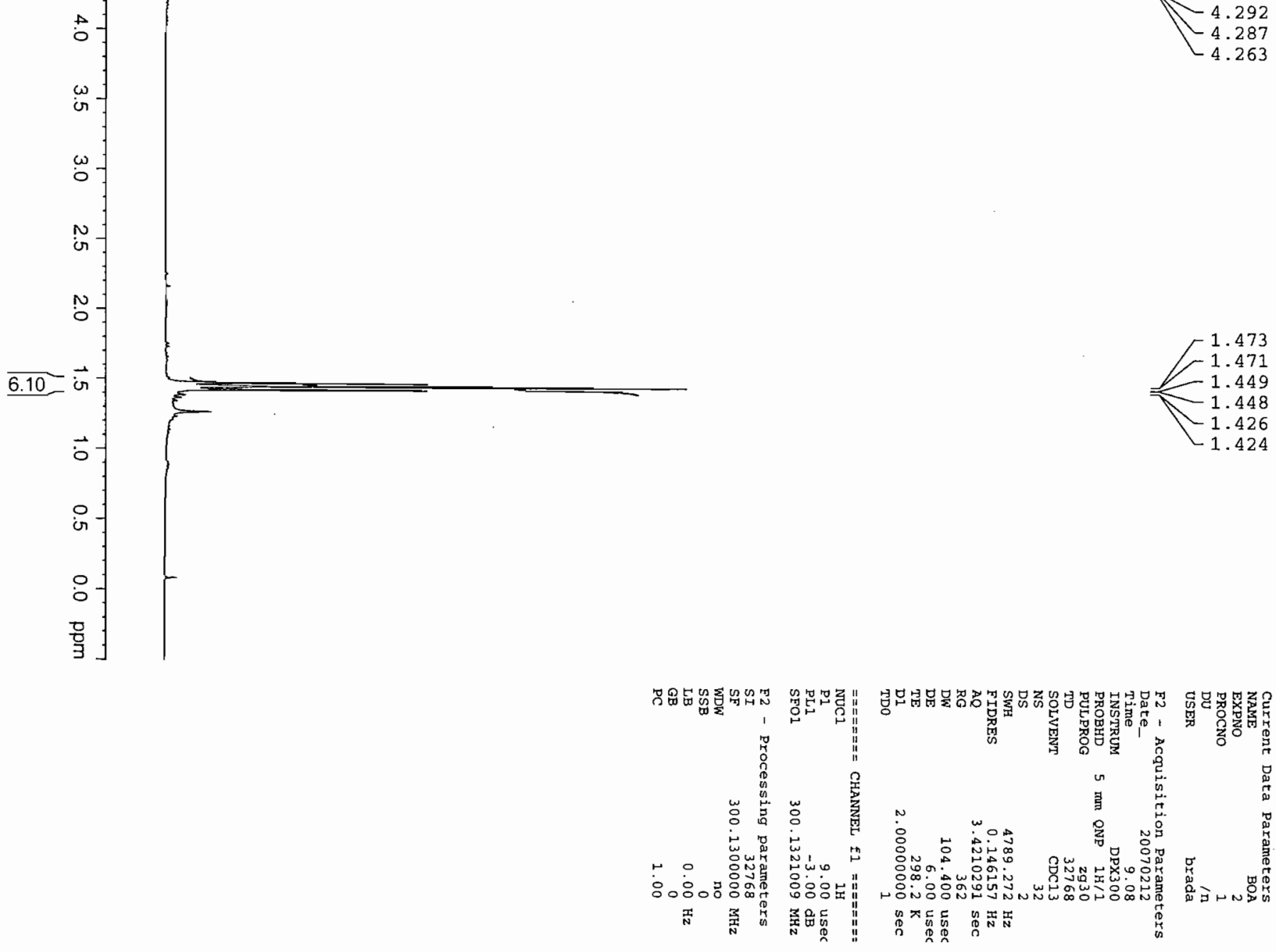


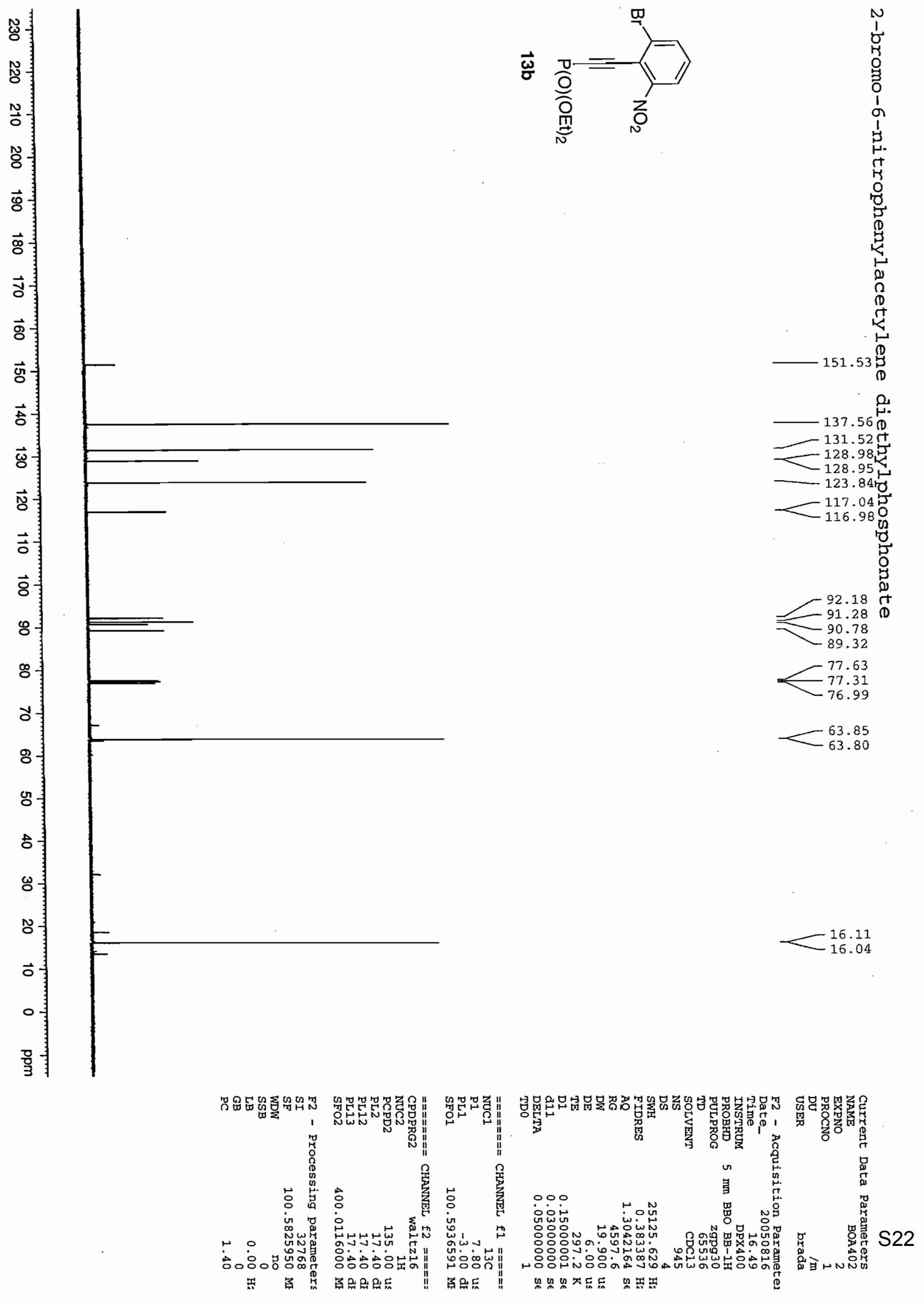



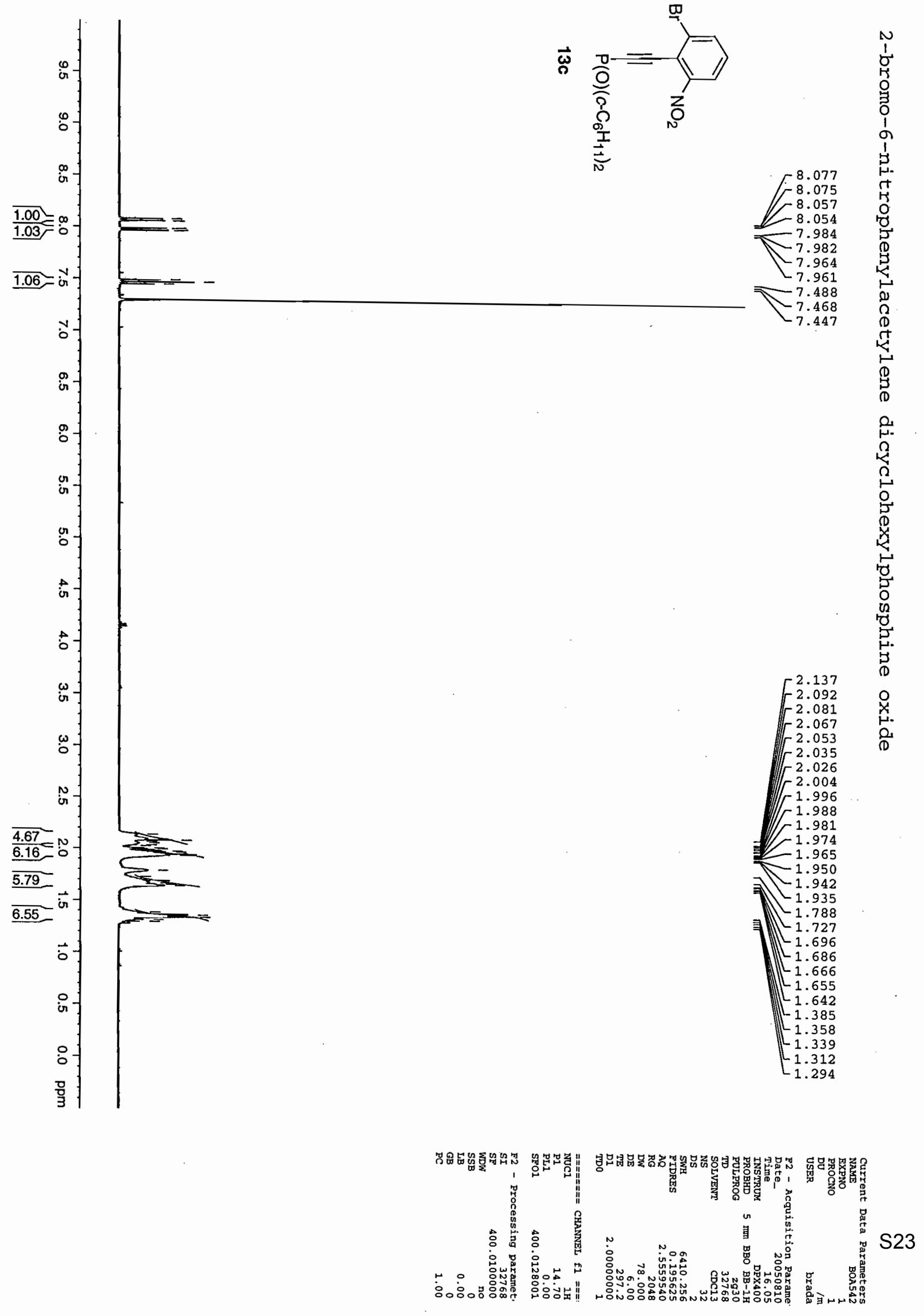

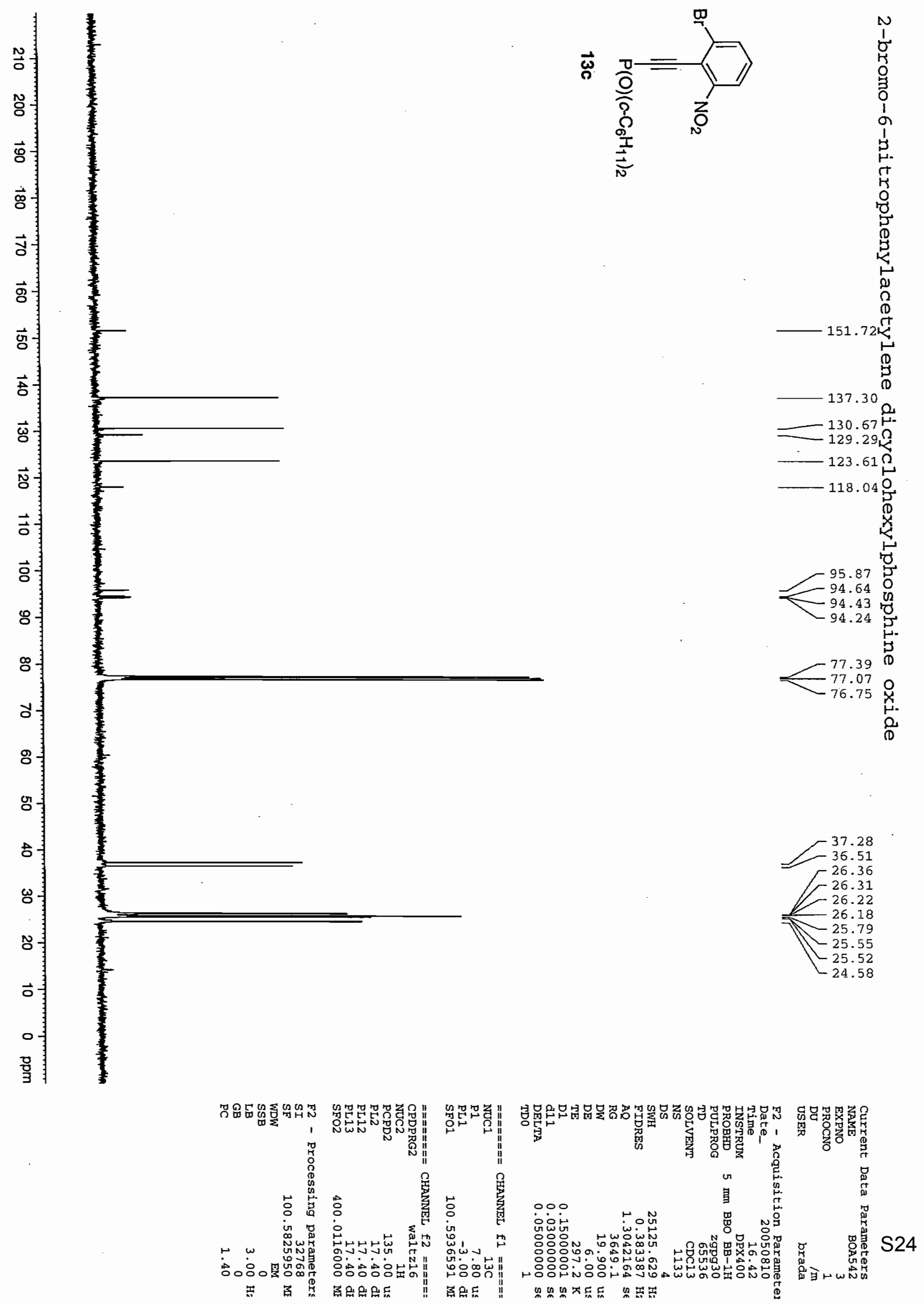

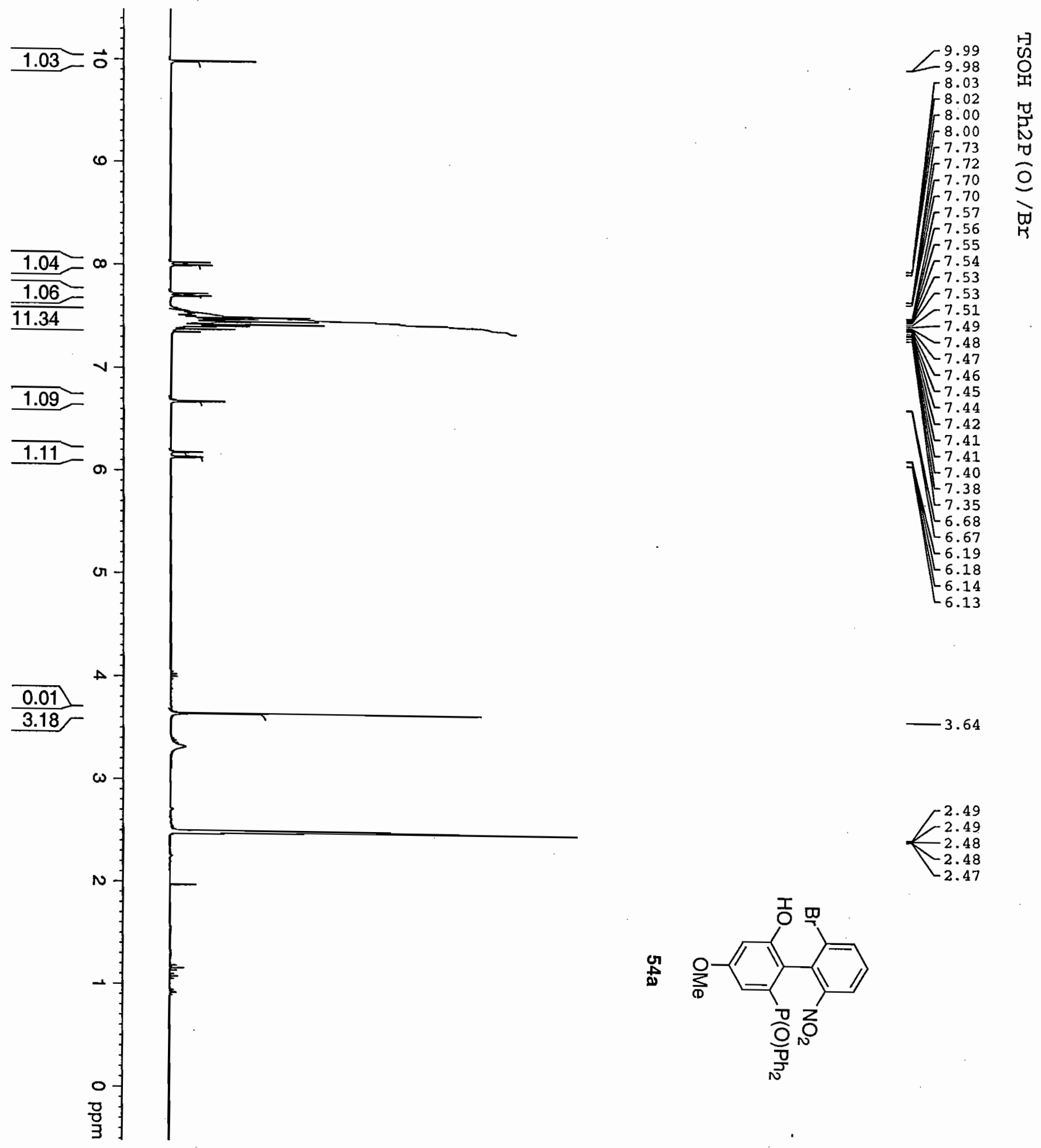

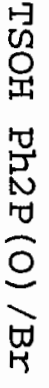

.64 


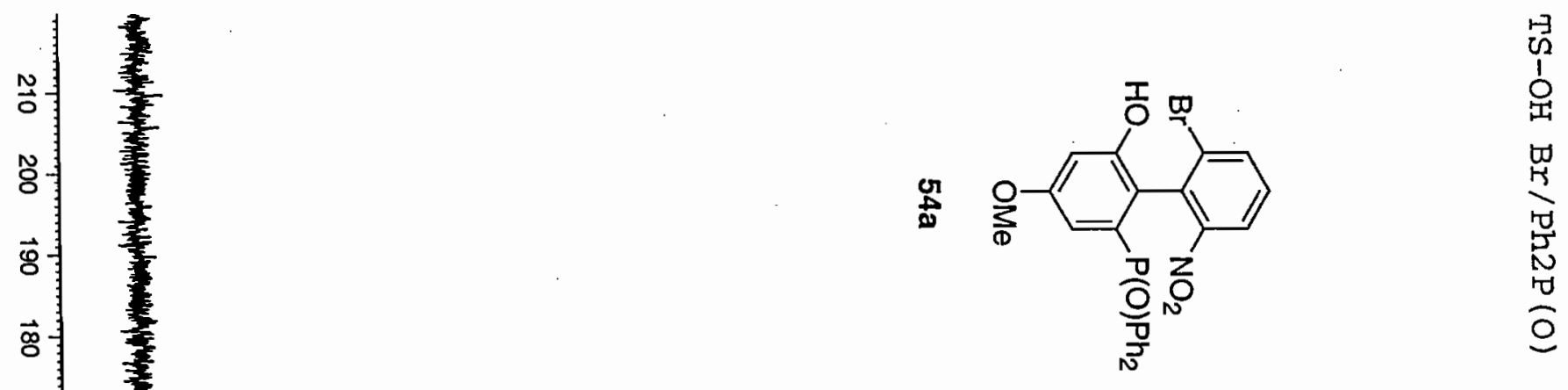

ㅎํ

$\overrightarrow{8}$

용

훙

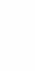

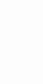 .}

\section{.}

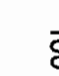

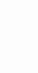

o ฮै

8

蹋 

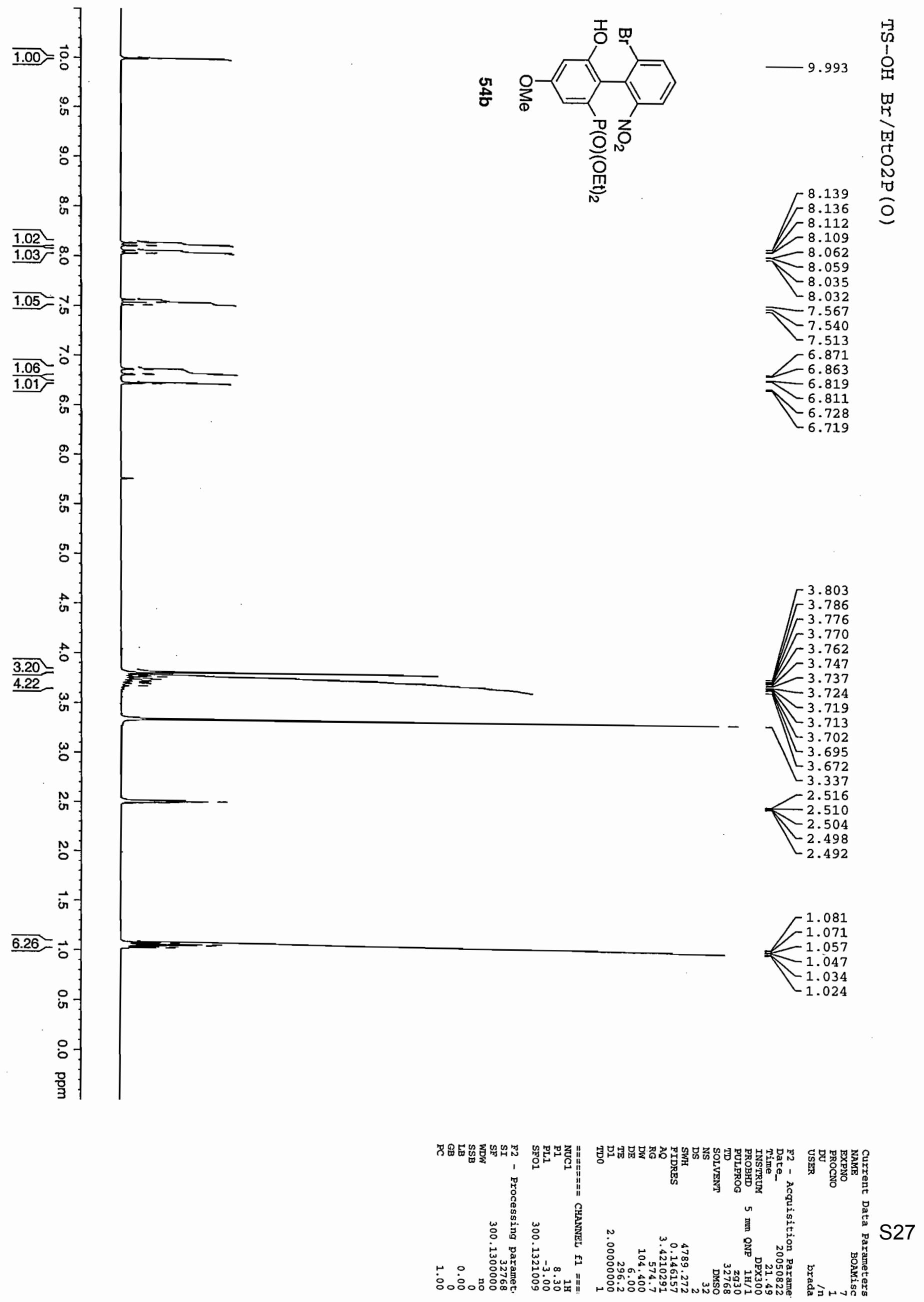


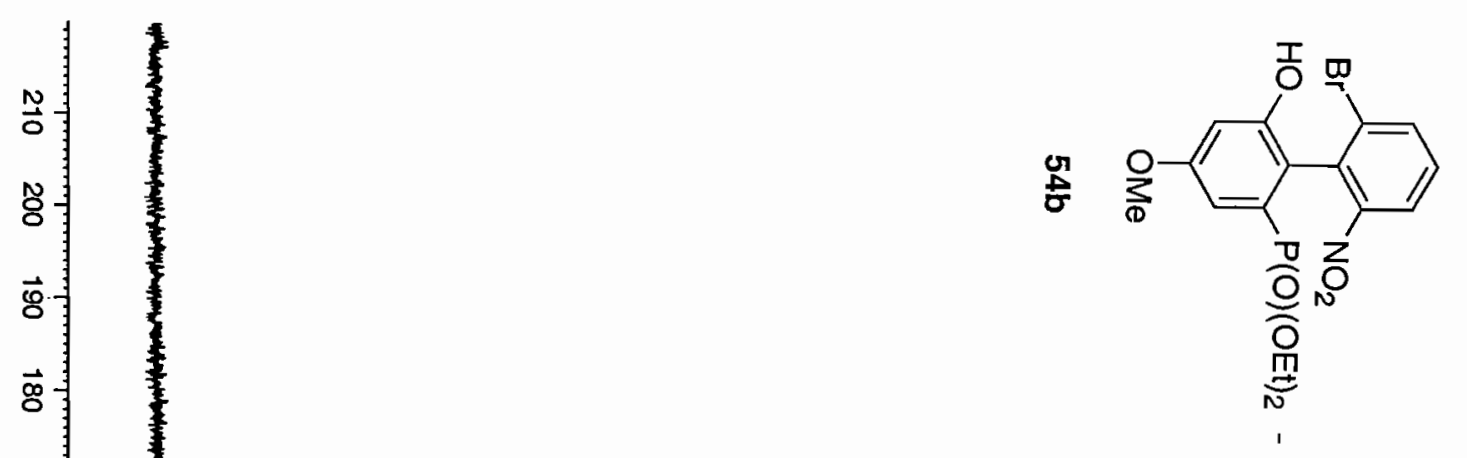

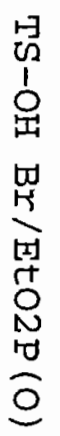

$\vec{\delta}$

$\overrightarrow{\mathrm{g}}$

$\overrightarrow{\mathrm{g}}$

$\overrightarrow{\mathrm{t}}$

$\vec{\phi}$

$\overrightarrow{\mathrm{g}}$

ᄒे

$\overrightarrow{\mathrm{o}}$

8

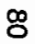

ơ

8

o

\&

బ

ก

$\overrightarrow{0}$

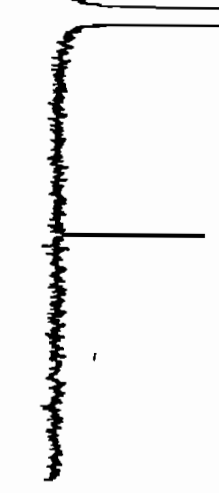

62.08

62.02 

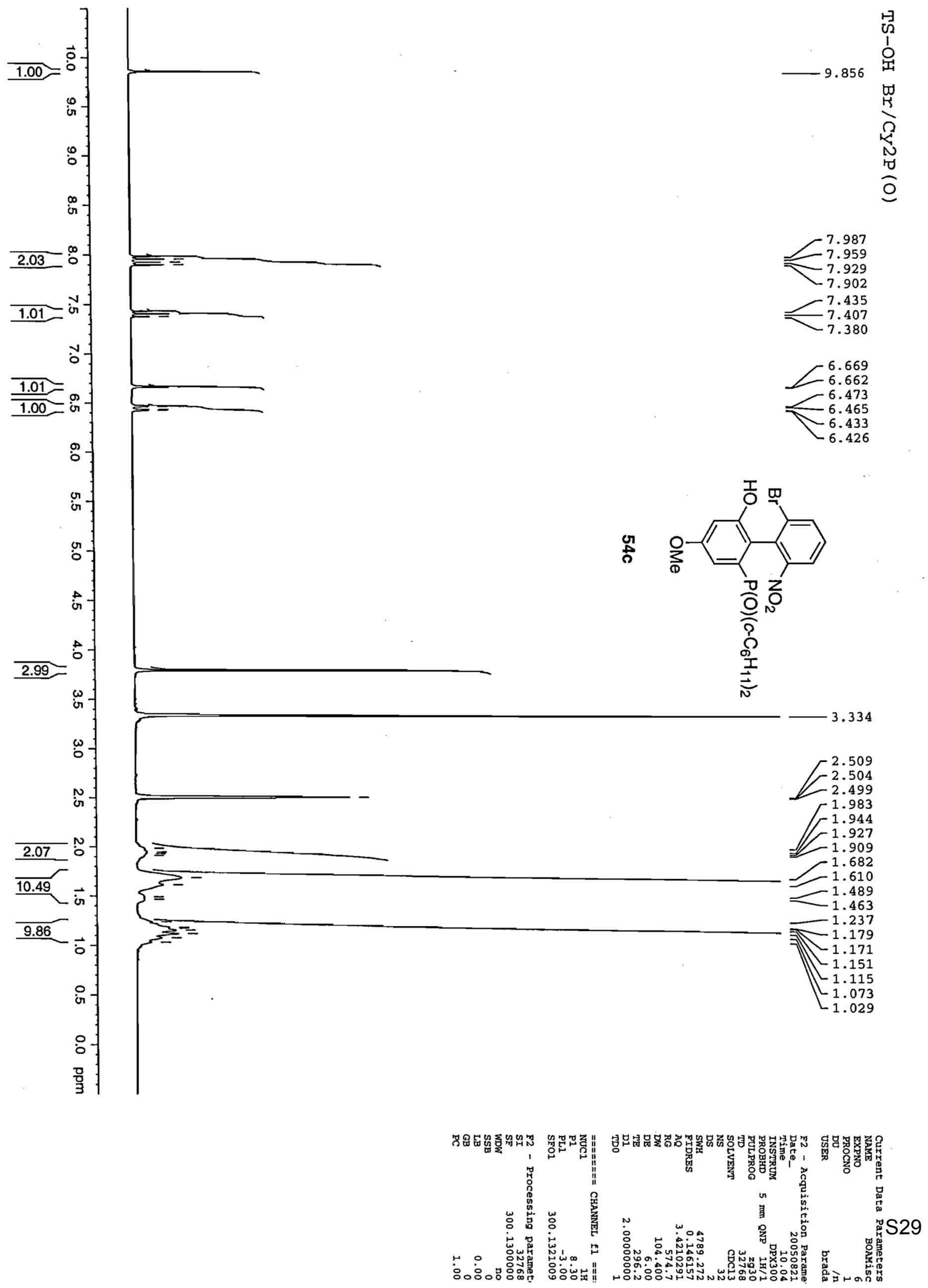

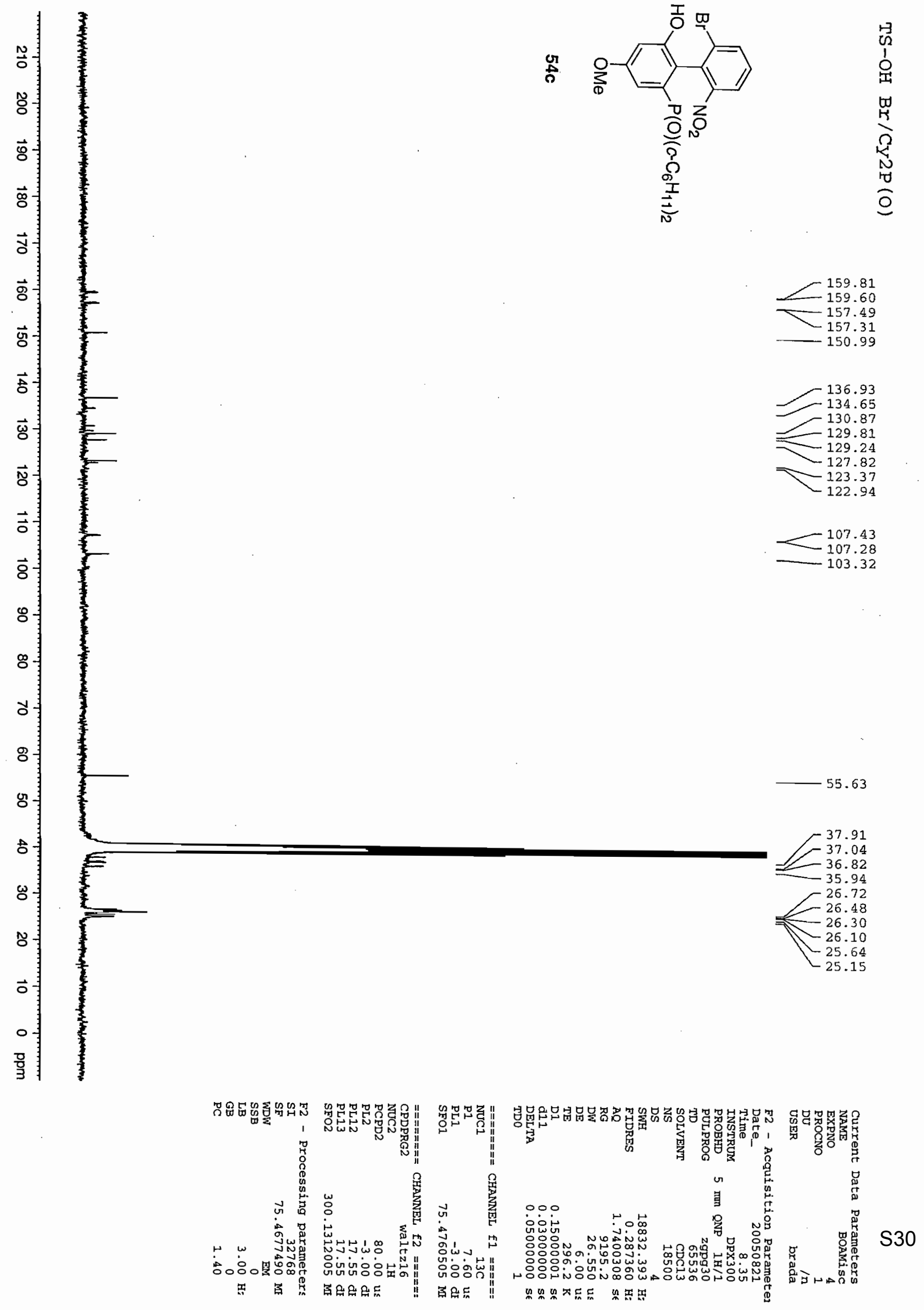

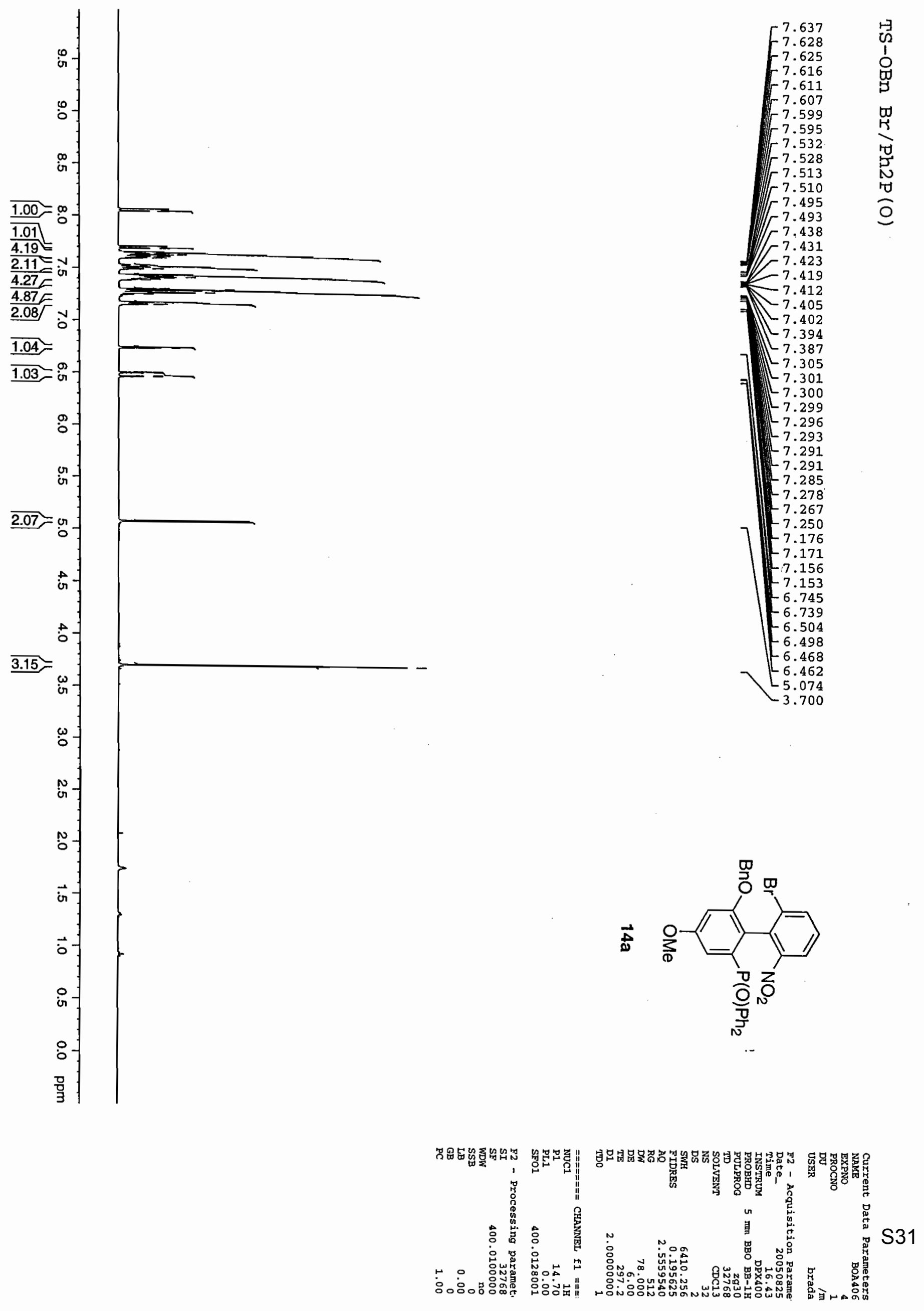


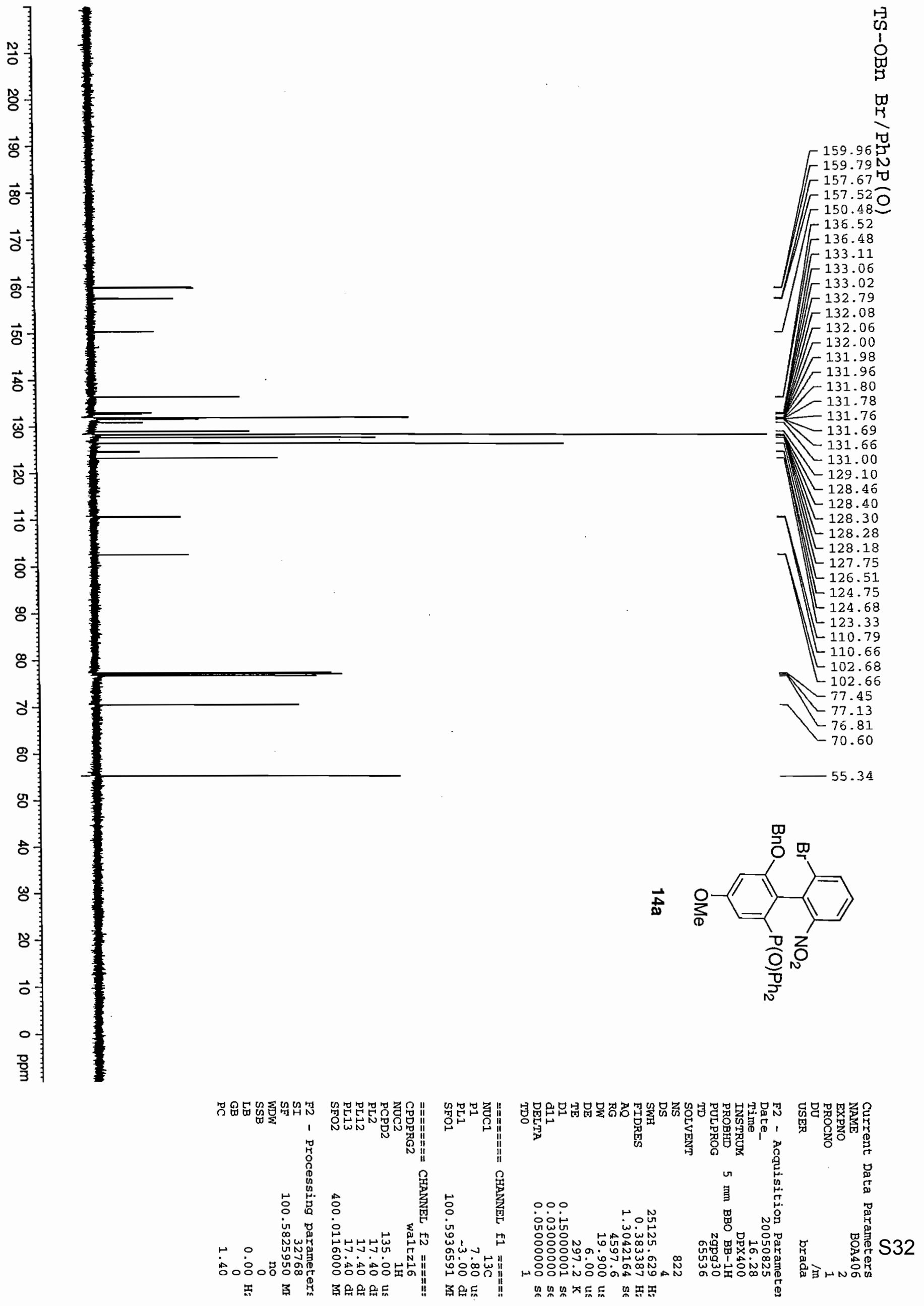



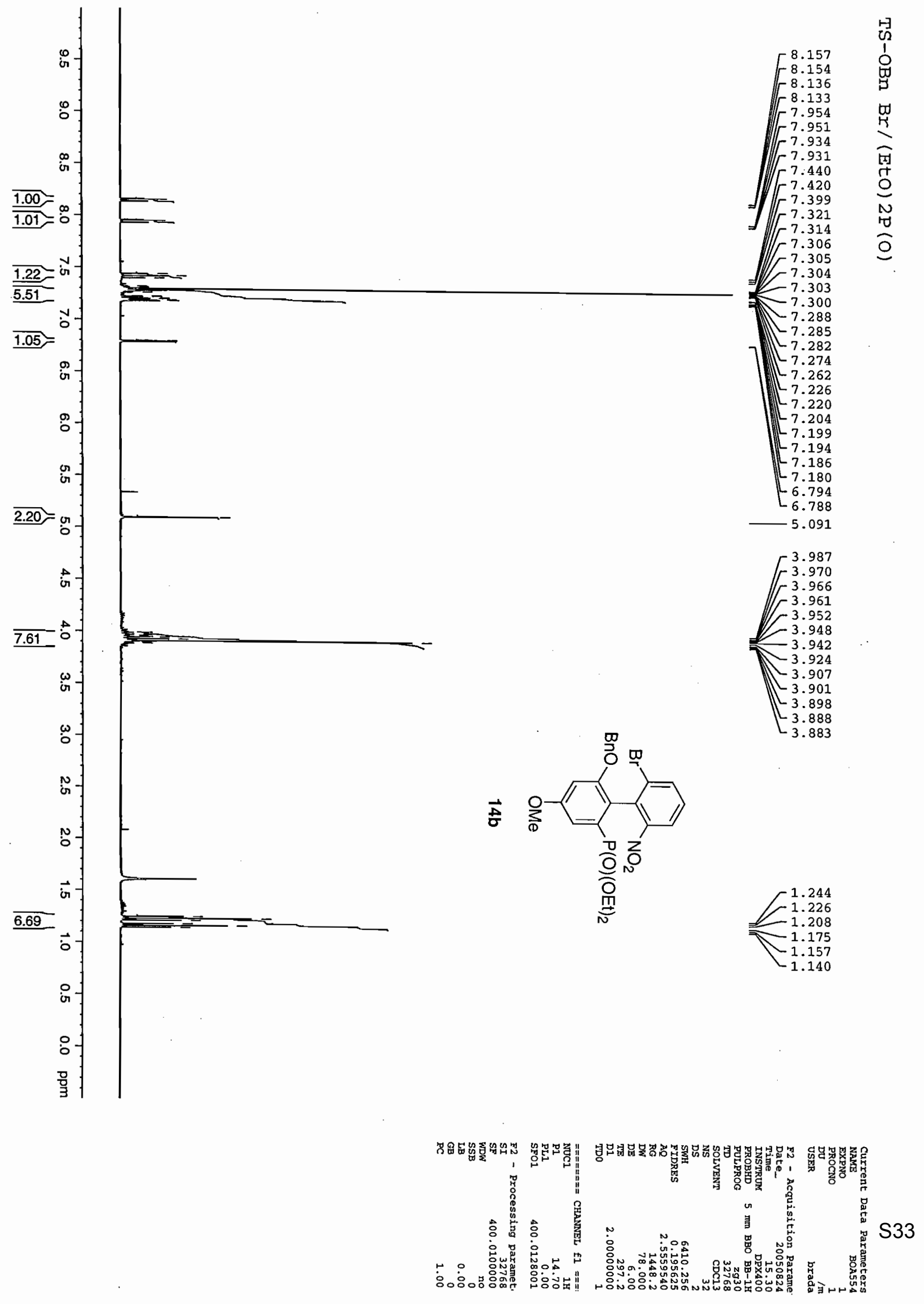

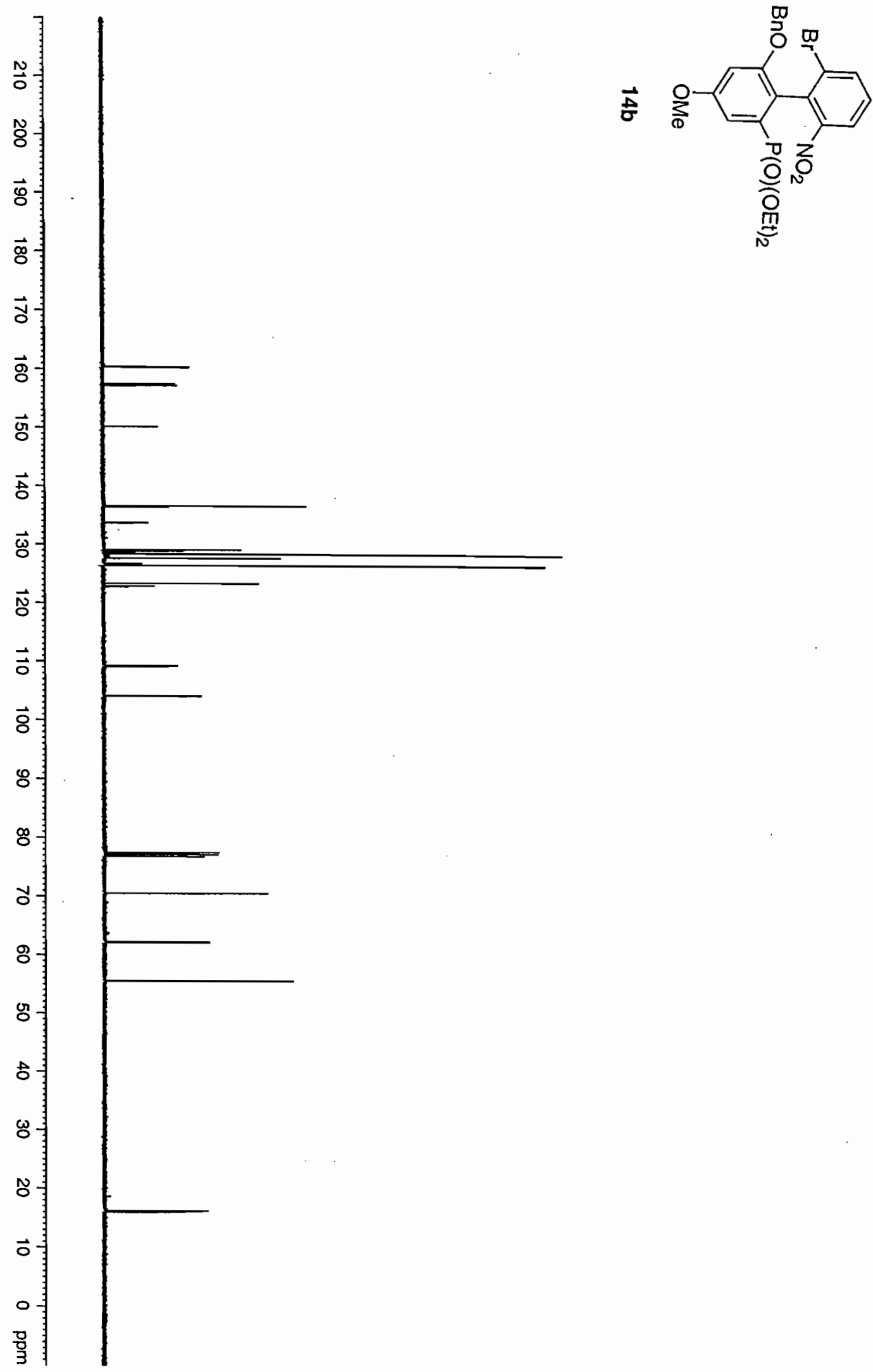

$-128.19$

$-127.89$

$\longrightarrow-127.73$

$-126.82$

$-126.53$

$-123.41$

122.89

$-109.32$

$\lcm{109.22}$
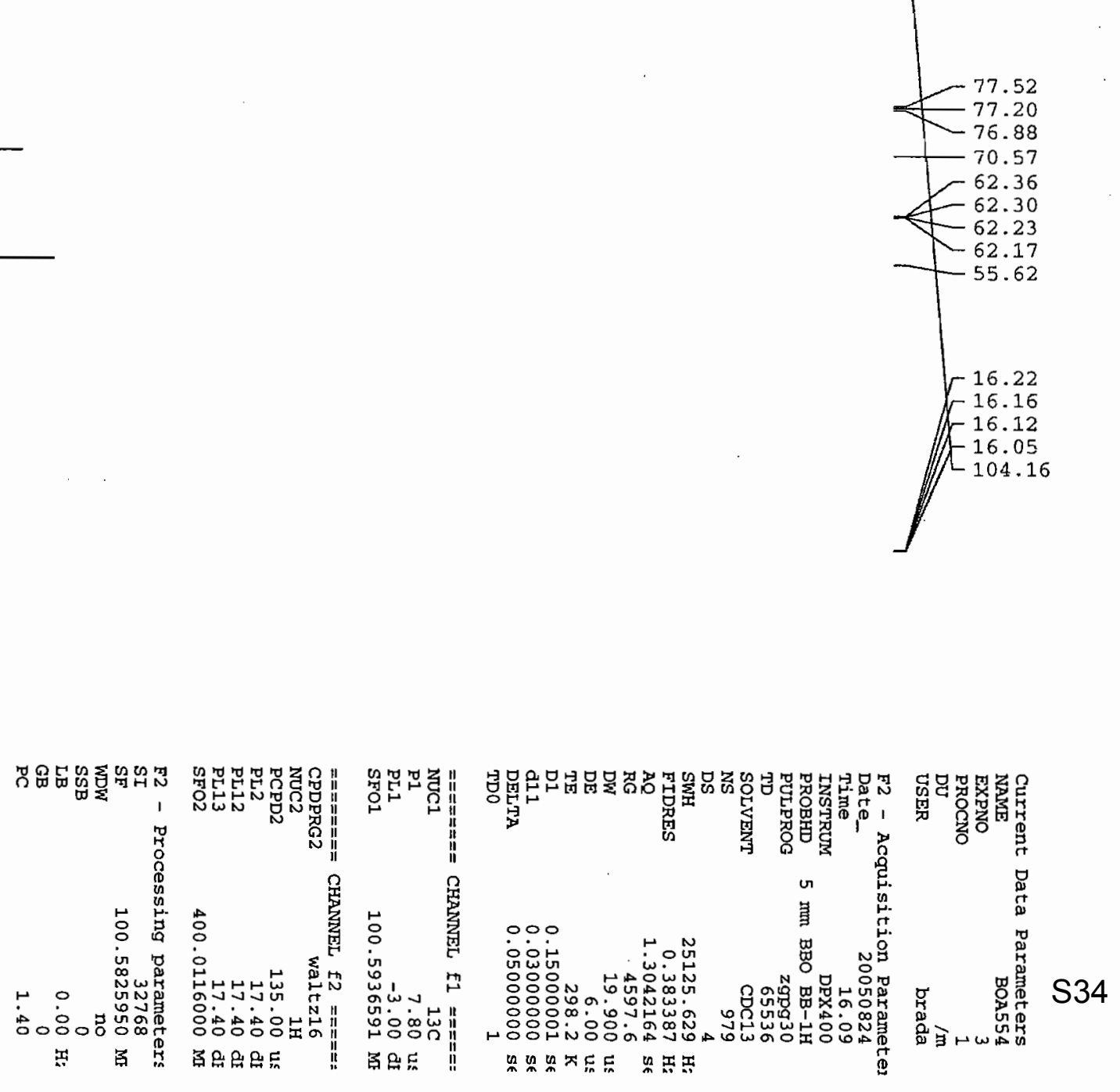

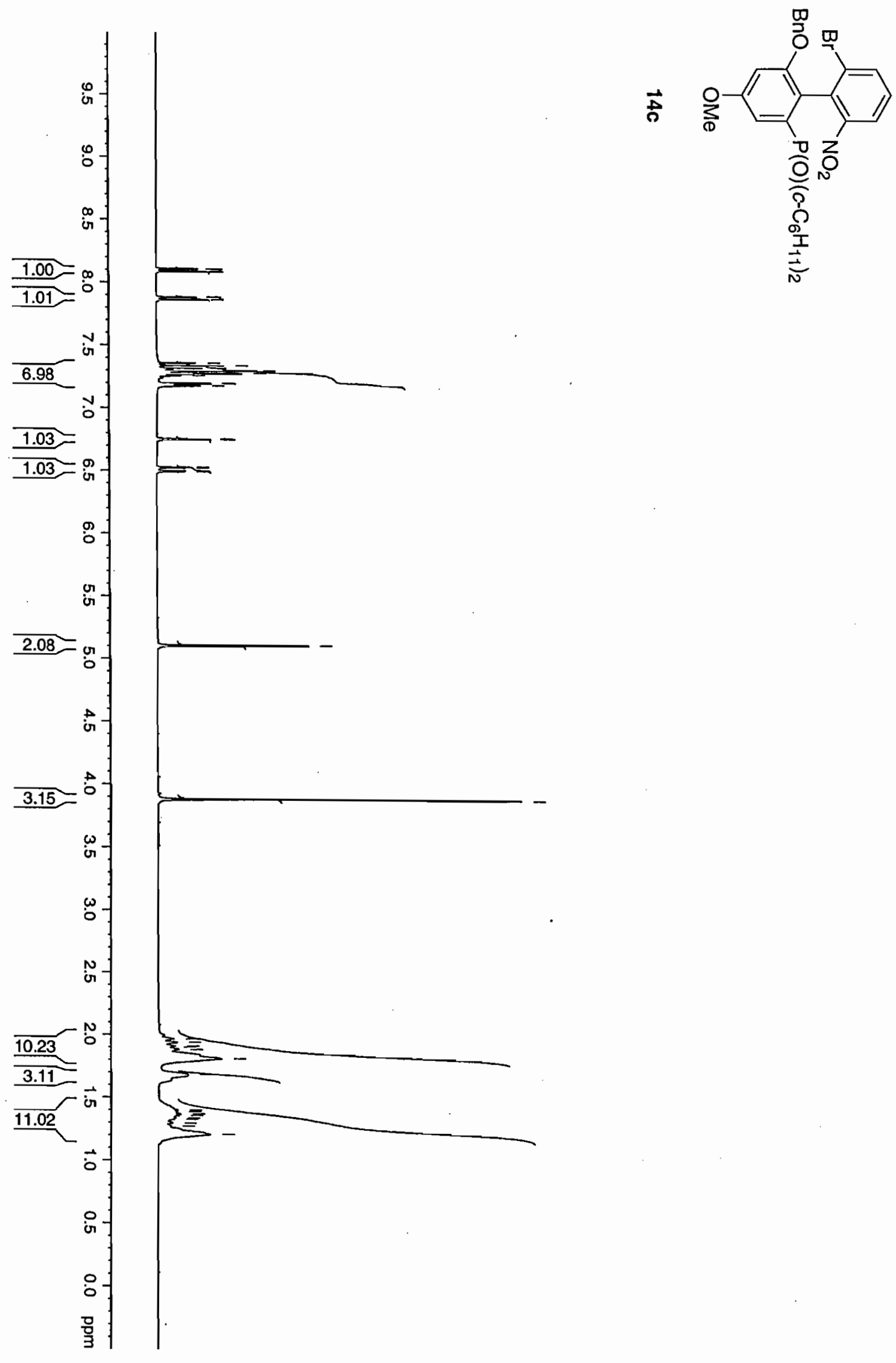

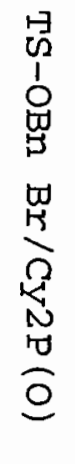

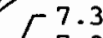

7.338

$F^{7.317}$

$-7.311$

$-7.296$

$-7.277$

$-7.269$

$-7.257$

7.197

$-7.193$

$7\left\lfloor\left[\begin{array}{l}7.177 \\ 7.175\end{array}\right.\right.$

$-6.752$

$-6.747$

6.526
6.520
6.497

6.497

6.492

5.101

3.879
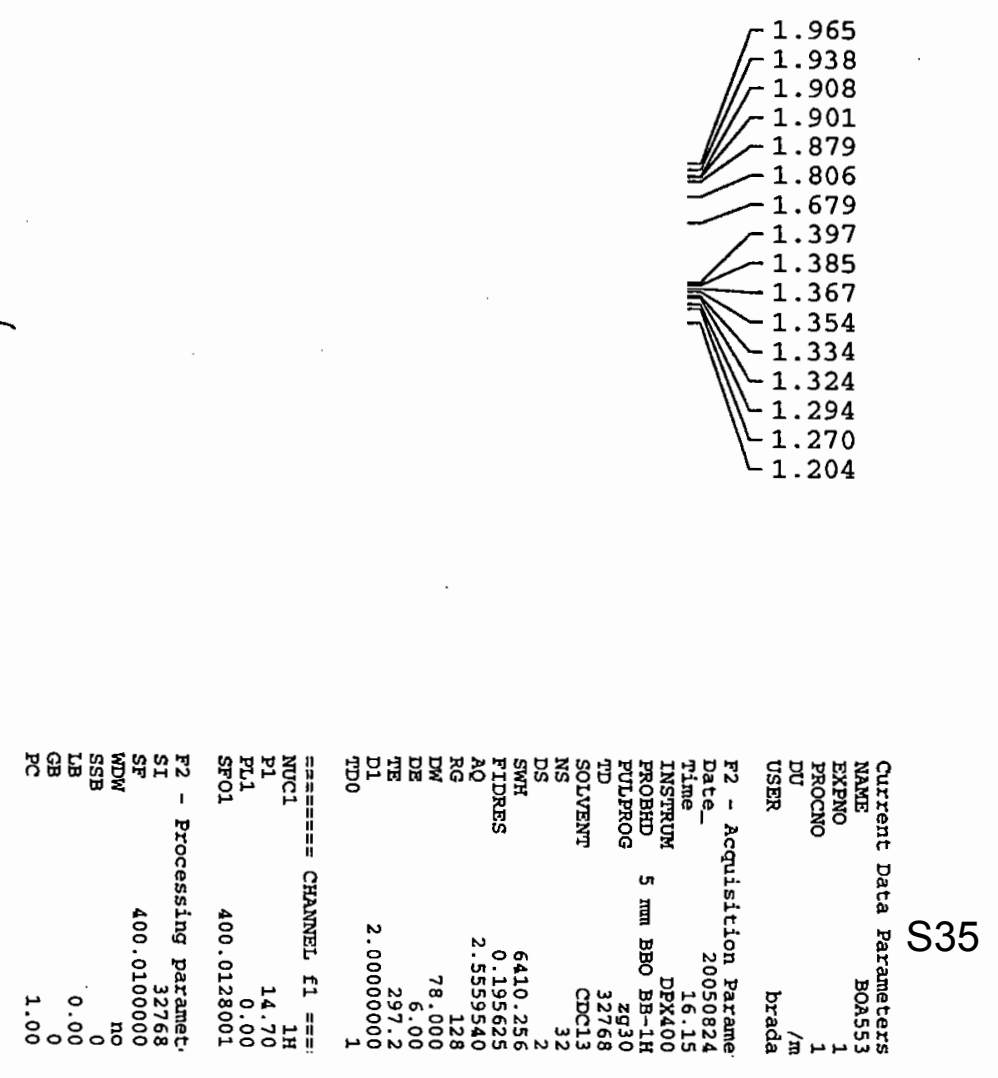


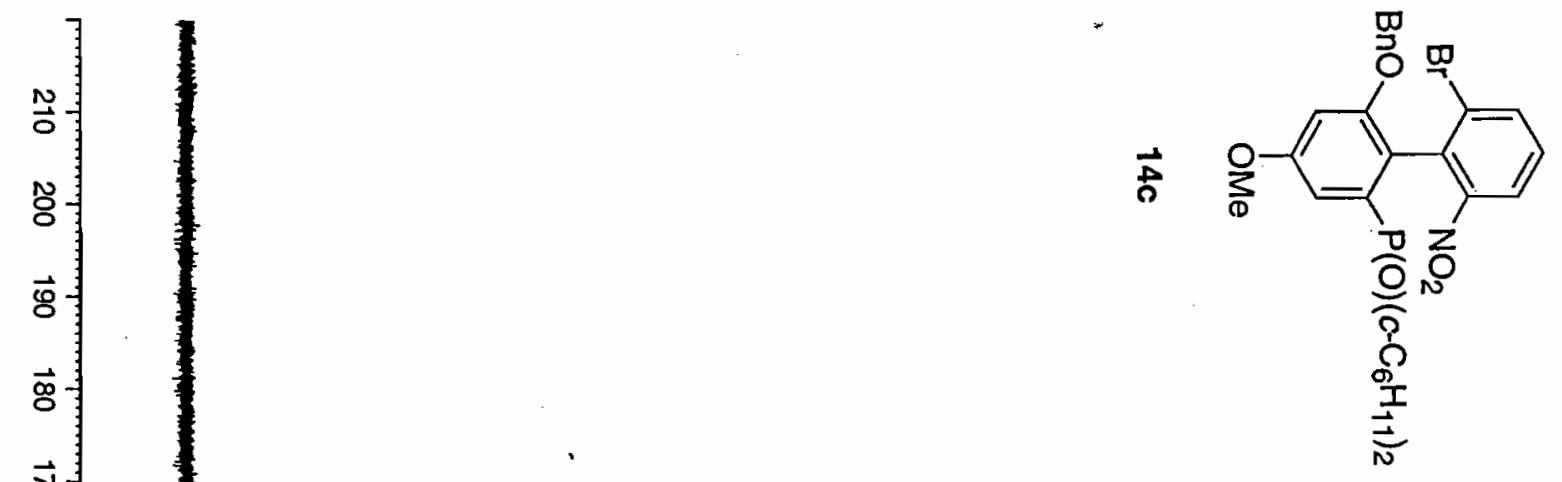

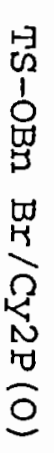

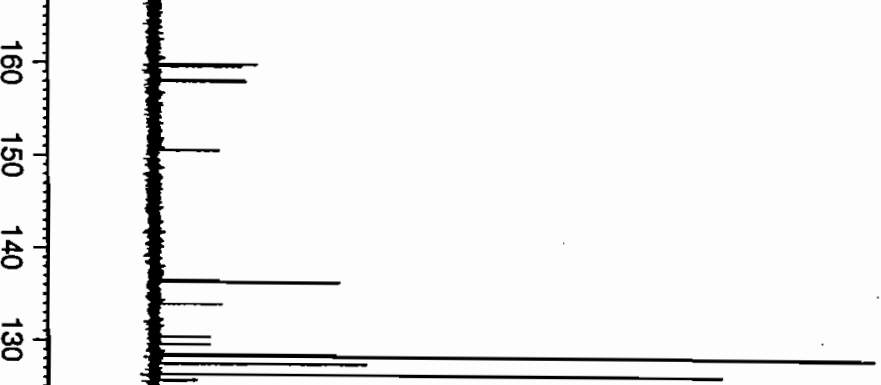

$\vec{N}$

$\vec{\partial}$

$\overrightarrow{8}$

8

\&

d

8

S

응

$\omega$

N

음

$\circ$

믕
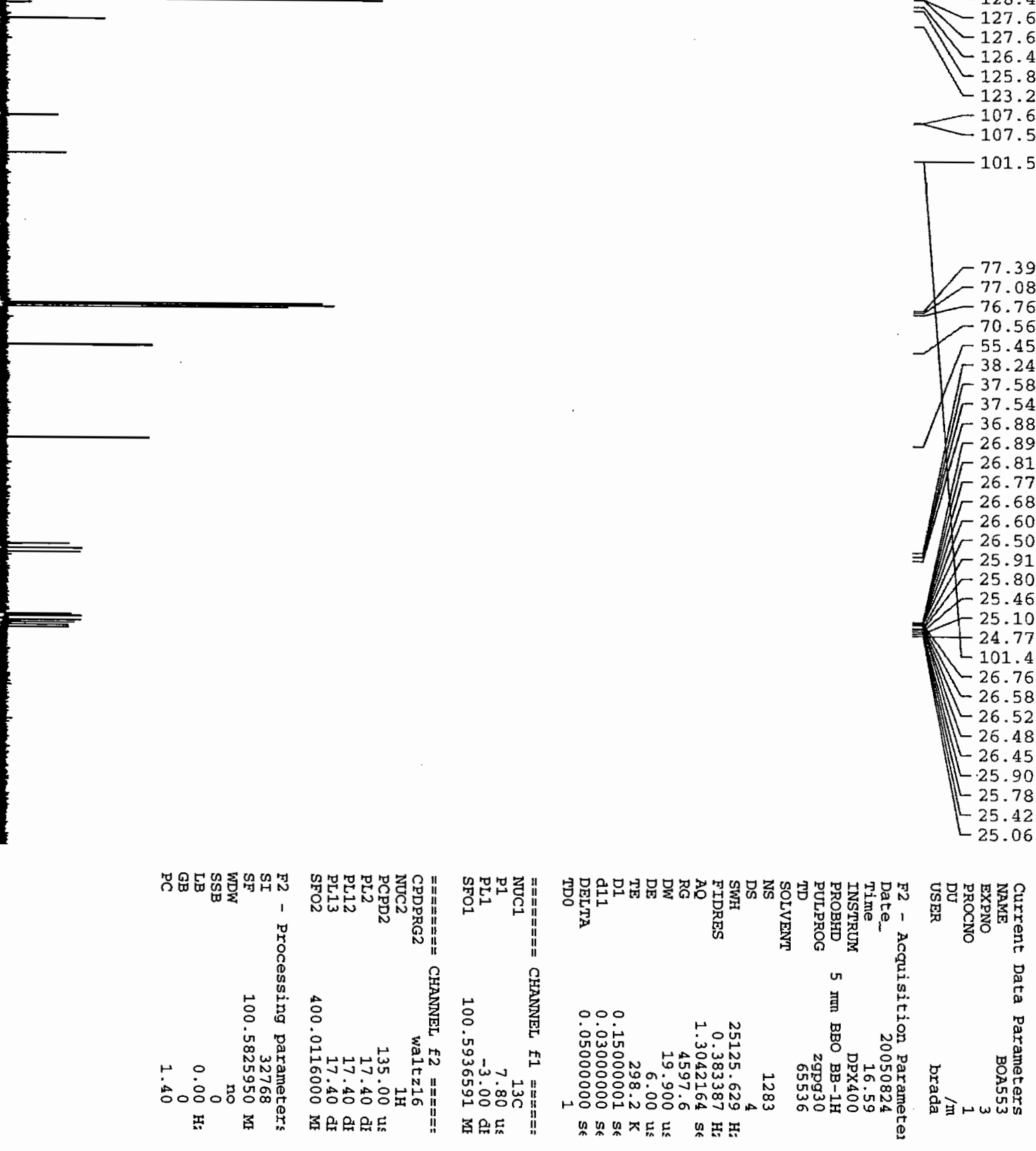

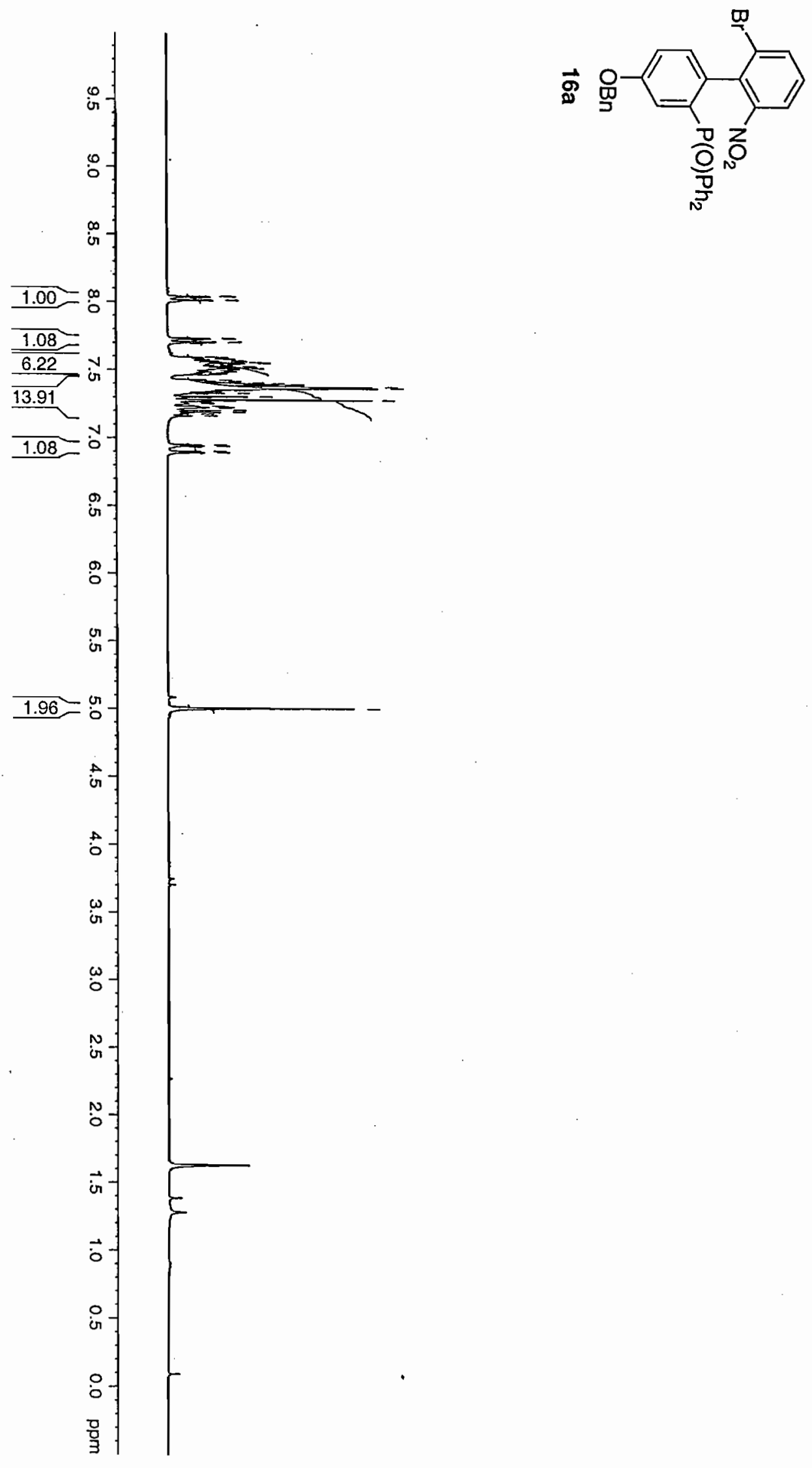

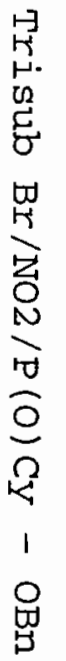

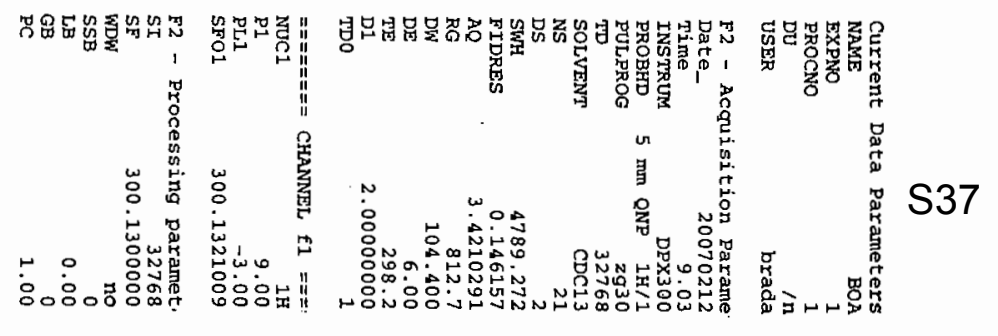



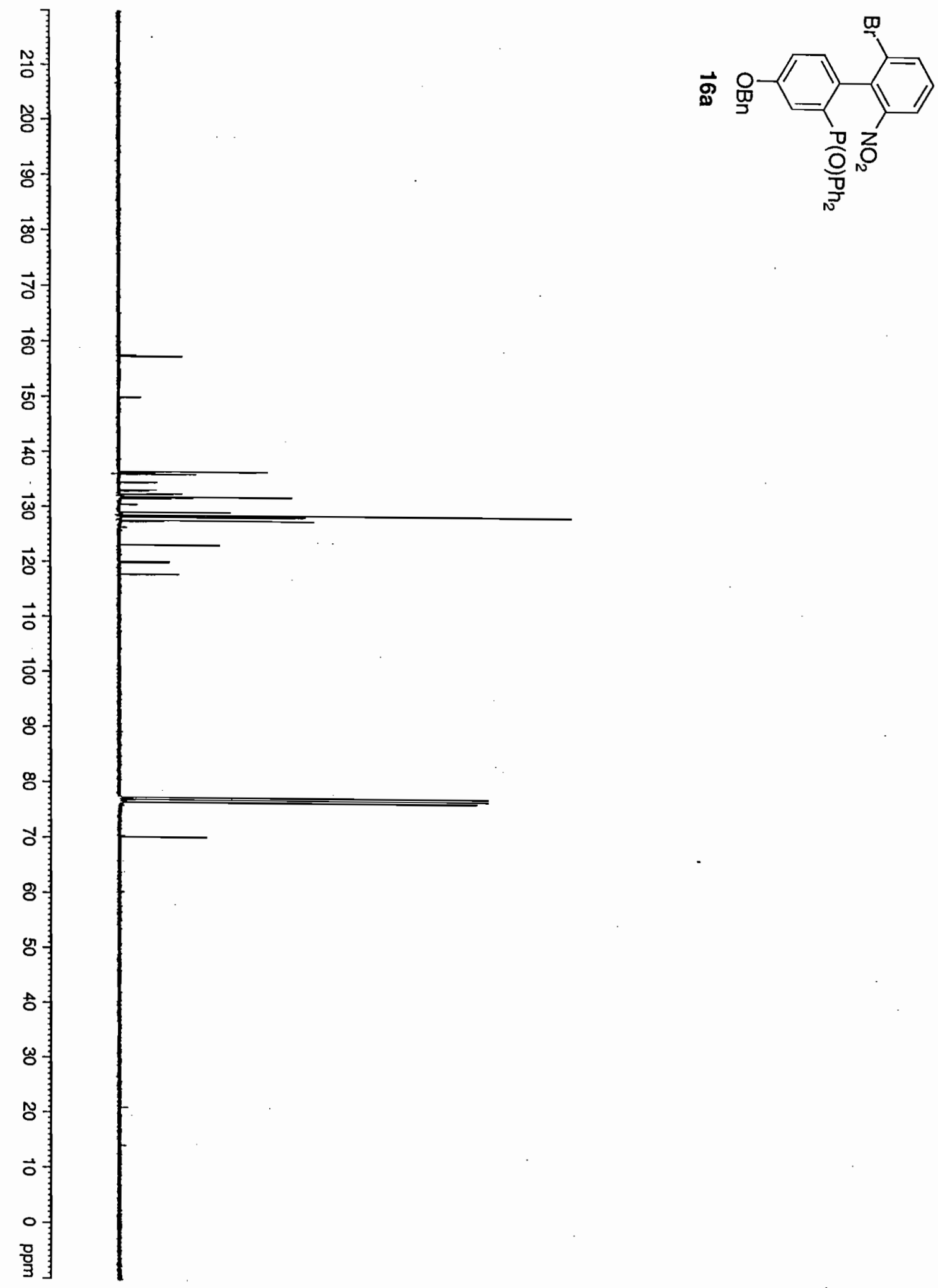

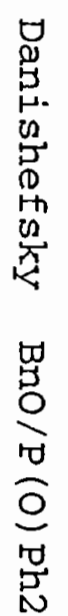

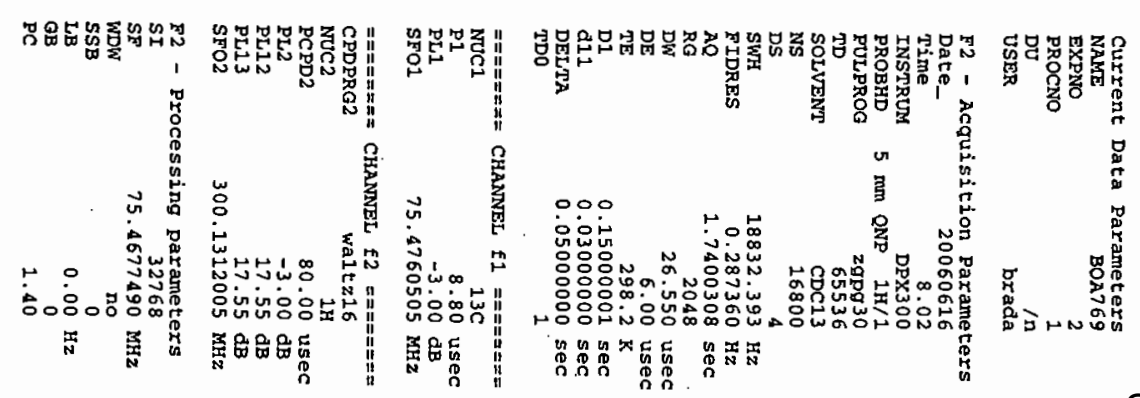



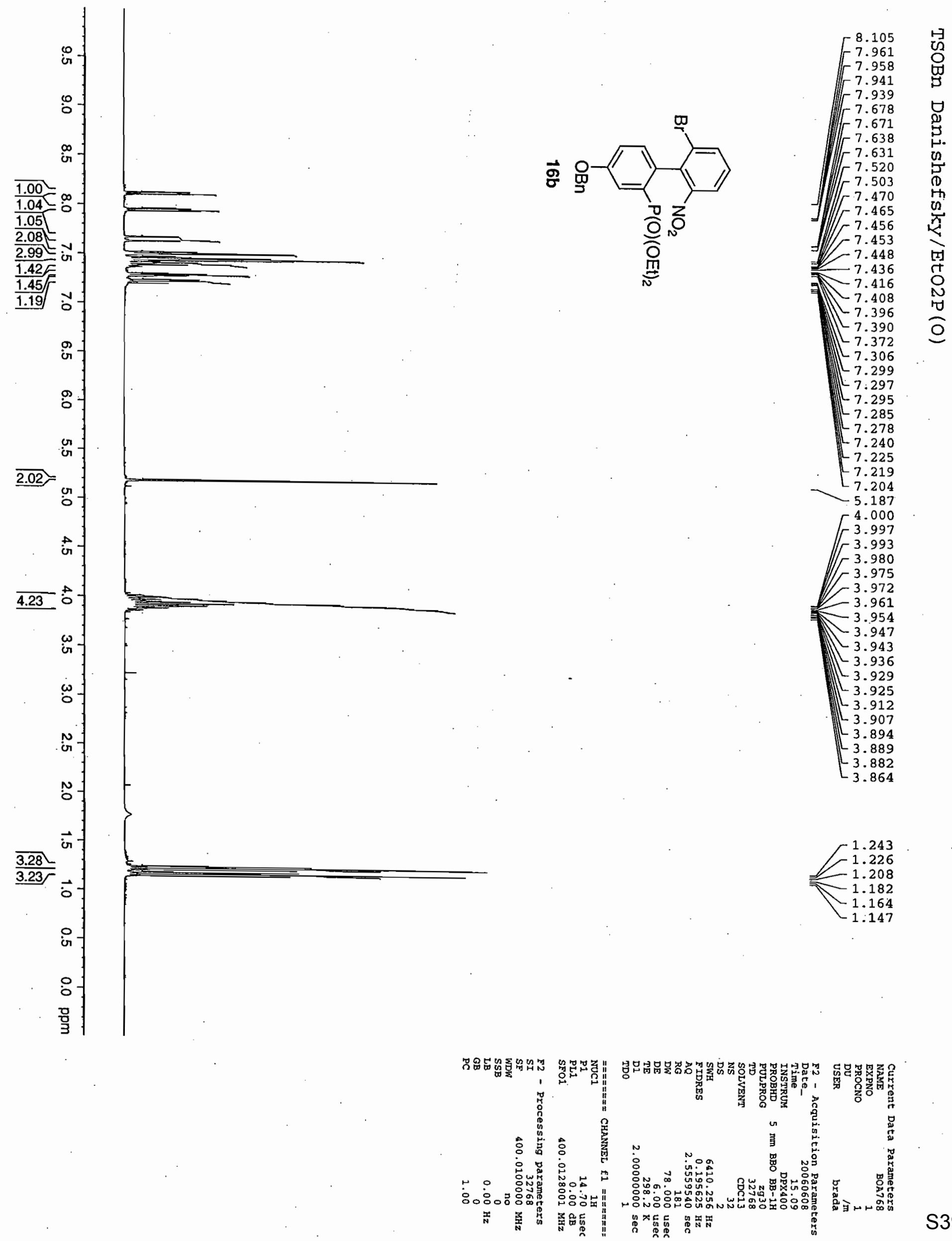


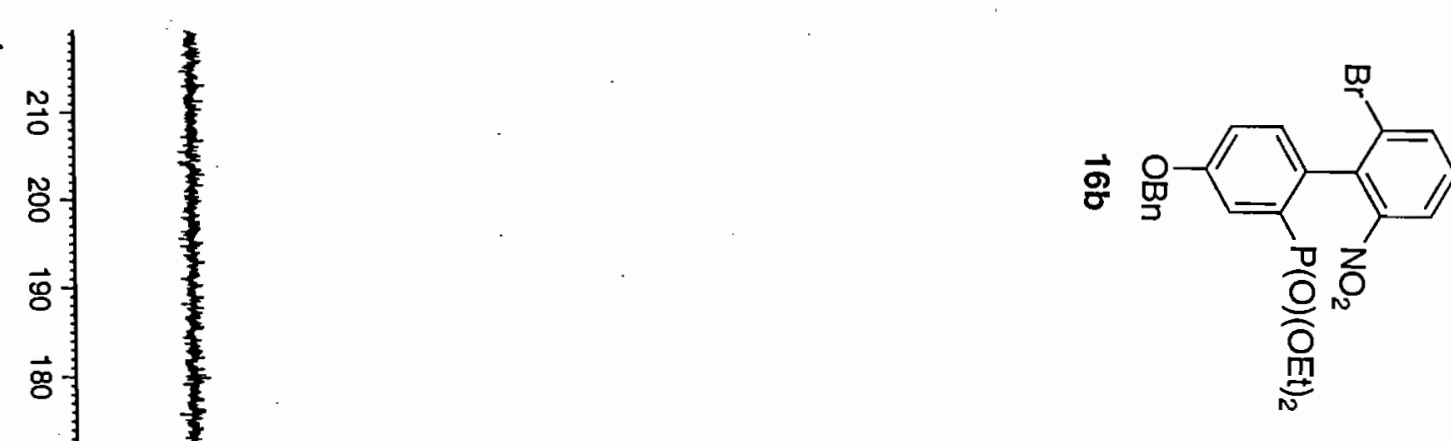

\begin{tabular}{l}
-3 \\
0 \\
0 \\
\hdashline
\end{tabular}

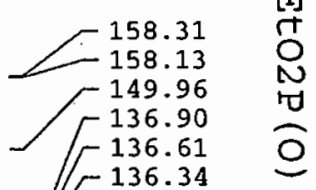

$-136.34$

$-132.96$

$-132.89$

$\begin{array}{r}132.19 \\ -132.03 \\ \hline\end{array}$

$-129.36$

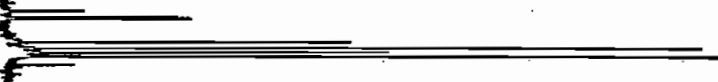

128.70

$\overrightarrow{0}$

항

$\overrightarrow{8}$

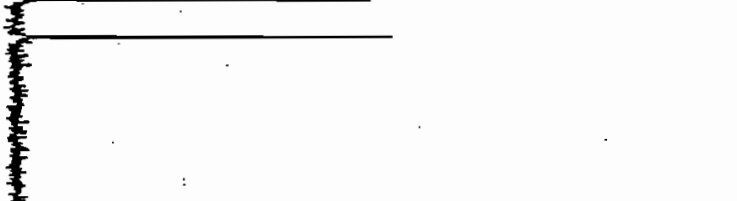

$-128.08$

$-127.72$

$\lcm{126.78}$

$-123.35$

$\longleftarrow \begin{array}{r}119.11 \\ 119.01\end{array}$

8

8

o

ธั

8

8

on

s

$\omega$

ก

$\overrightarrow{0}$

응
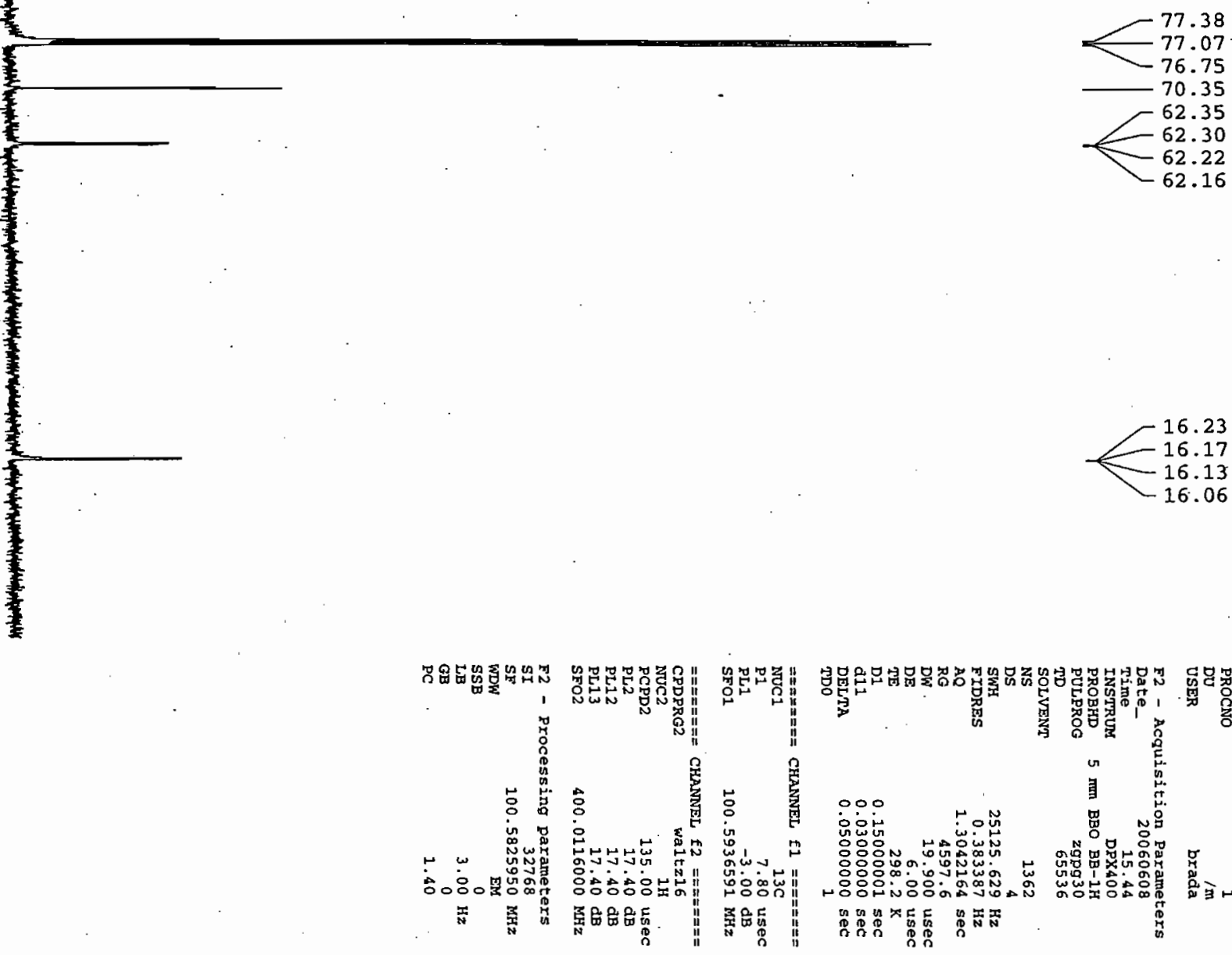

16.23

$-16.17$

$-16.13$ 

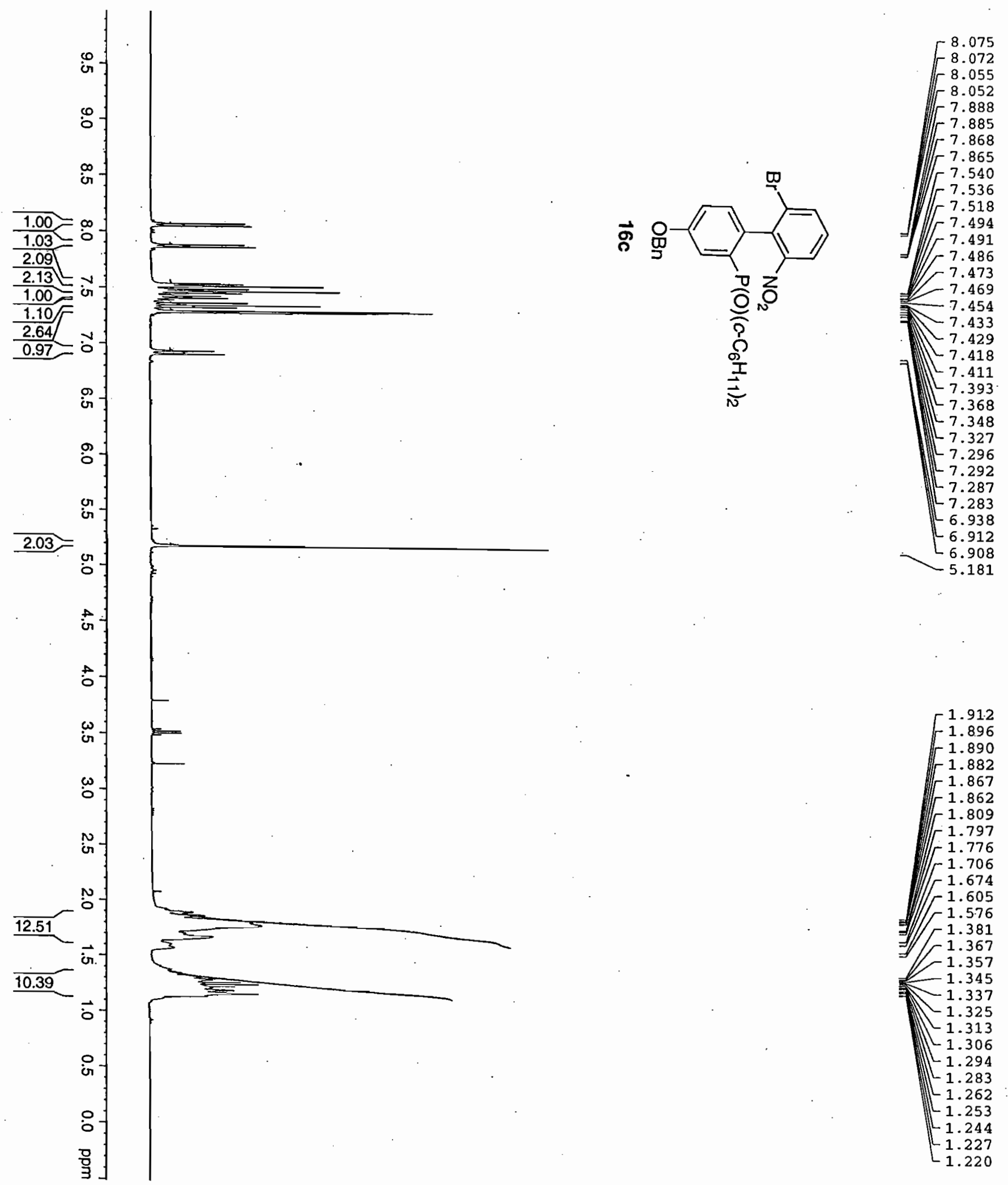

봉
团
号

7.885

T.8.85

III 7.540

7.536

7.494

$\Gamma^{7.491}$

$-7.473$

$-7.469$

$-7.454$

-7.433
-7.429

$-7.418$

$-7.411$

$-7.393$

7.368

$-7.348$

ㄴ 7.327

7.296

[ 7.292

L 7.287

[ 7.283

$-6.938$

$-6.912$

6.908
-5.181

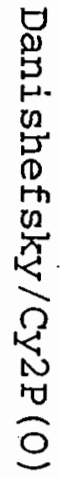

5.181
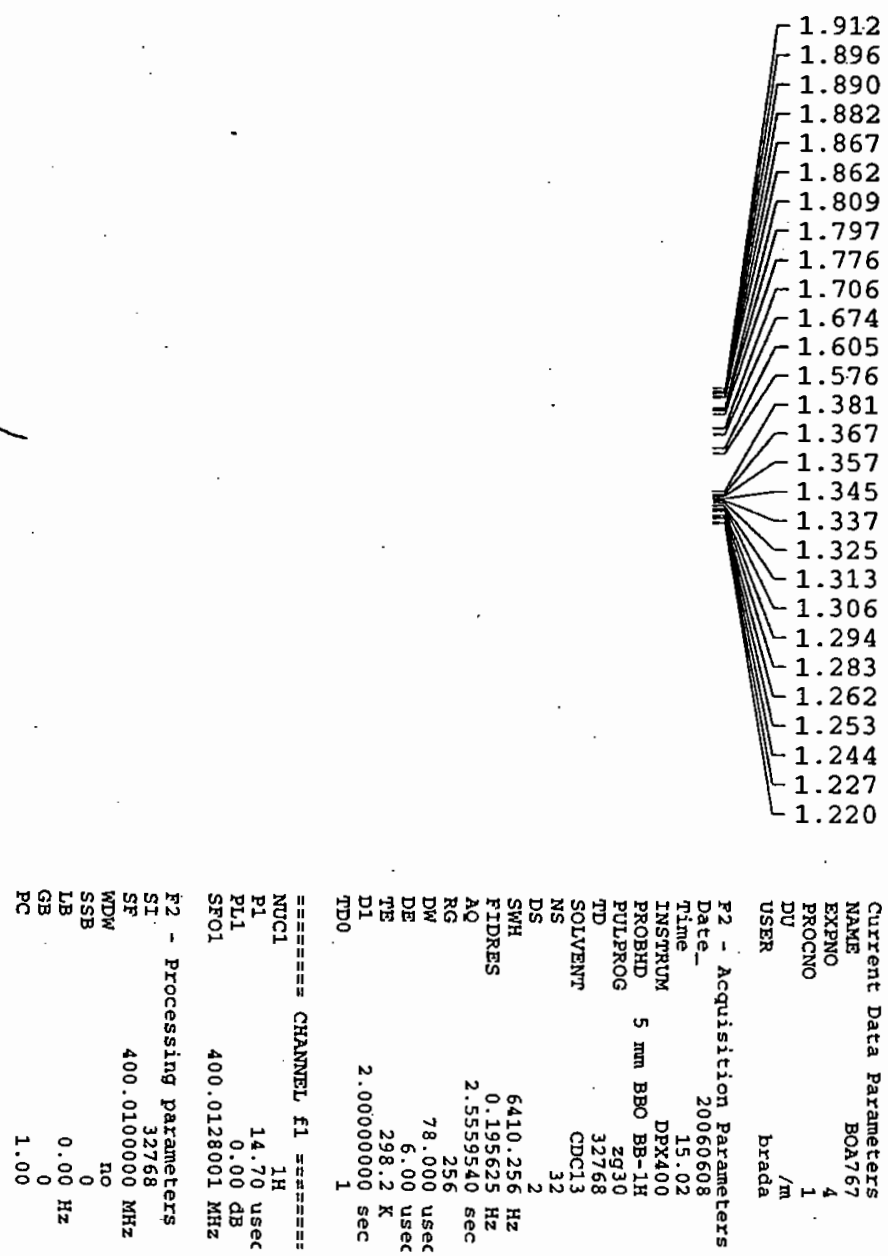

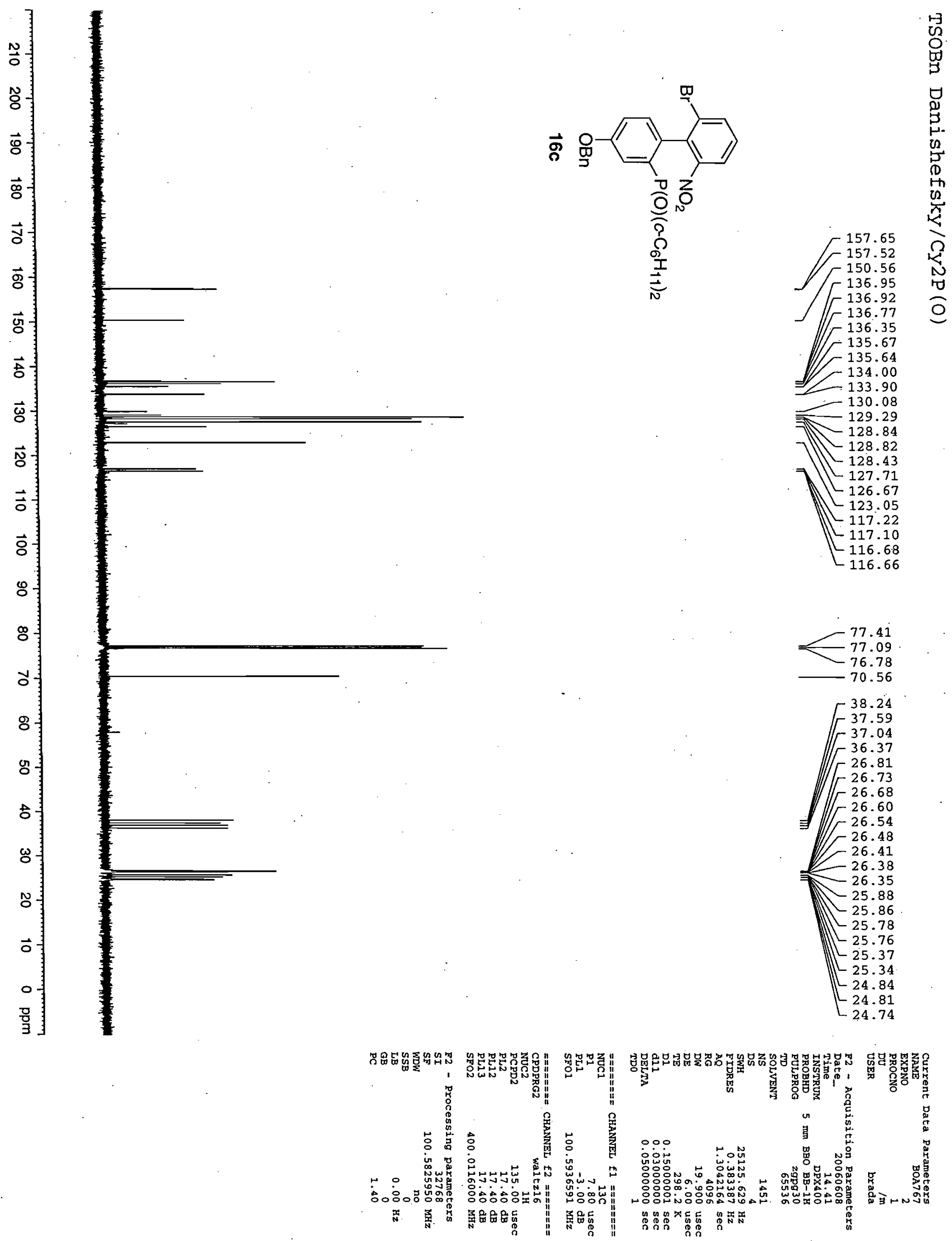

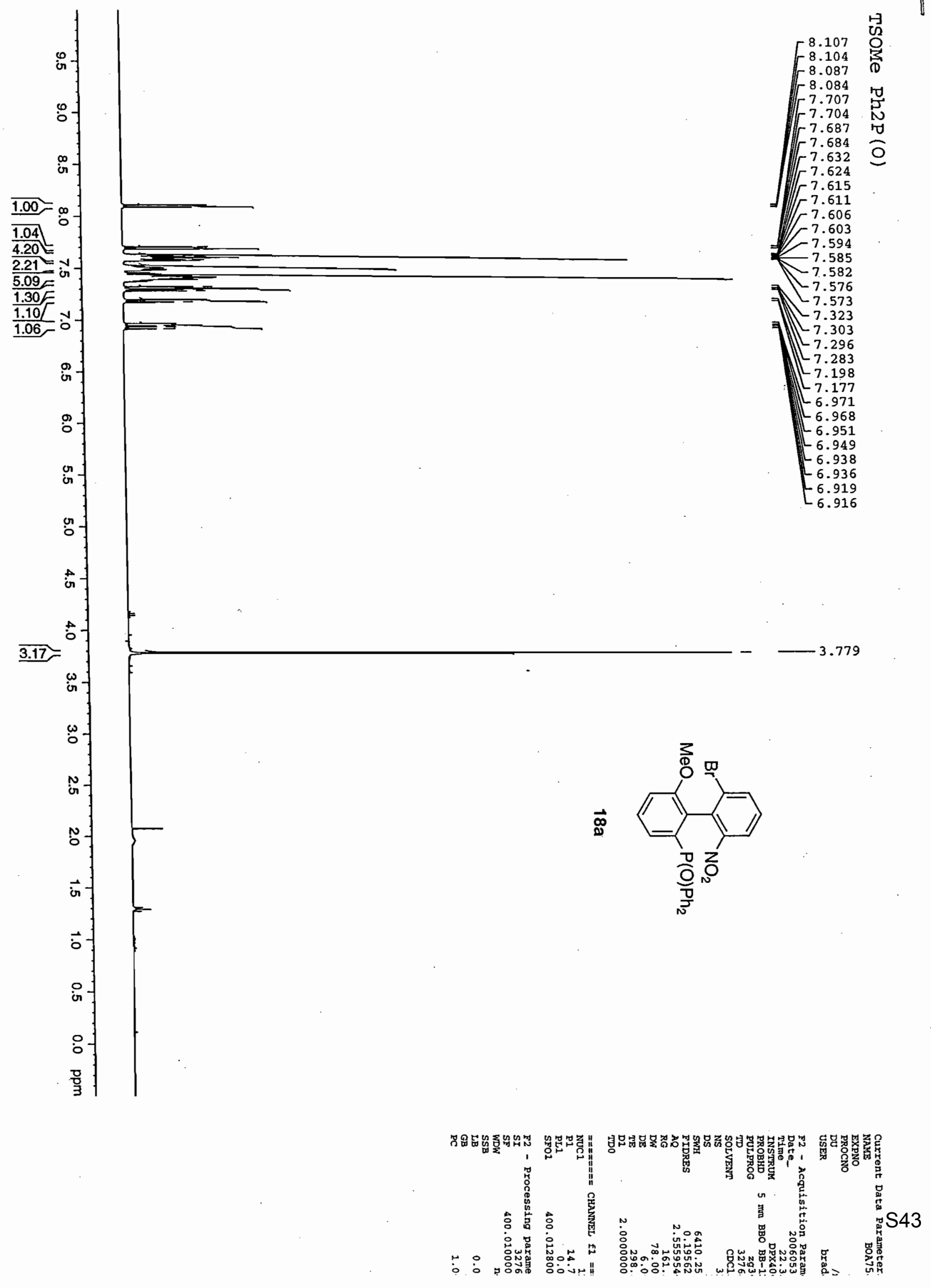

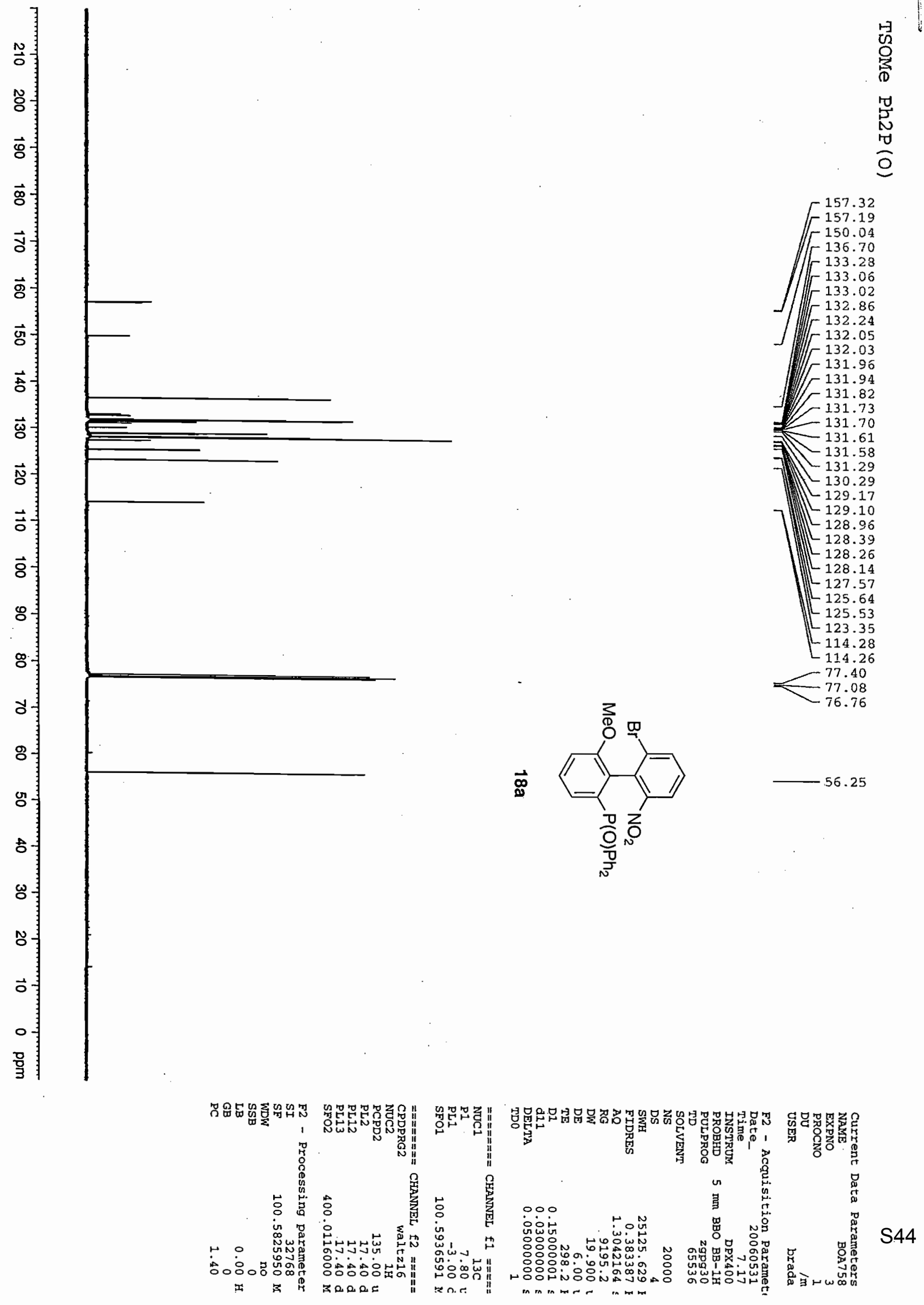


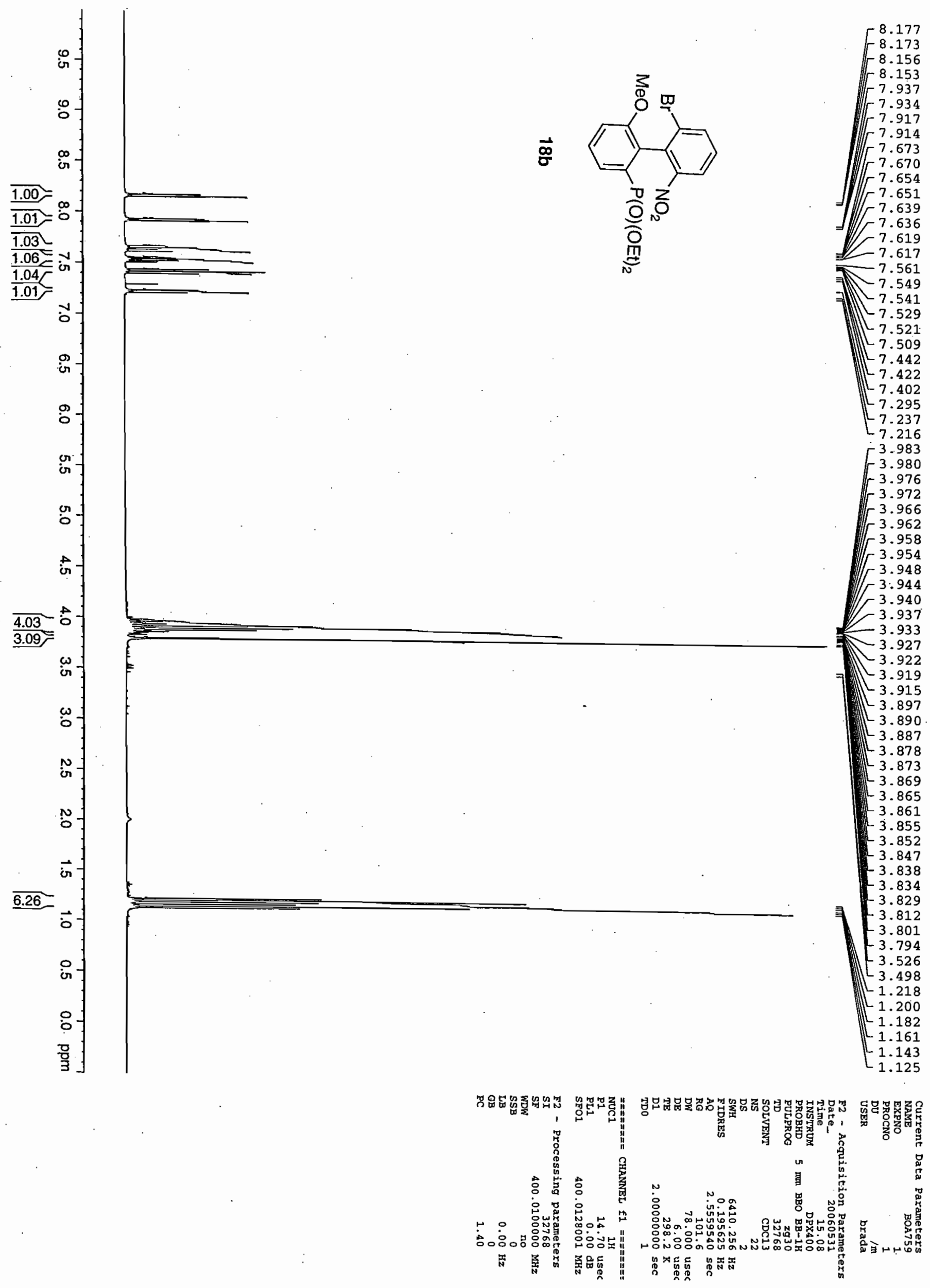

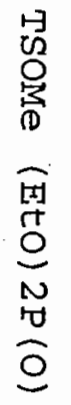



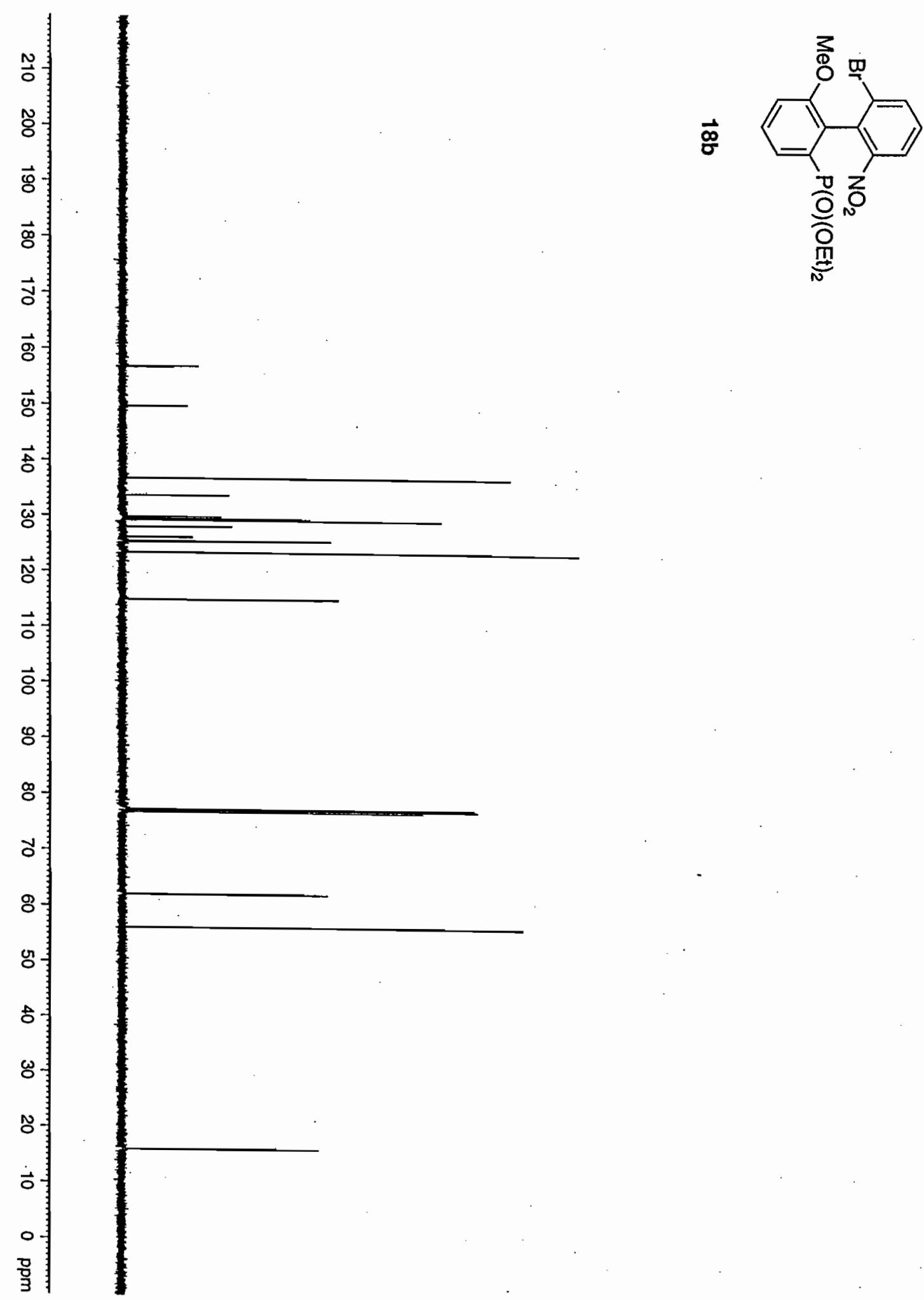

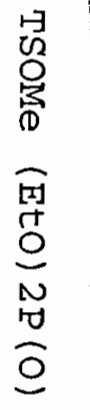
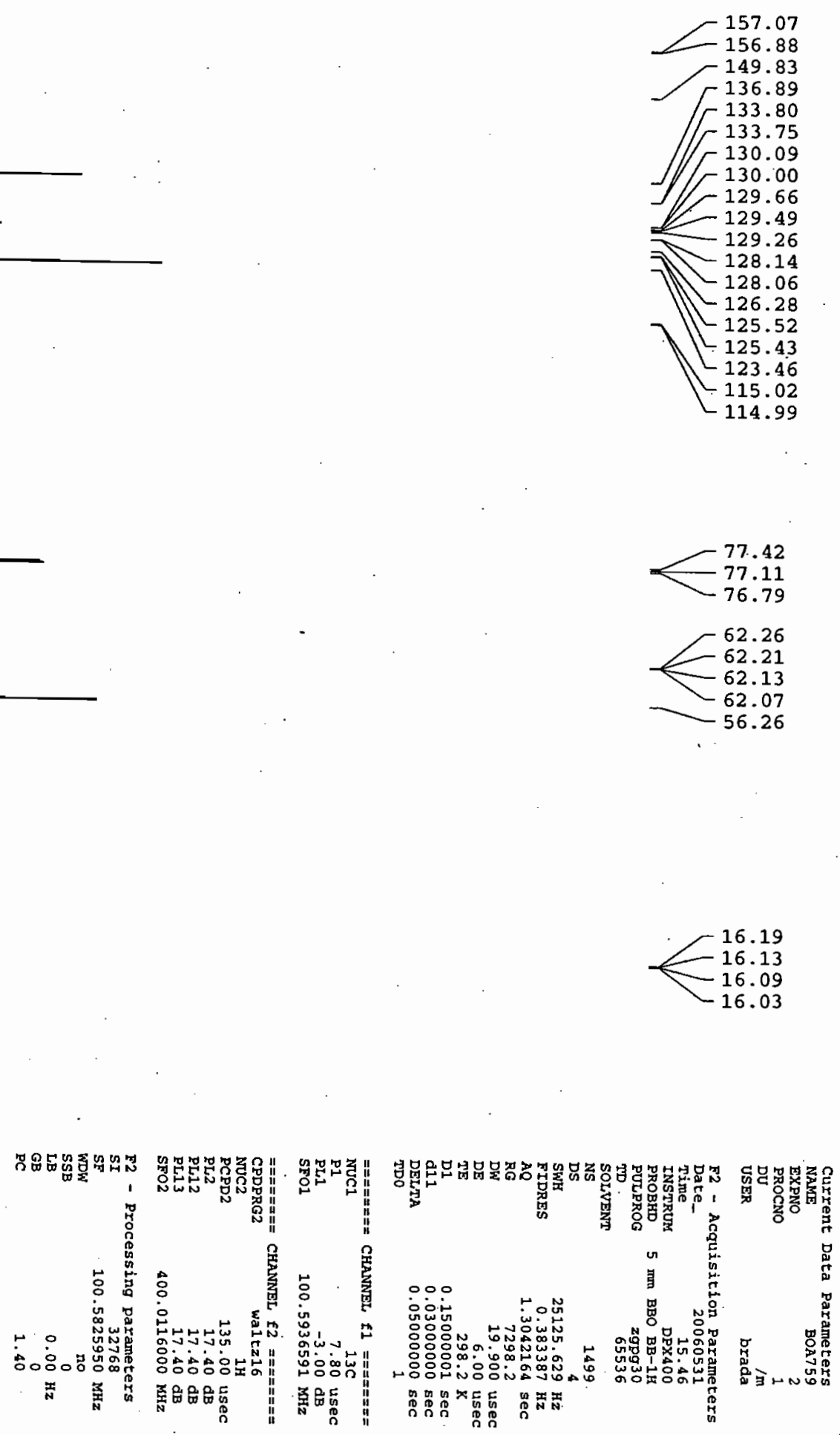


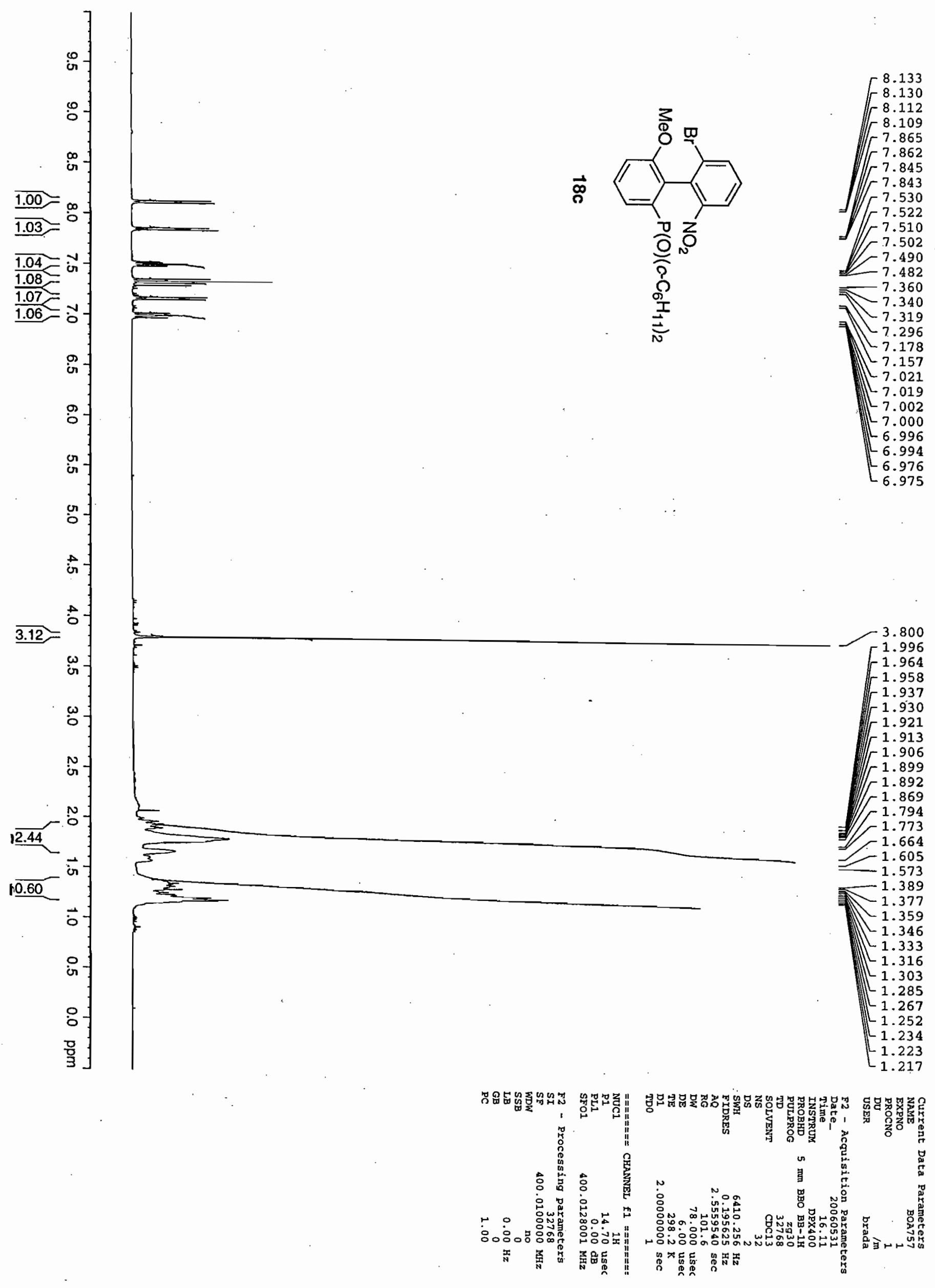

是 

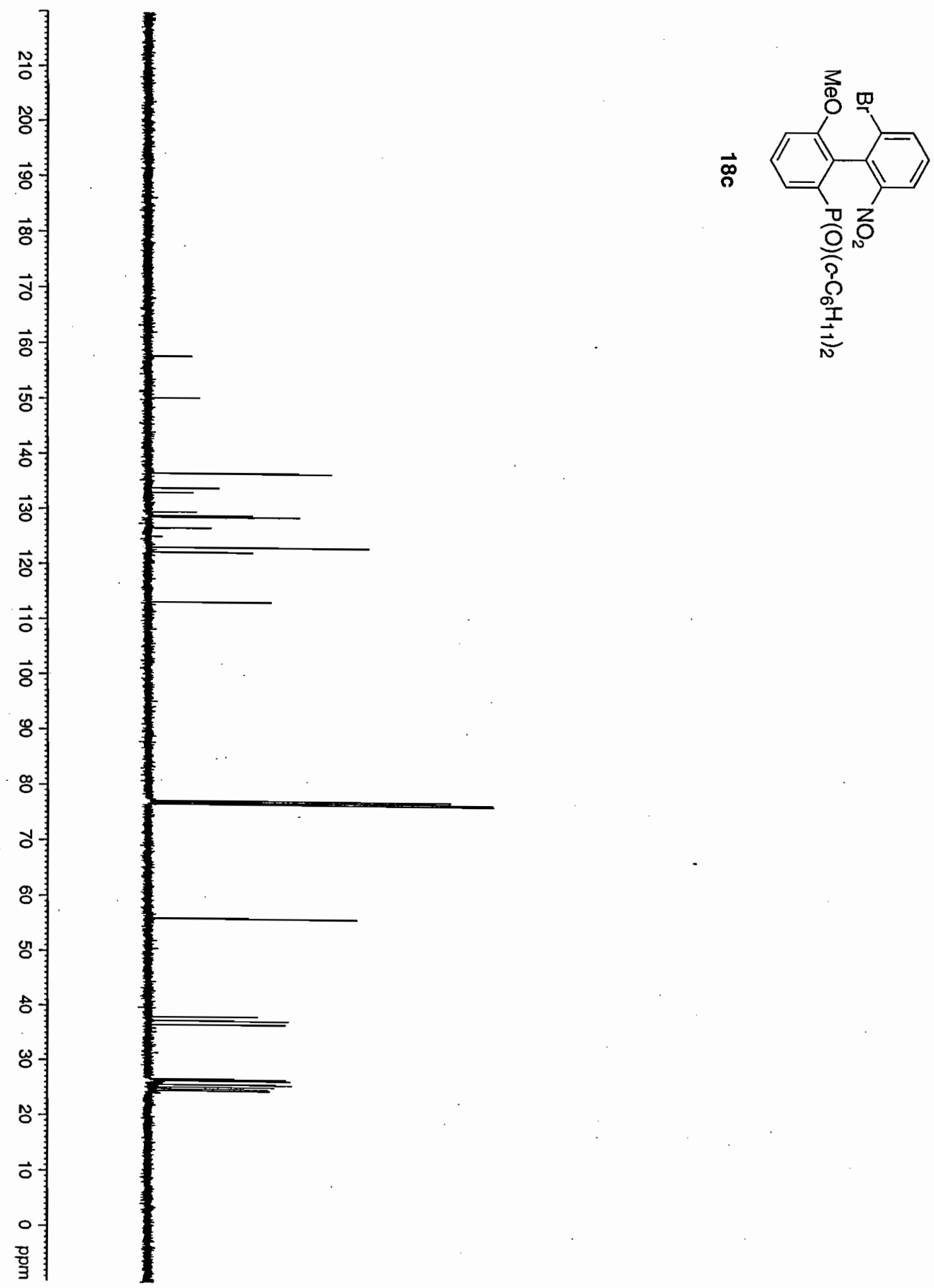

是
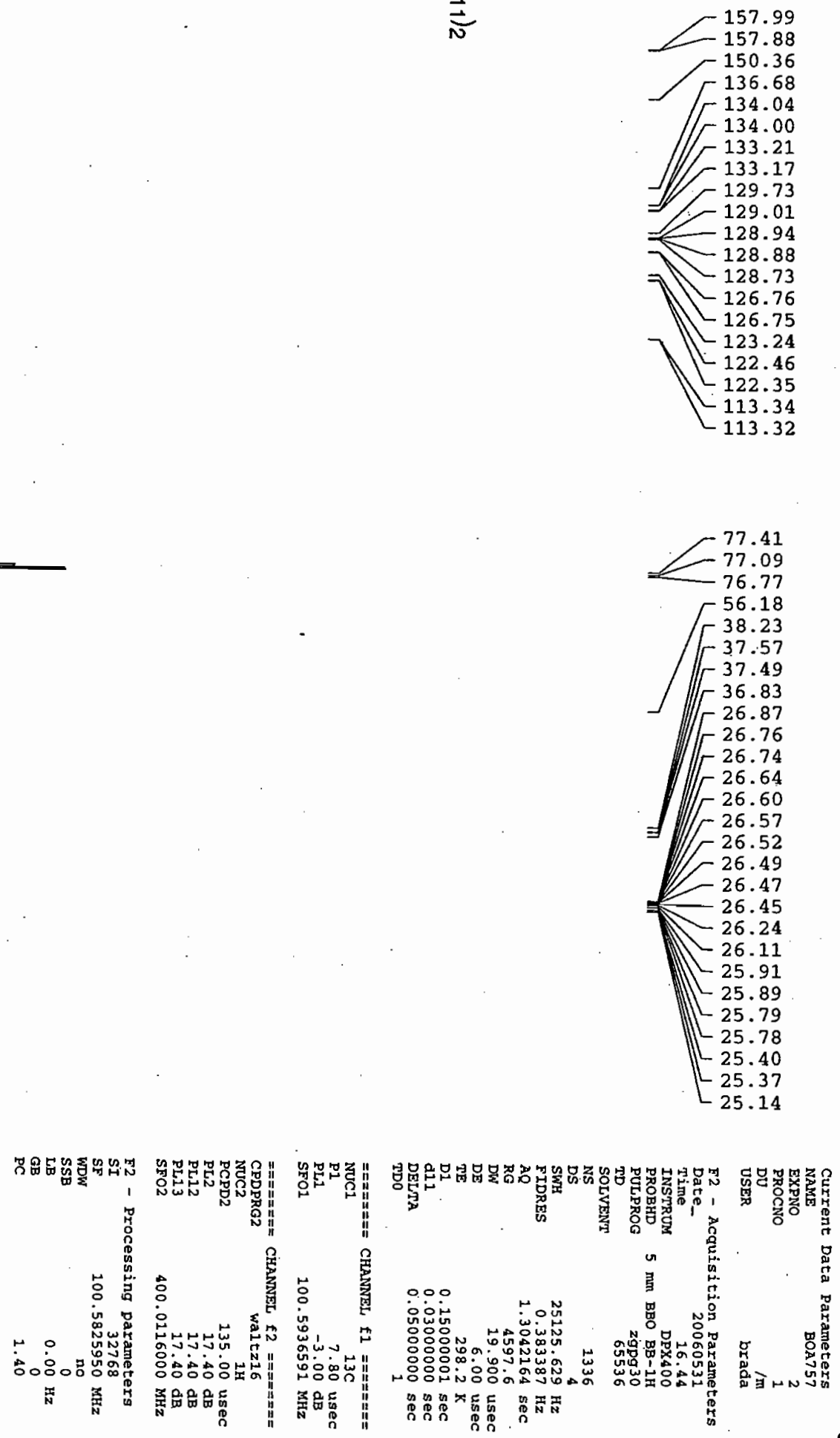

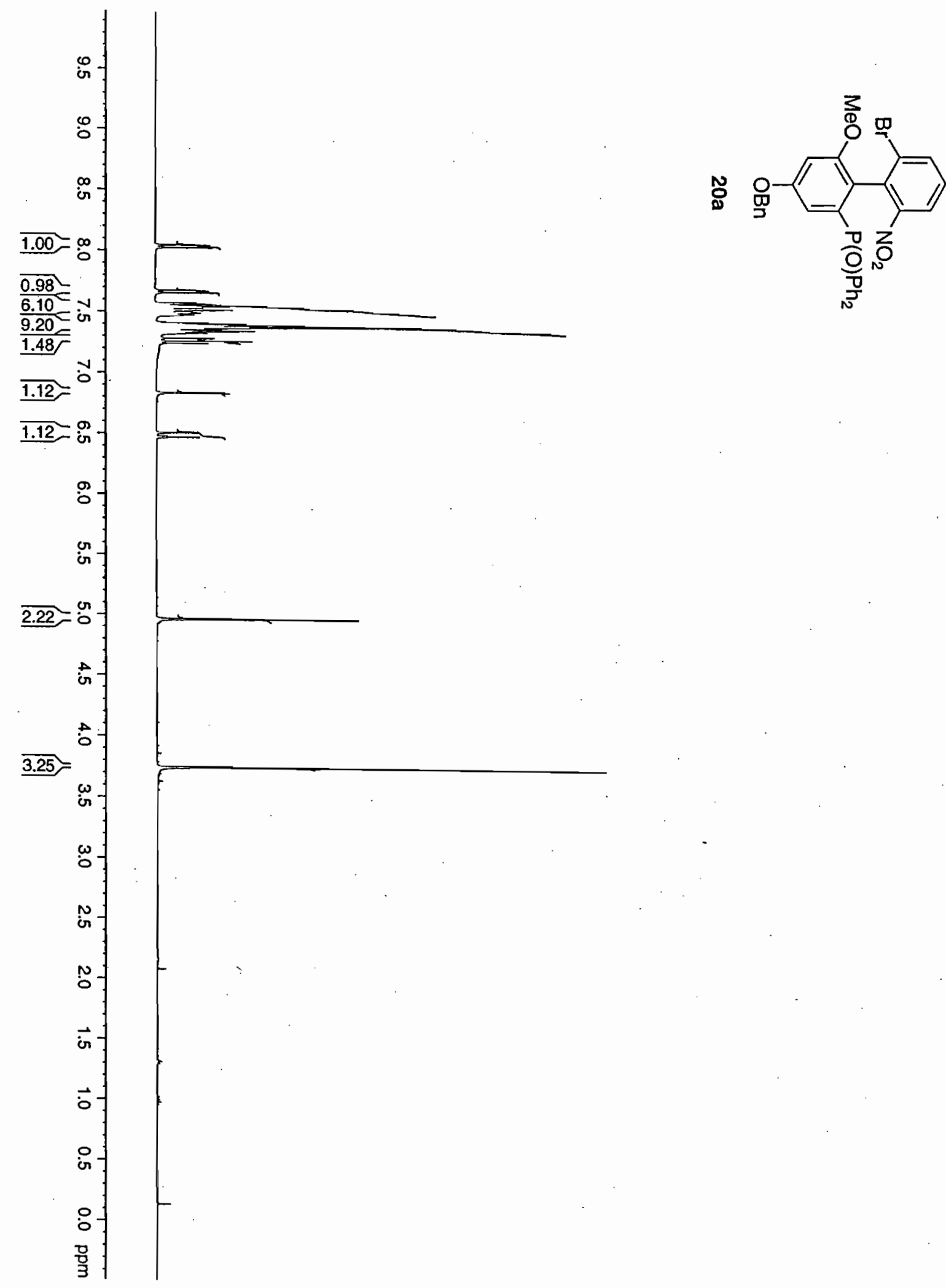

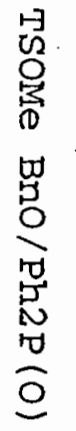

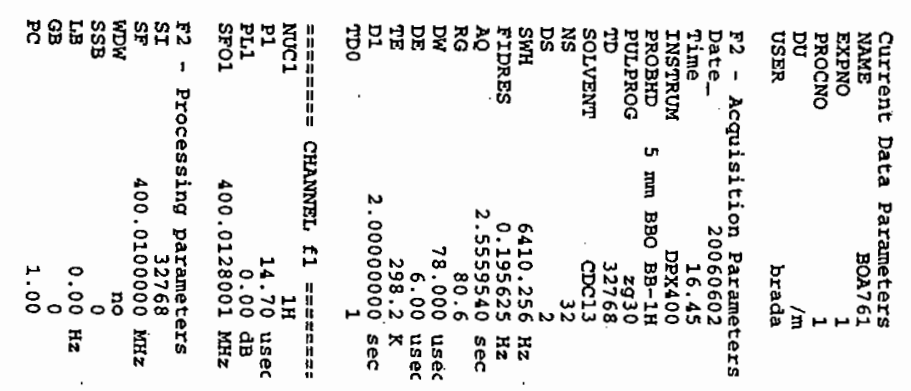




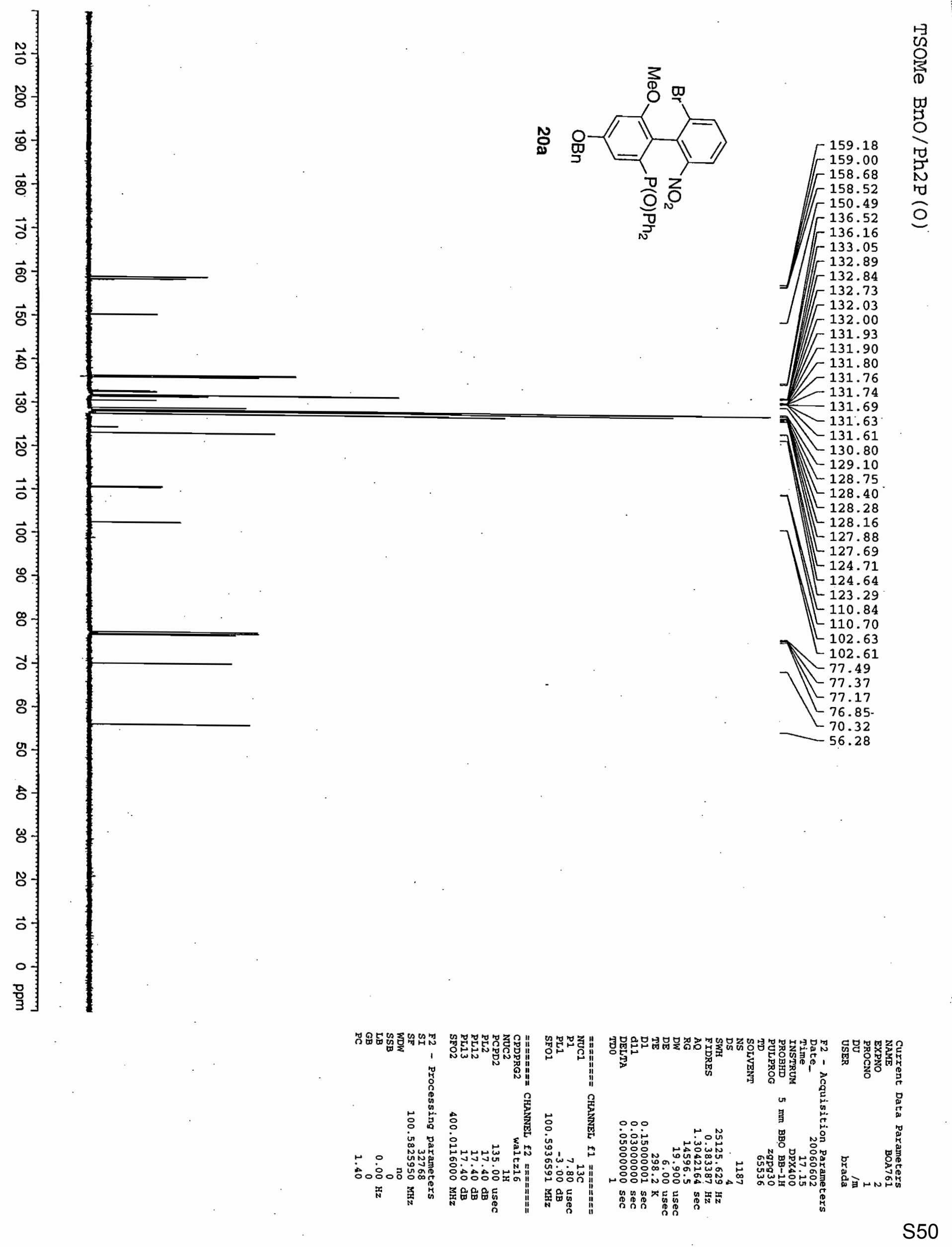




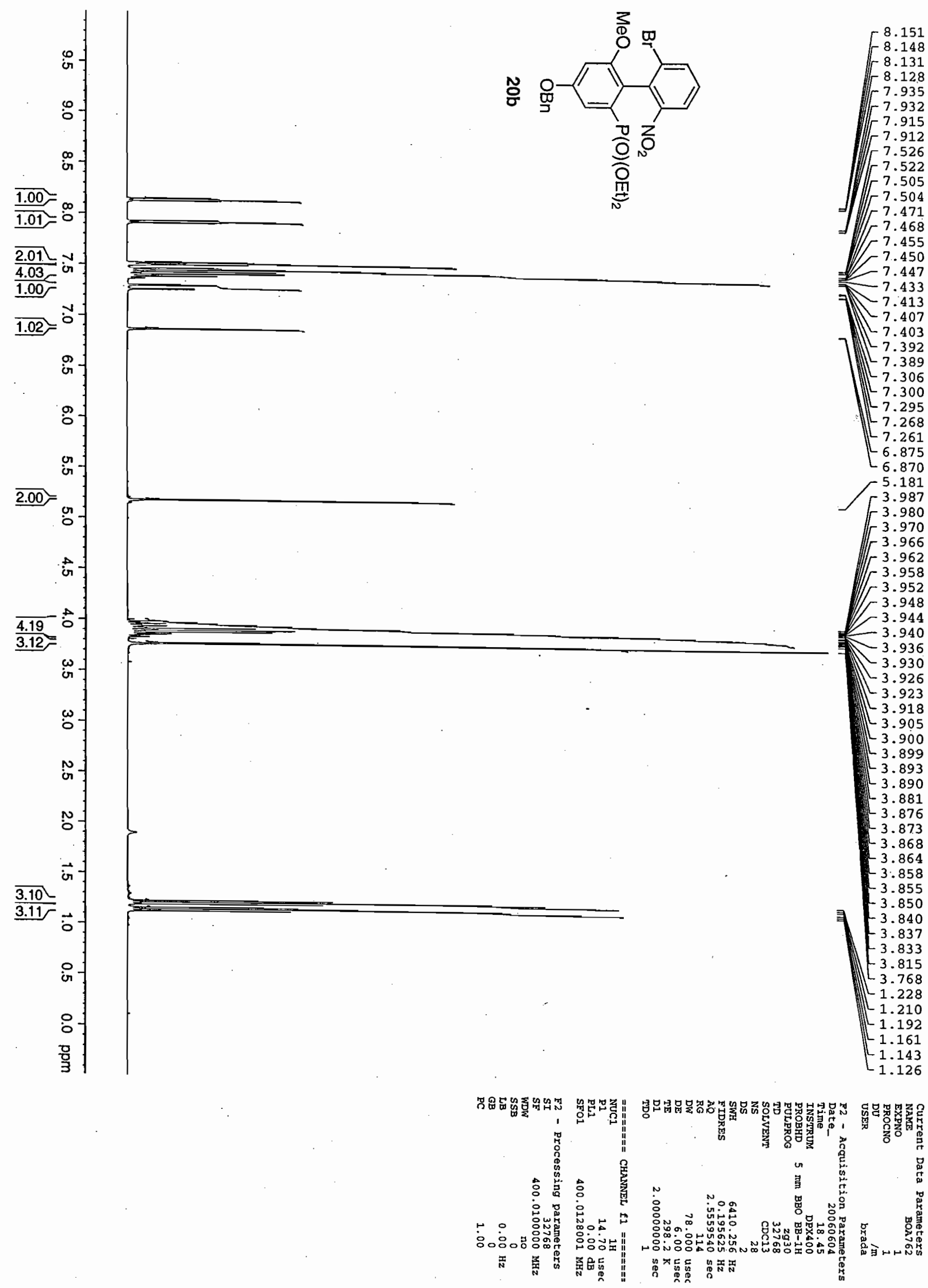

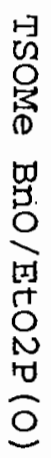




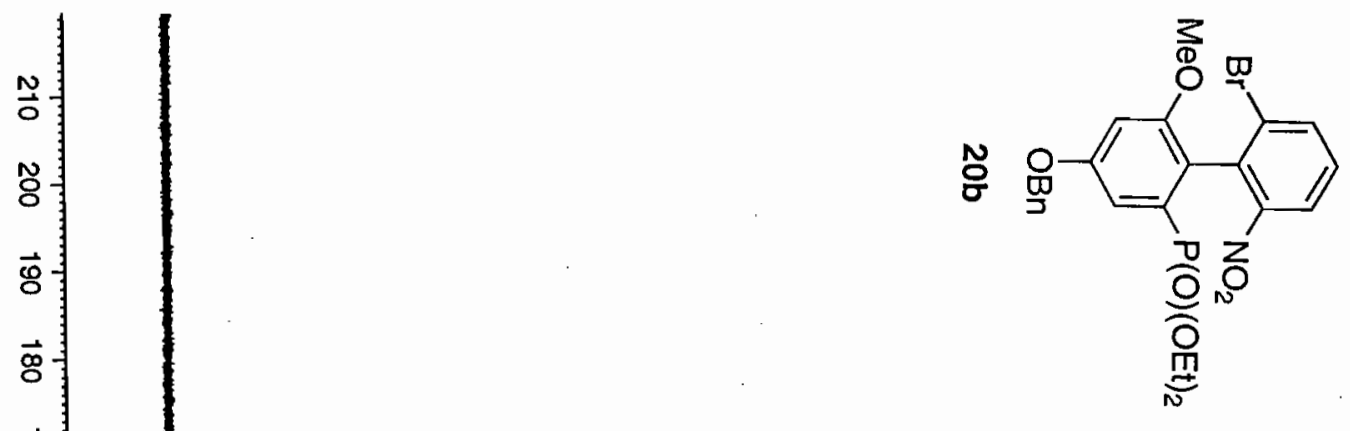

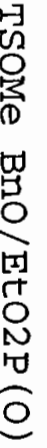

ఫ̊

홍

बํ.

官

ผ

N

$$
\text { a }
$$

$$
8
$$

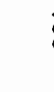
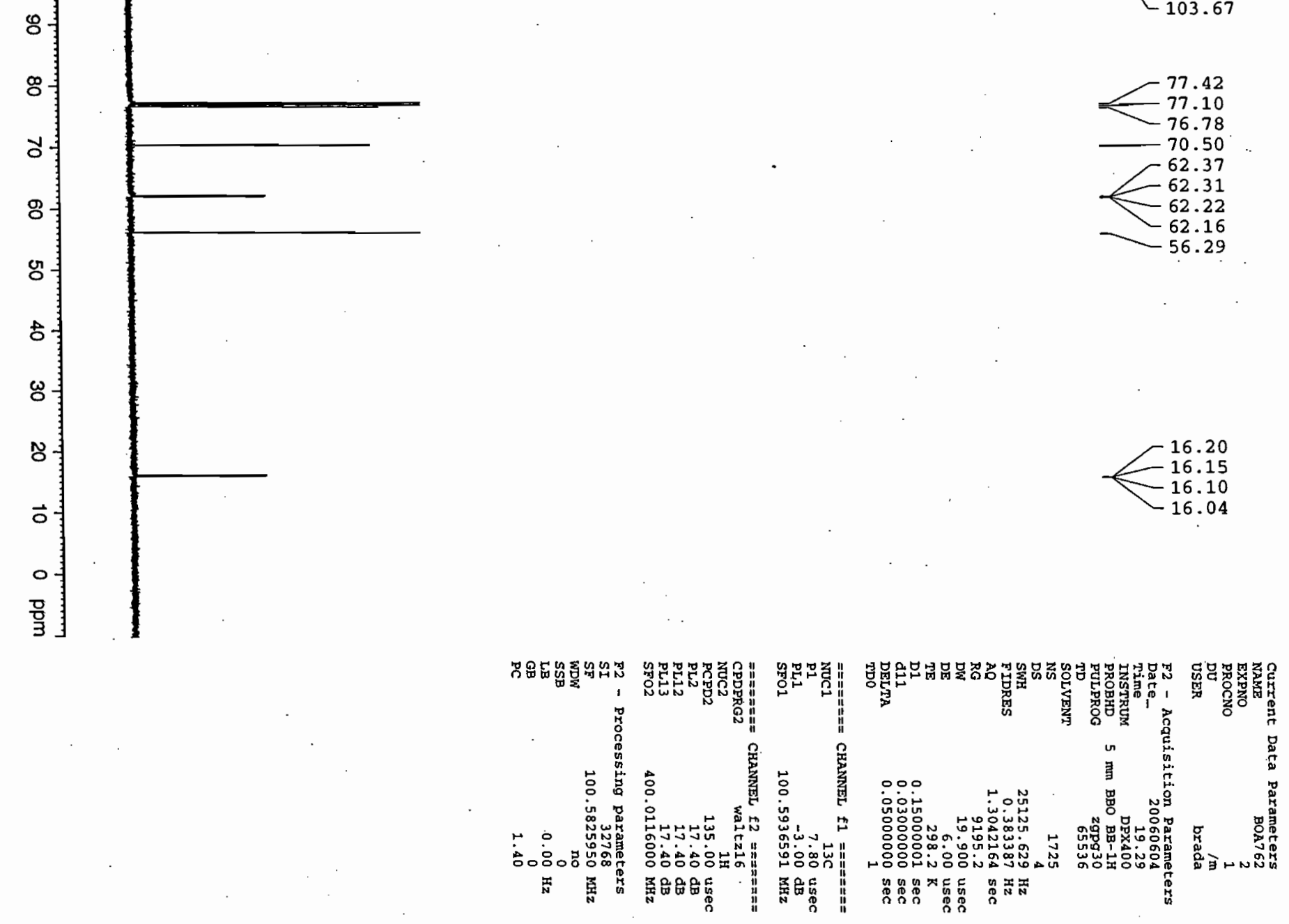


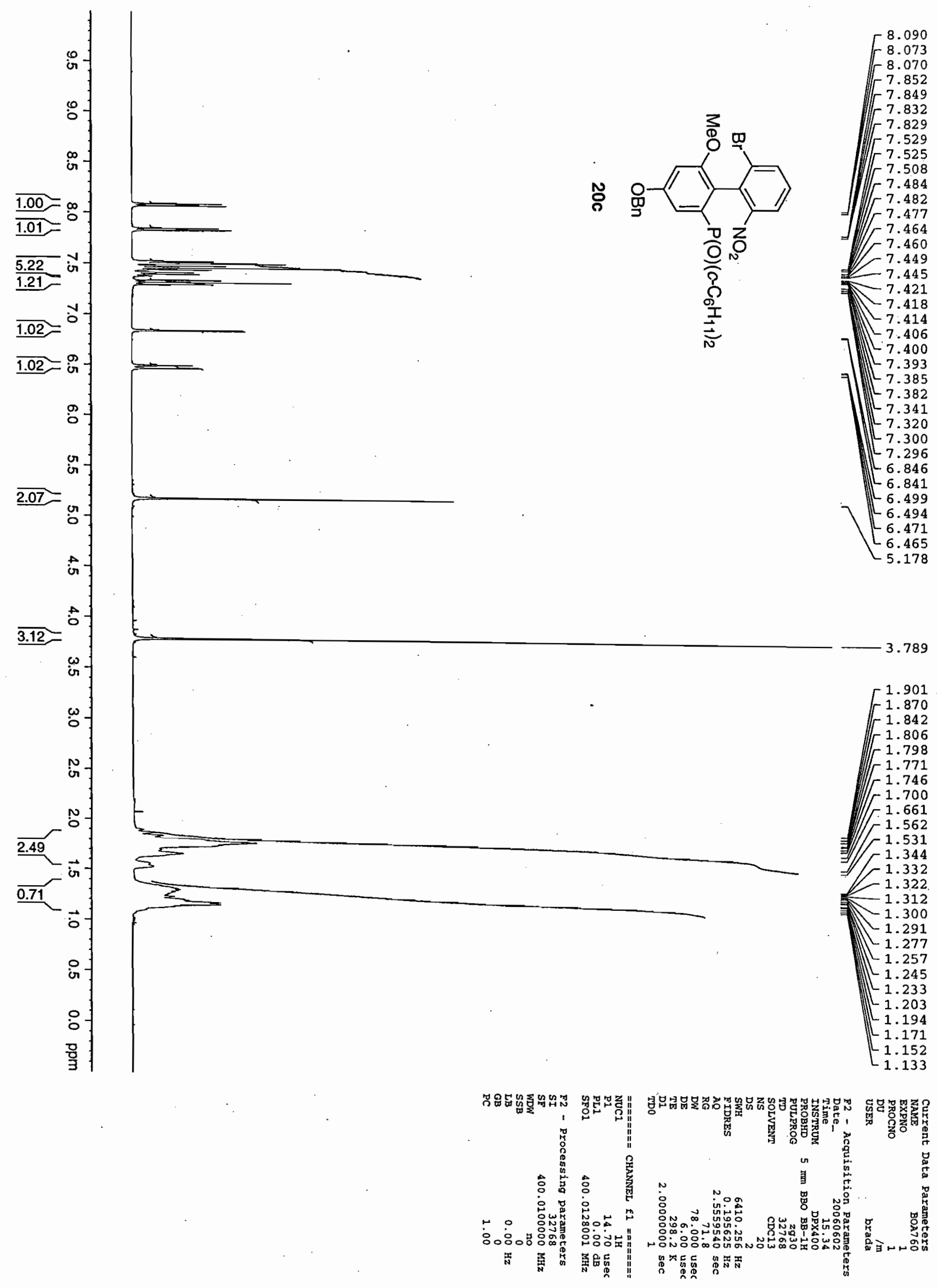

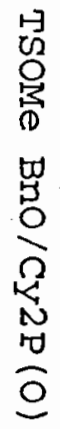



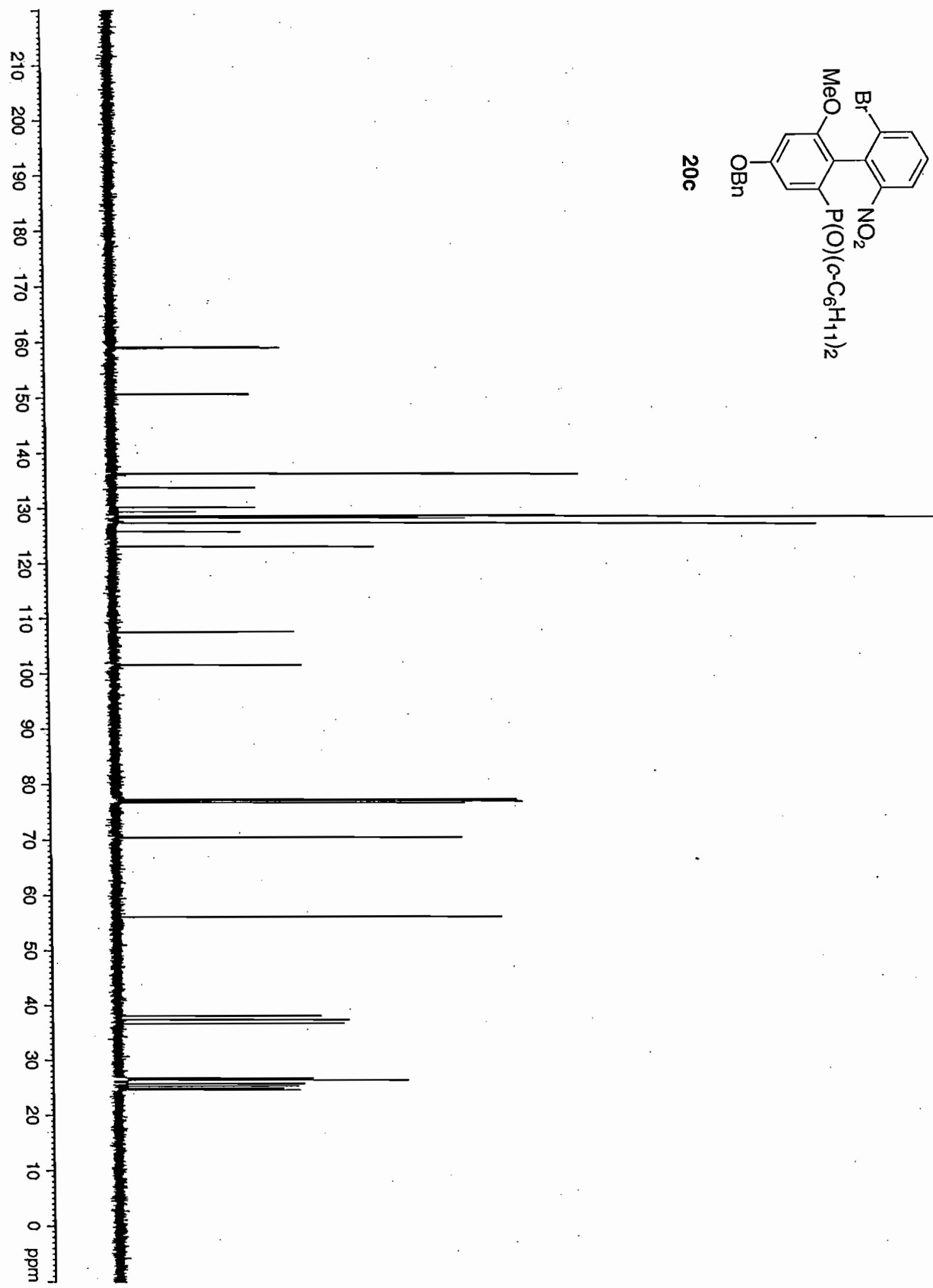

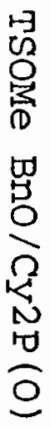

159.31

159.19

159.16

150.79

136.49

-136.45

$\Gamma^{133.90}$

F 133.87

$-129.53$

128.85

128.62
-128.39

$-127.52$

$-125.90$

$-125.86$

123.18

107.71
-107.60

$\checkmark 101.64$

$-101.62$

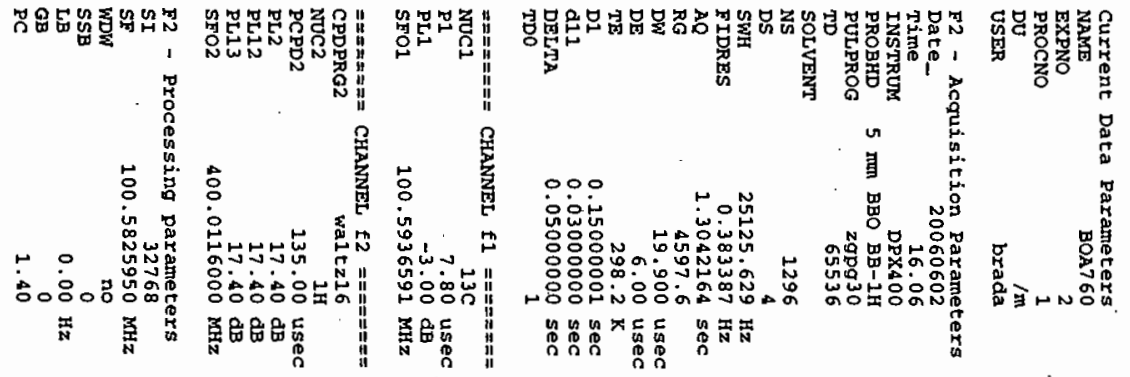



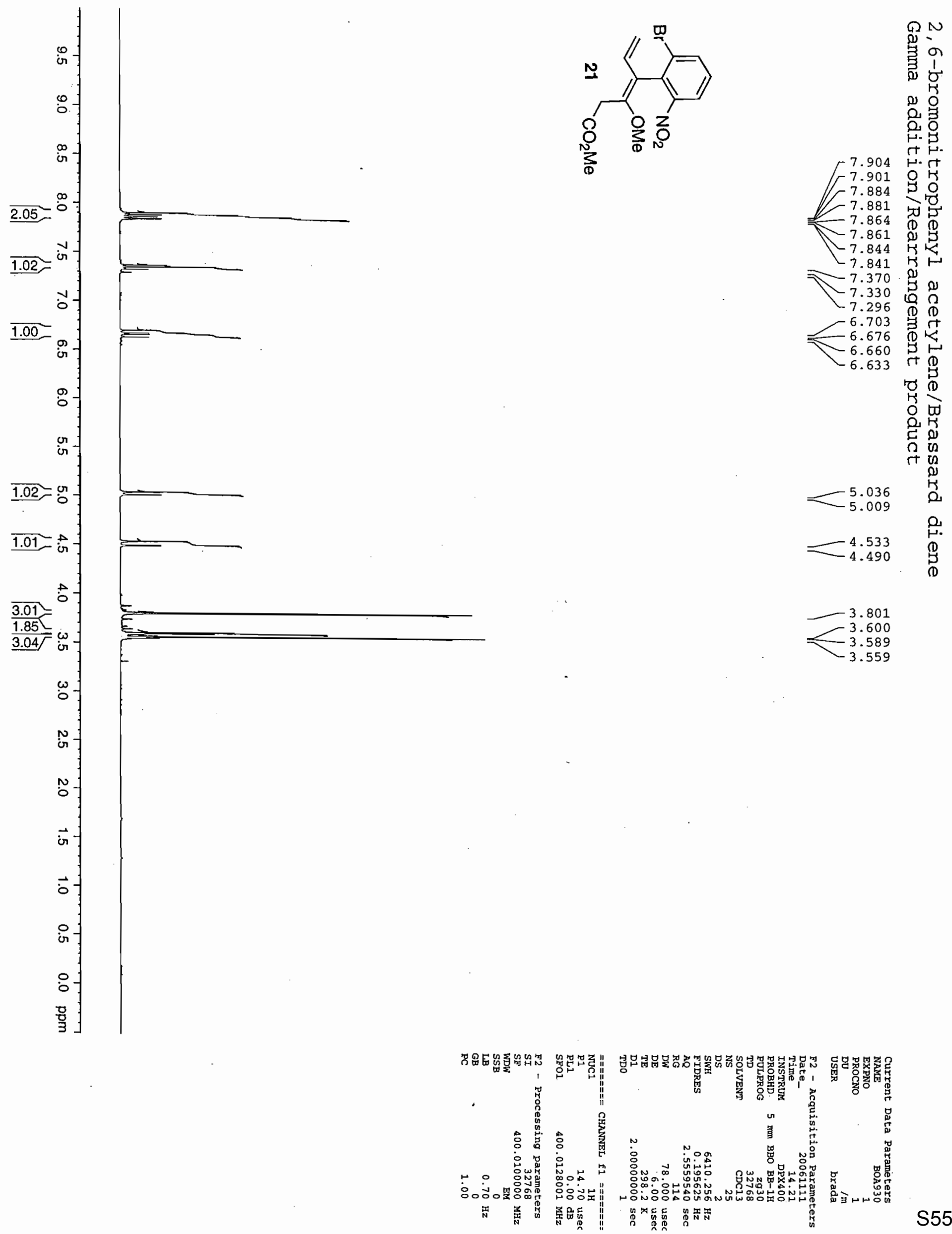


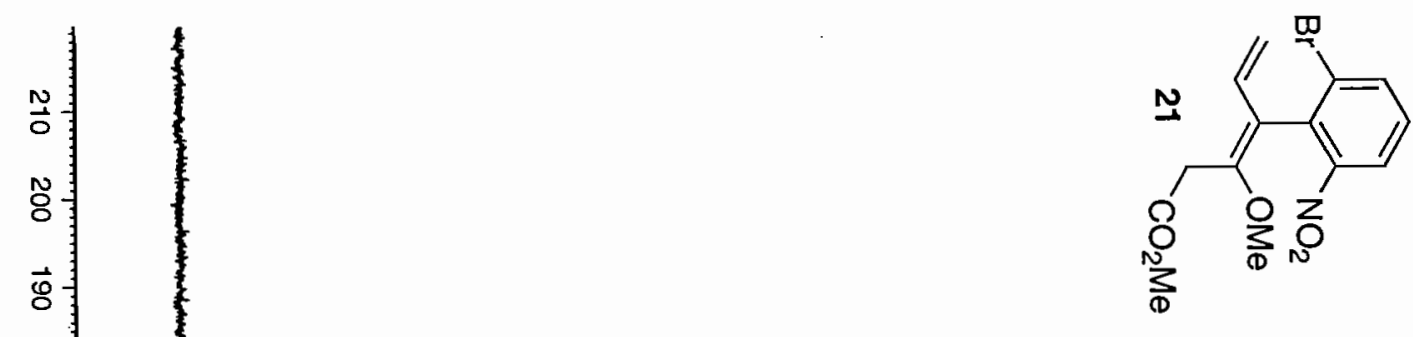

$\overrightarrow{\mathrm{o}}$

$\vec{\partial}$

형

ज्ञ

$\overrightarrow{\mathrm{f}}$

$\overrightarrow{\mathrm{\omega}}$

$\overrightarrow{\widetilde{N}}$

పे

$\overrightarrow{8}$

8

\$

ปे

8

용

s

$\omega$

ㅇ

$\vec{o}$

흥
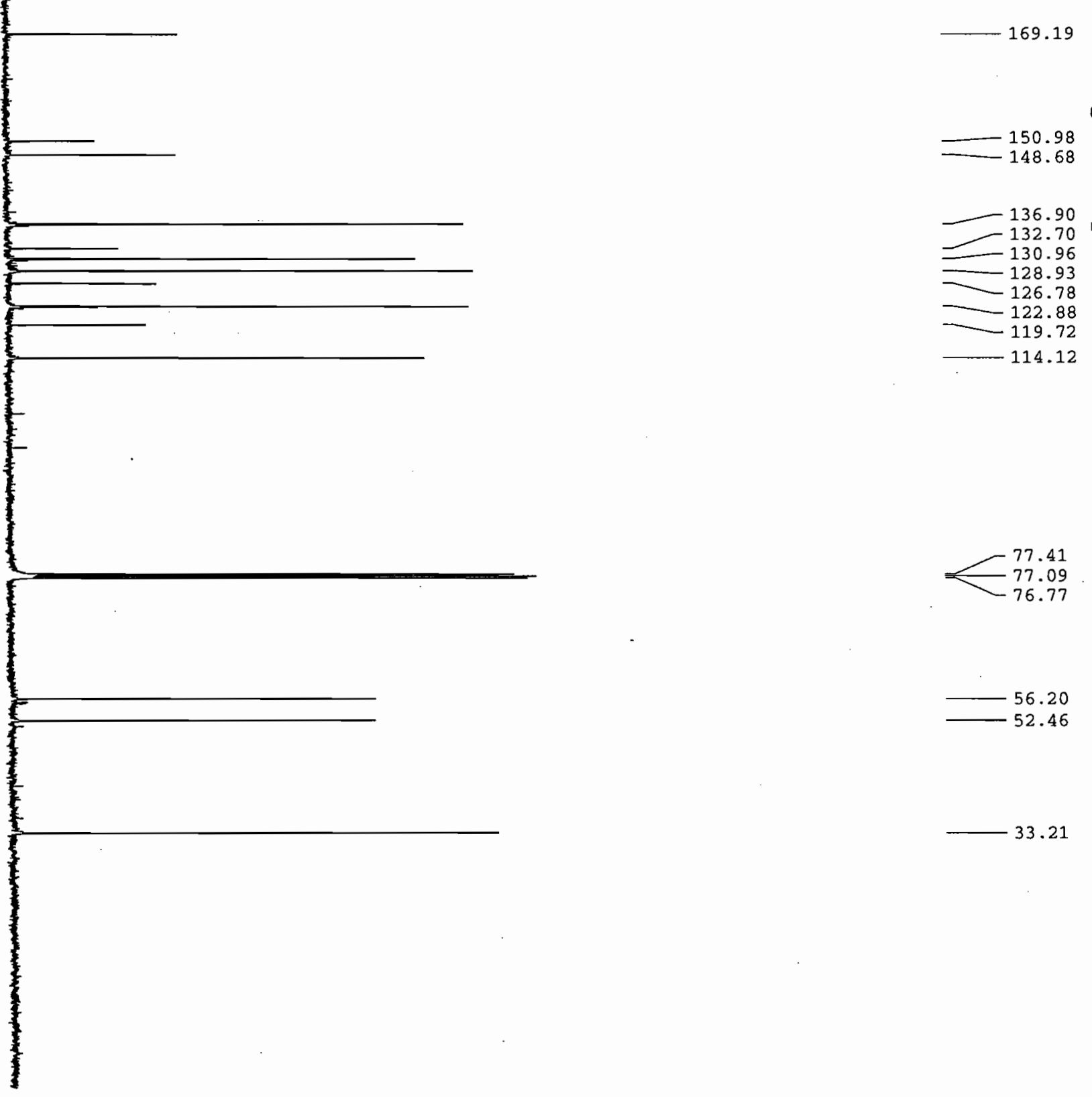
$\square$
$=$ 130.96 $=128.93$ $-126.78$ - 122.88

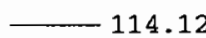
119.72
114.12 $Q N$

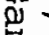
5 $\frac{1}{0}$ (

은

ㅇ. tri H.

ถ

(D) (D 芩 年 $+\mathbb{D}$ o $D$ मे Q त

$\Omega$

吕

7.41

77.09

$-76.77$

56.20

52.46

33.21

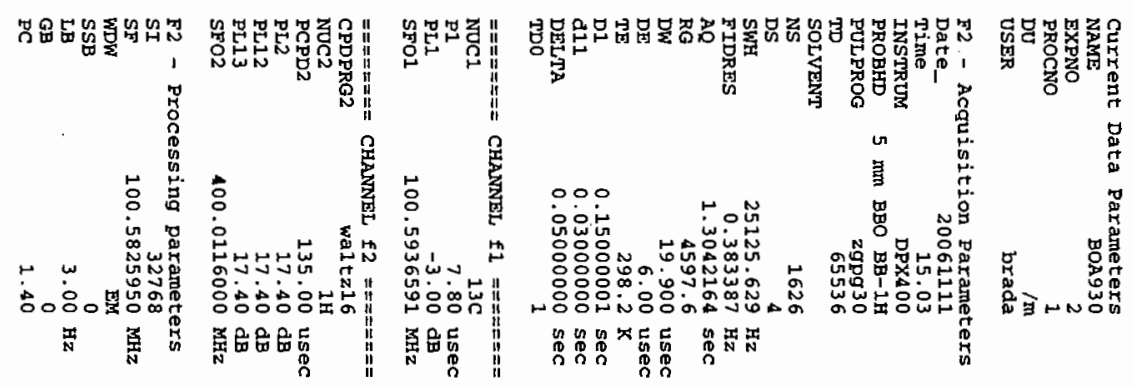



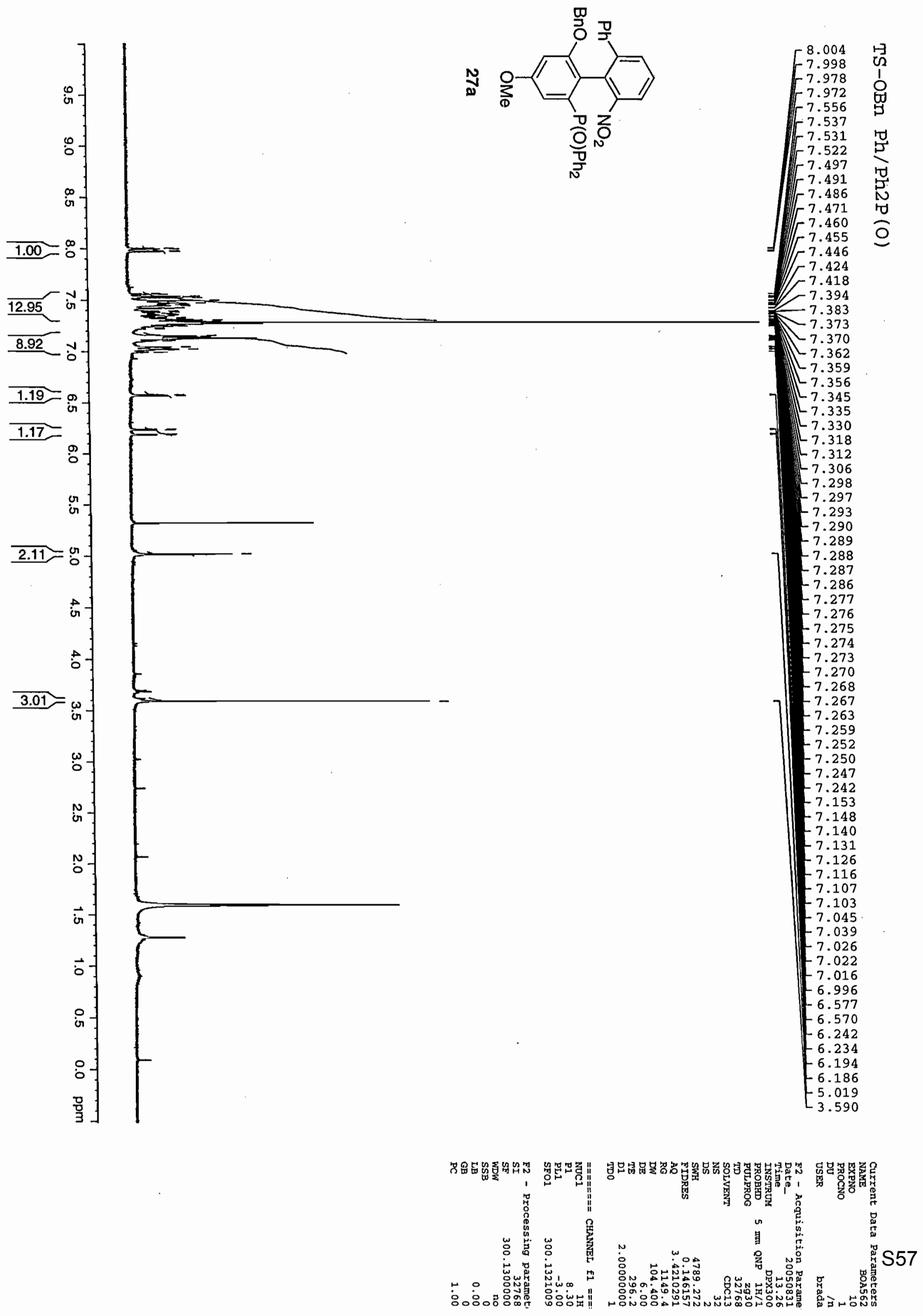


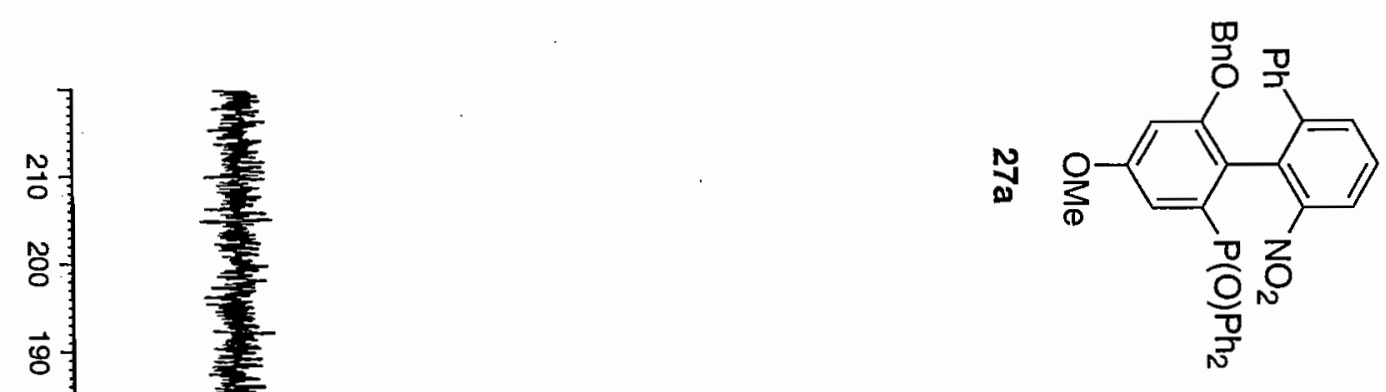

-1
0
0
0
0
0
0
0
0
0
0
0
0

8

$\vec{\partial}$

$$
\text { . }
$$

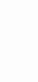

\section{\&}

$\vec{n}$

$\overrightarrow{0}$

용

8

ø

ปे

o

g.

吕

$\omega$

No

요

$\circ$

목
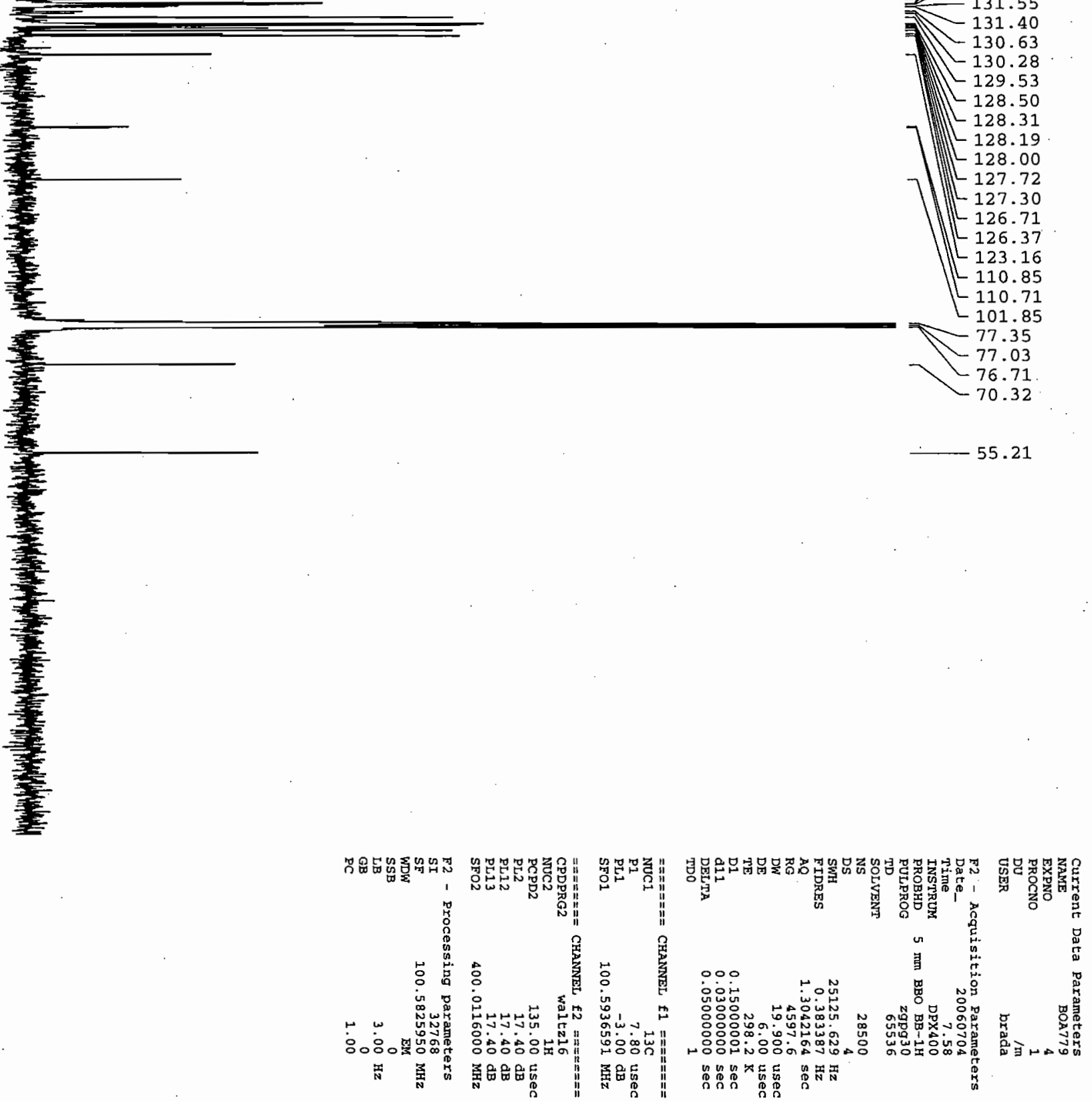

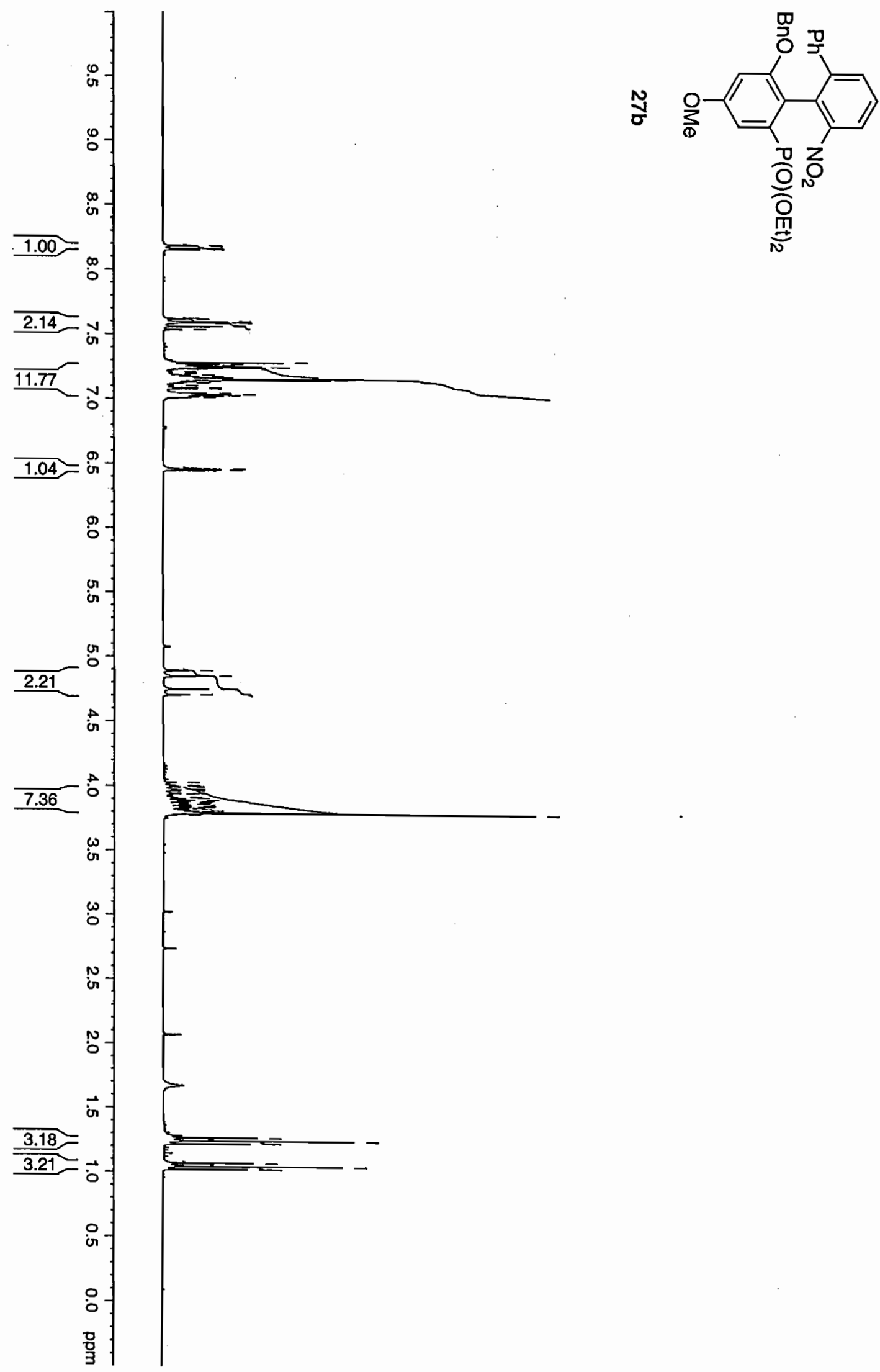

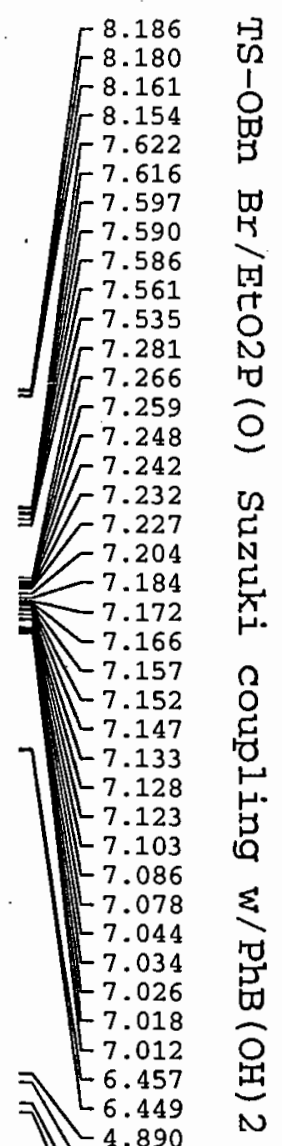

$-4.848$

$-4.746$

4.704

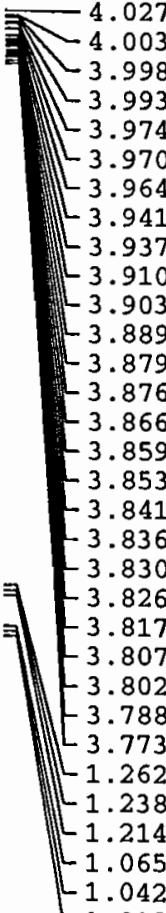

$L_{1.018}$

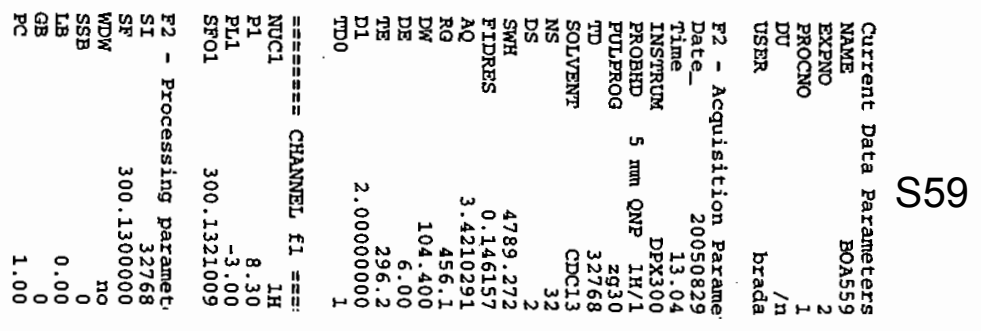



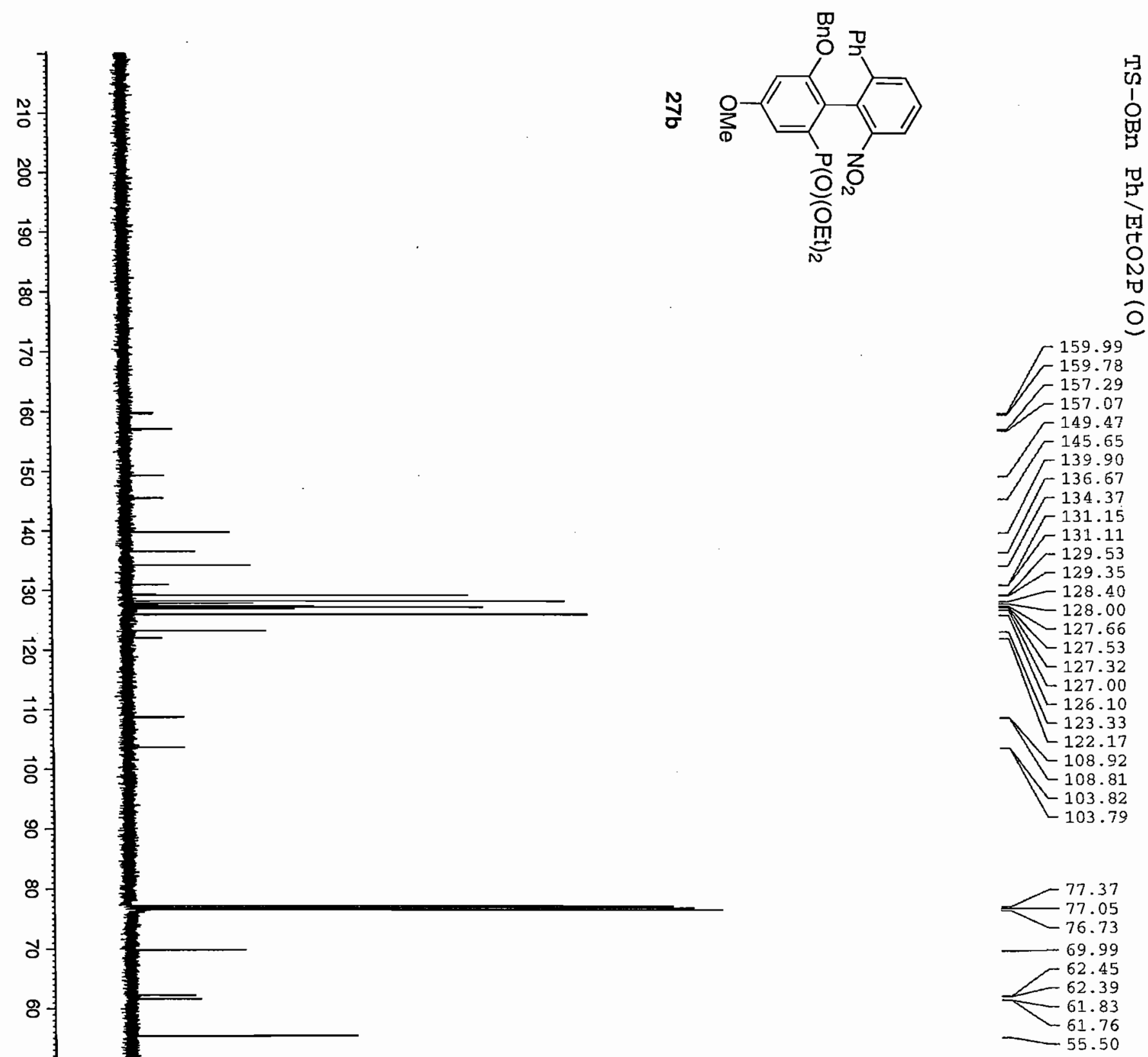

잉

to

$\omega$

ธ

$\overrightarrow{0}$

뭉

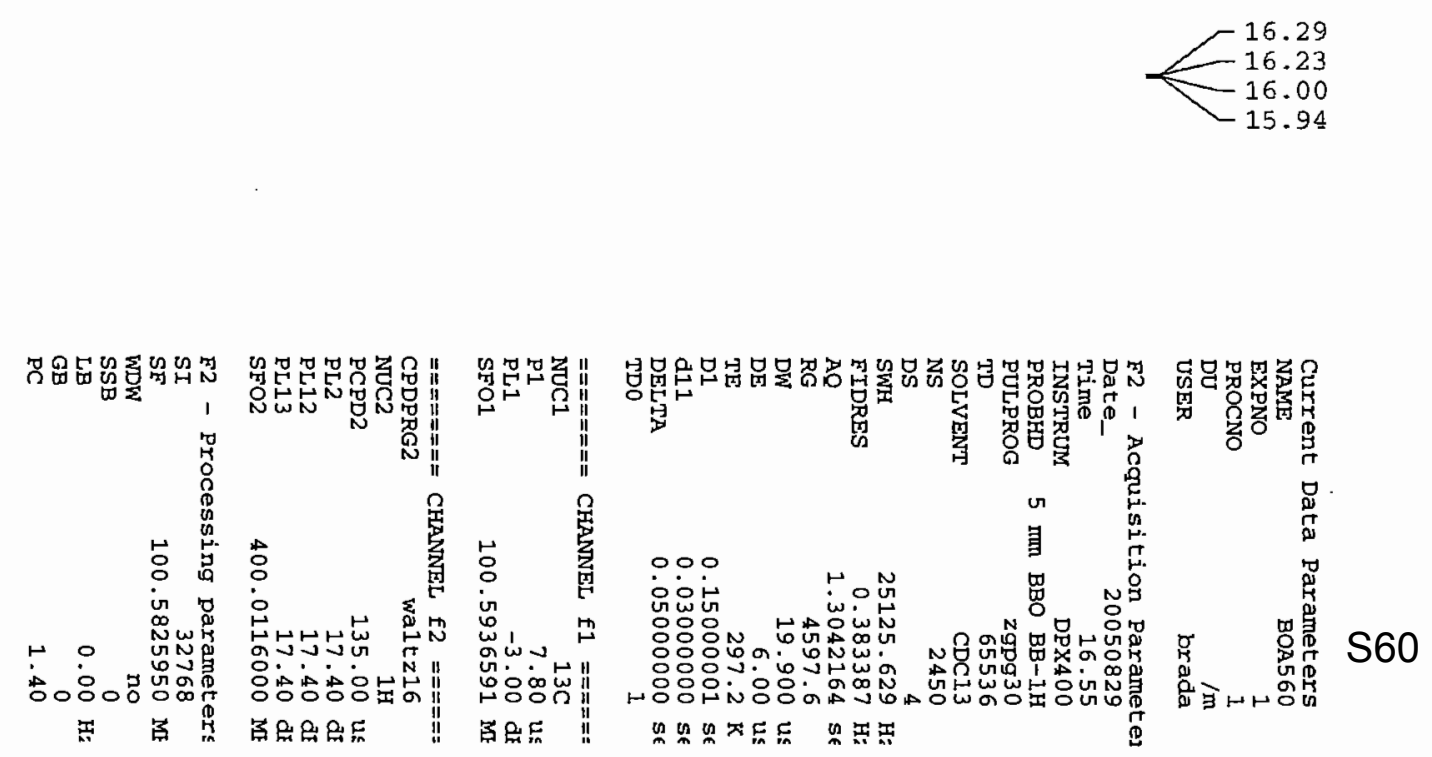



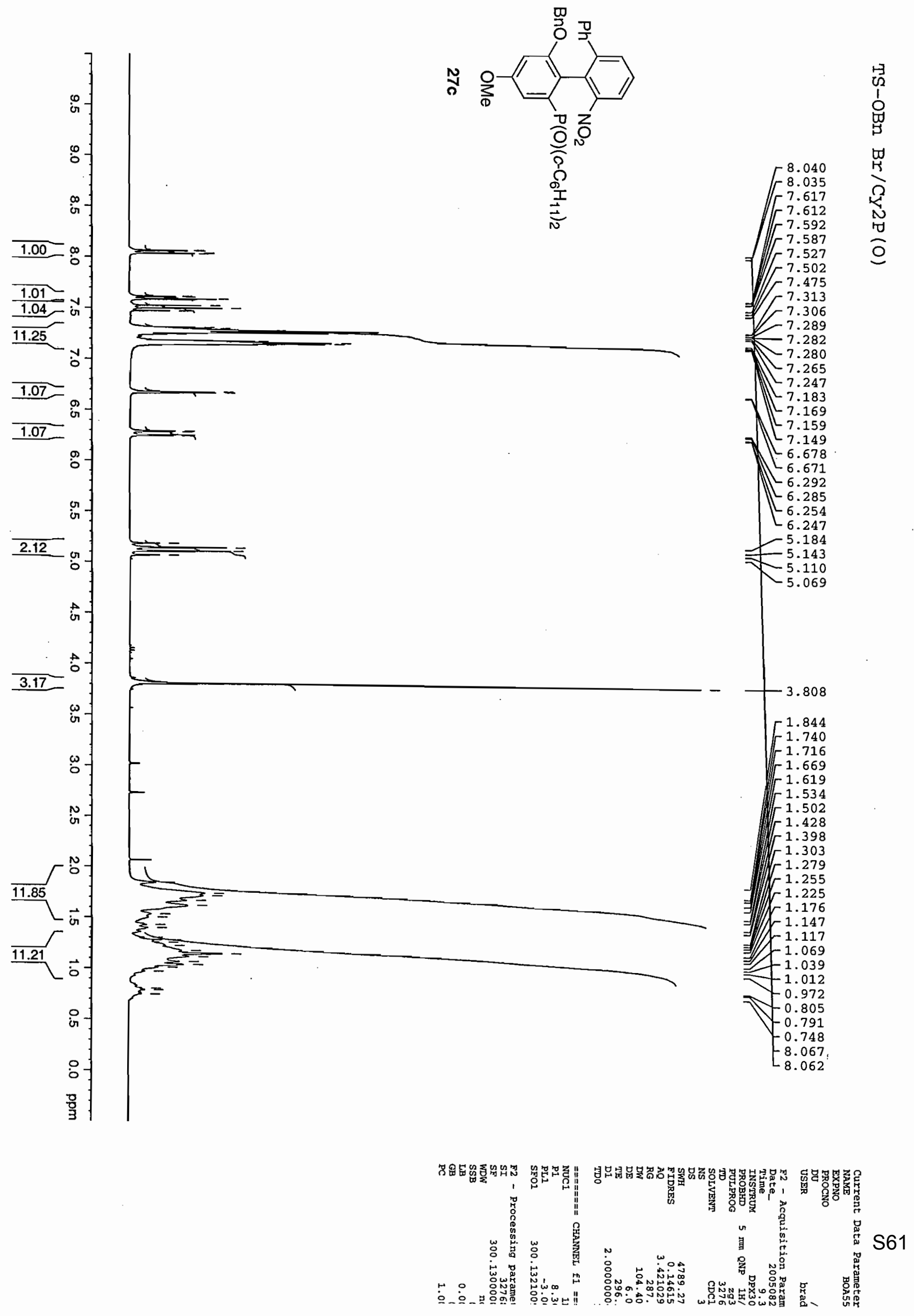

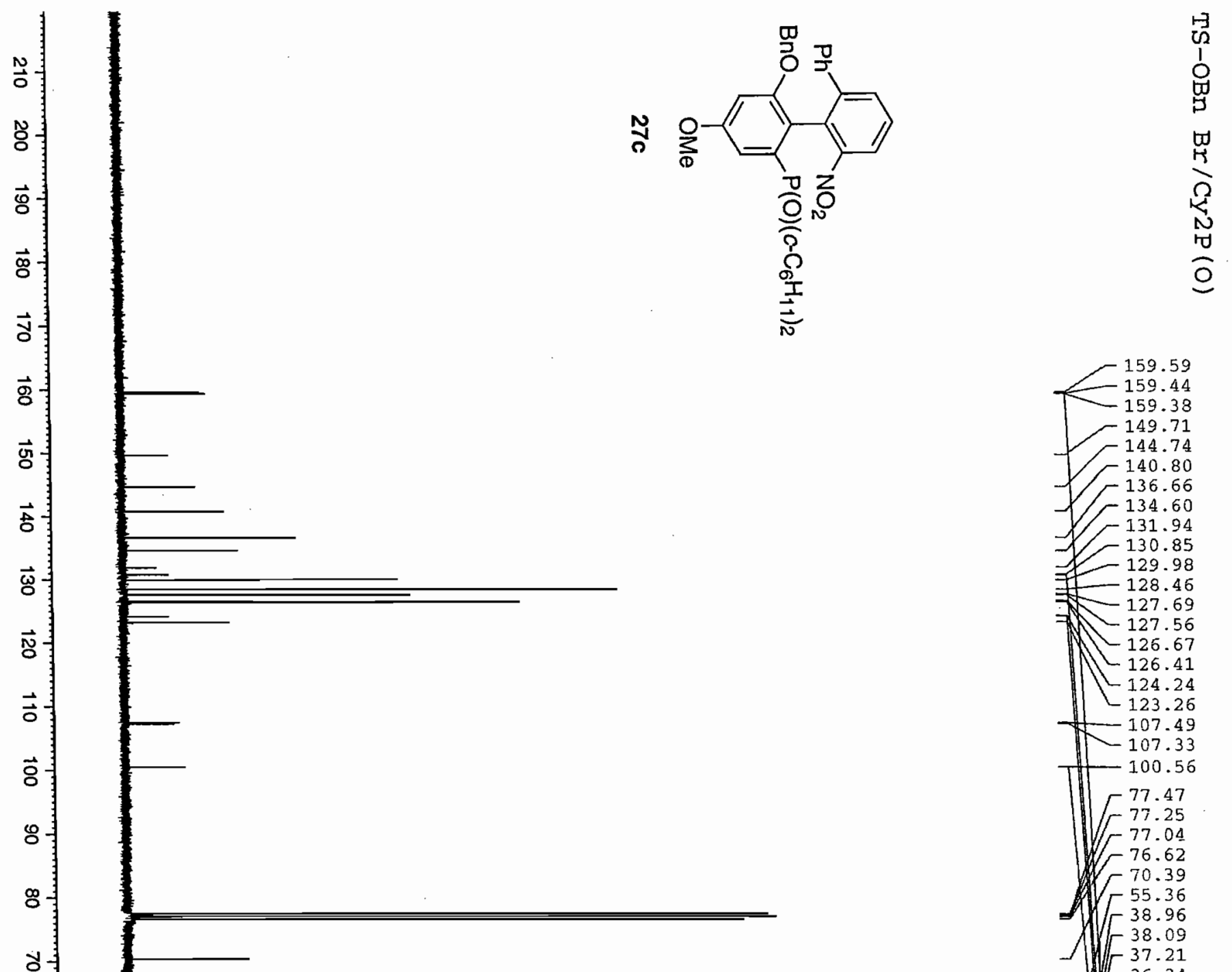

8

o

s

ฆ

N
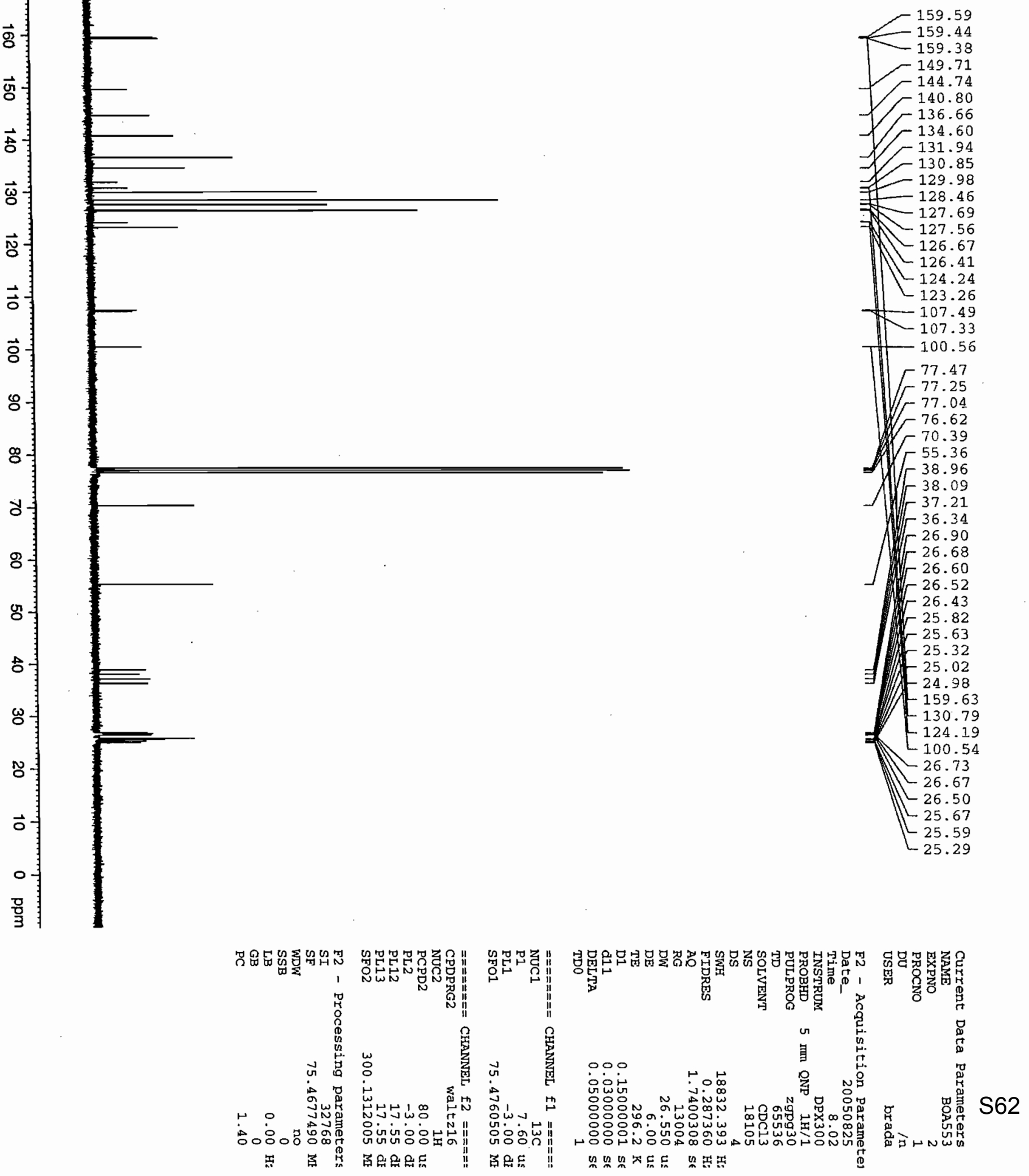

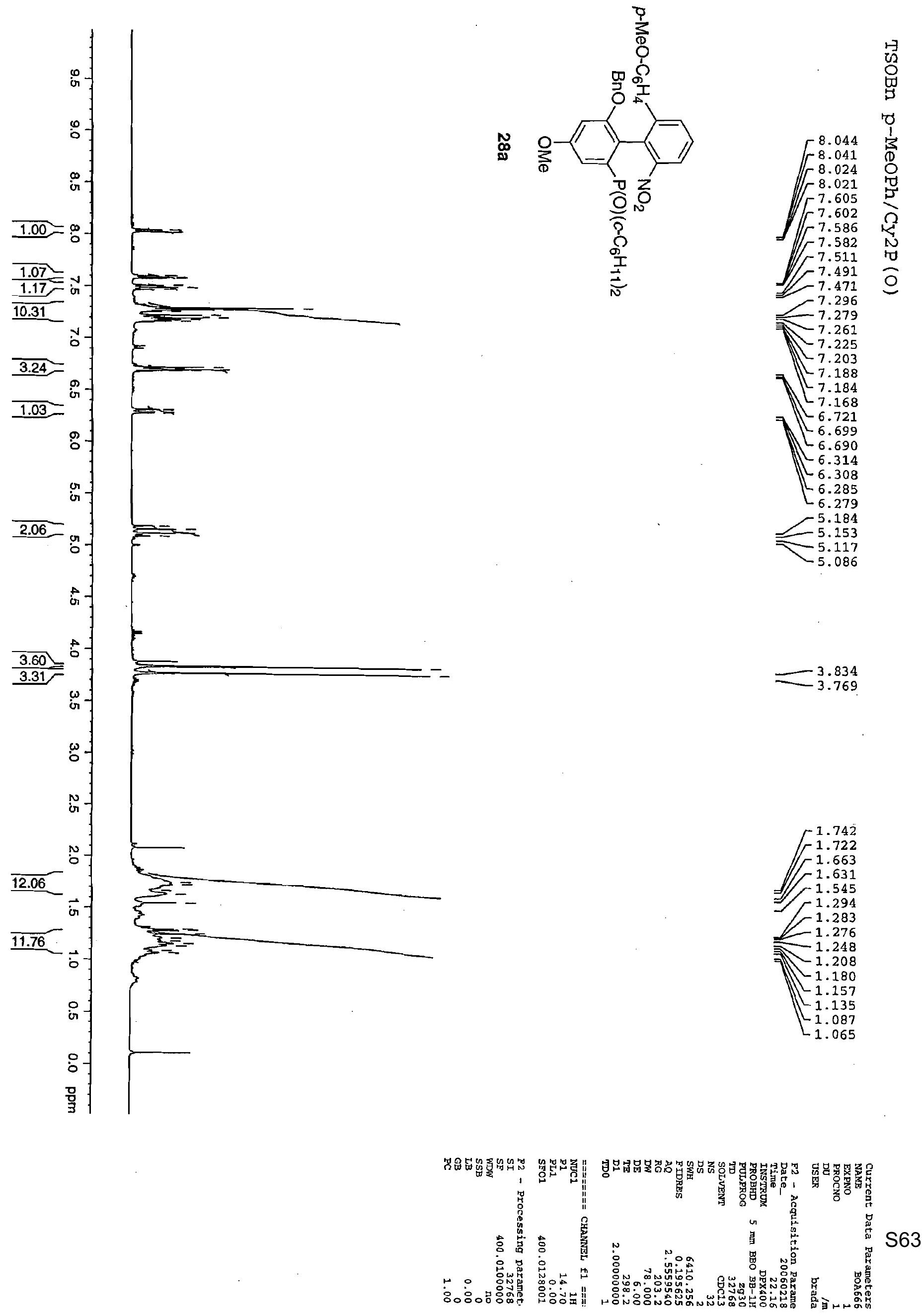


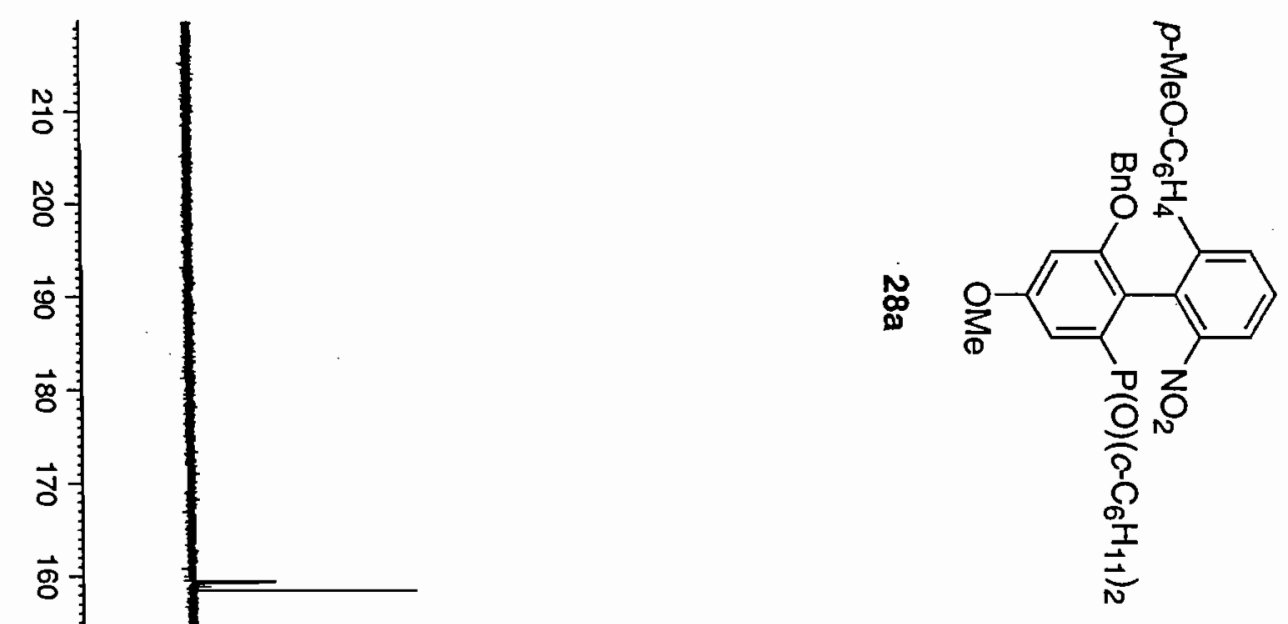

ç

$\overrightarrow{\mathrm{\sigma}}$

$\vec{N}$

$\overrightarrow{0}$

호

8

\&

a

\section{8}

\section{용}

$$
\text { o }
$$

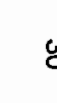
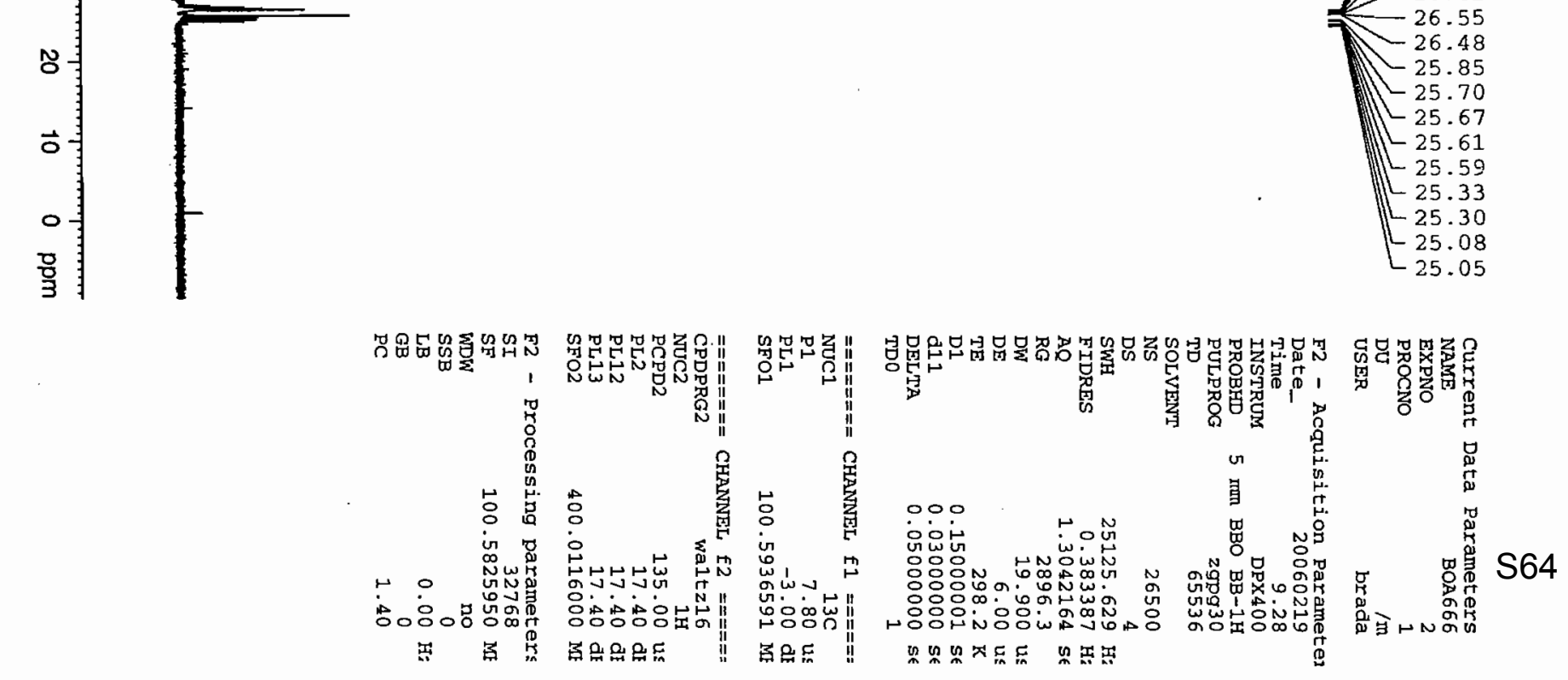

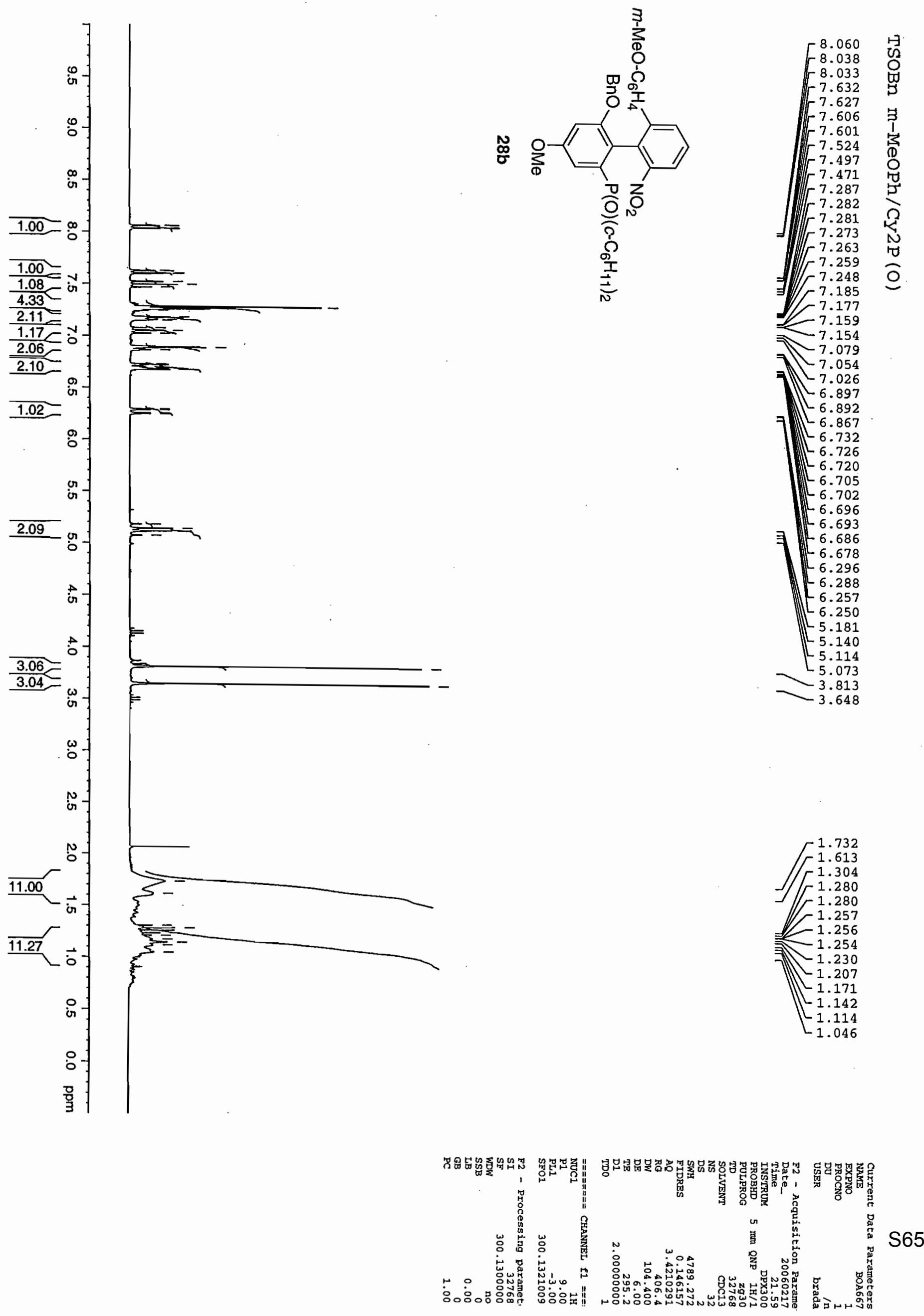


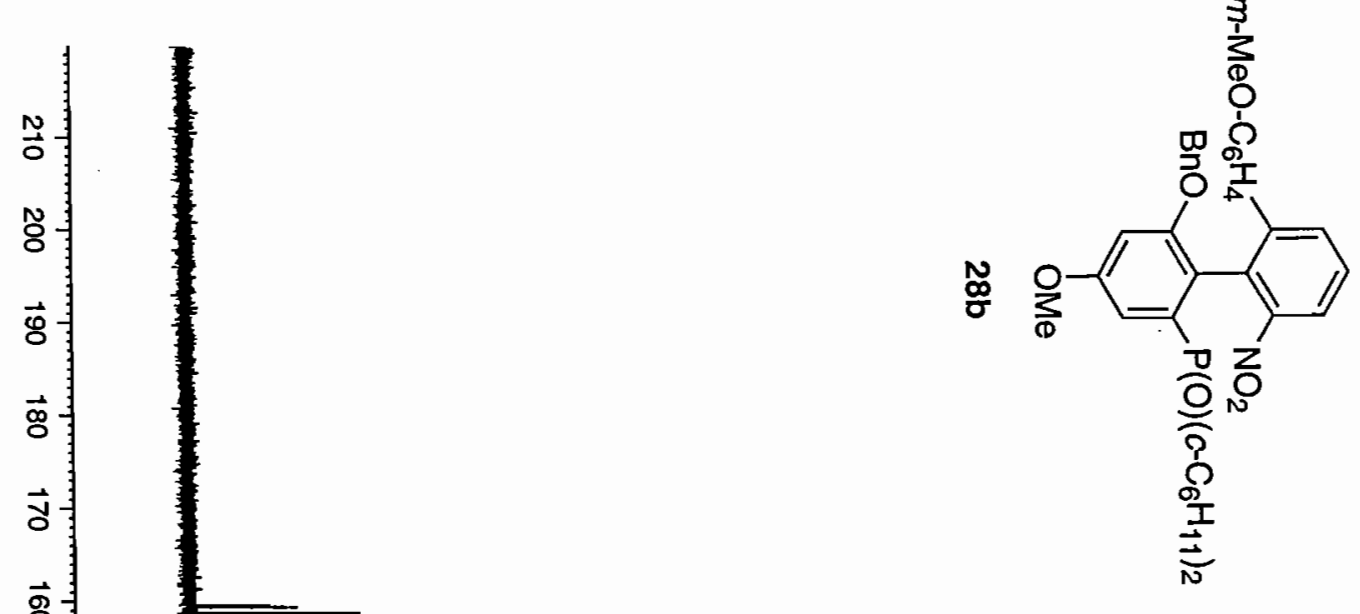

횽

홍

8$$
\text { 하 }
$$
s $\varnothing$ ø
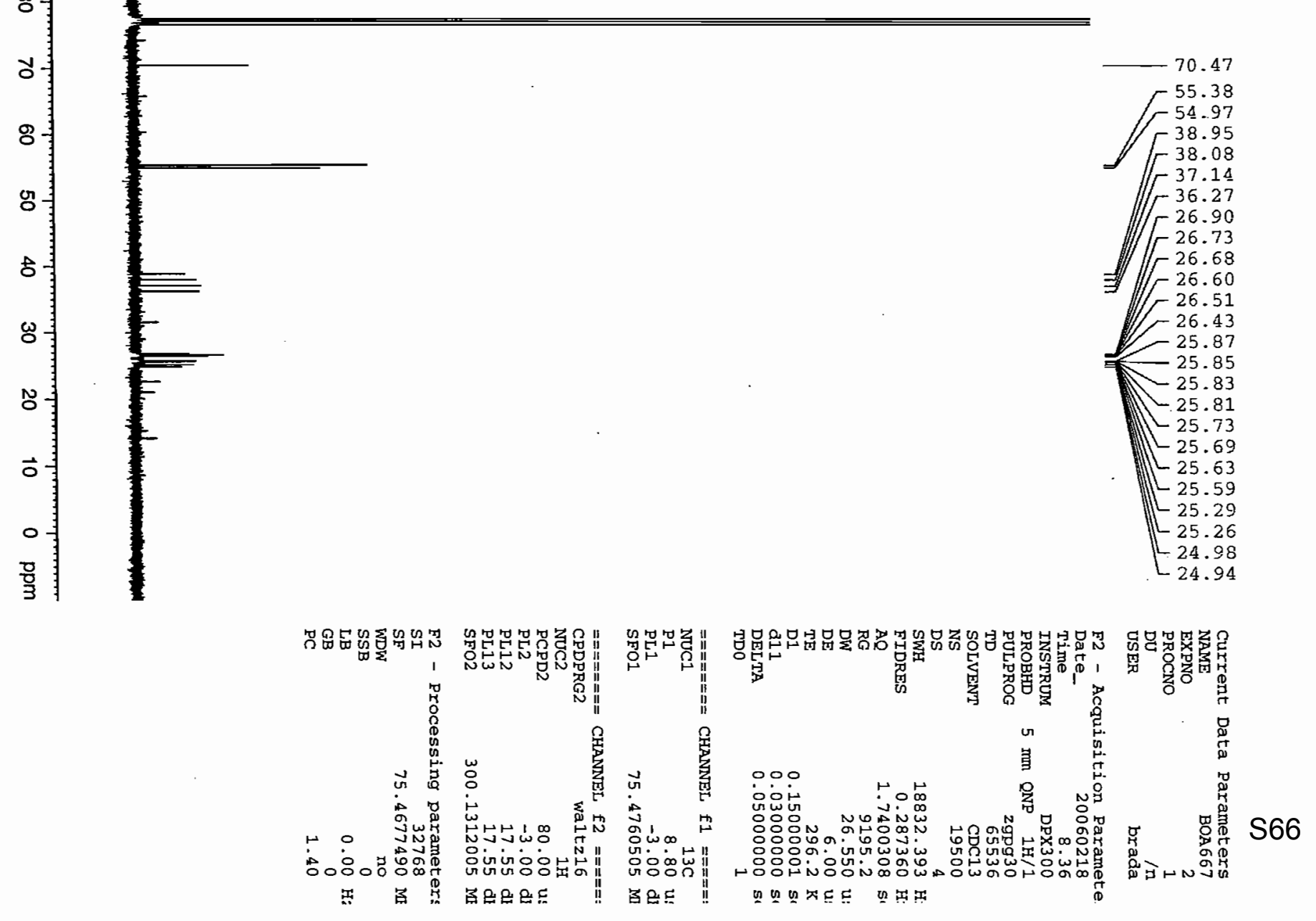

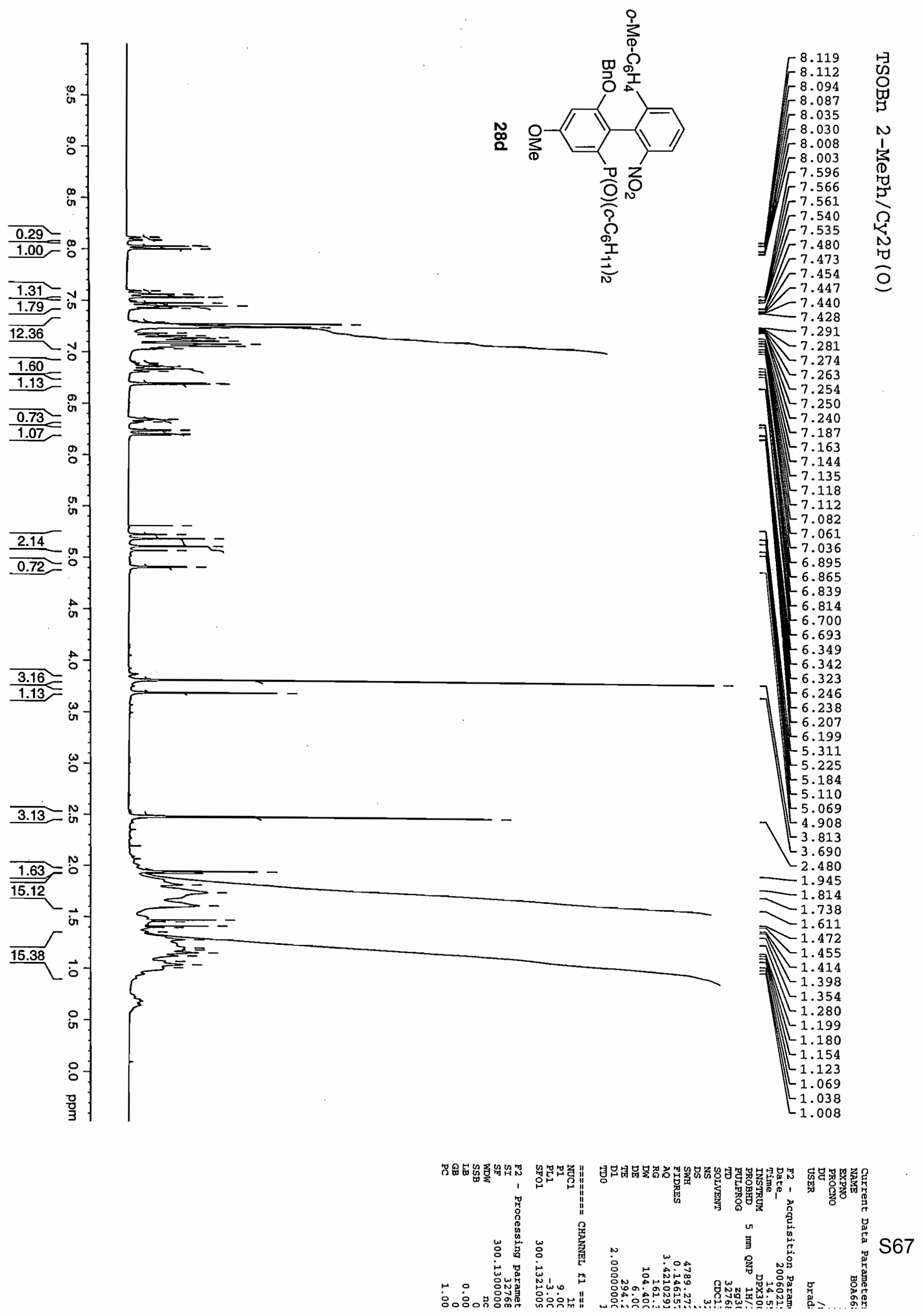

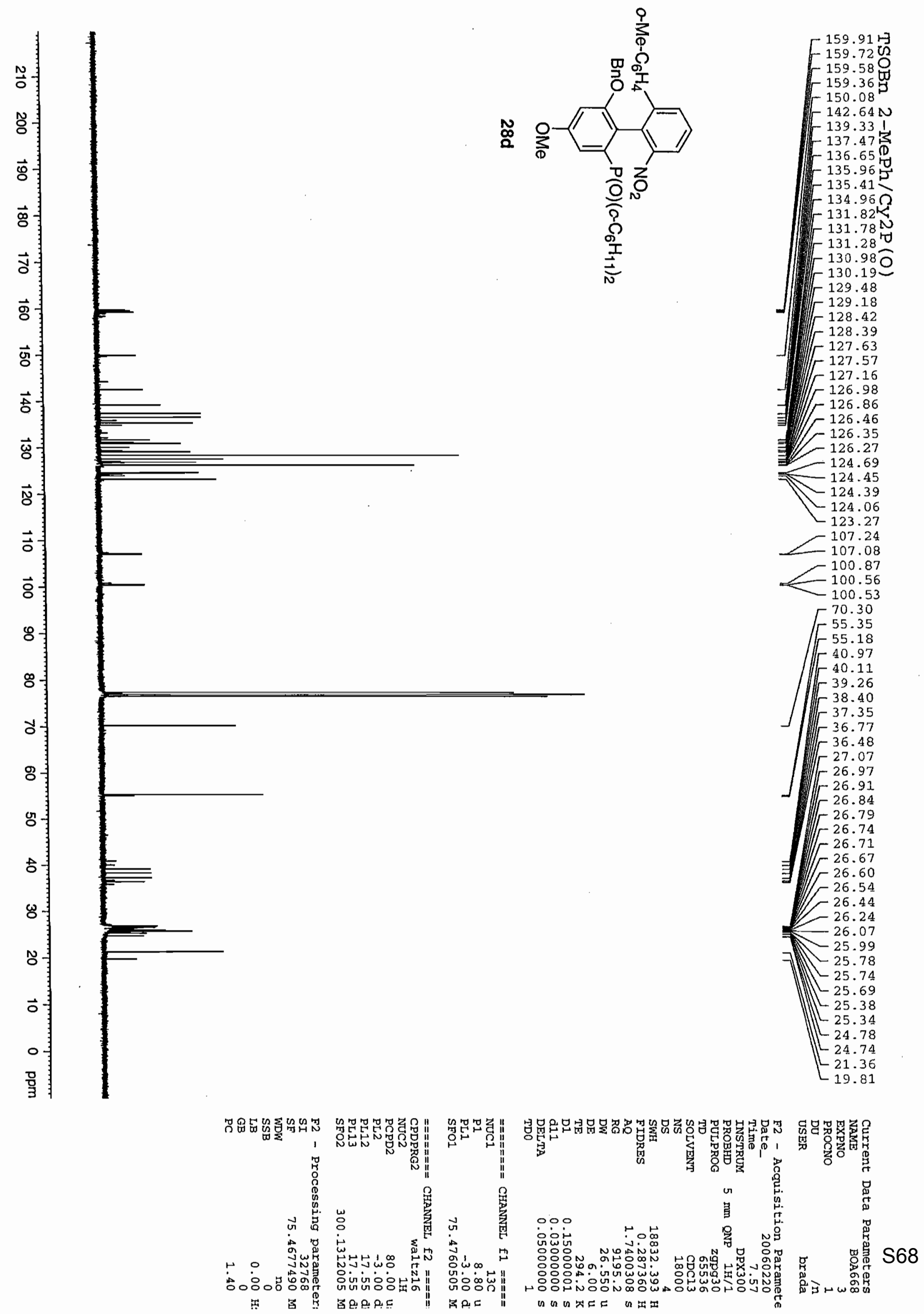

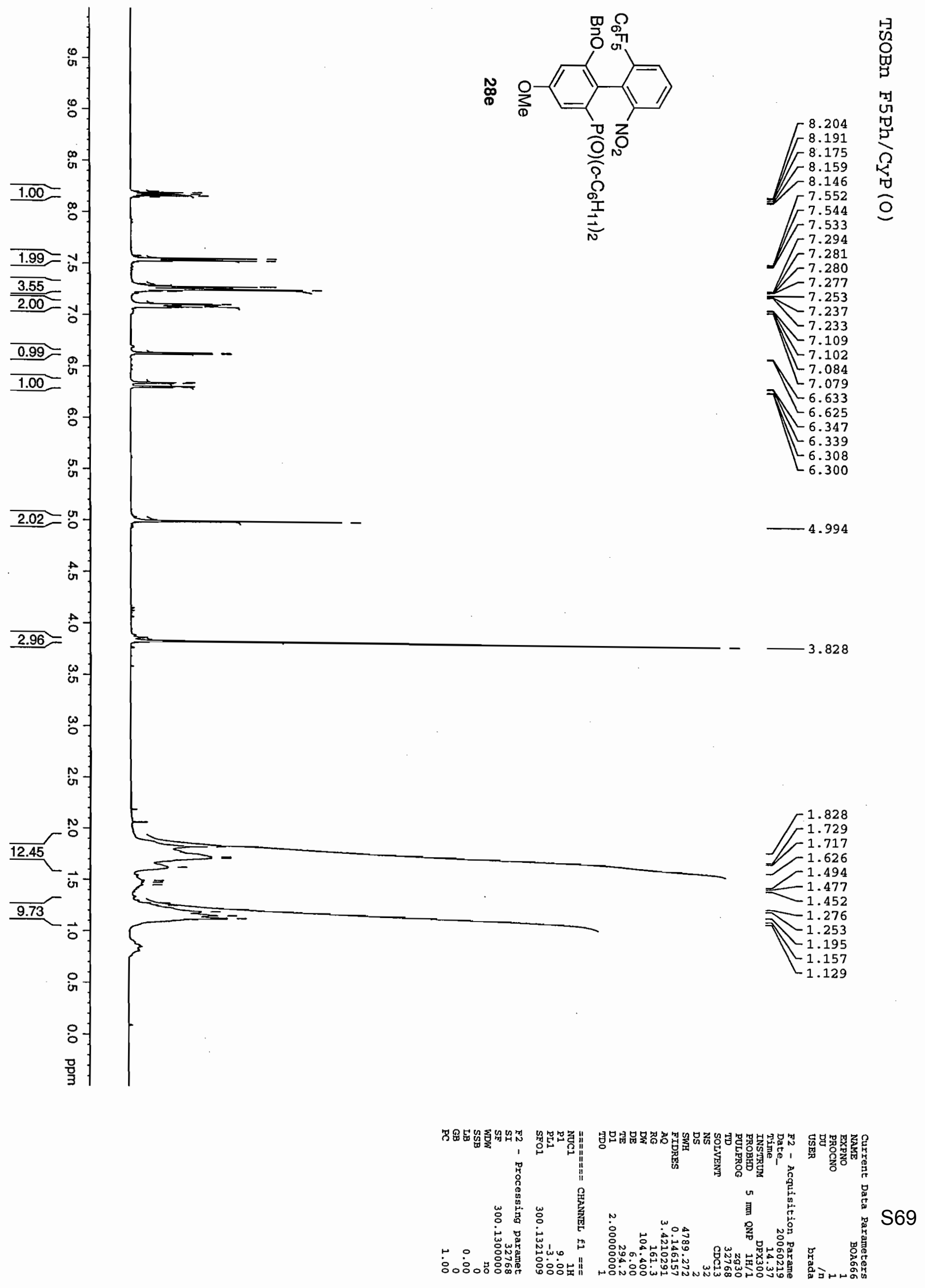


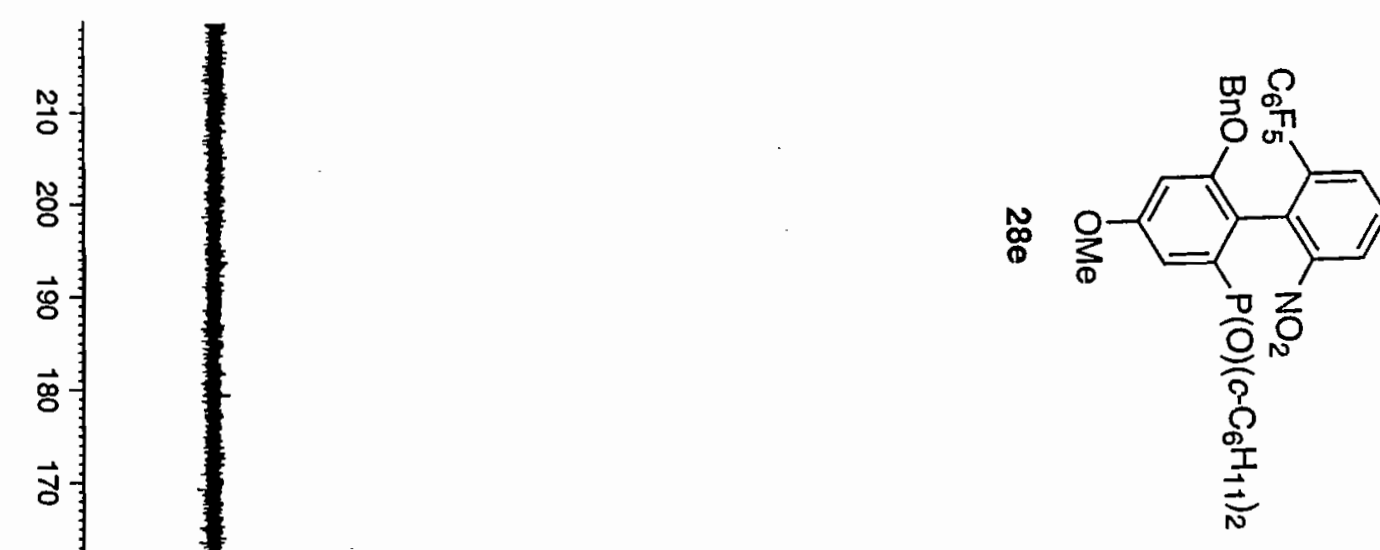

$\overrightarrow{8}$

ज्ञ

$\overrightarrow{8}$

$\vec{\omega}$

$\vec{N}$

$\overrightarrow{0}$

$\overrightarrow{8}$

8

\&

ò

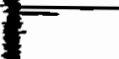

글

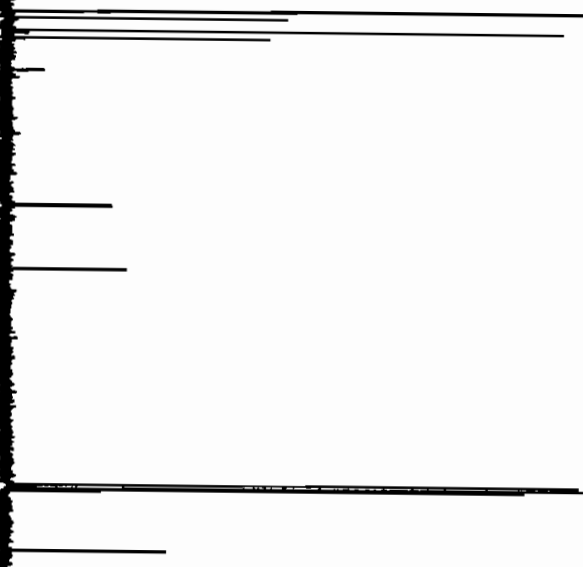

8

용-

8

\&

今

$\overrightarrow{0}$

$\circ$

뭉
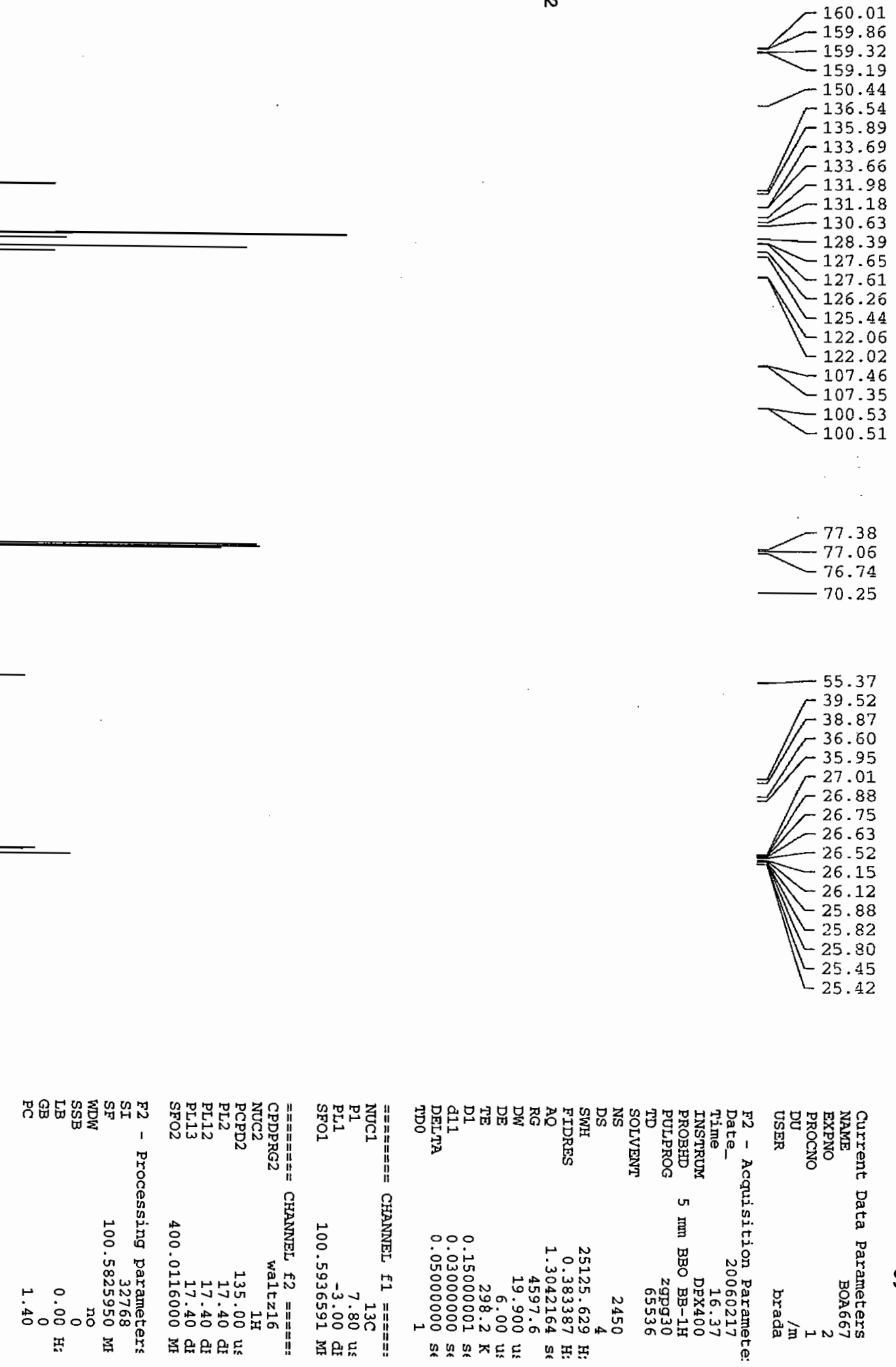

70.25

25.42 

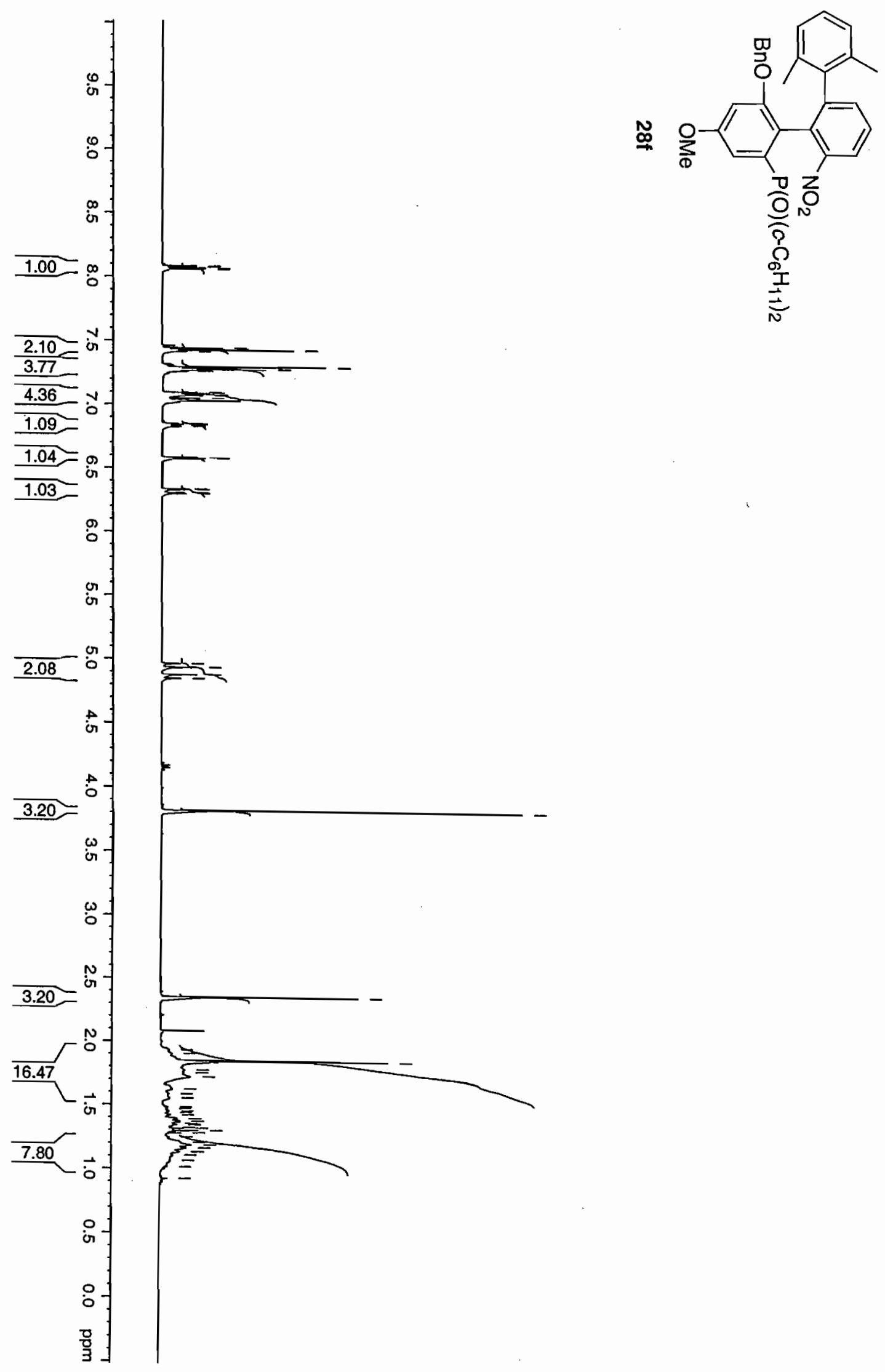

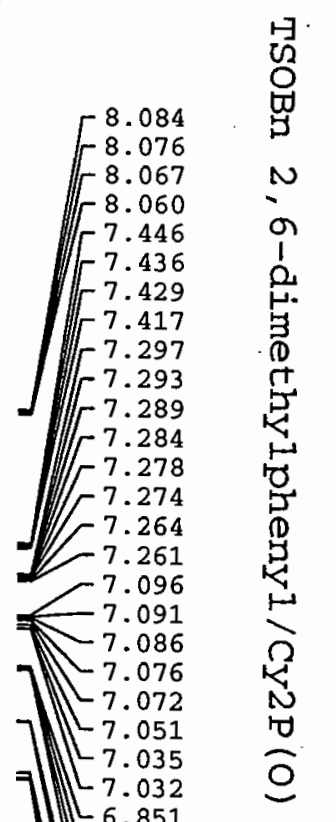

[6.834

- 6.829

$-6.583$

$-6.578$

6.336

$-6.330$

6.306

6.300

$-4.963$

$-4.933$

$-4.876$

4.846

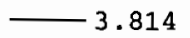

2.346

1.930

$-1.902$

$-1.843$

$-1.772$

$-1.750$

I. 1.718

- $\Gamma^{1.621}$

- $\Gamma^{1.584}$

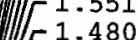

$r 1.468$

r 1.449

III 1.437

1.419

$-1.388$

$-1.369$

$-1.352$

$-1.341$

1.321

ㄴ.296

$-1.278$

1.246

1.205

$-1.184$

ㄴ.161

$\left[\begin{array}{r}1.131 \\ 1.104\end{array}\right.$

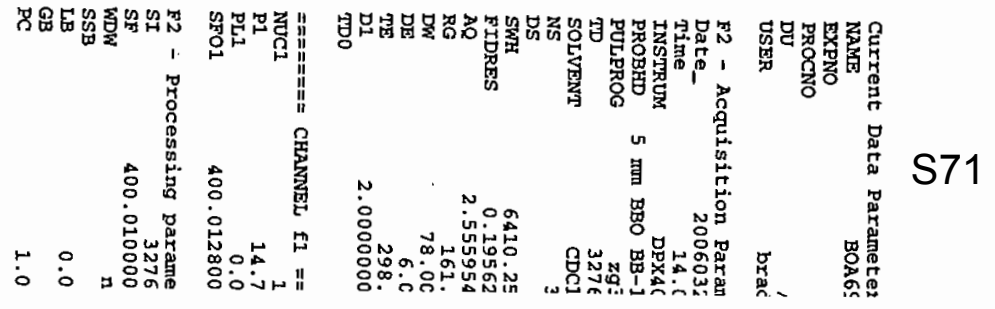




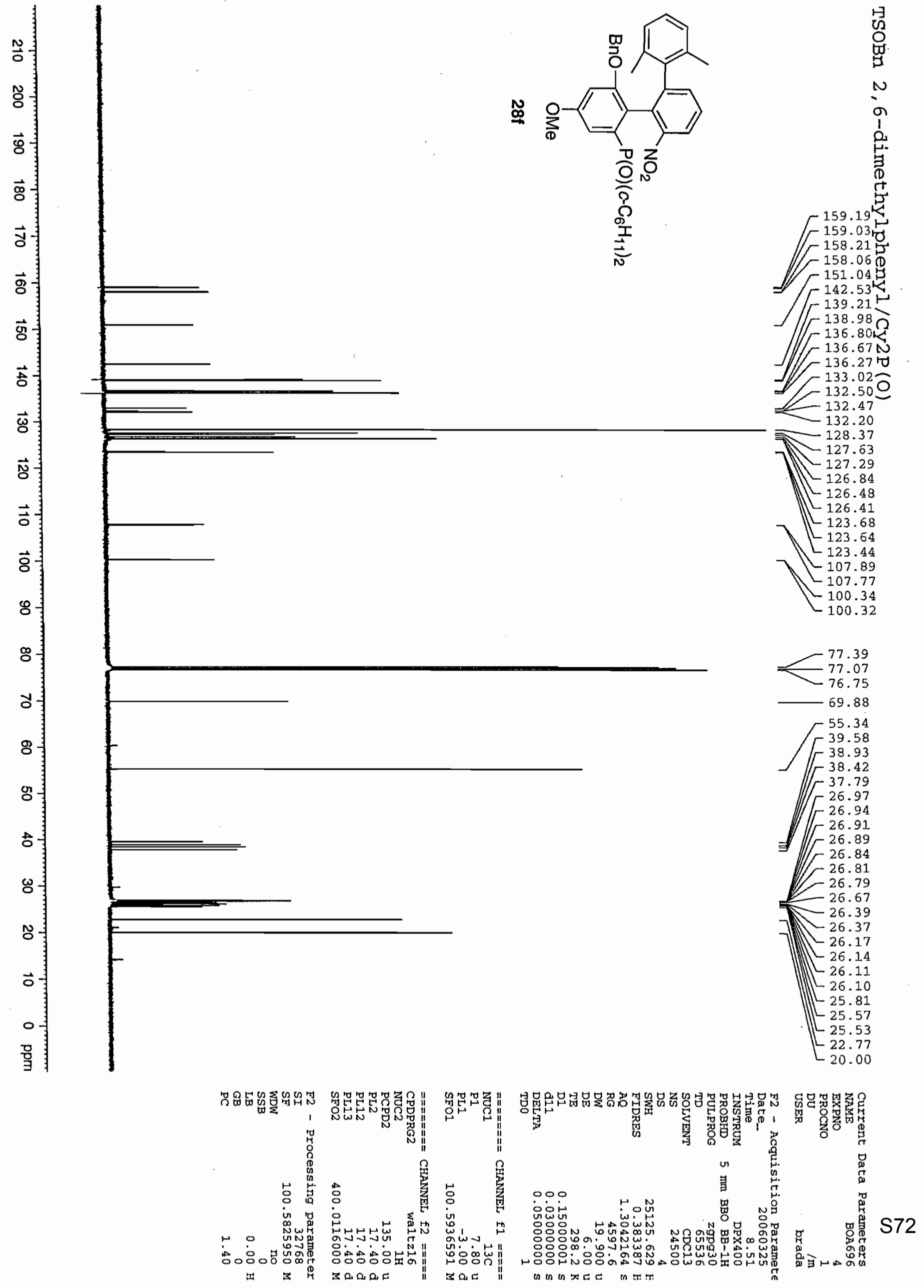



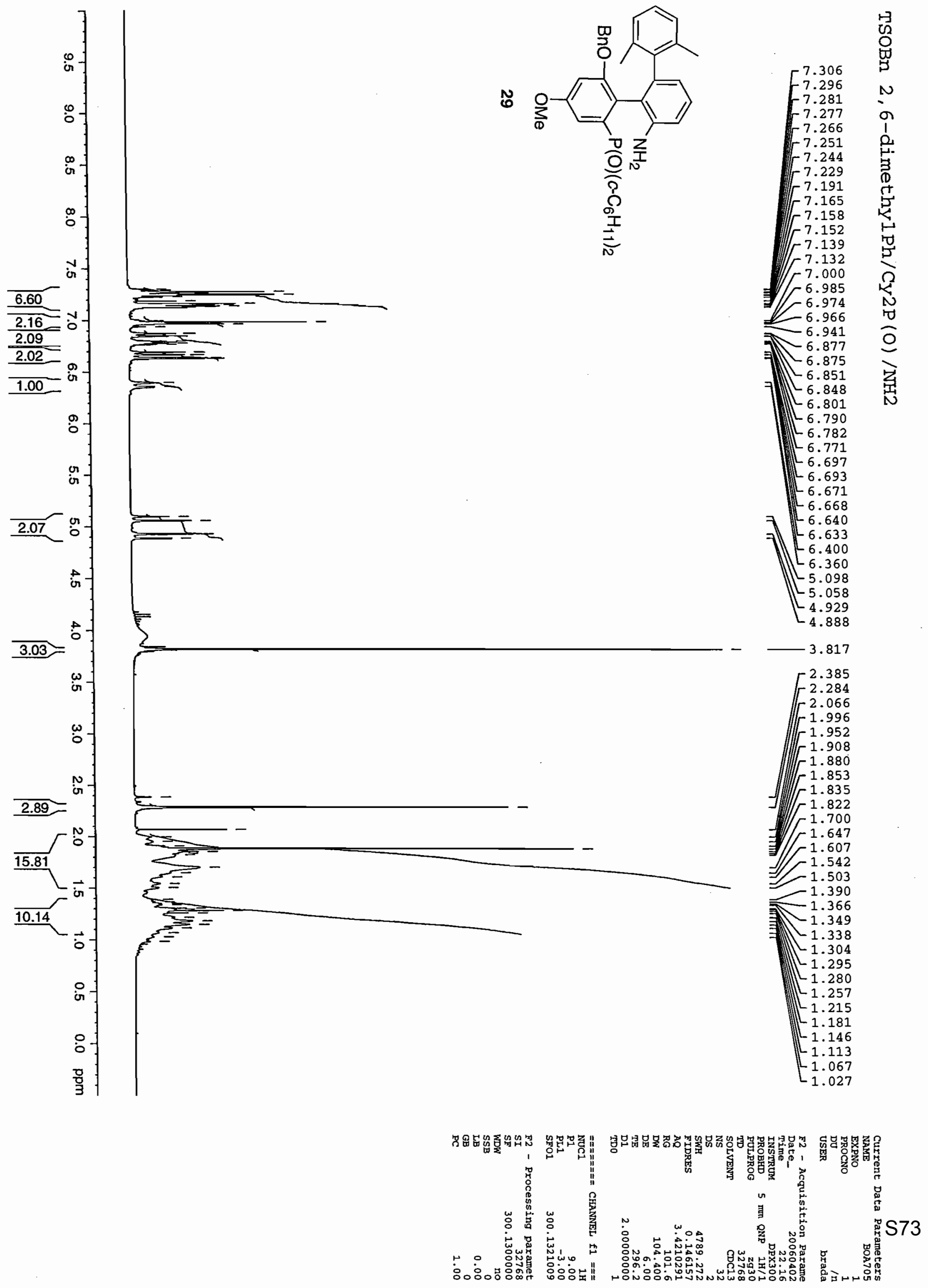



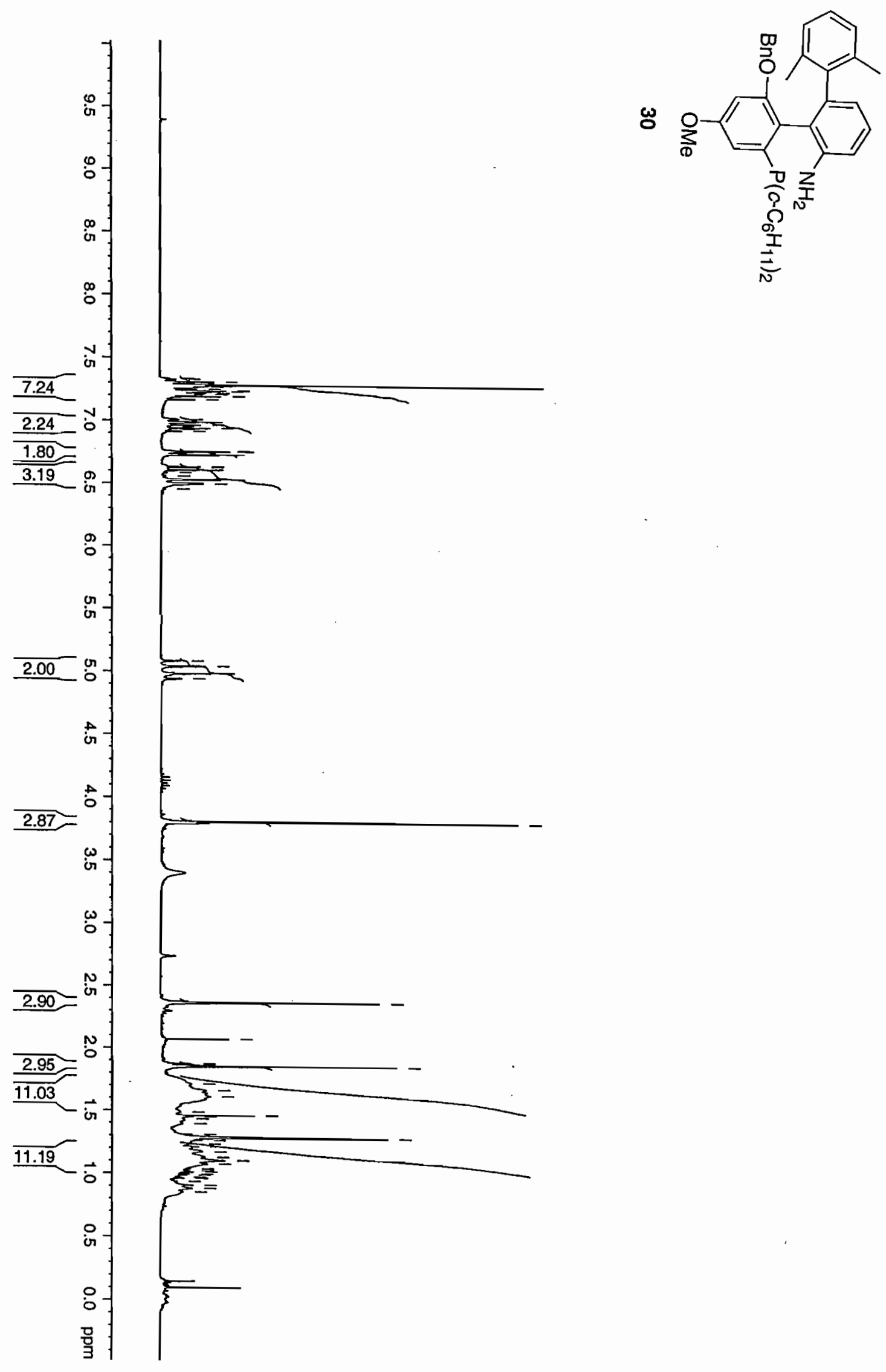

$-5.080$

$\left[\begin{array}{r}5.039 \\ 4.981\end{array}\right.$

$\begin{array}{r}4.940 \\ \hline\end{array}$
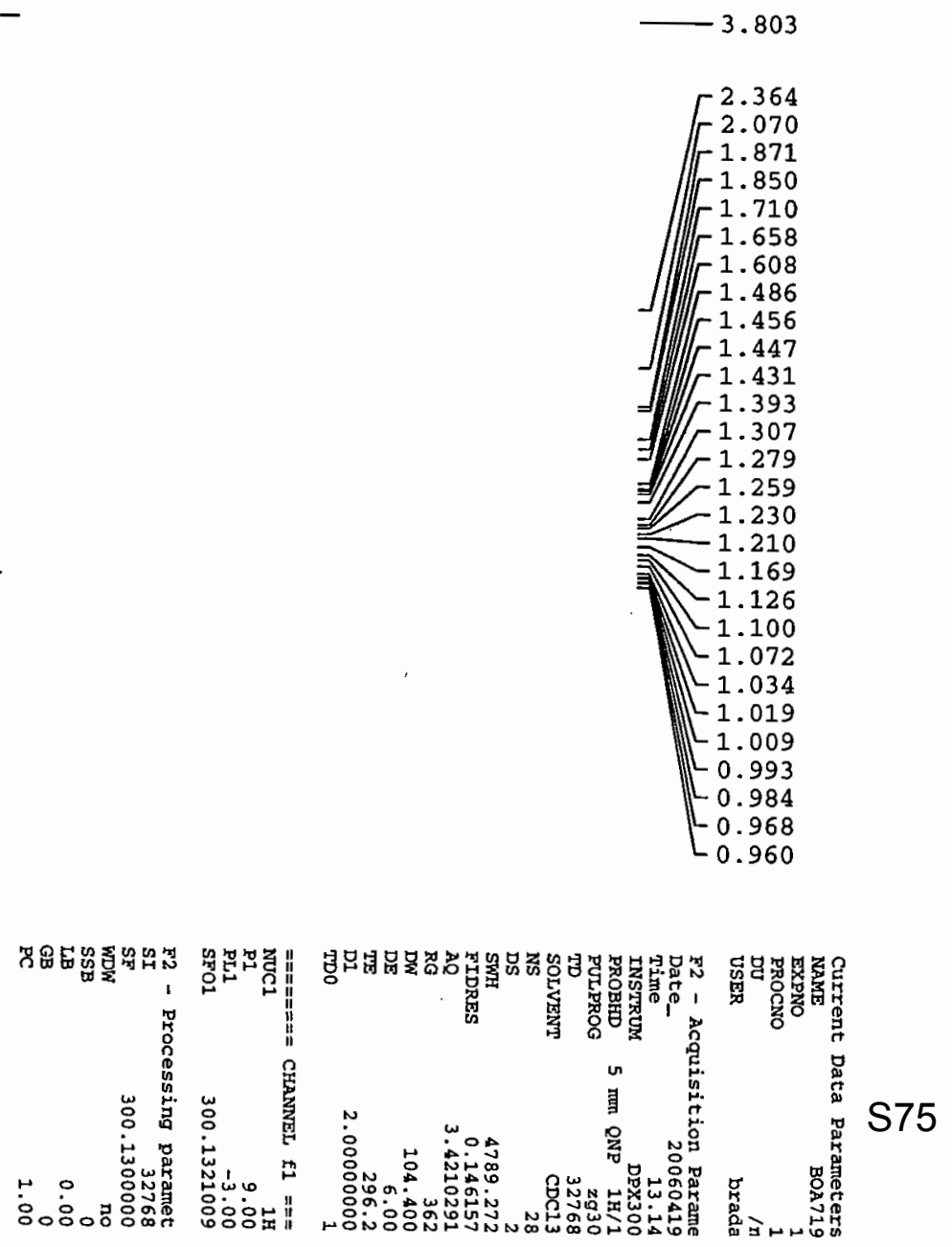


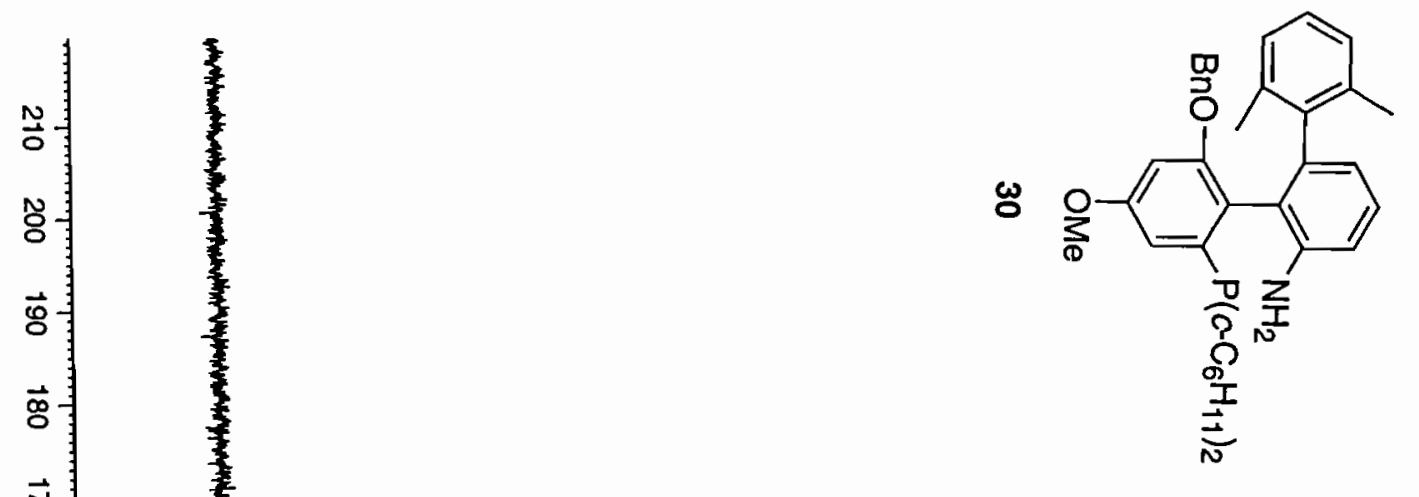

봉

Ј

gㅇㅇㅇ

$\overrightarrow{8}$

행

$\vec{b}$

$\bar{\sigma}$

ฉิ

ة ธ 8

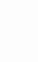
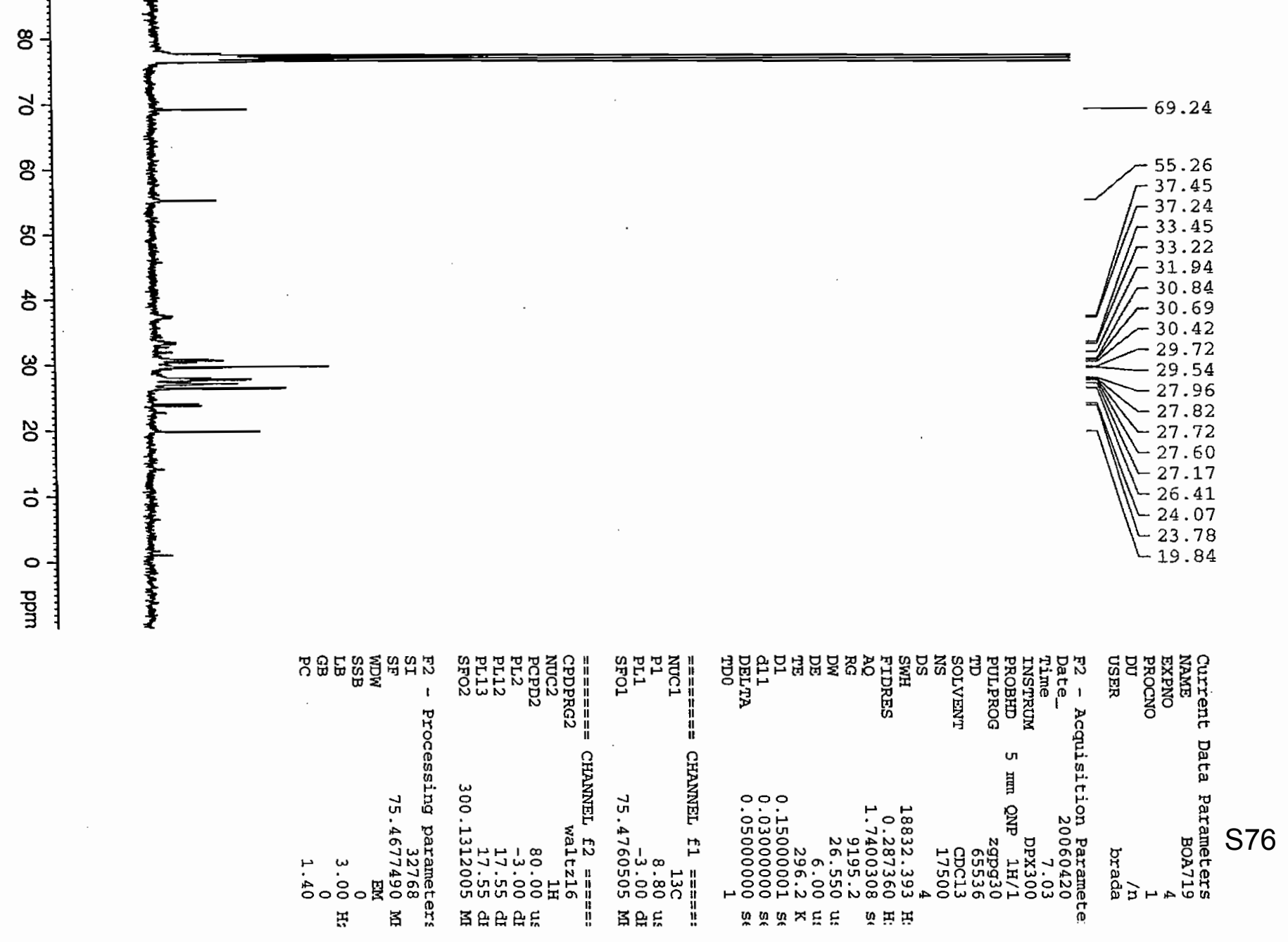

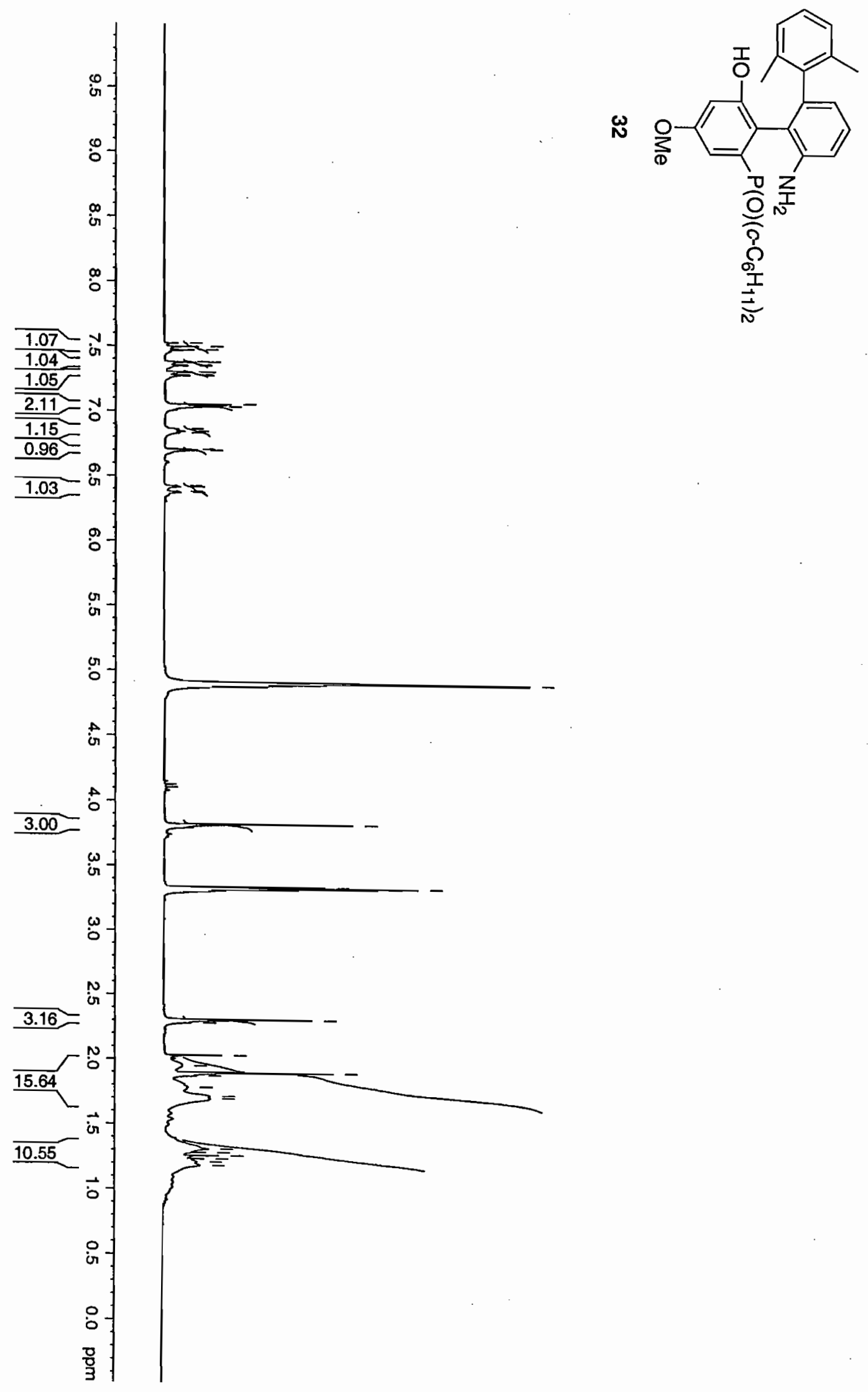

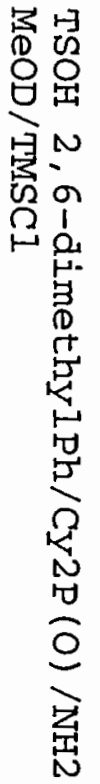

7.524

7.524
7.472
7.472

F 7.478 7.376

7.354

7.350

7.303

7.299

7.278

$-7.051$

$-7.039$

7.033

$-6.862$

$2[-6.833$

$-6.705$

$-6.698$

6.425

$\left[\begin{array}{l}6.382 \\ 6.374\end{array}\right.$

$-4.900$ 

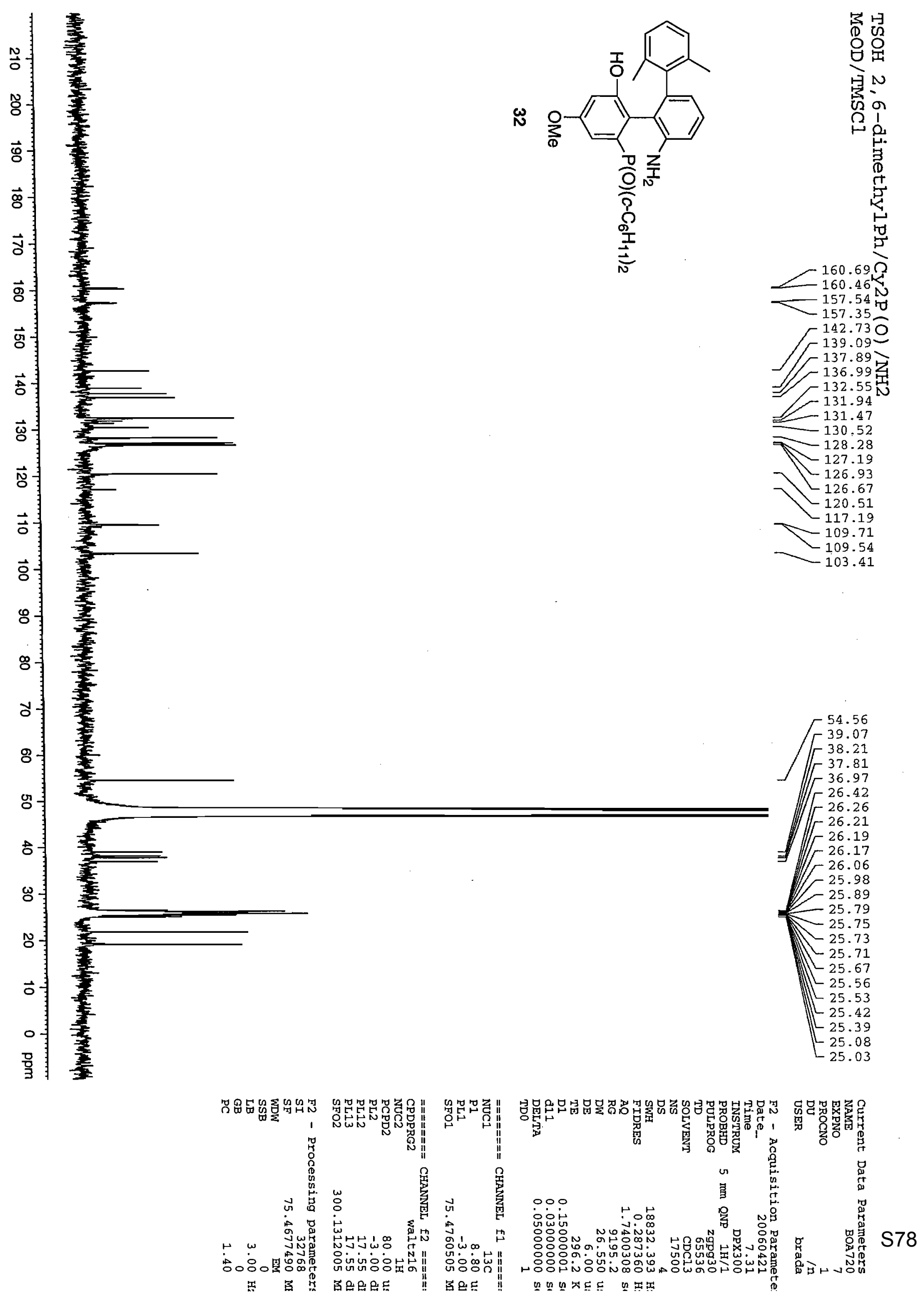

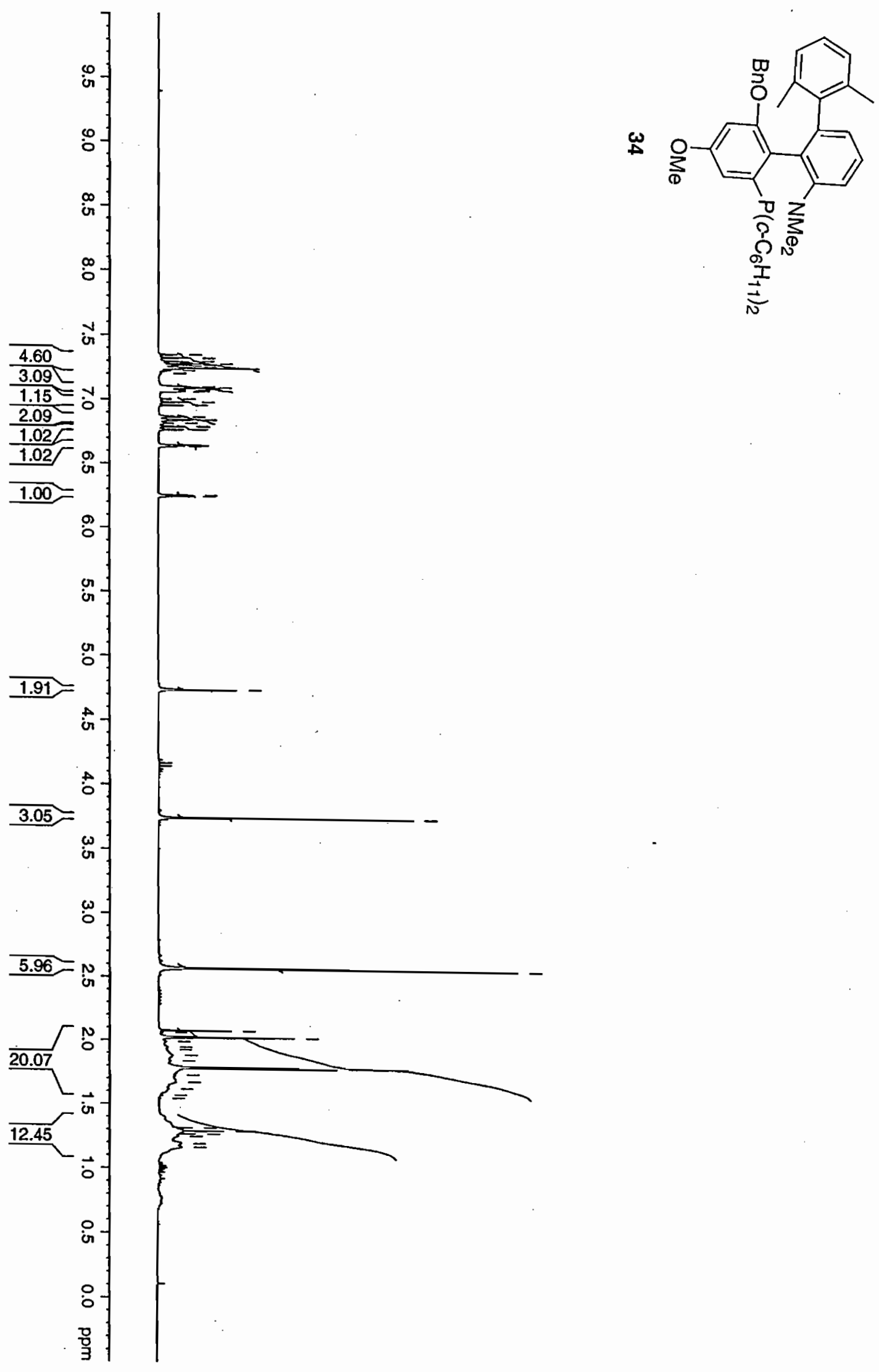

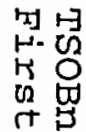

$Q N$

D.

ए

?

Q

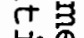

‥

7.240

7.207

.201

7.103

$-7.095$

7.090

7.077

7.072
7.068
7.063

7.063
-7.006

$-6.981$

$-6.957$

6.868

6.844

$-6.819$

6.794

6.790

6.769

$-6.765$

46.648

$-6.642$

6.635

$-6.253$

6.245

4.735

今

可占

담요

a

点

3.740

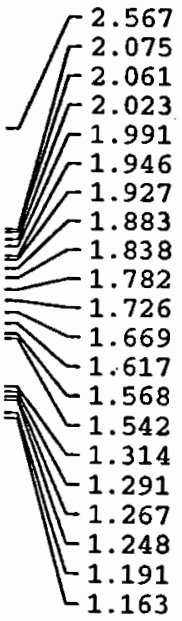

点

(1)

2.023

1.946

1.927

1.838

.669

1.542

1.291

1.191

1.163 

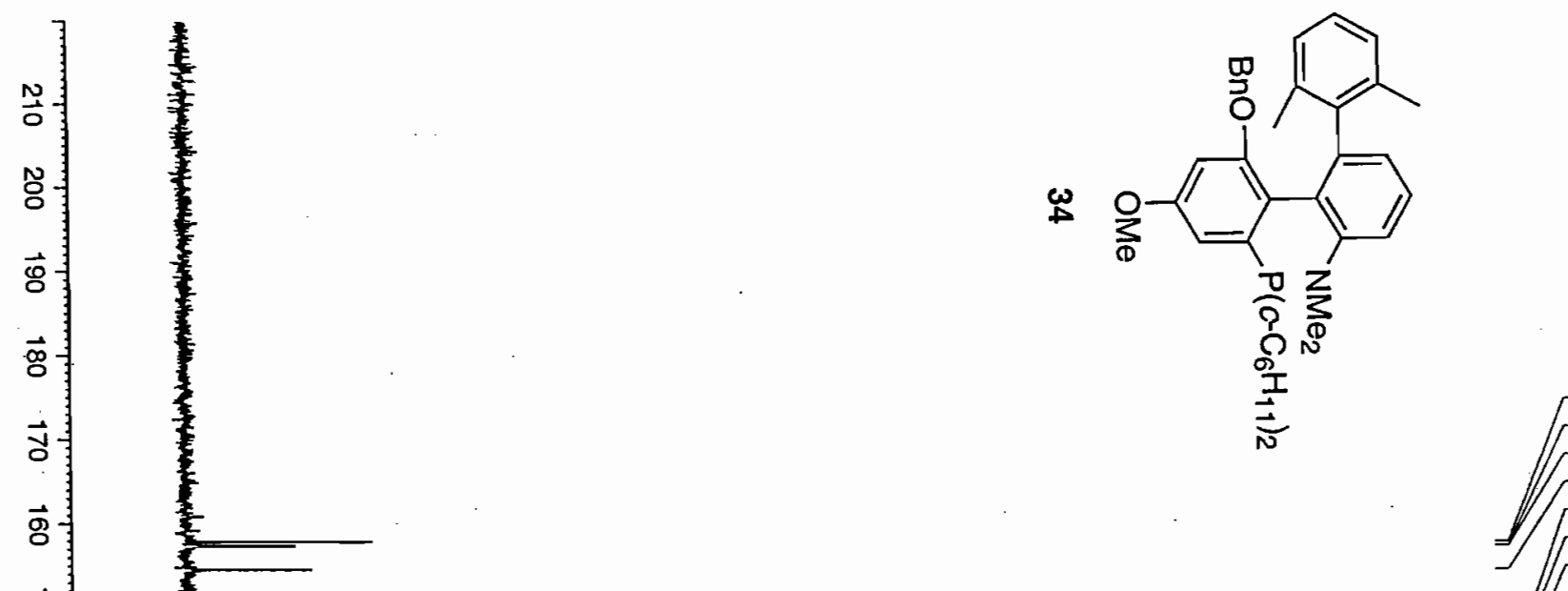

157.98

157.53

- 157.42

154.65

$\Gamma^{142.61} 141.91$

139.62. Q

139.39

137.53

$-137.50$

136.62
-130.46

$-130.41$

130.41
128.28

$\vec{\omega}$

.

กิ

$\overrightarrow{0}$

$\overrightarrow{\mathrm{s}}$

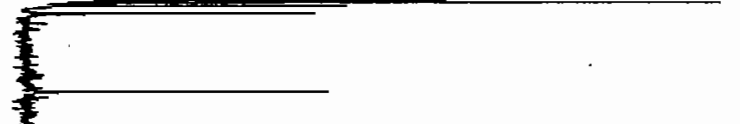

8

\&

o

g

G

f

w.

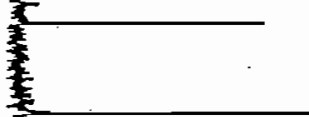

N-

O웅

$\circ$

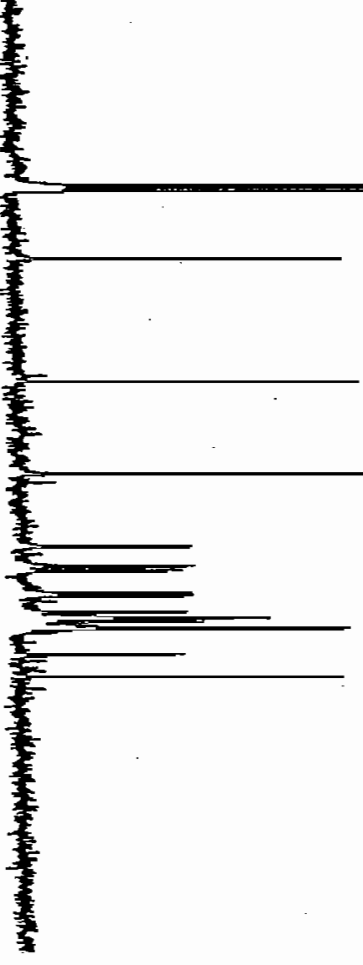

거송

ro

용.

त马

H.

马号

$\mapsto$

0

号号

ب

空

$-127.7$

$-127.26$

$-127.24$

] $\longleftarrow 126.66$

$-126.61$

$-126.35$

125.96

125.10

$-116.08$

-98.99
-109.24

77.37
77.05

$-76.73$

69.02

$\Gamma^{55.01}$

$-36.15$

- 35.97

- 33.89

$\mid \begin{array}{r}33.71 \\ 33.37\end{array}$

III 30.78

]

$-30.46$

- 30.29

$-28.56$

$-28.42$

28.03
-27.98

$-27.85$

$-27.81$

$-27.75$

$-27.65$

27.41

$-27.31$

$-26.98$

$-26.90$

26.68

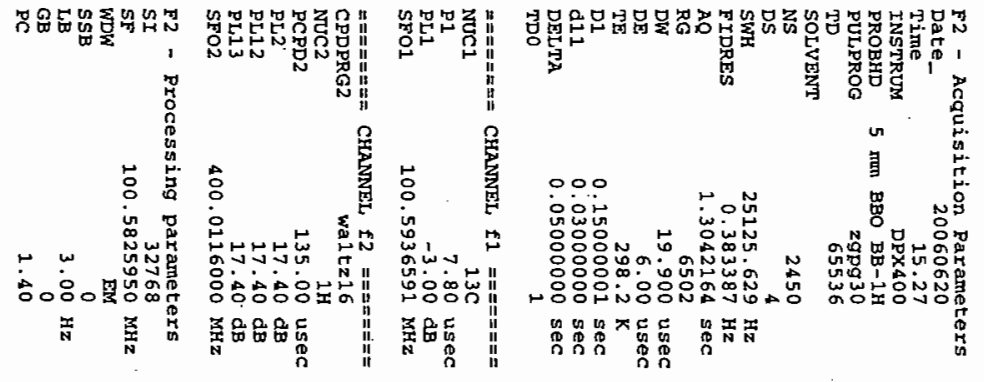

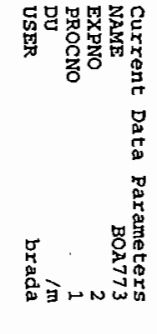





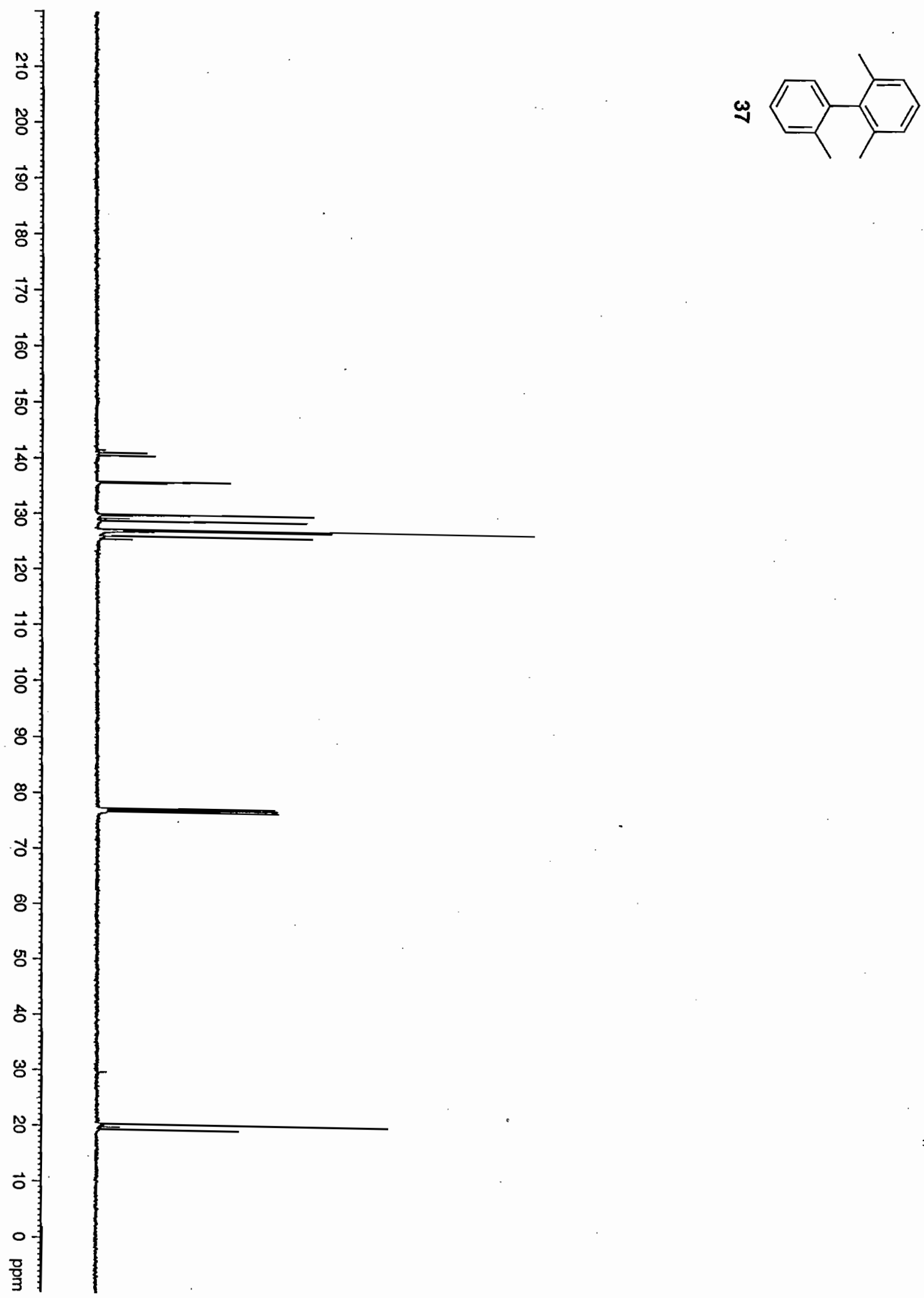

时 N

$5 N$

-

1

(1) त

S

D

๑)

芯莫

95

남용

ڤ

\&

它

8

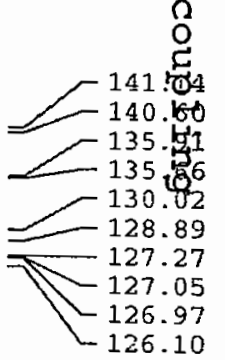

4

356

27.05

126.10

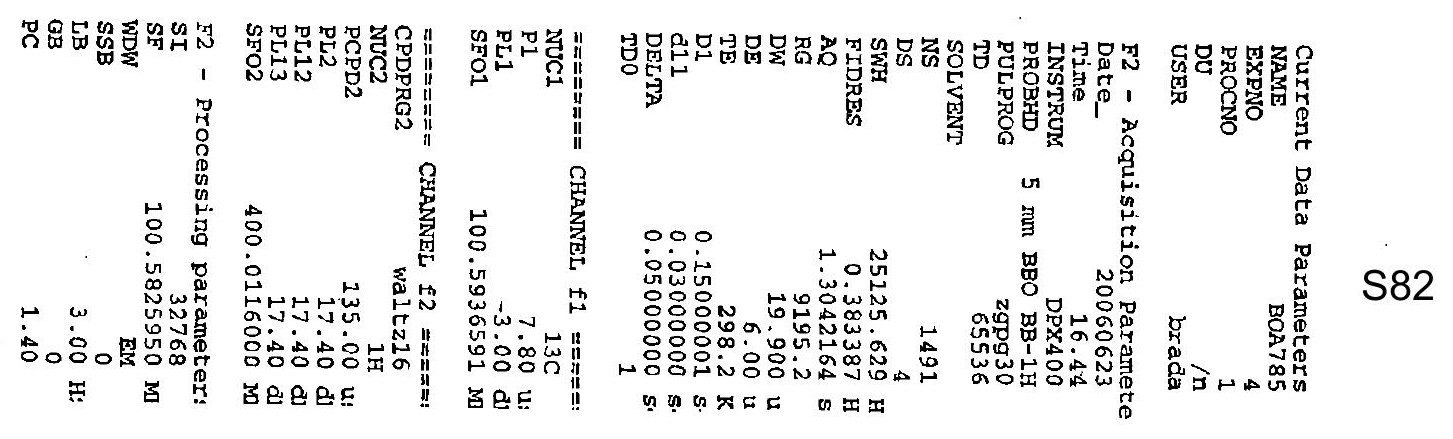



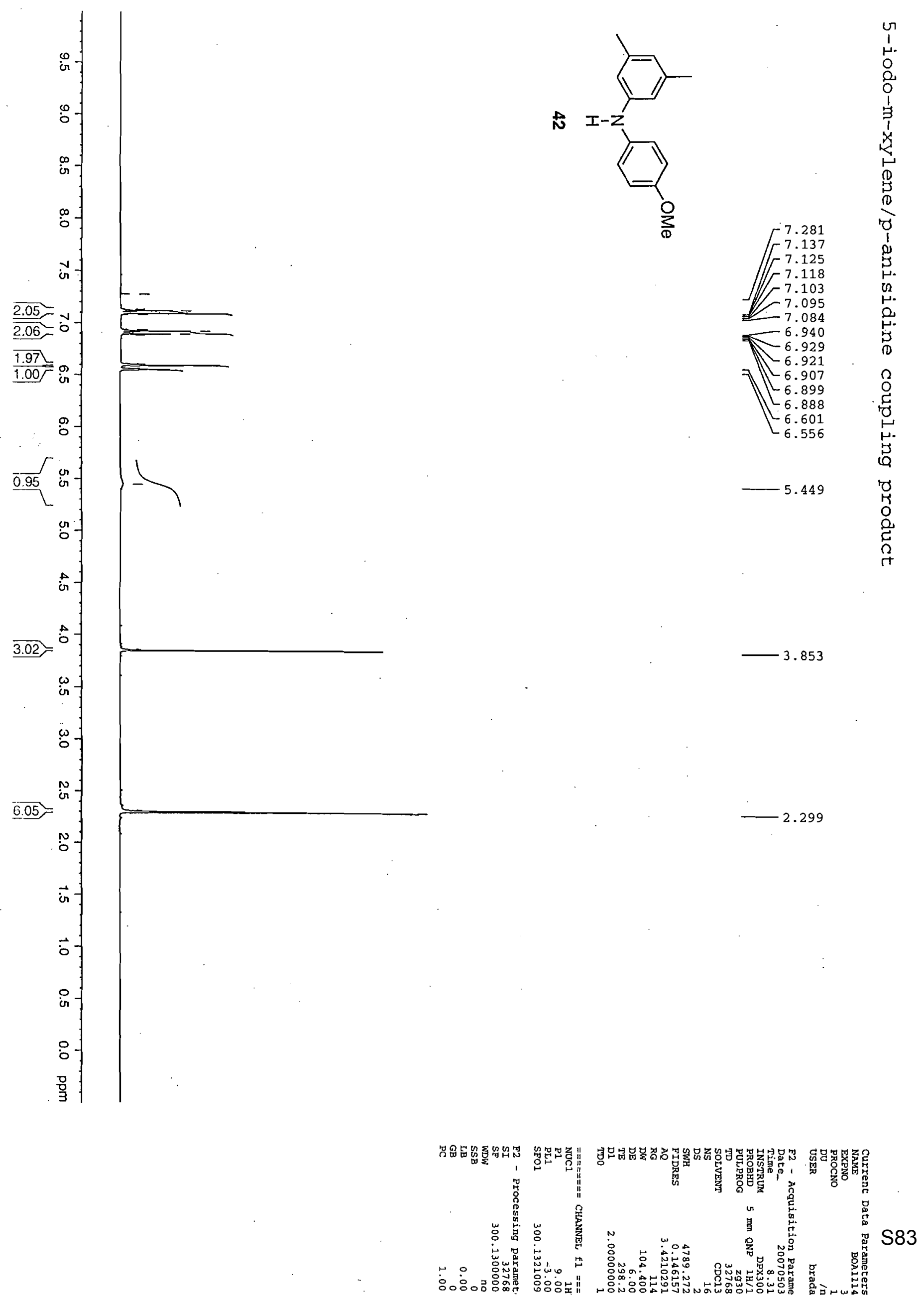

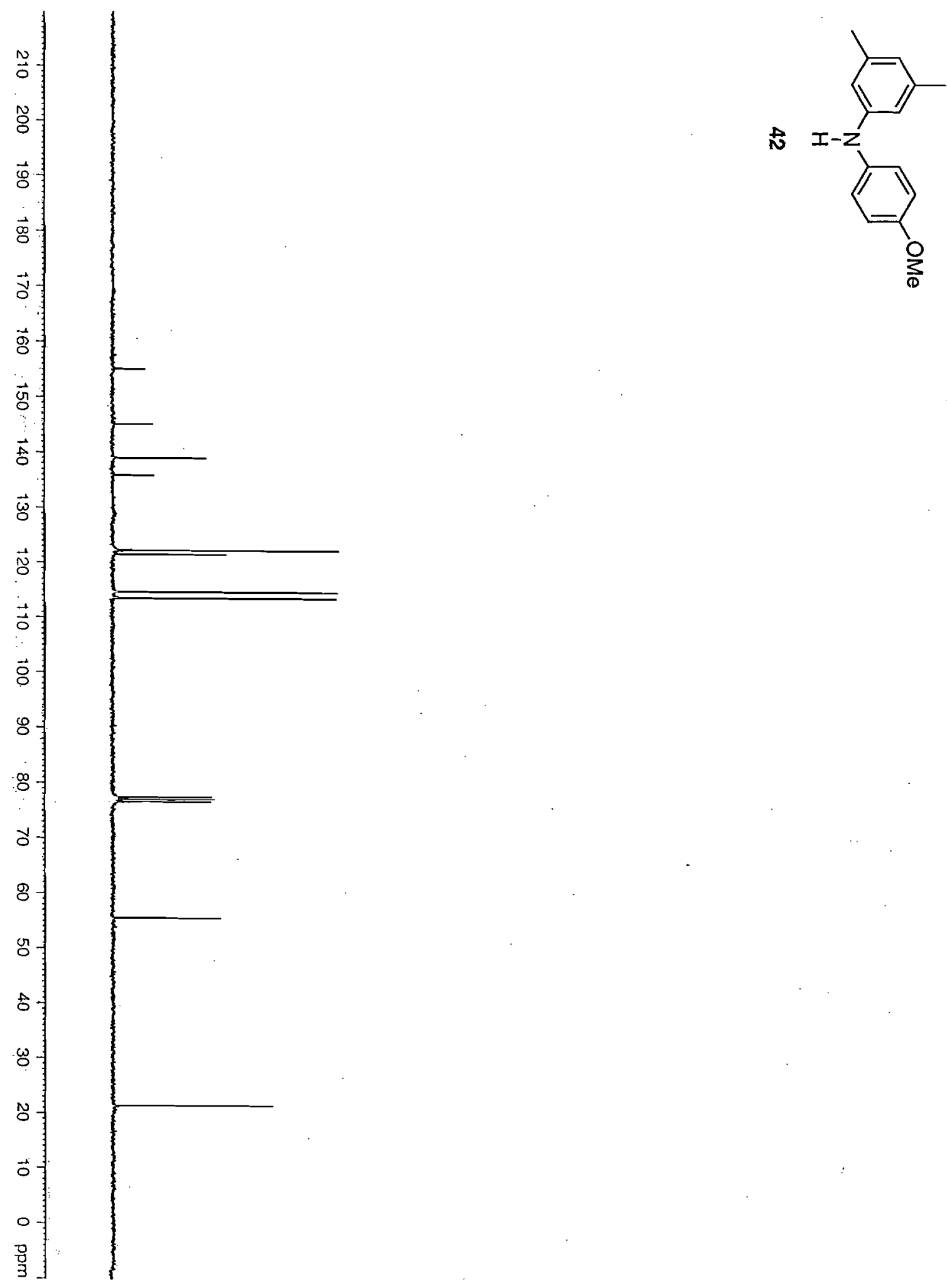

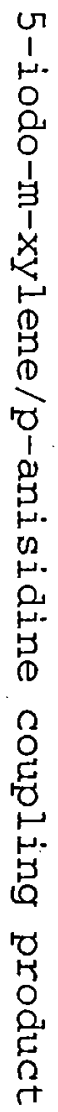
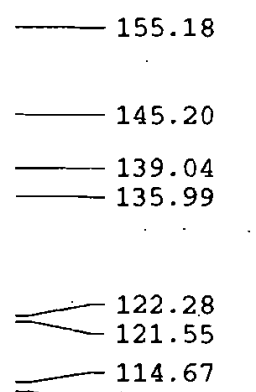

113.55

77.52
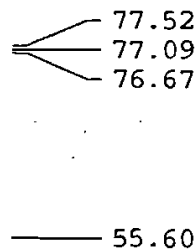

5.60
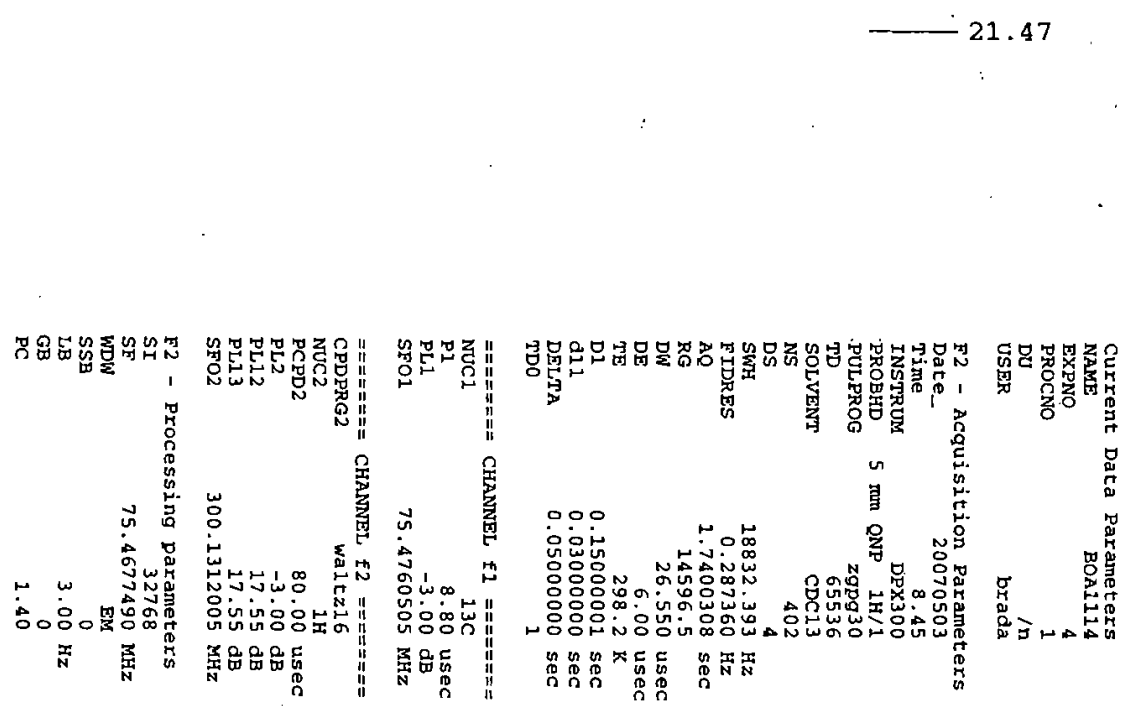

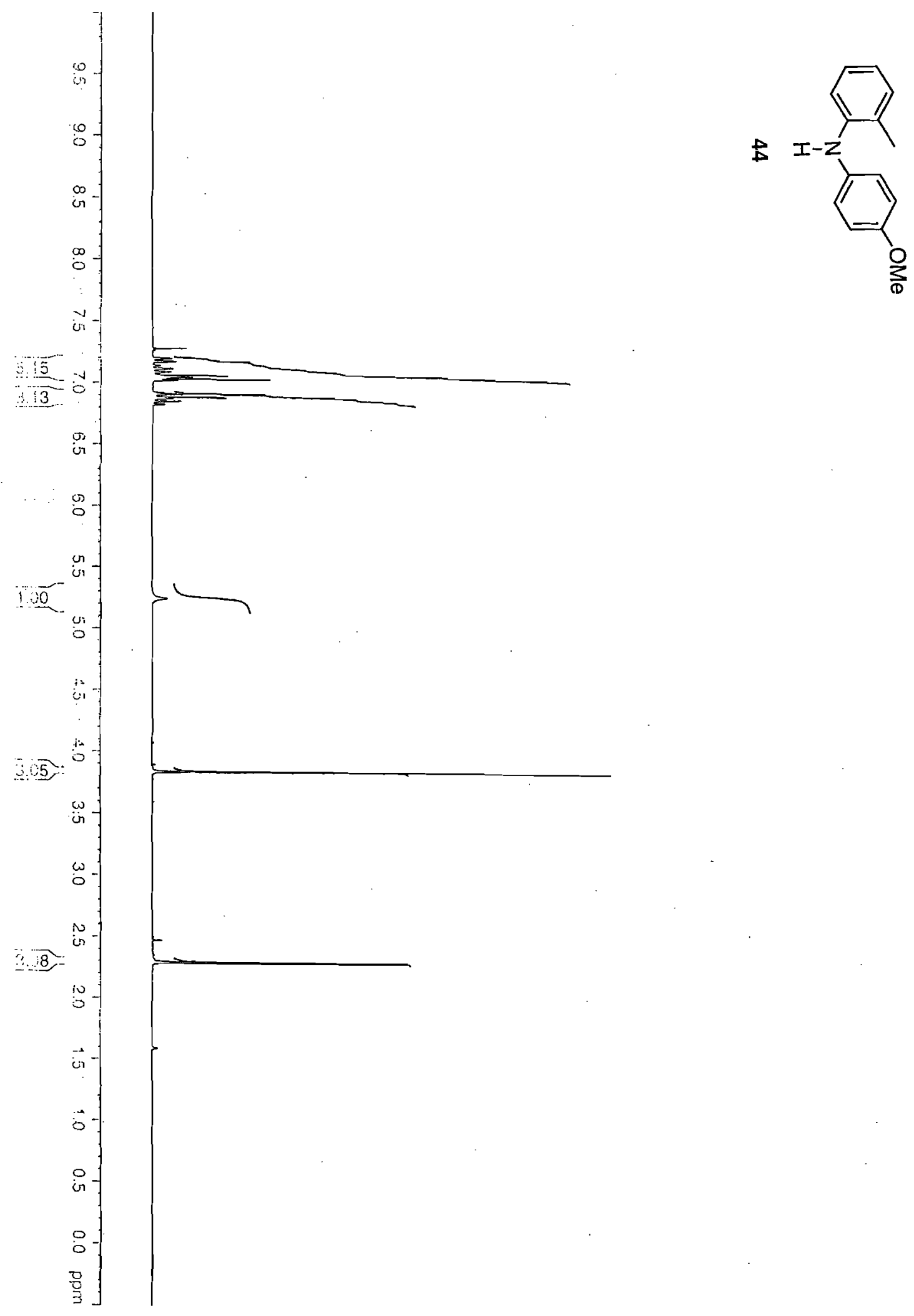

0
1
0.
0
0
0
0
0
0
0
0
0
0
0
0
0
1
0
5
0.
0
0.
0
0
0
0
0
0
0
0
0
0
0
0
0
0
0
0
0
0
0
0
0
0

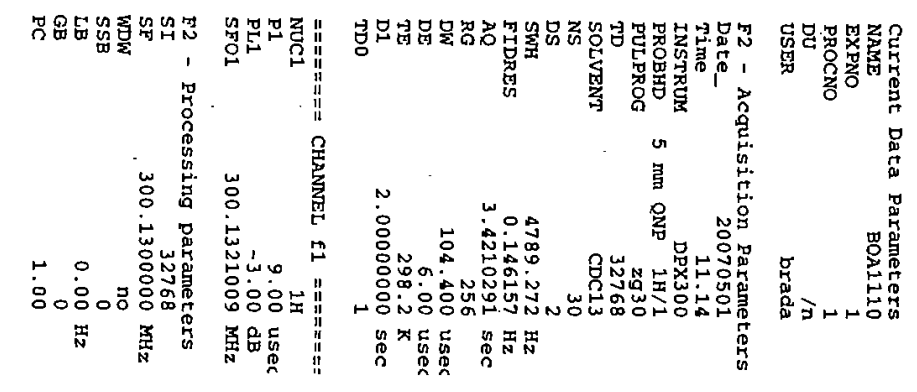



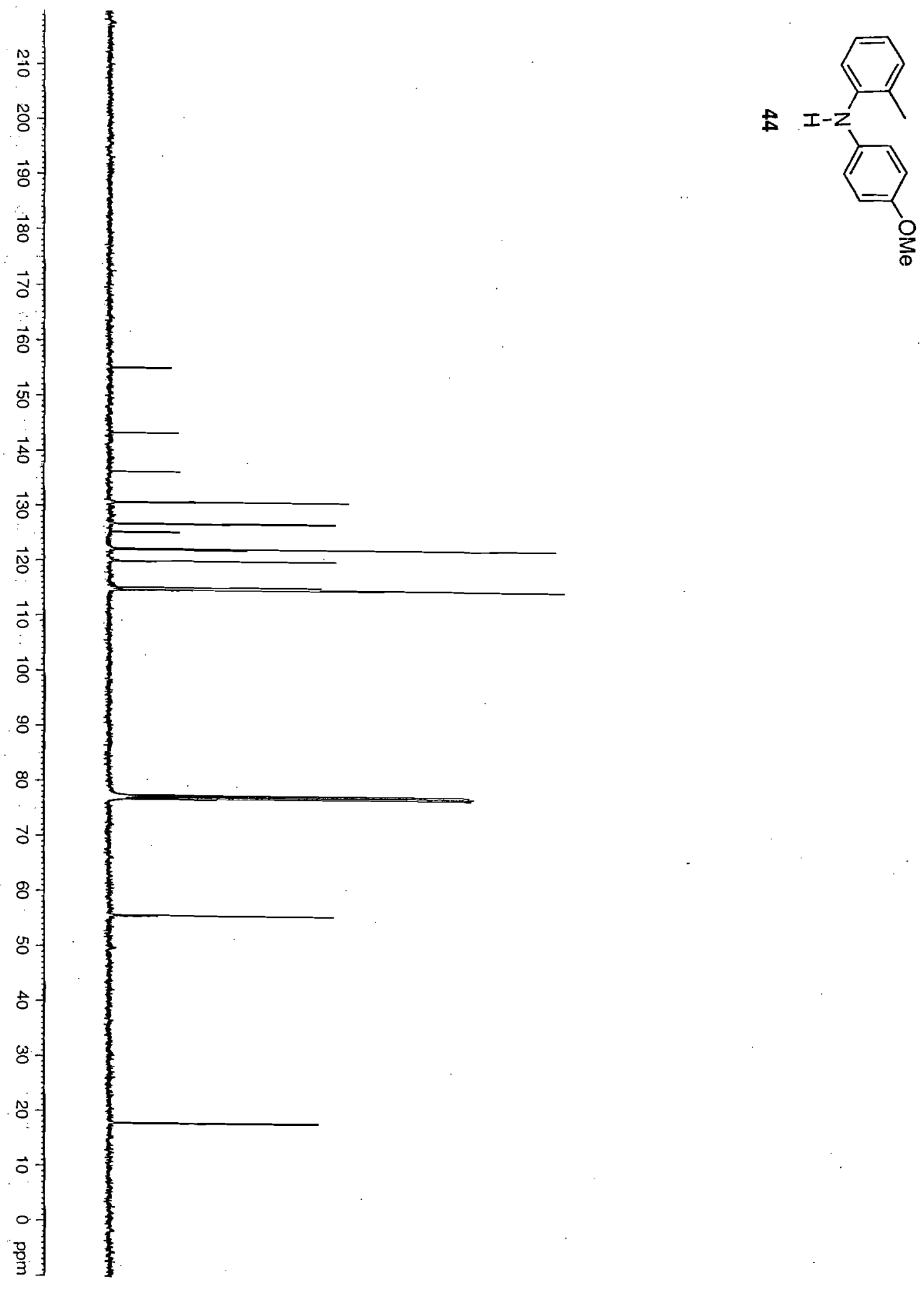

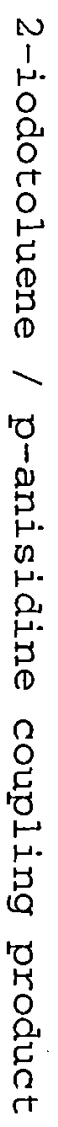

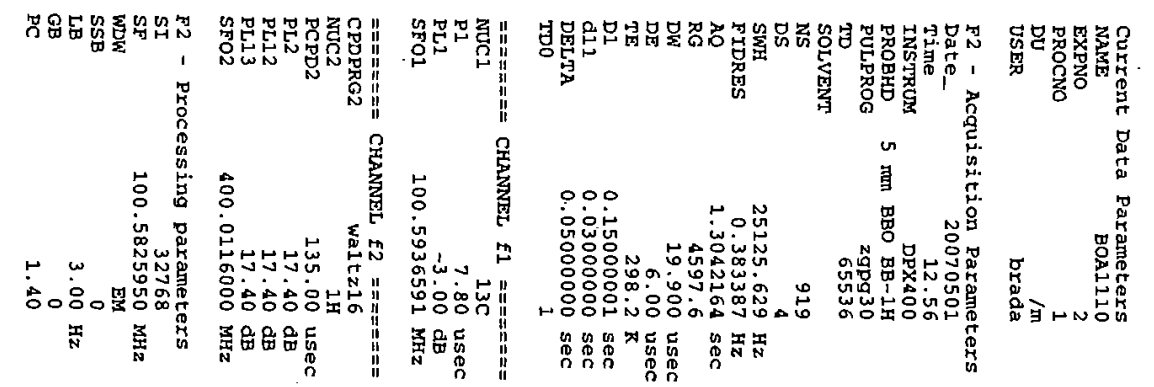



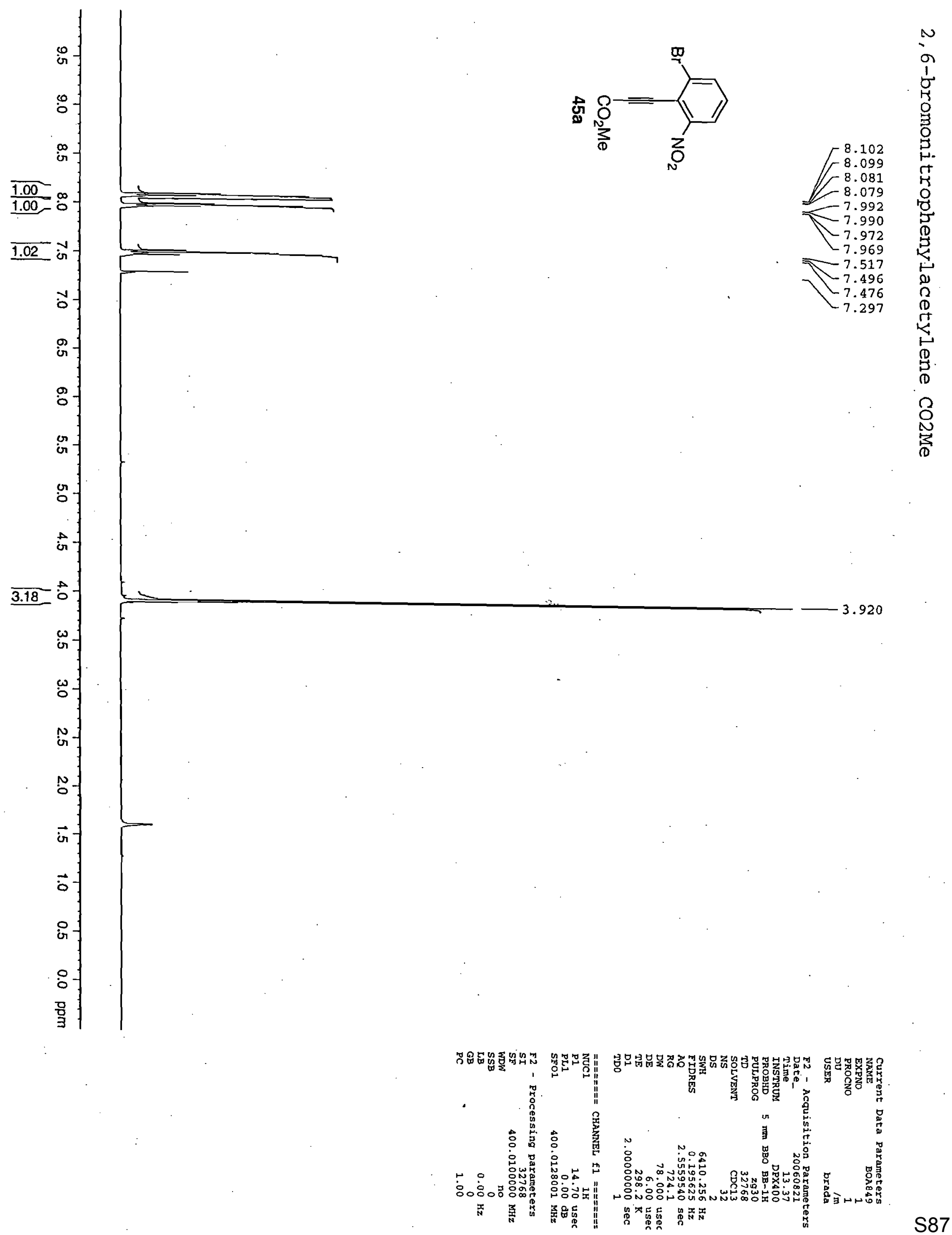


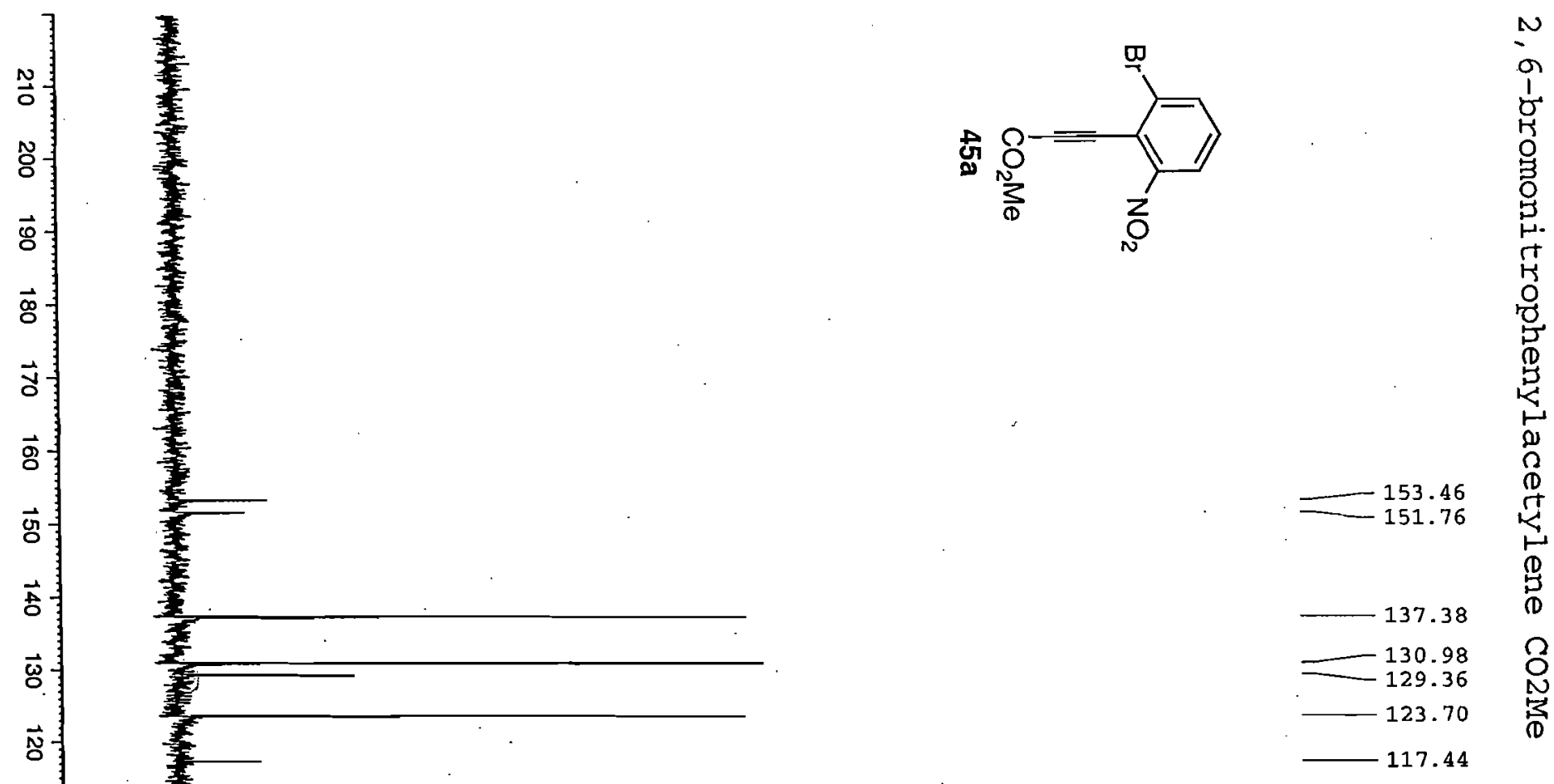

91.13

8

\&

ò

8

잉

s

w

No.

하

$\circ$

맙
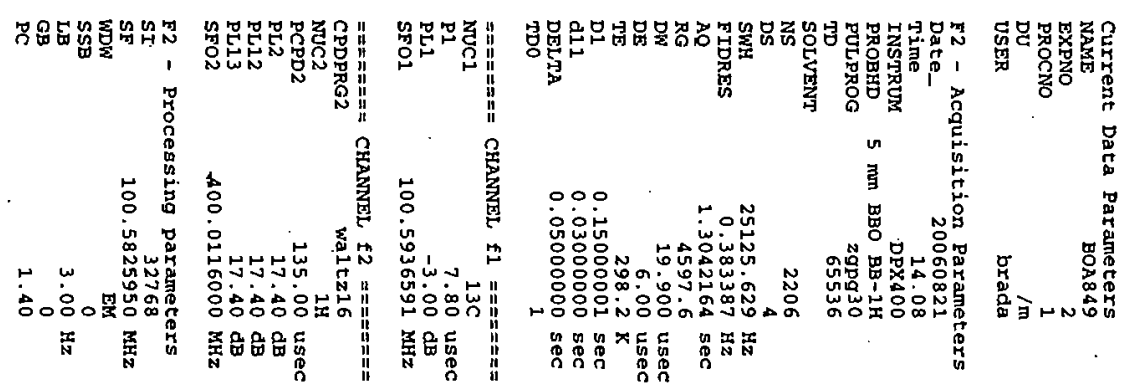

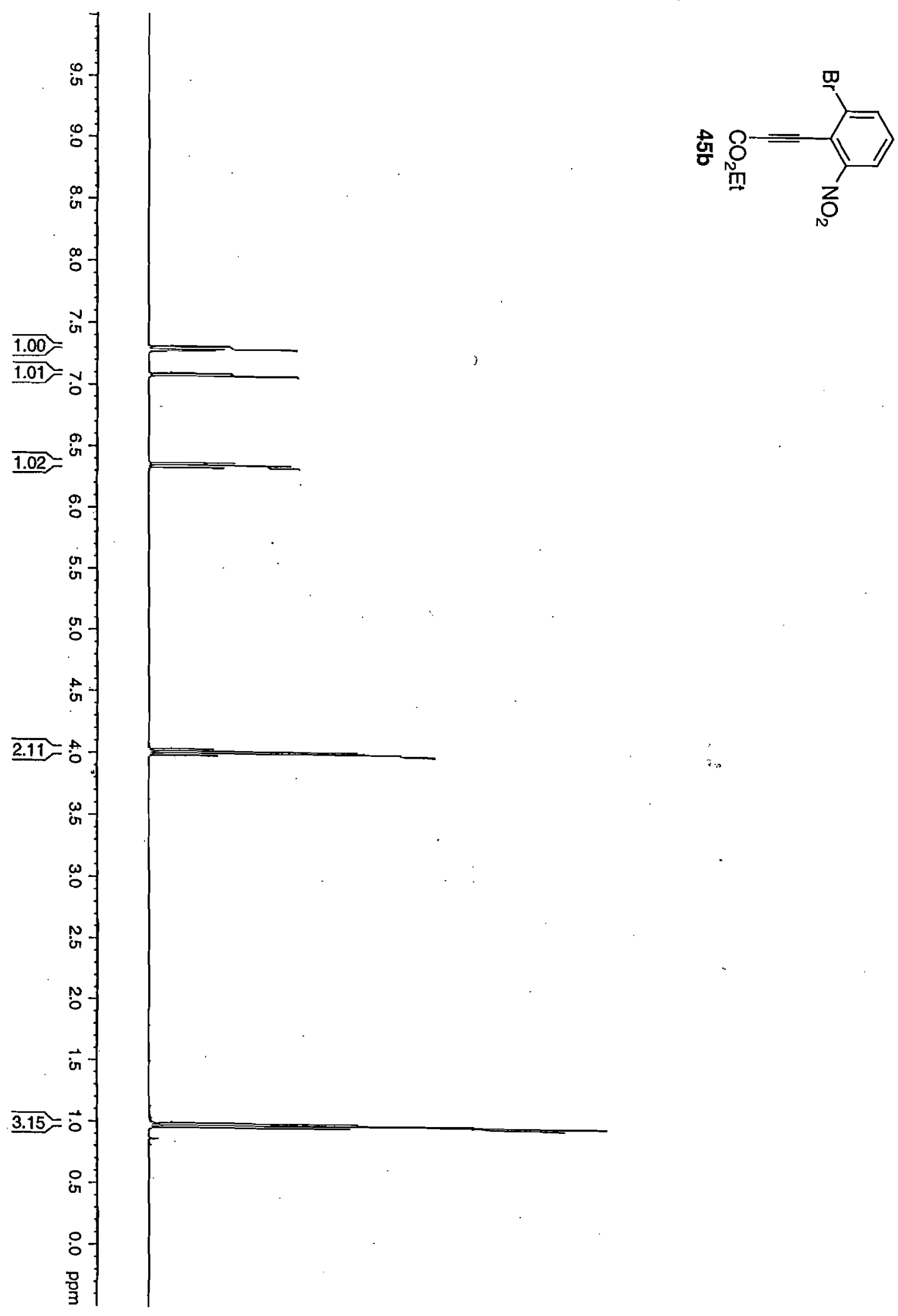

N

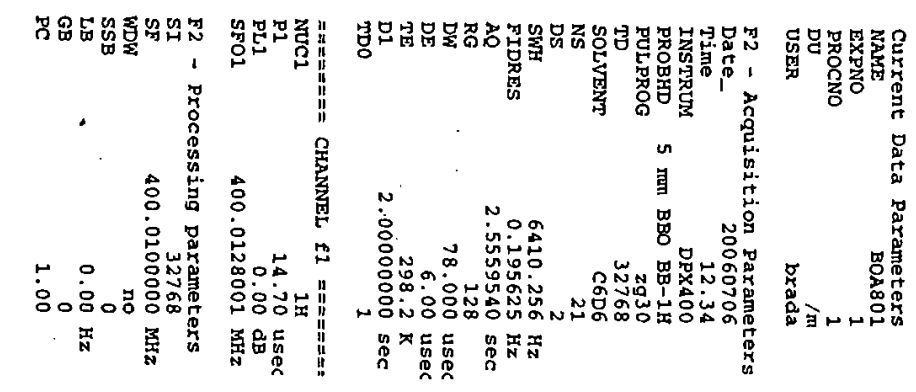




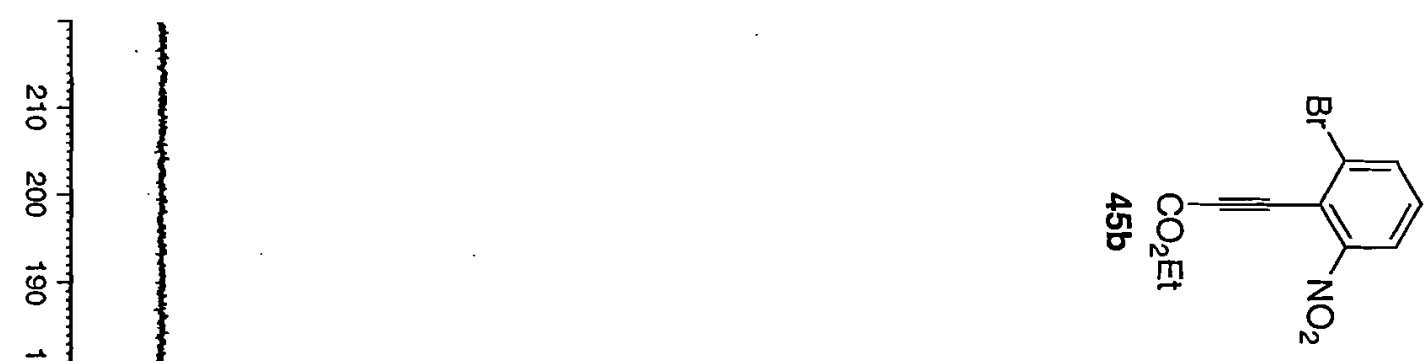

8

$\vec{\delta}$

8

$\overrightarrow{0}$

t

$\vec{\Phi}$

ㅁ.

a

$\overrightarrow{8}$

8

8

o

8

on

ㅇ

$\omega$

ธ

$\overrightarrow{0}$

윽 

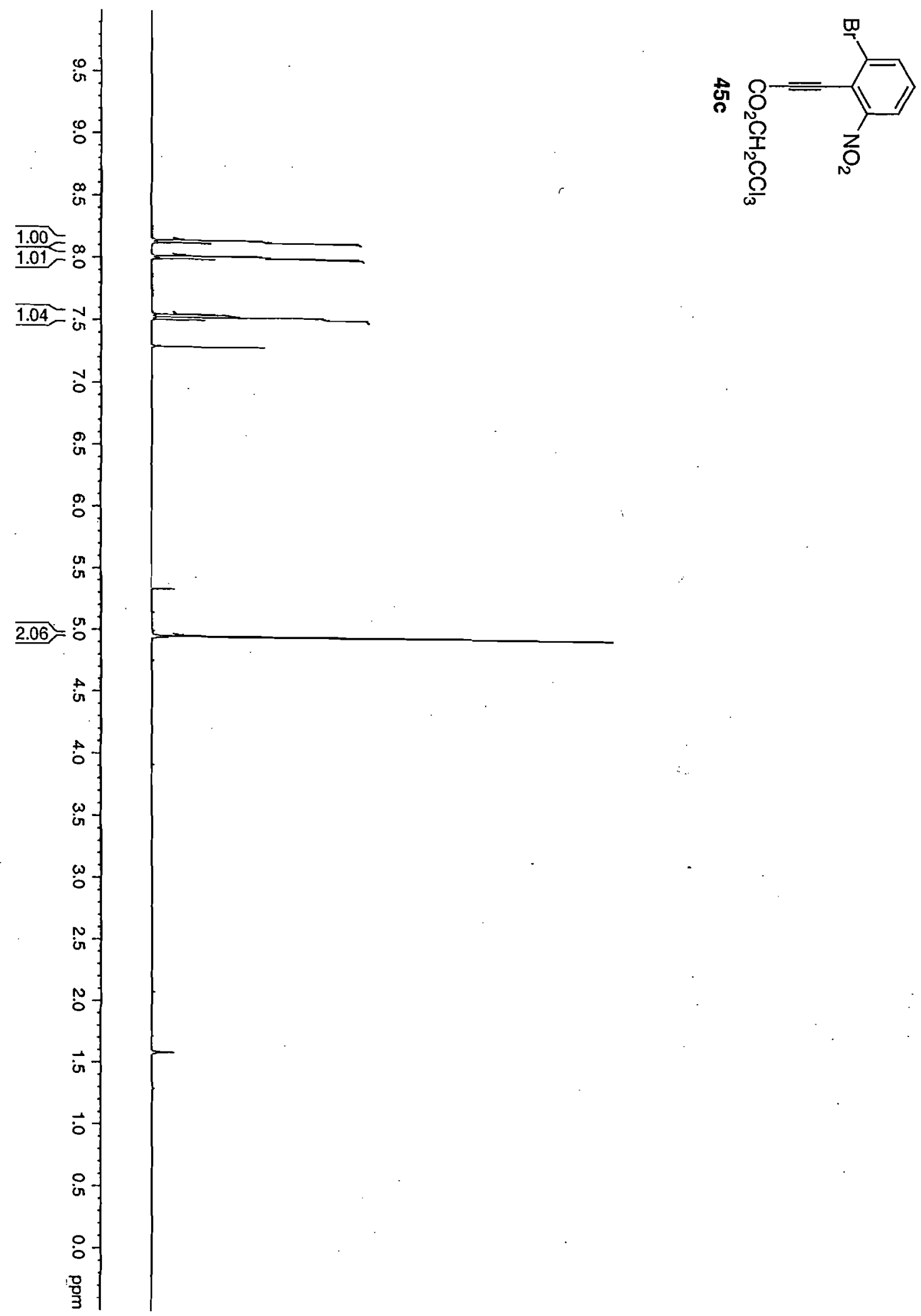

0
0
0
1
0
0
0
0
0
0
0.
0
0
0
0
0
0
0
0
0
5
0
0
0
0
0
0
0
0
0
0
0
0
$N$
0
0
0
0
0
0
0

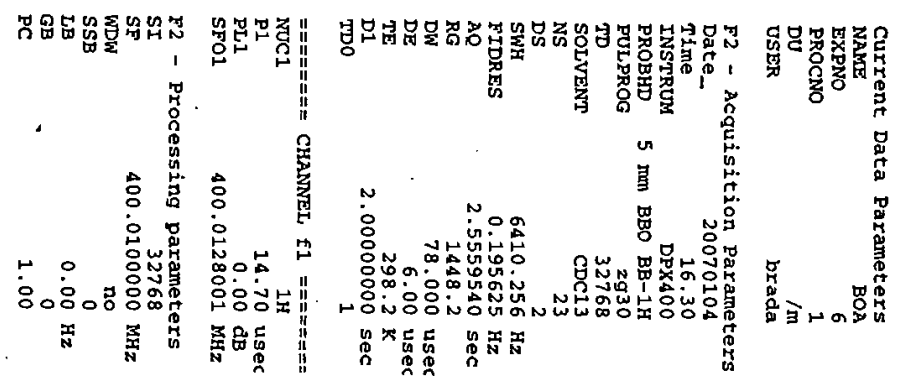



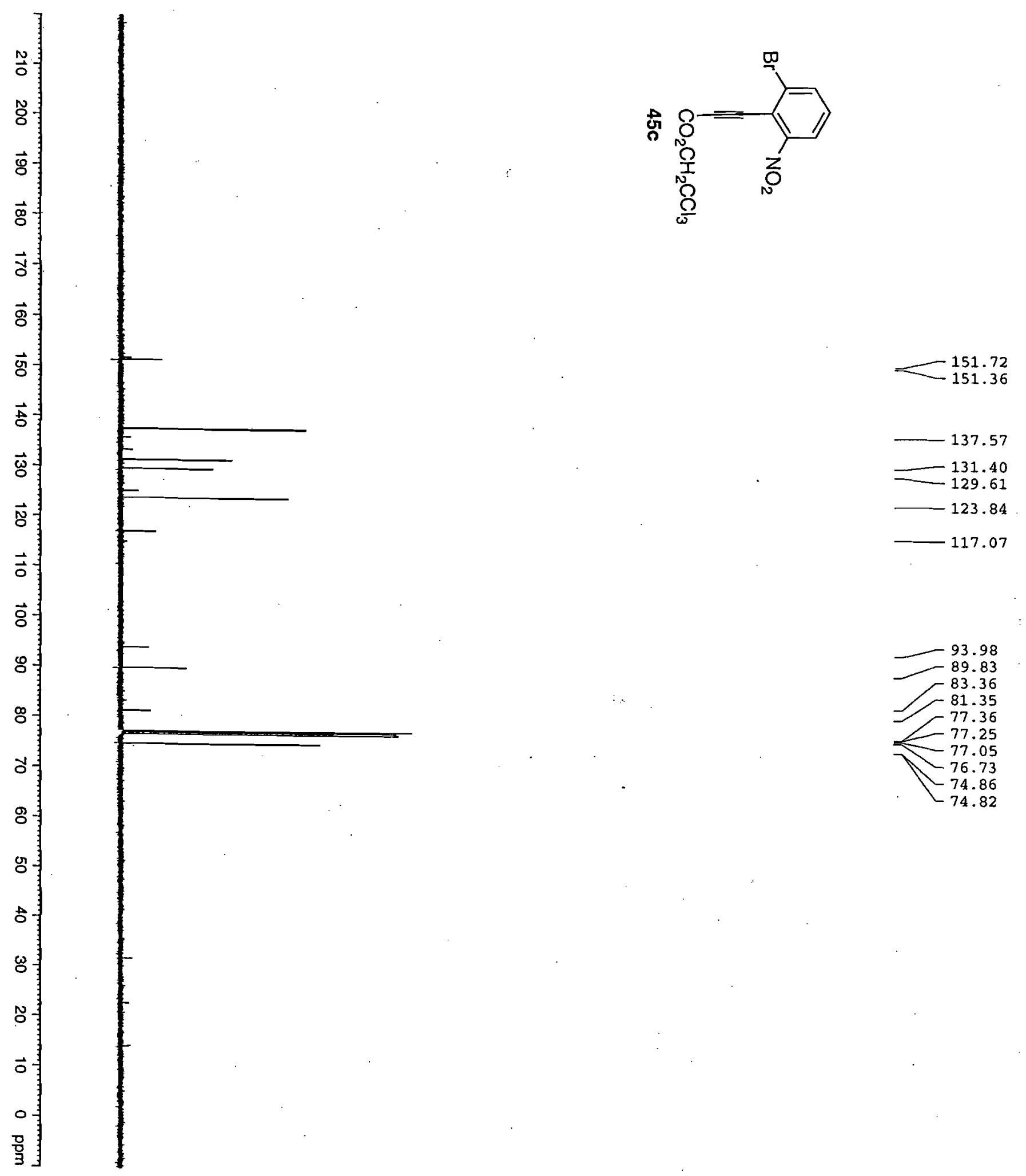

N

O

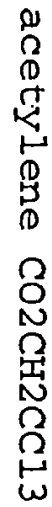

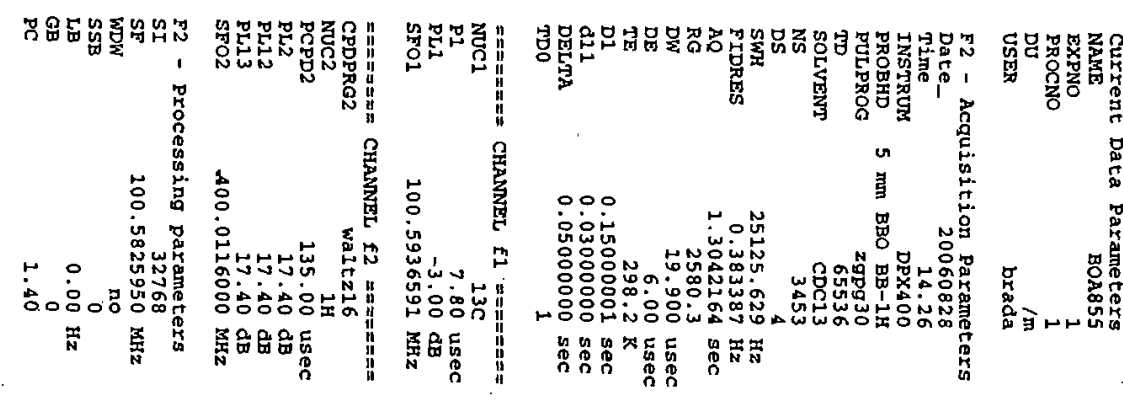



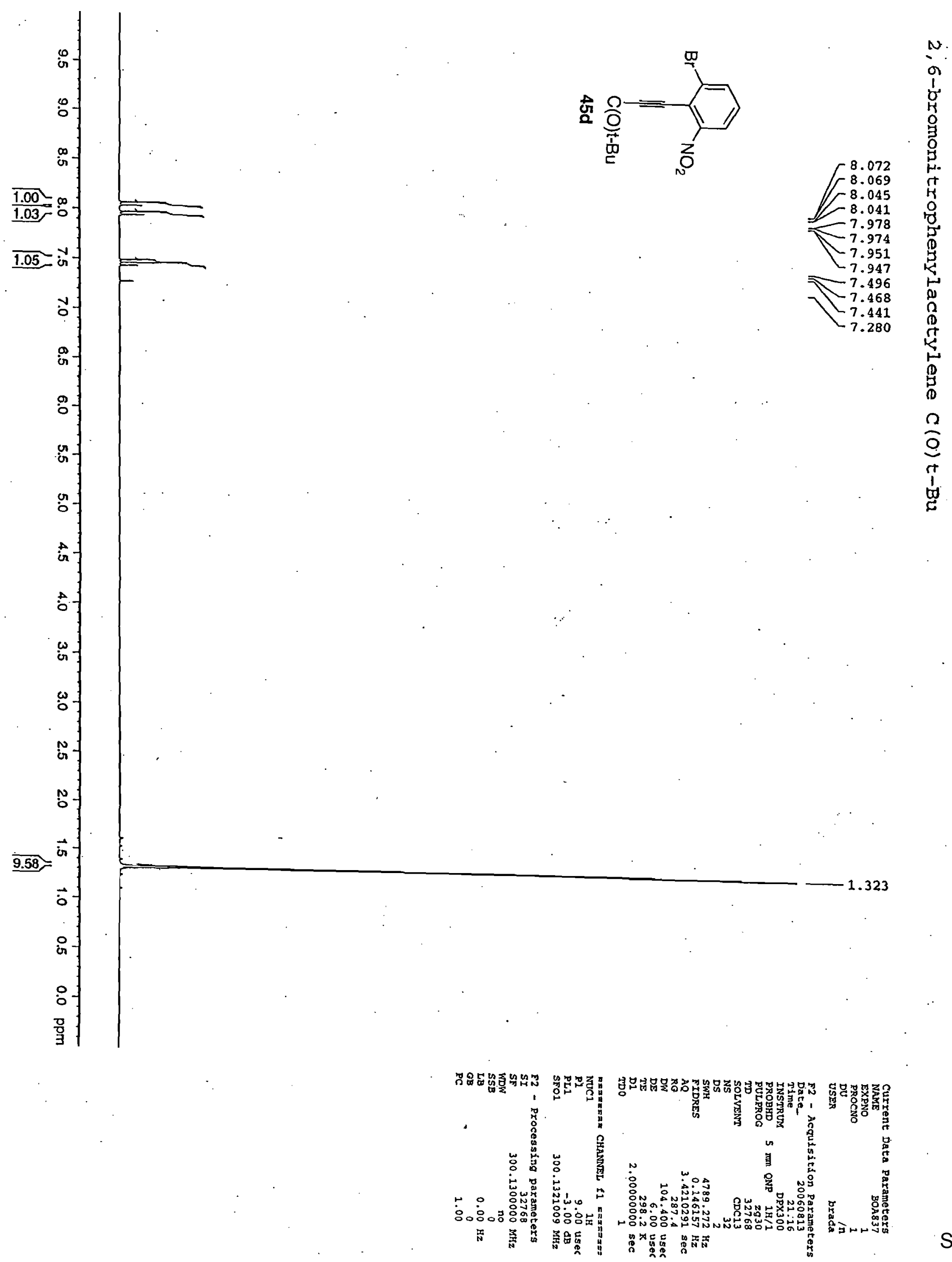


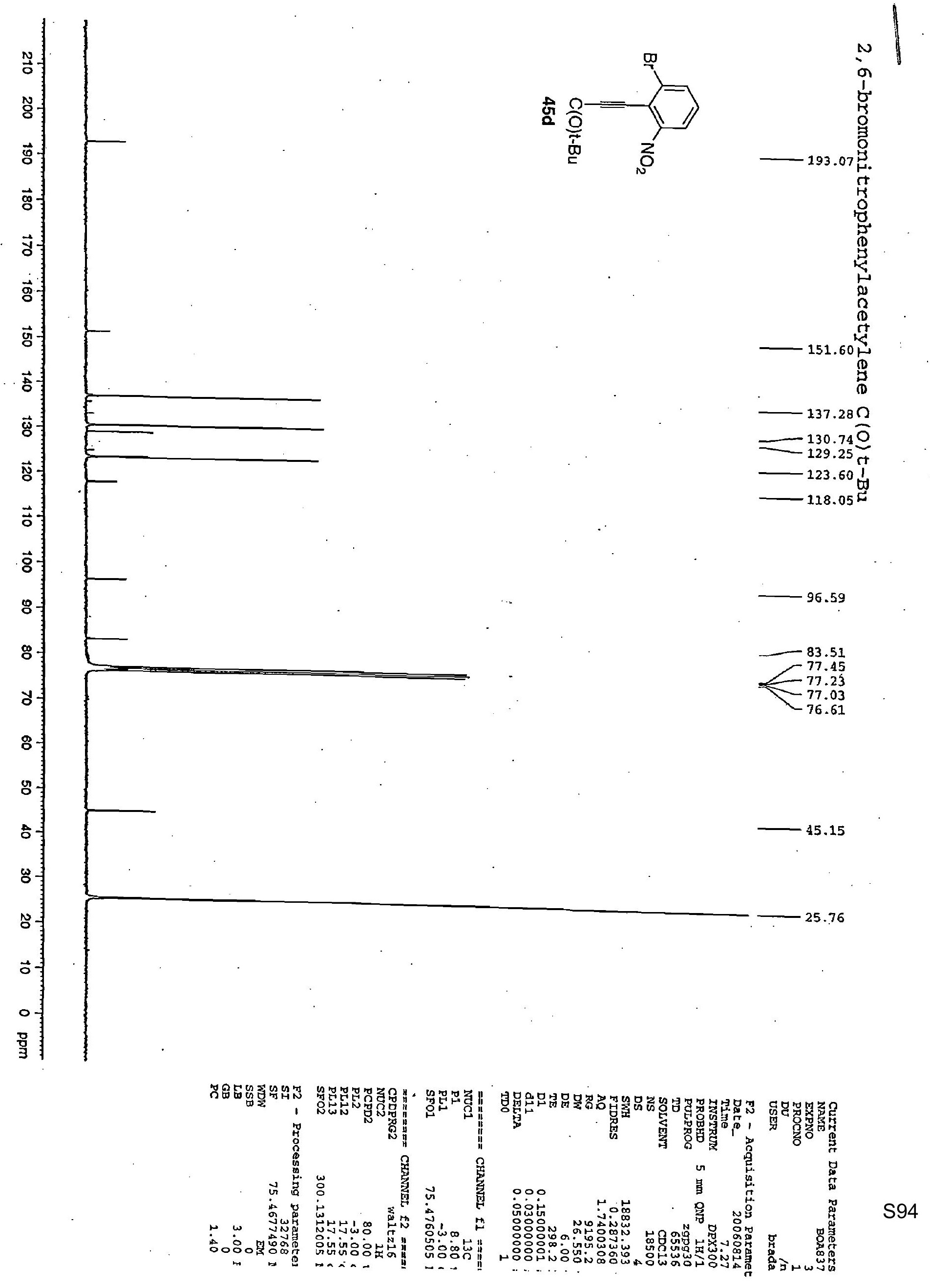




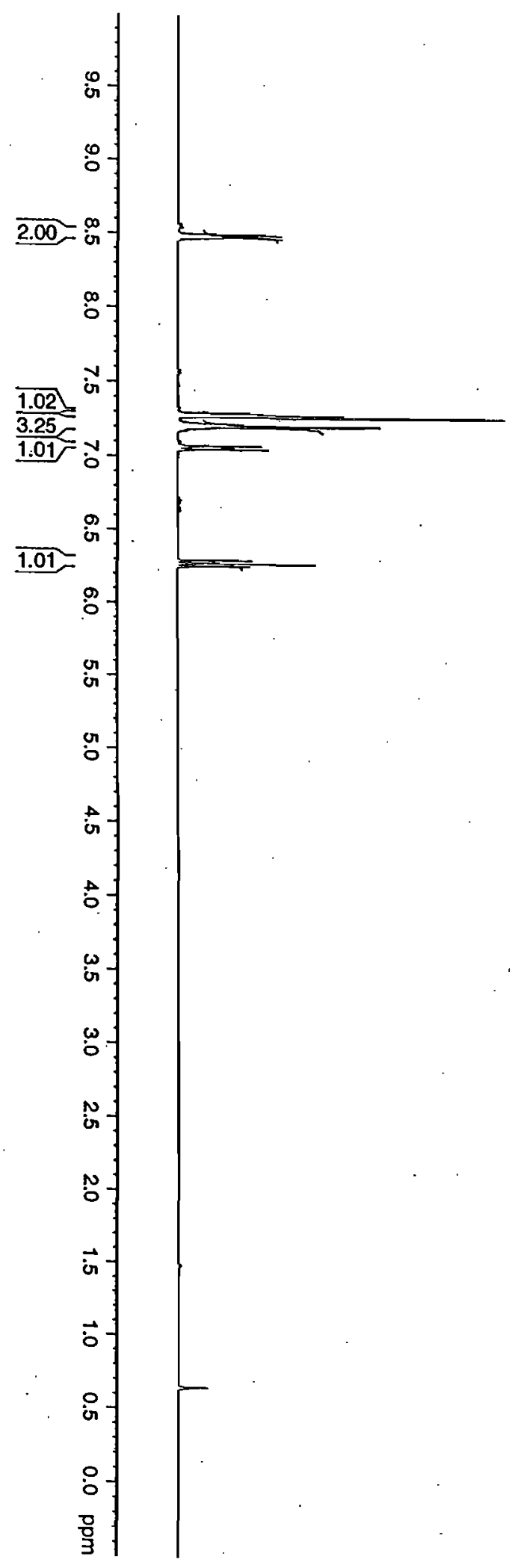

$-7.202$

$-7.195$.

7.191

$-7.077$

7.075

$-7.057$

7.054

6.300

6.280

'

$\frac{\Omega}{0}$

음

D 


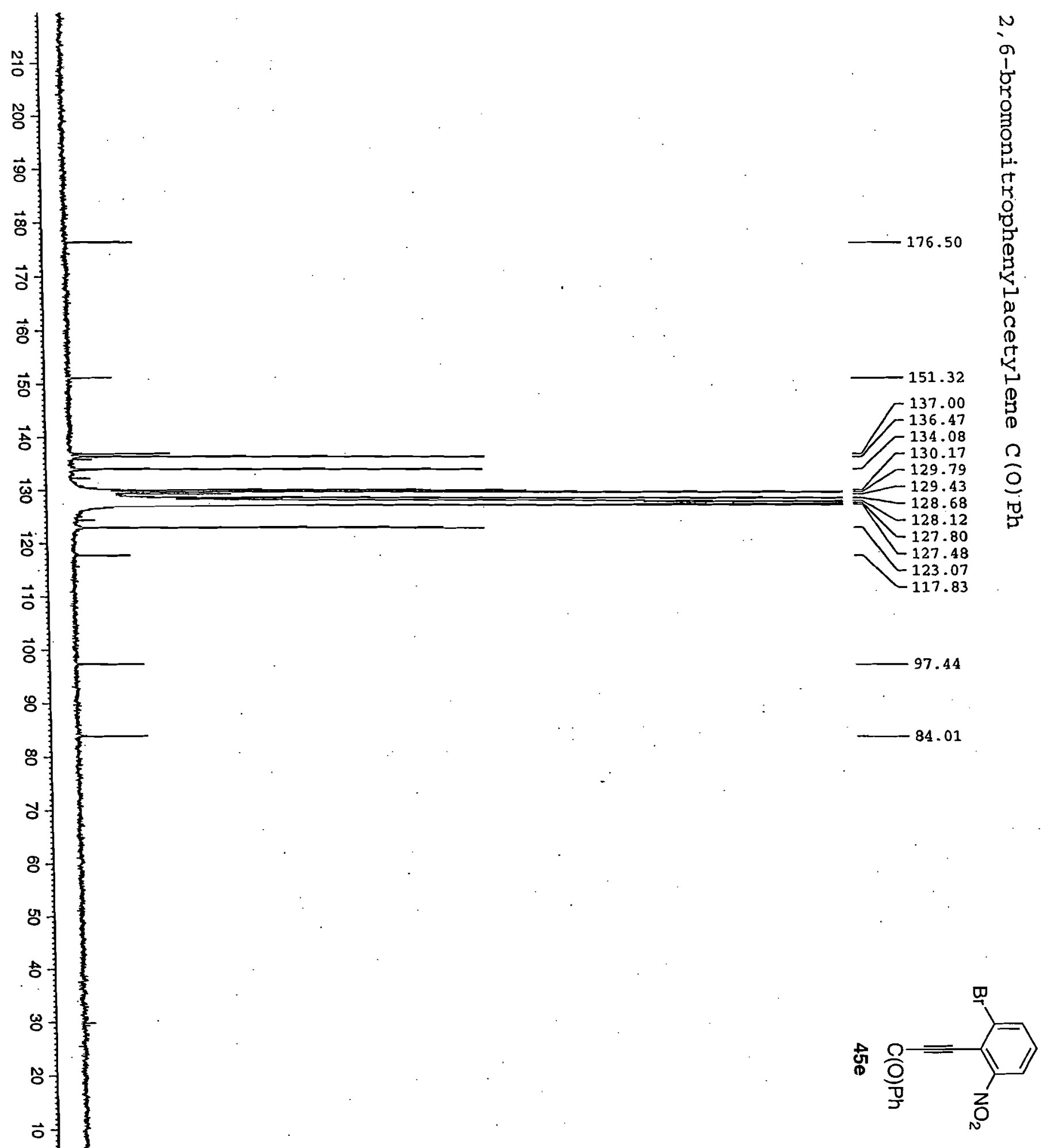



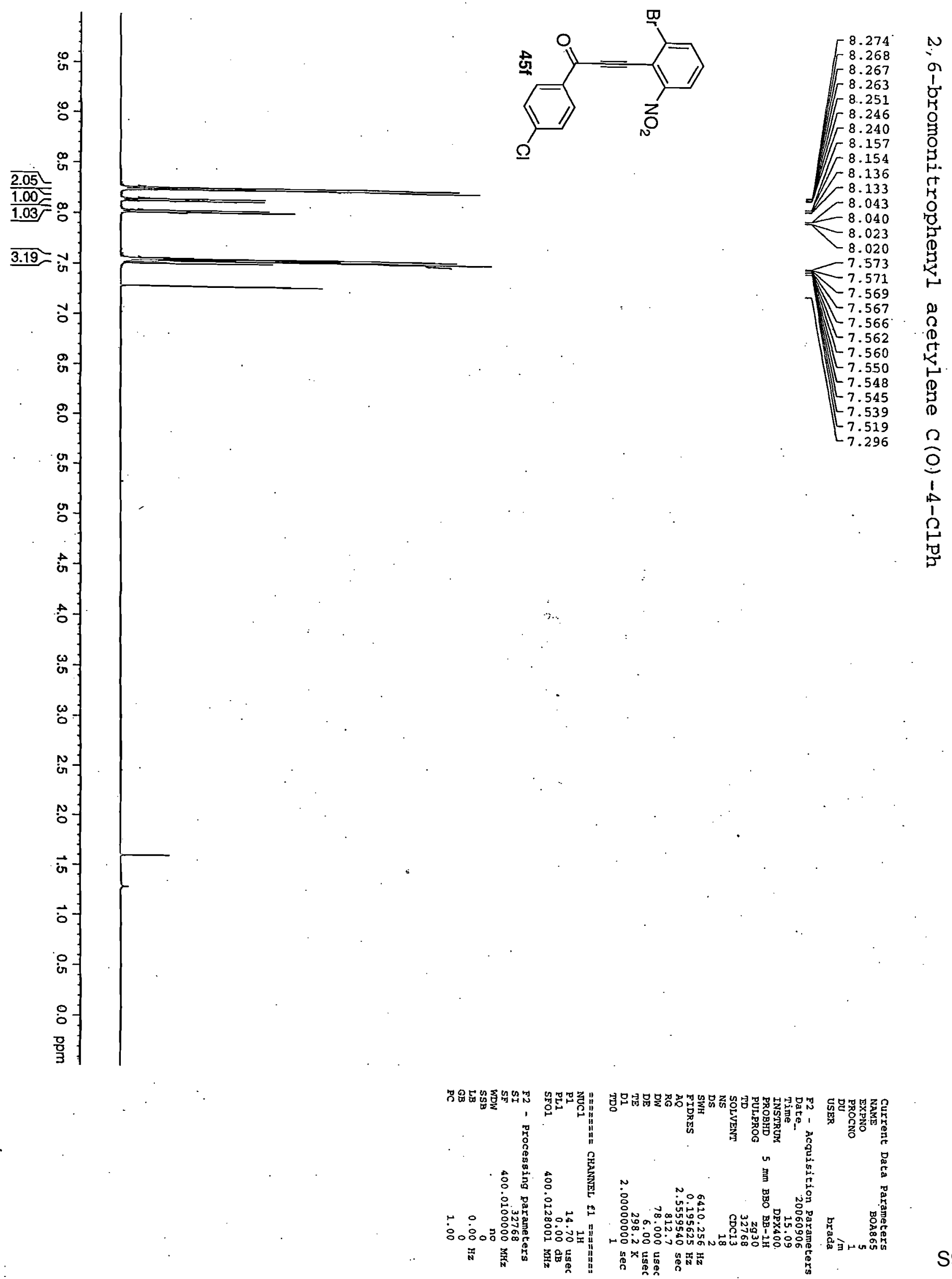

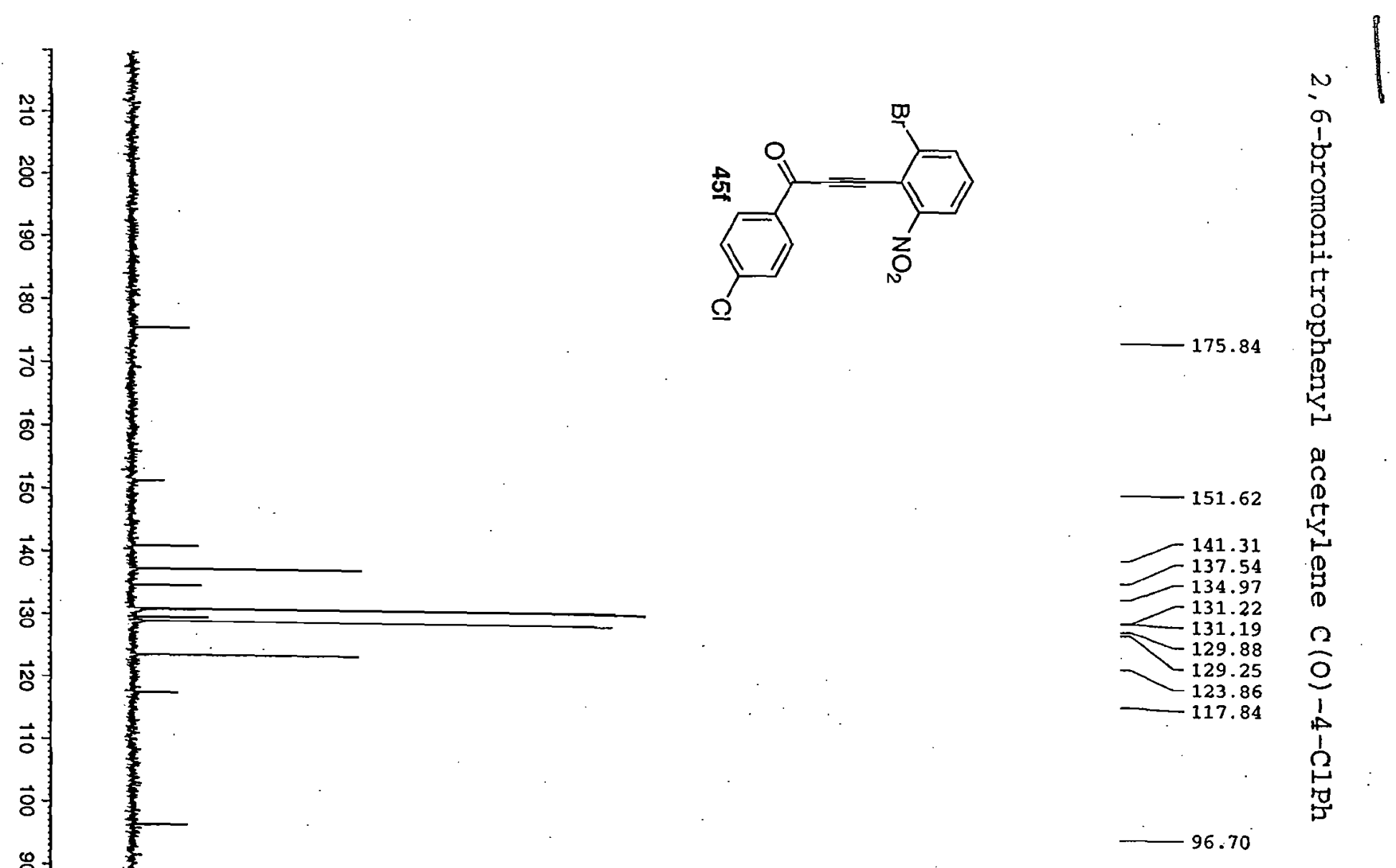

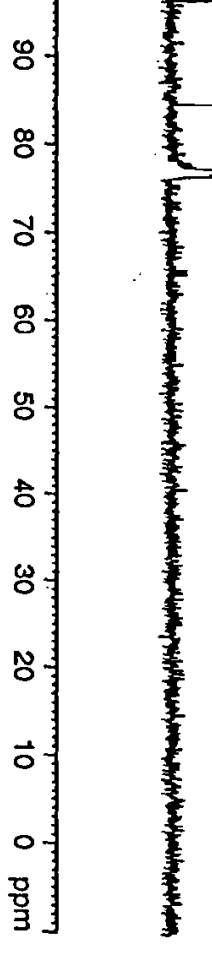

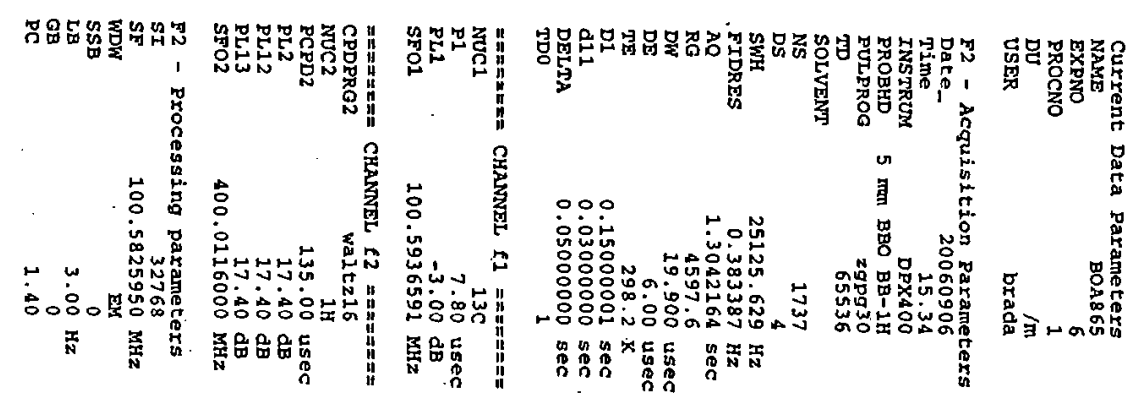



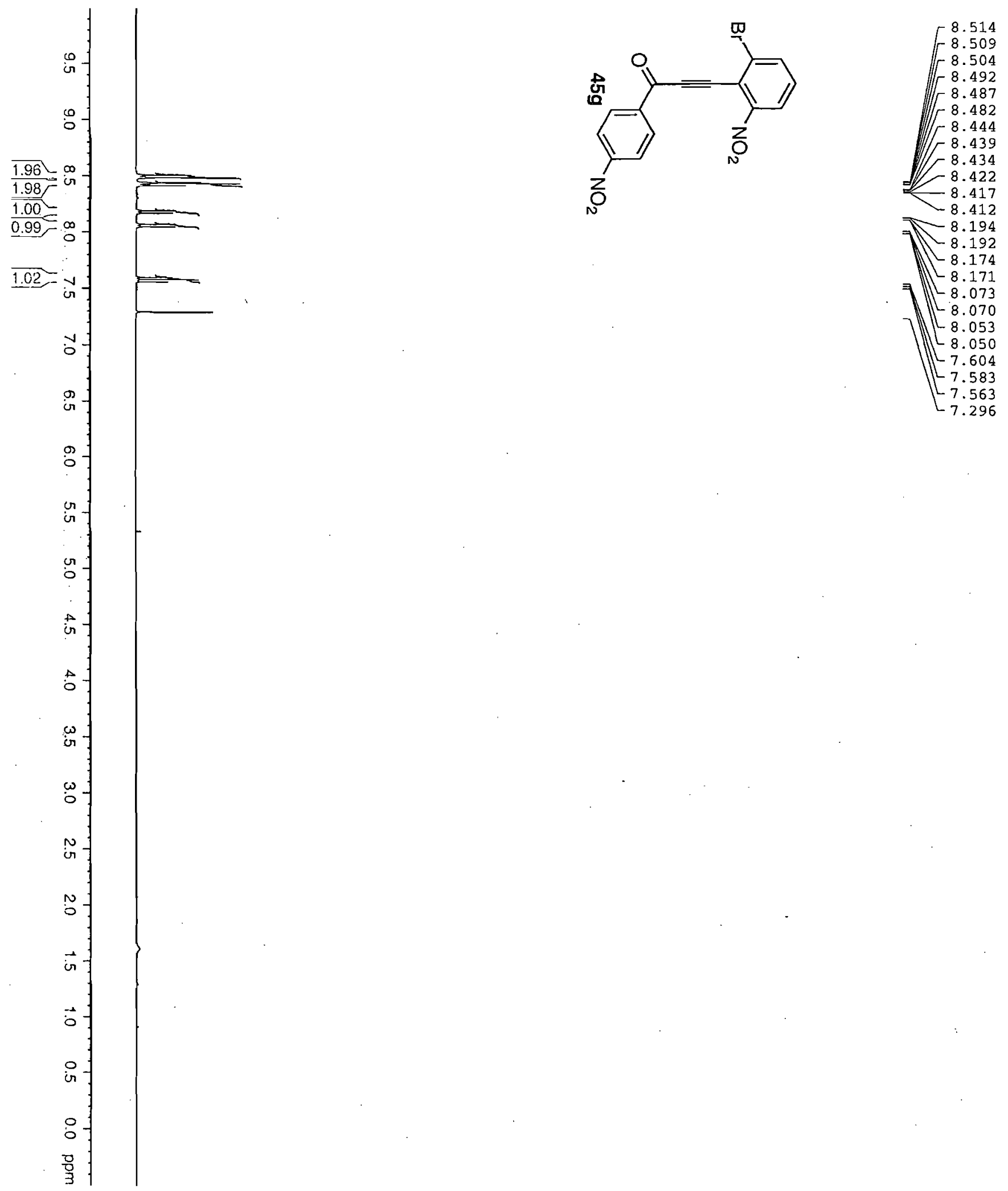

N

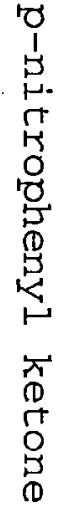

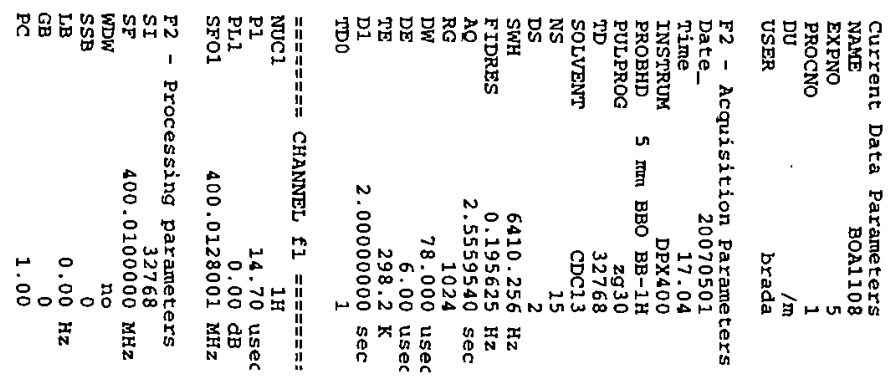



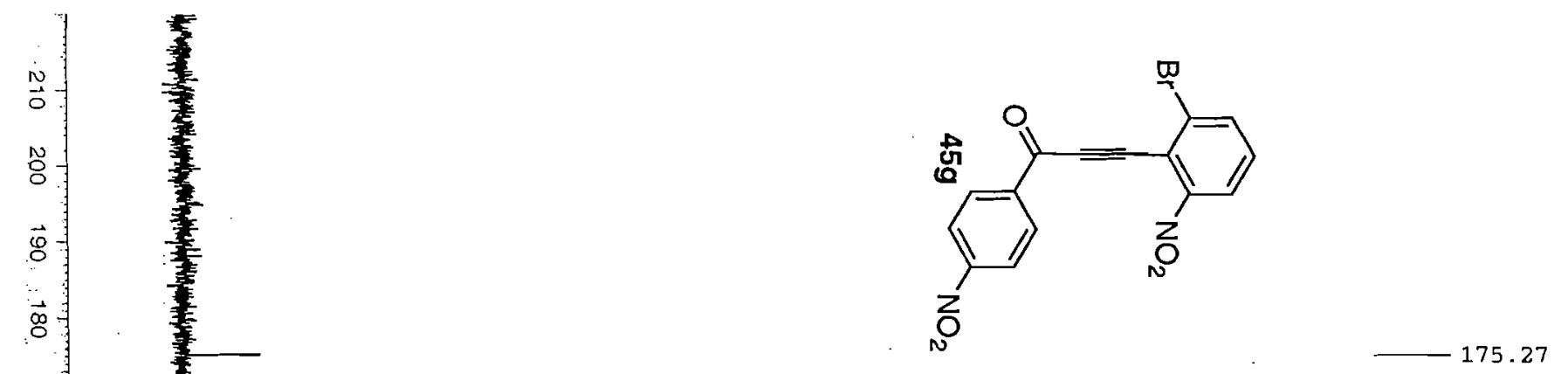

a

宊

$\vec{\vartheta}$

$\overrightarrow{0}$

$\vec{\omega}$

$\vec{N}$

$\overrightarrow{0}$

$\overrightarrow{8}$

8

$\stackrel{\infty}{\circ}$

ชั
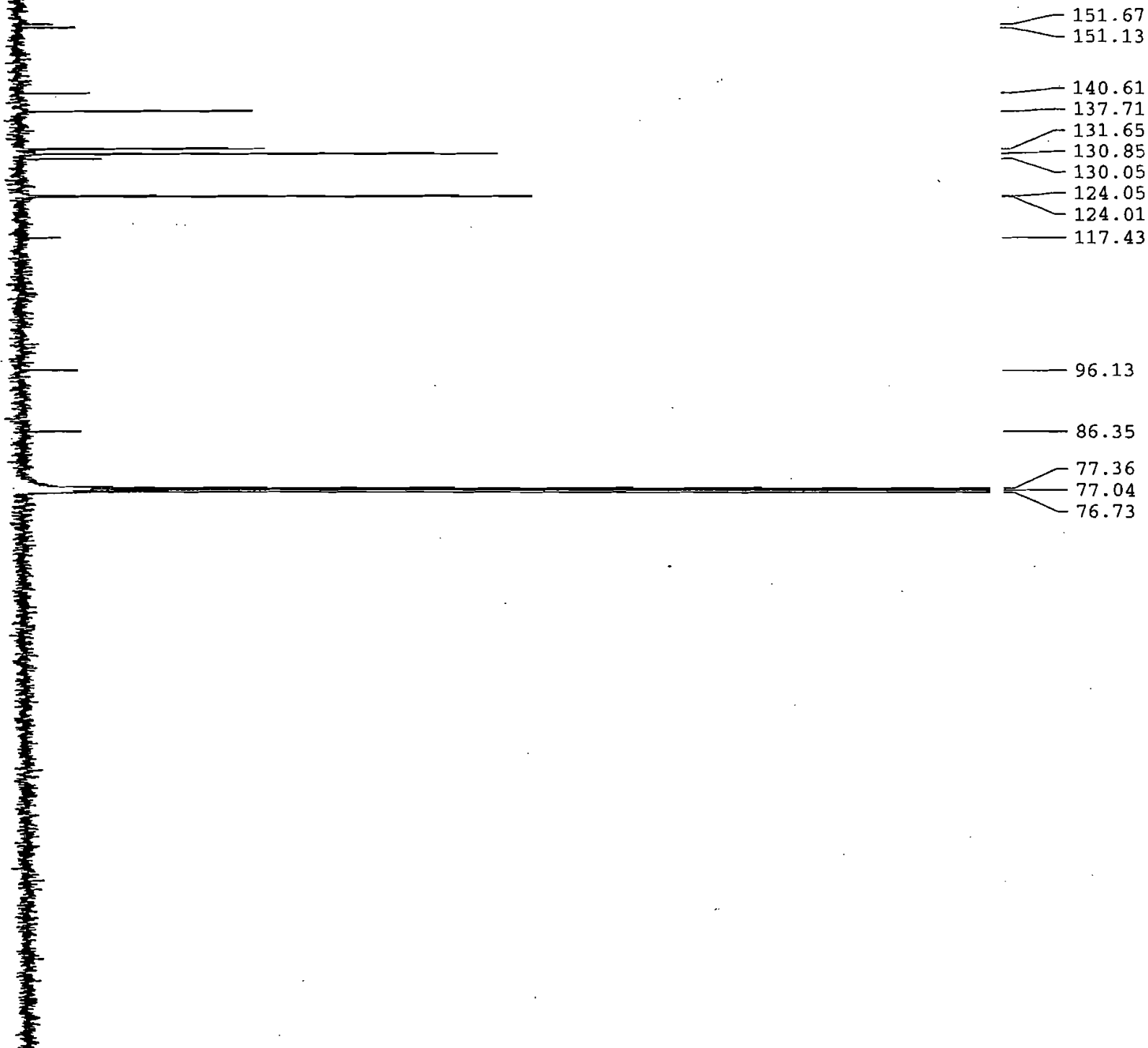

$\begin{array}{r}-140.61 \\ -137.71 \\ \hline\end{array}$

$-131.65$

$-130.85$

$-130.05$

$-124.05$
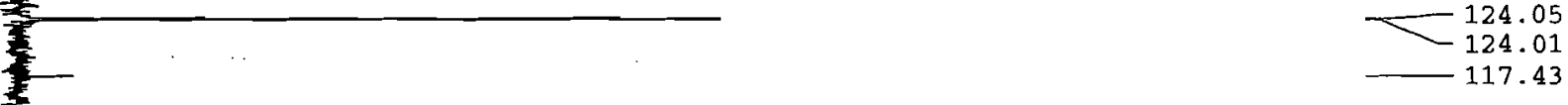

$-96.13$

$-86.35$

$-77.36$

77.04

西

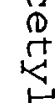

疍

to

苫

苜

'ס્5

怘

\section{8}

ज्

o

$\omega$

N

$\ddot{\circ}$

$\circ$

윽

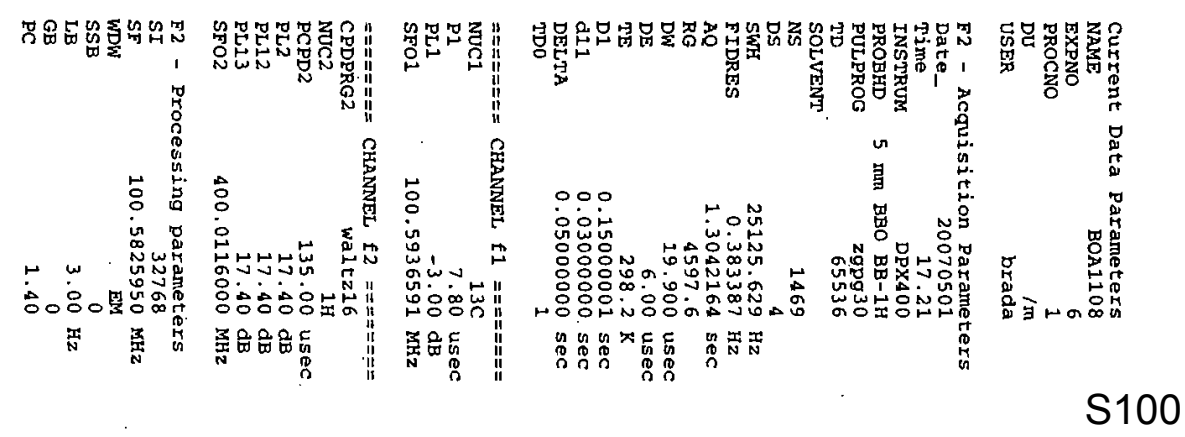




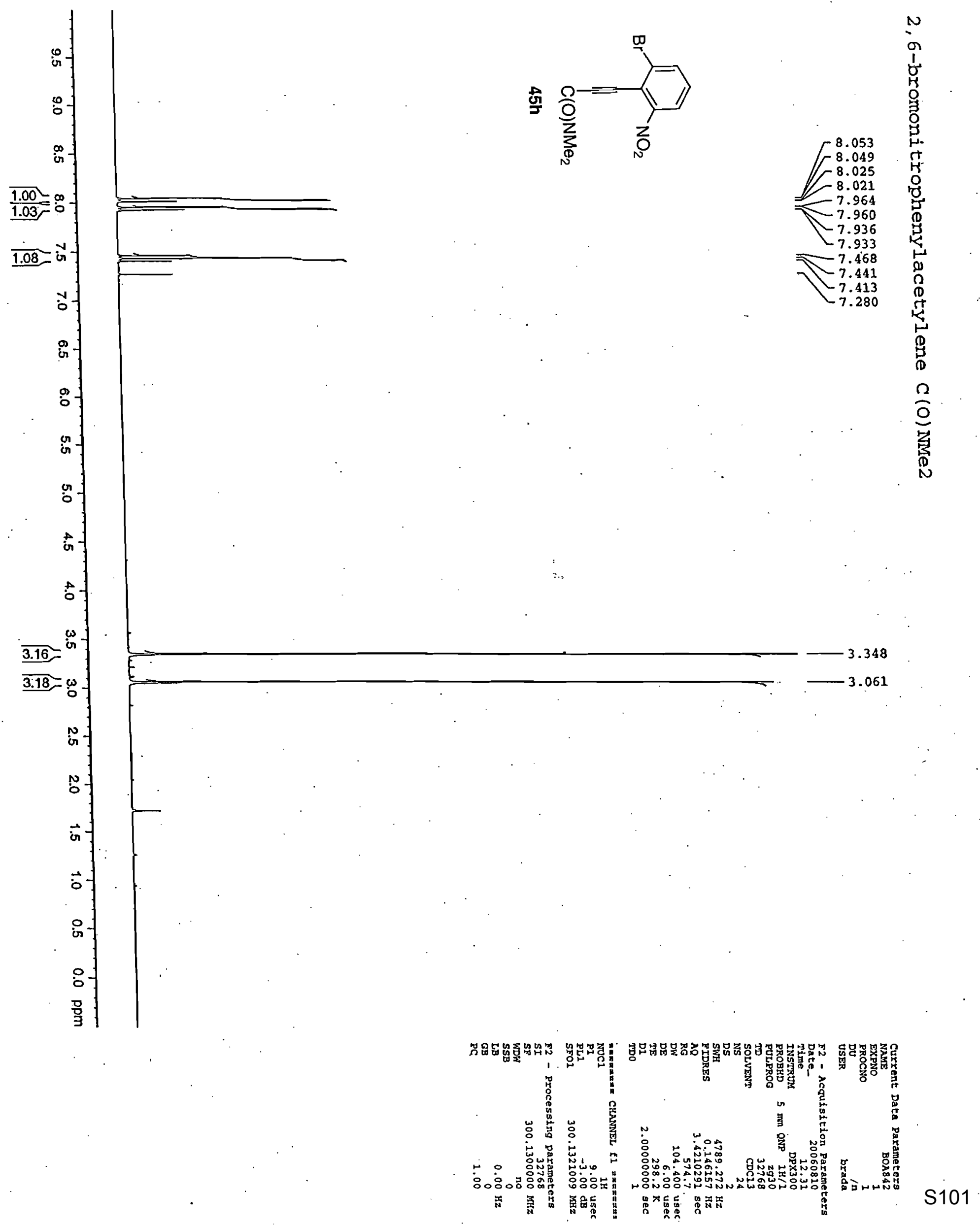



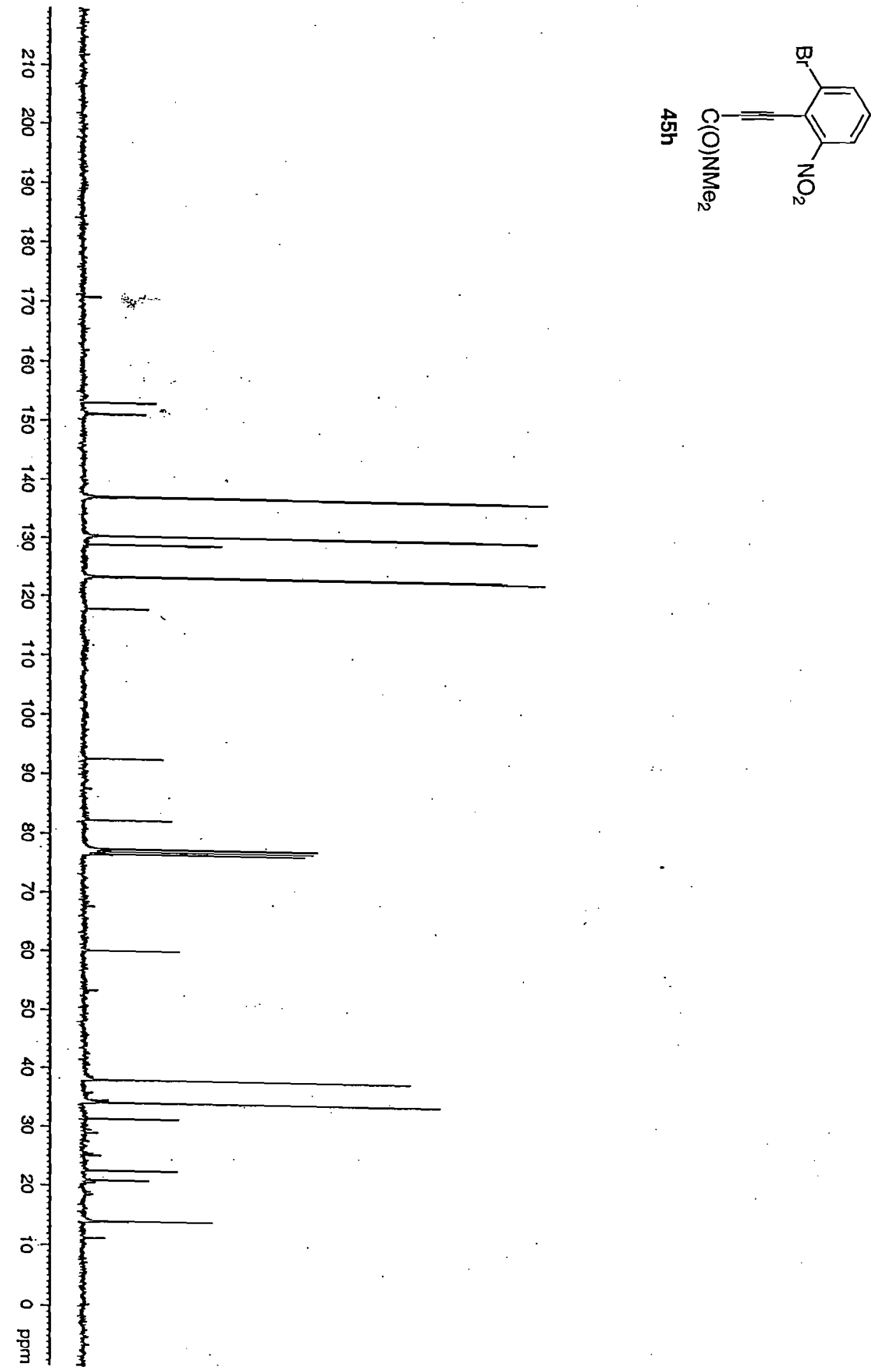

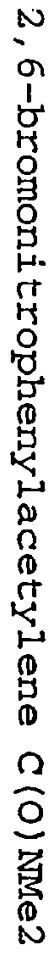

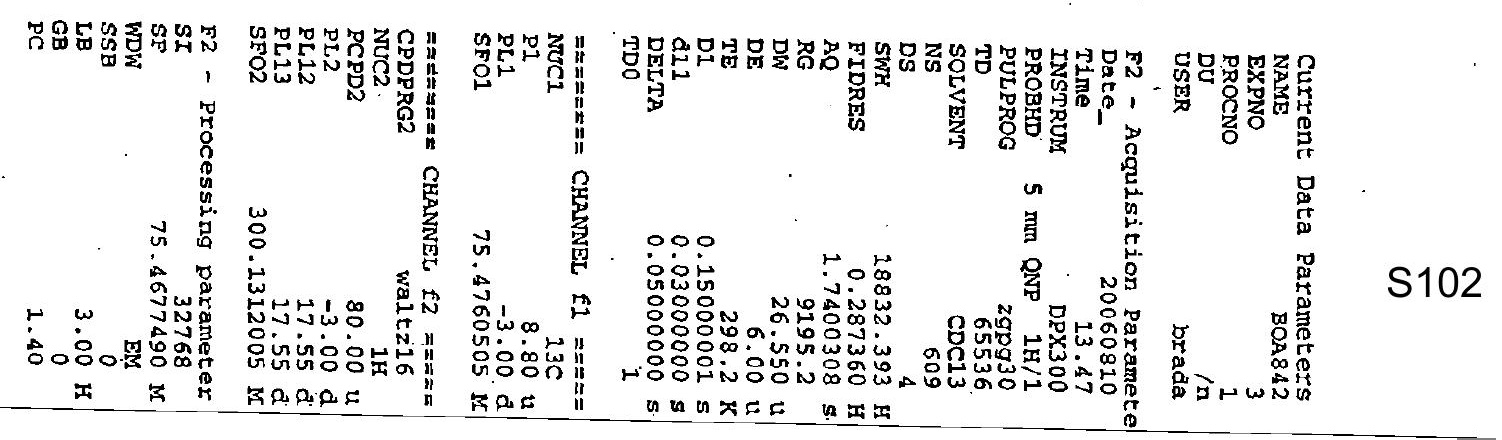



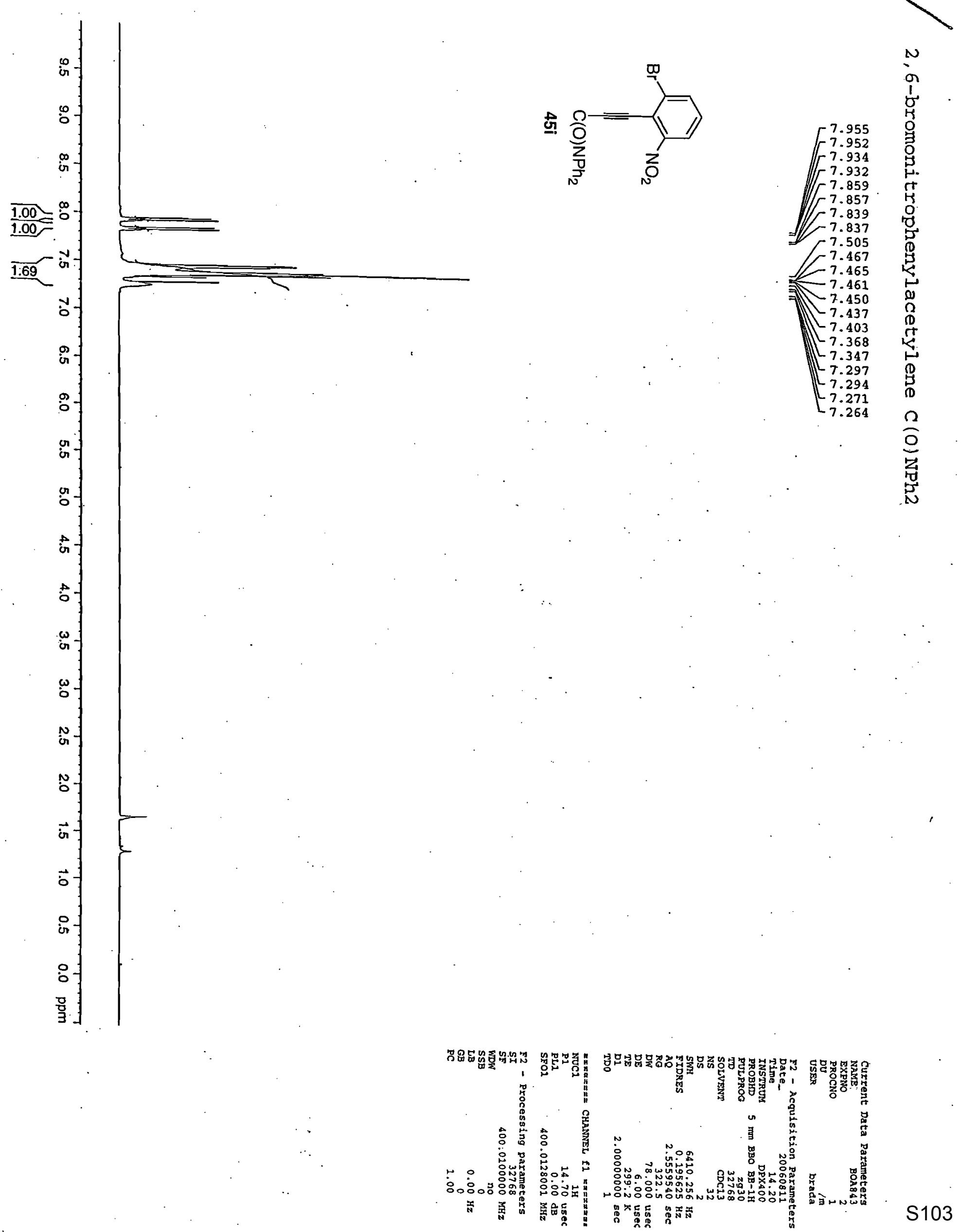

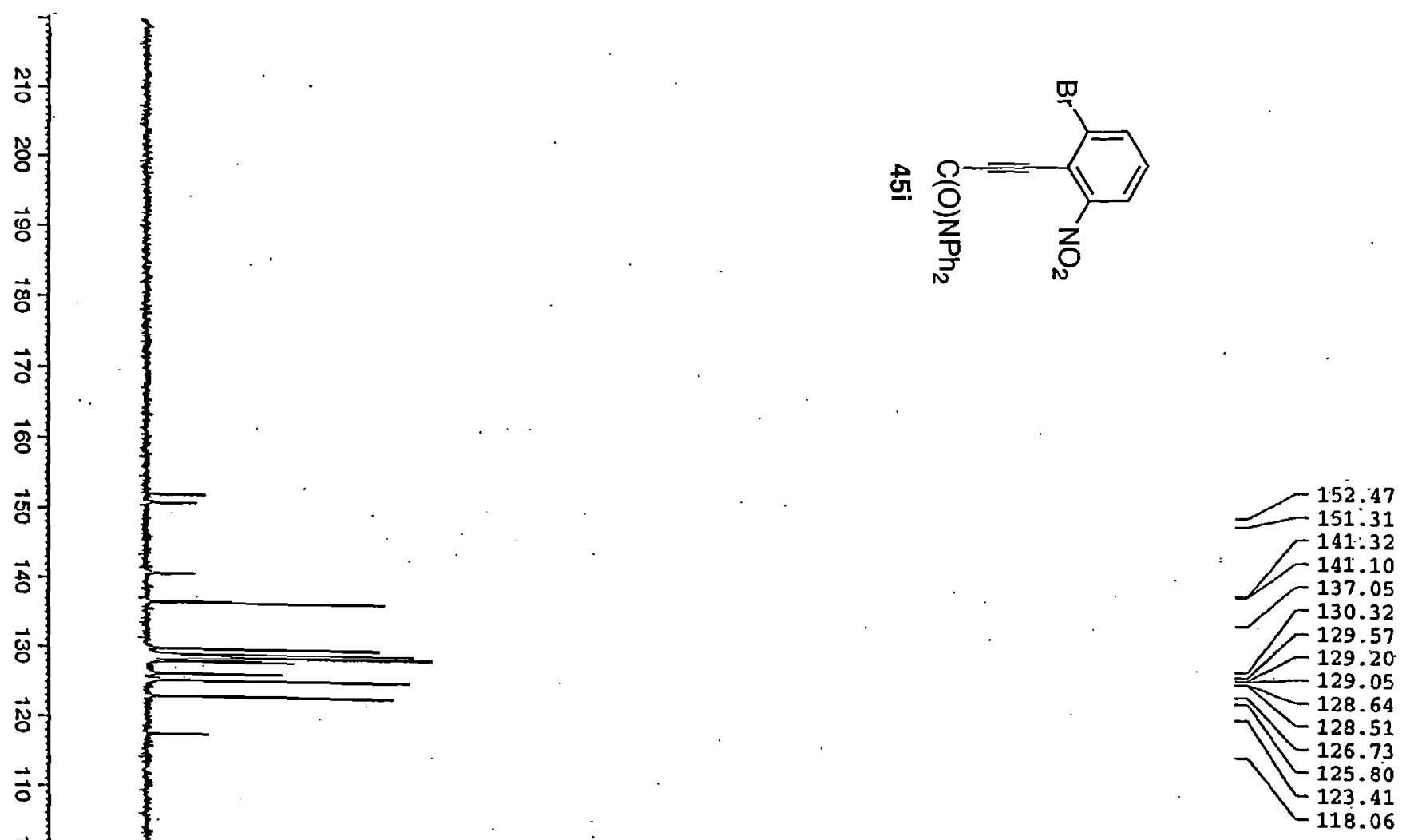

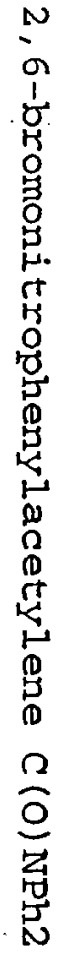
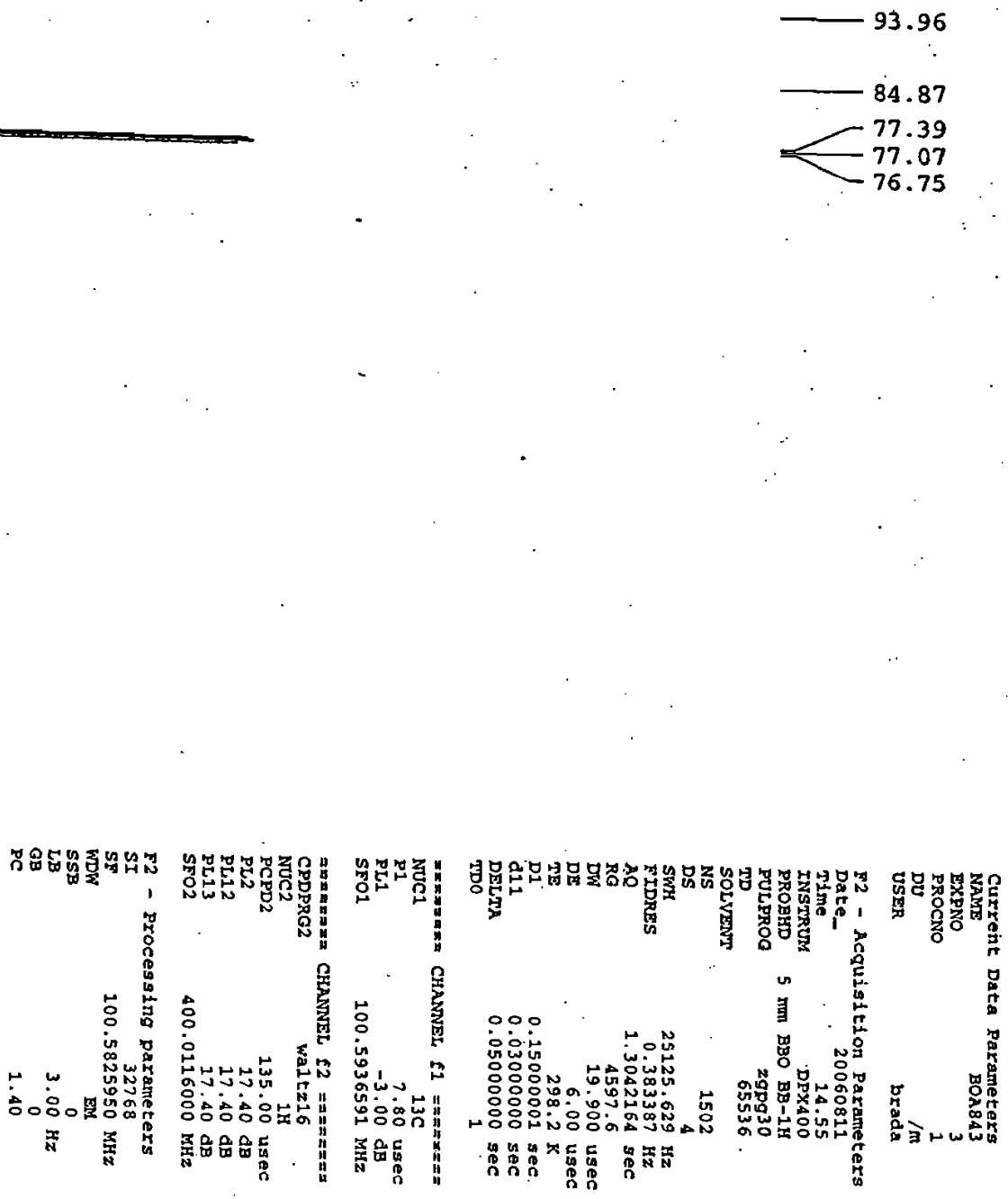

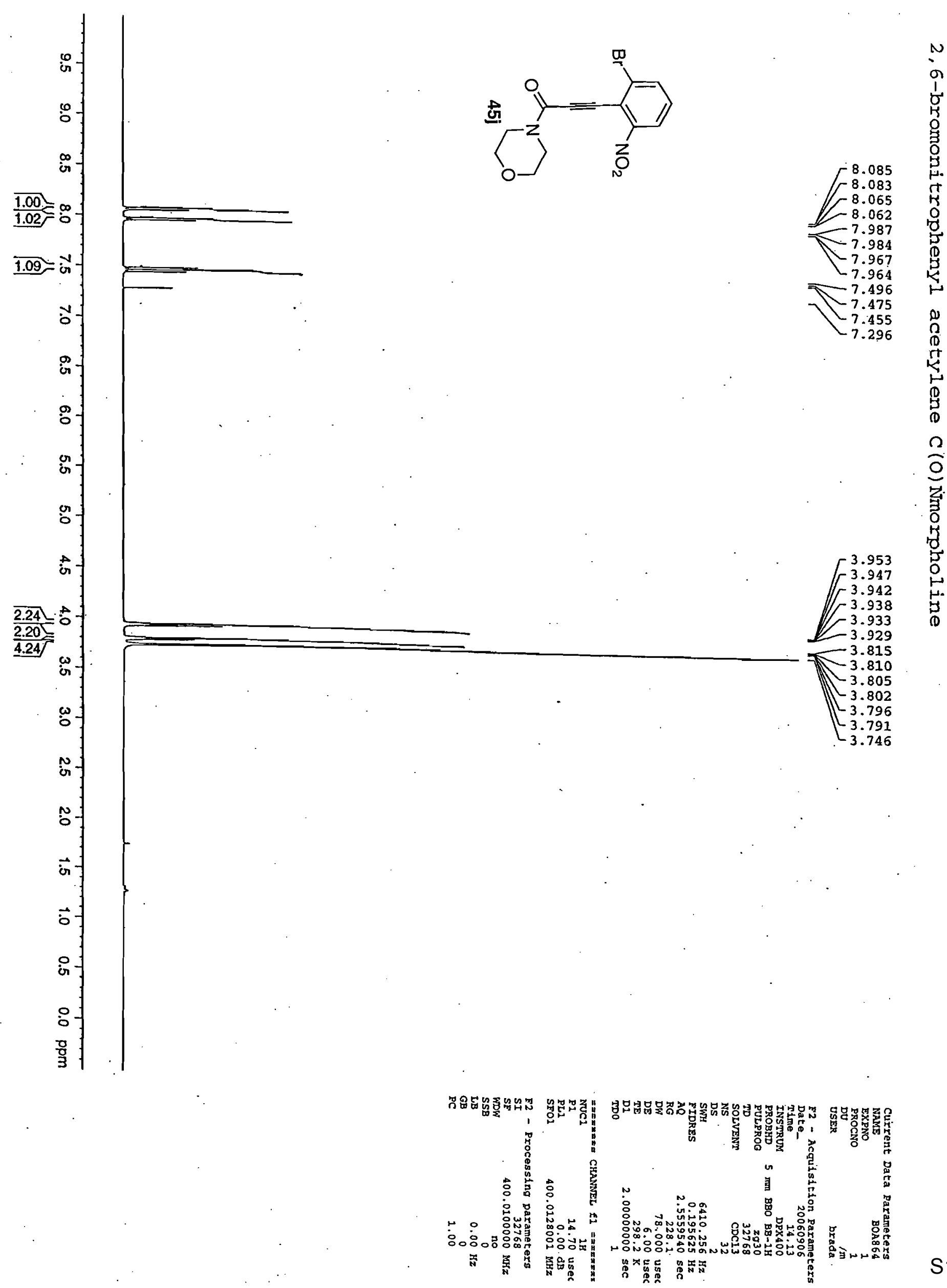

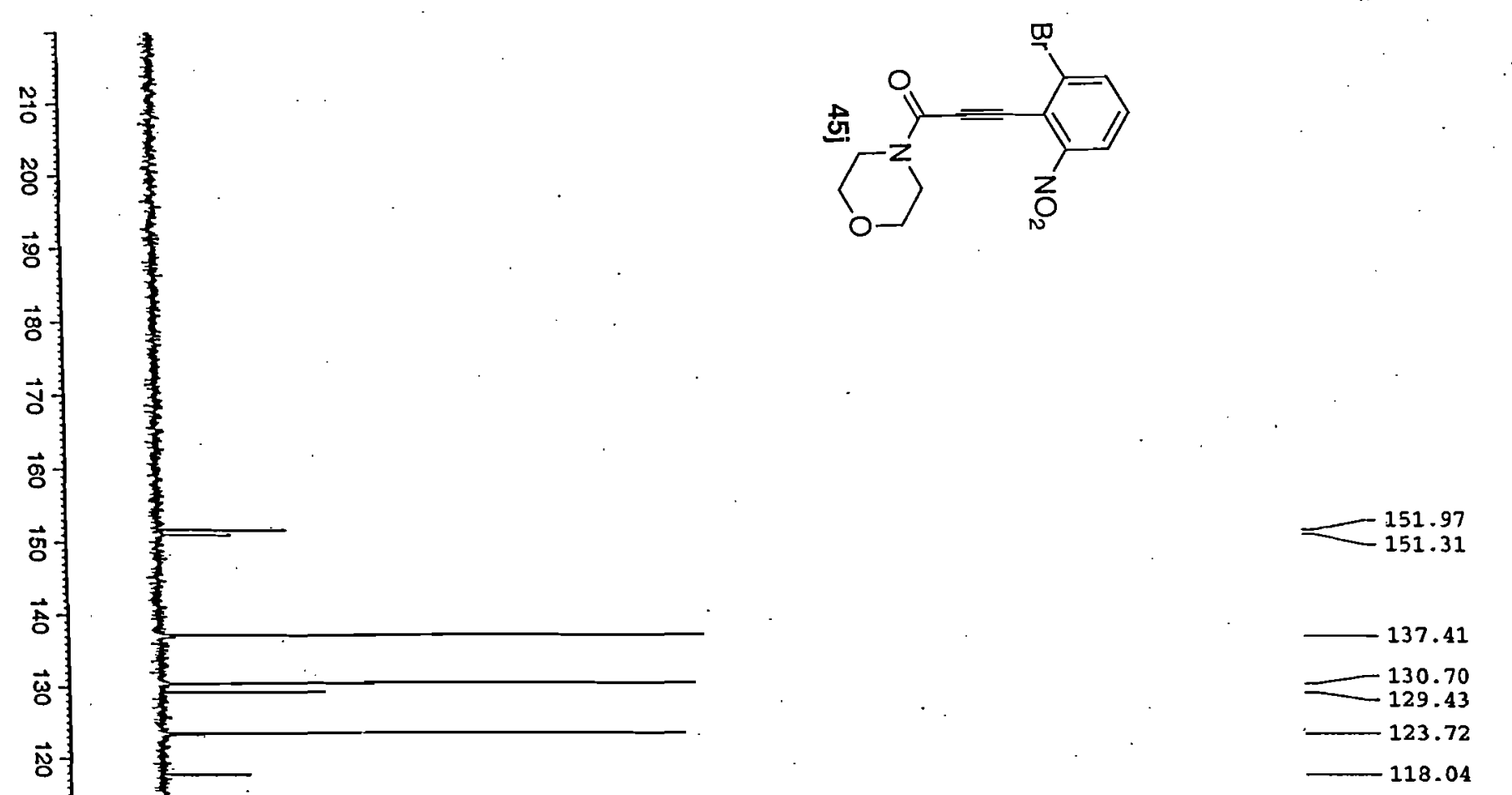

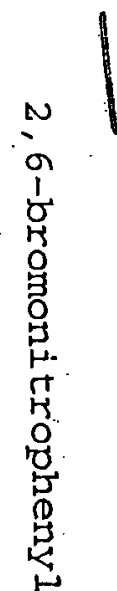

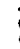

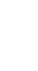

.

8

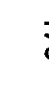




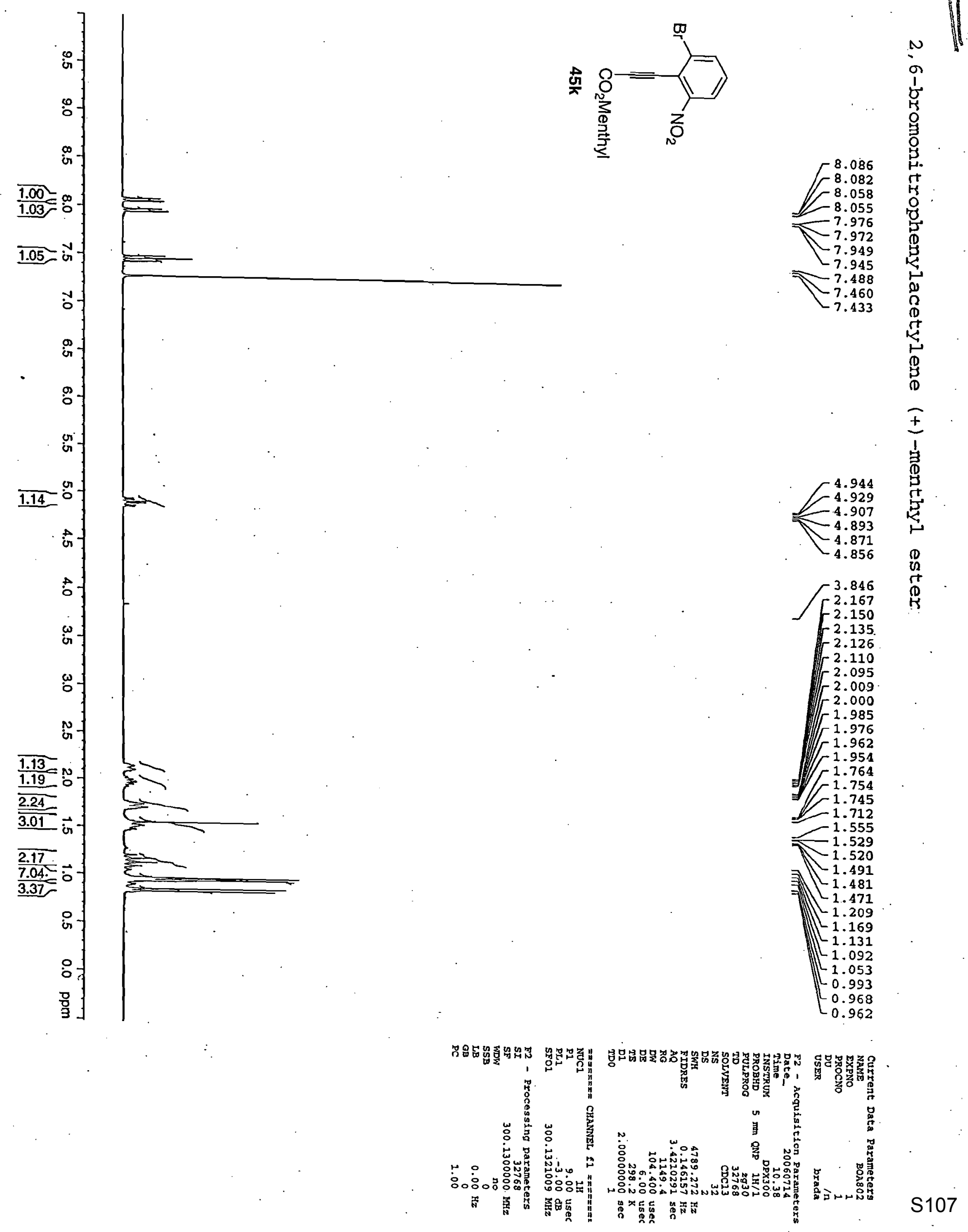



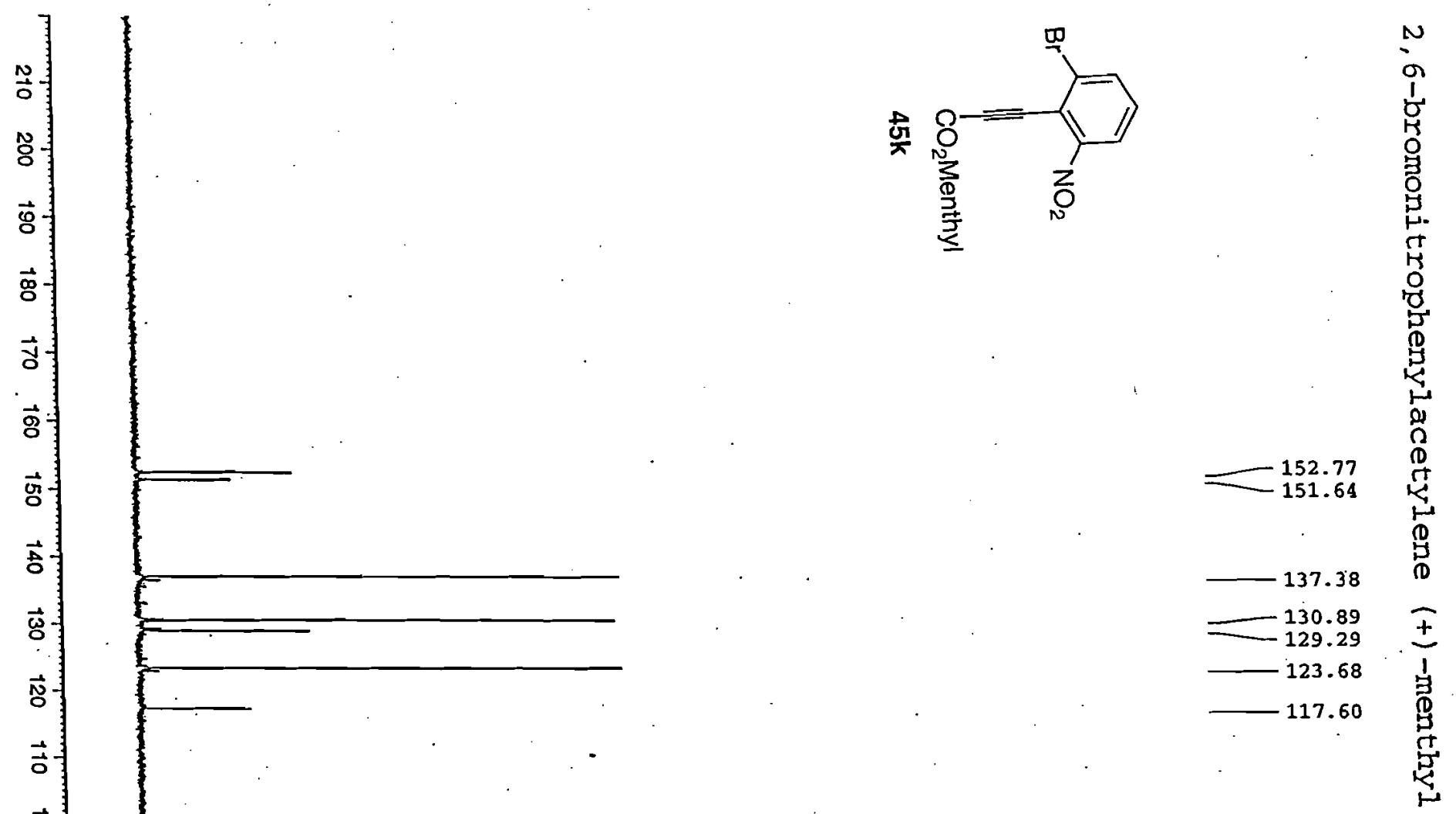

91.83

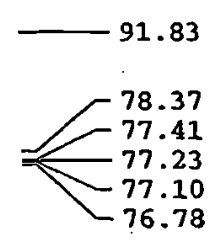

0
0
T
0
1
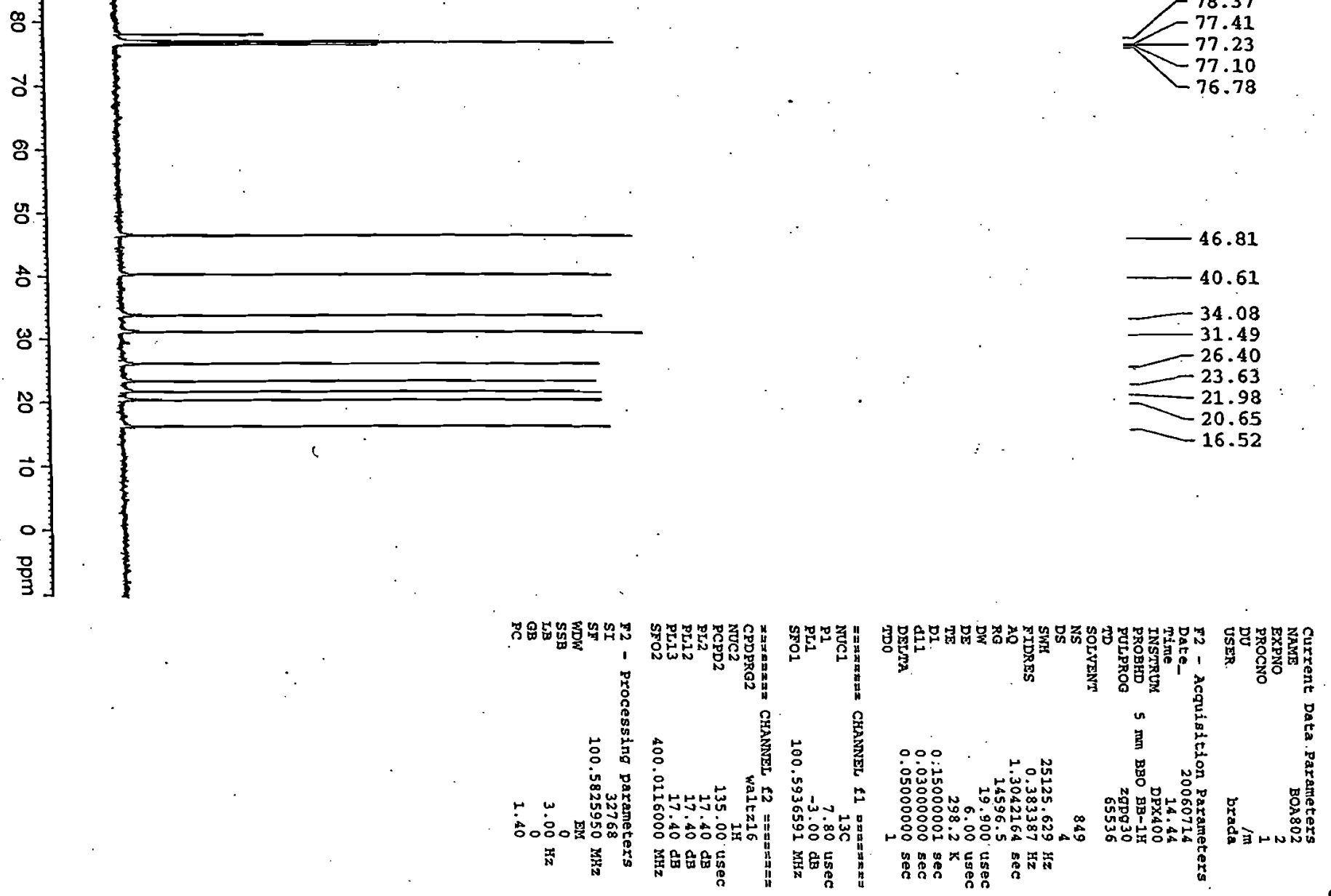


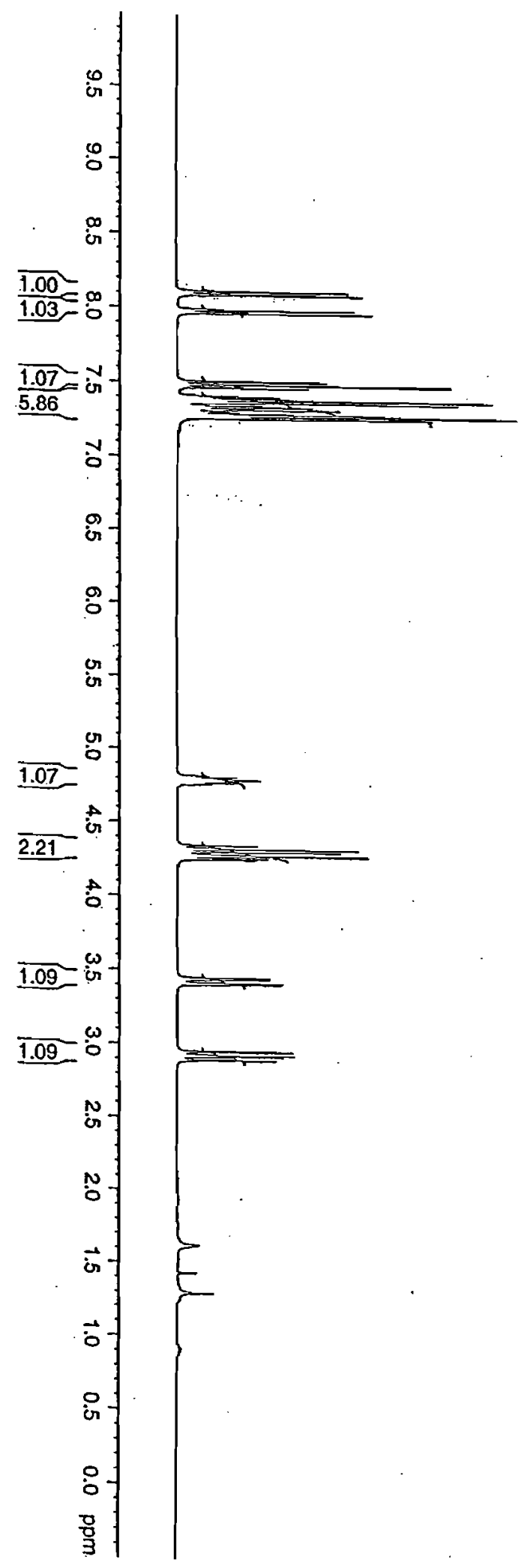

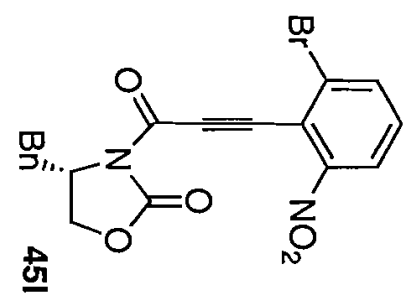

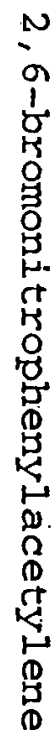

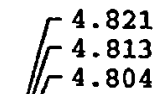

$\begin{array}{r}4.794 \\ \hline\end{array}$

$\mathrm{F}_{-4.790}^{4.781}$

4.781

-4.781
-4.763
-4.346

4.346

$-4.323$

4.304
4.283

$-4.283$

$-4.276$

$-4.260$

4.253

3.450
-3.442

$-3.416$

$-3.408$

$-2.953$

$-2.929$

2.919
-2.895

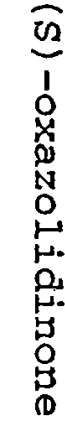

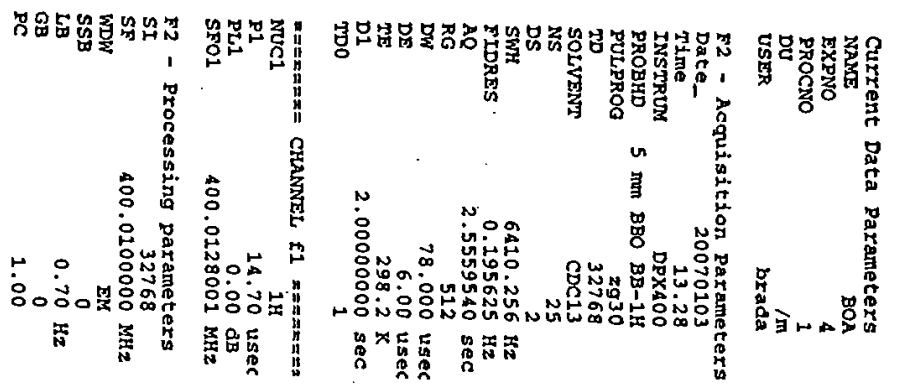


:

$\overrightarrow{\mathrm{\iota}}$

$\overrightarrow{\mathrm{g}}$

$\vec{z}$

aี

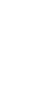
. a

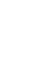

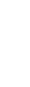

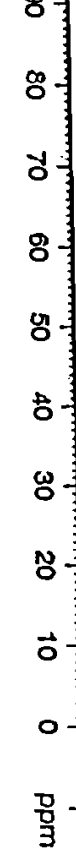

年章

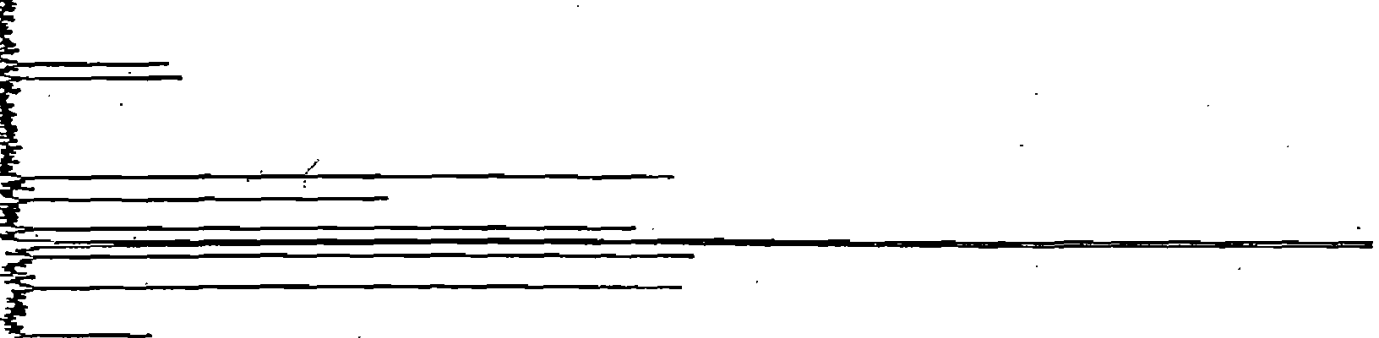

8

8

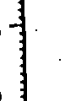

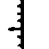

章

龺
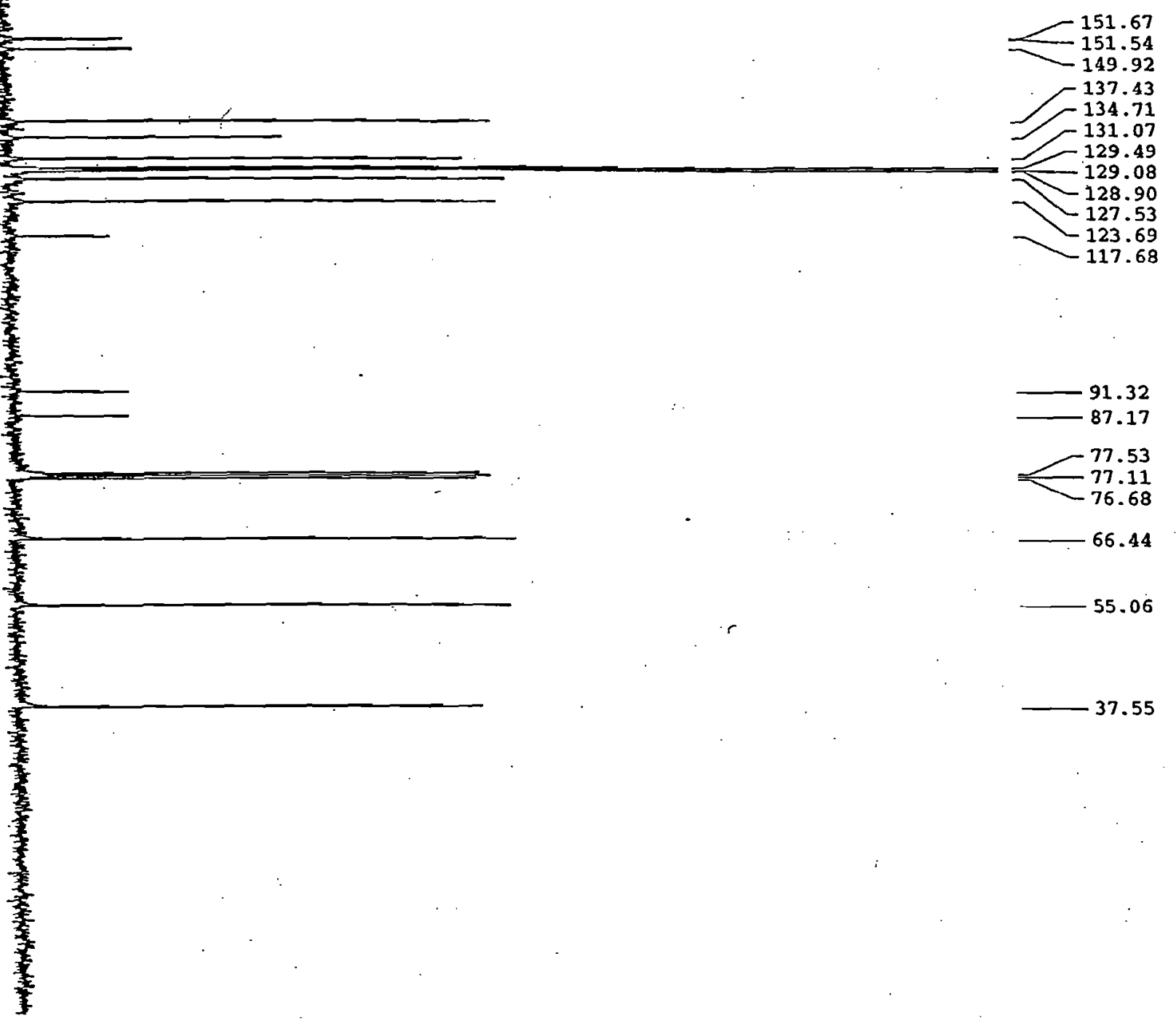

$-77.53$

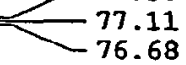

66.44

55.06

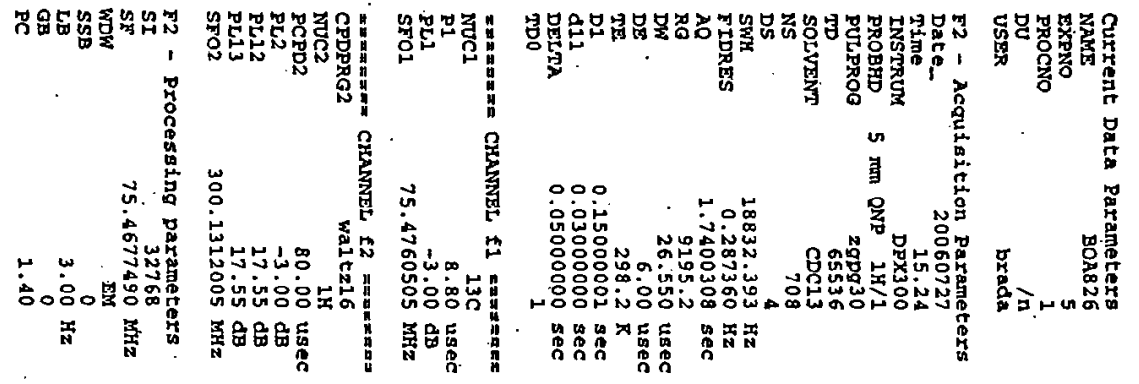



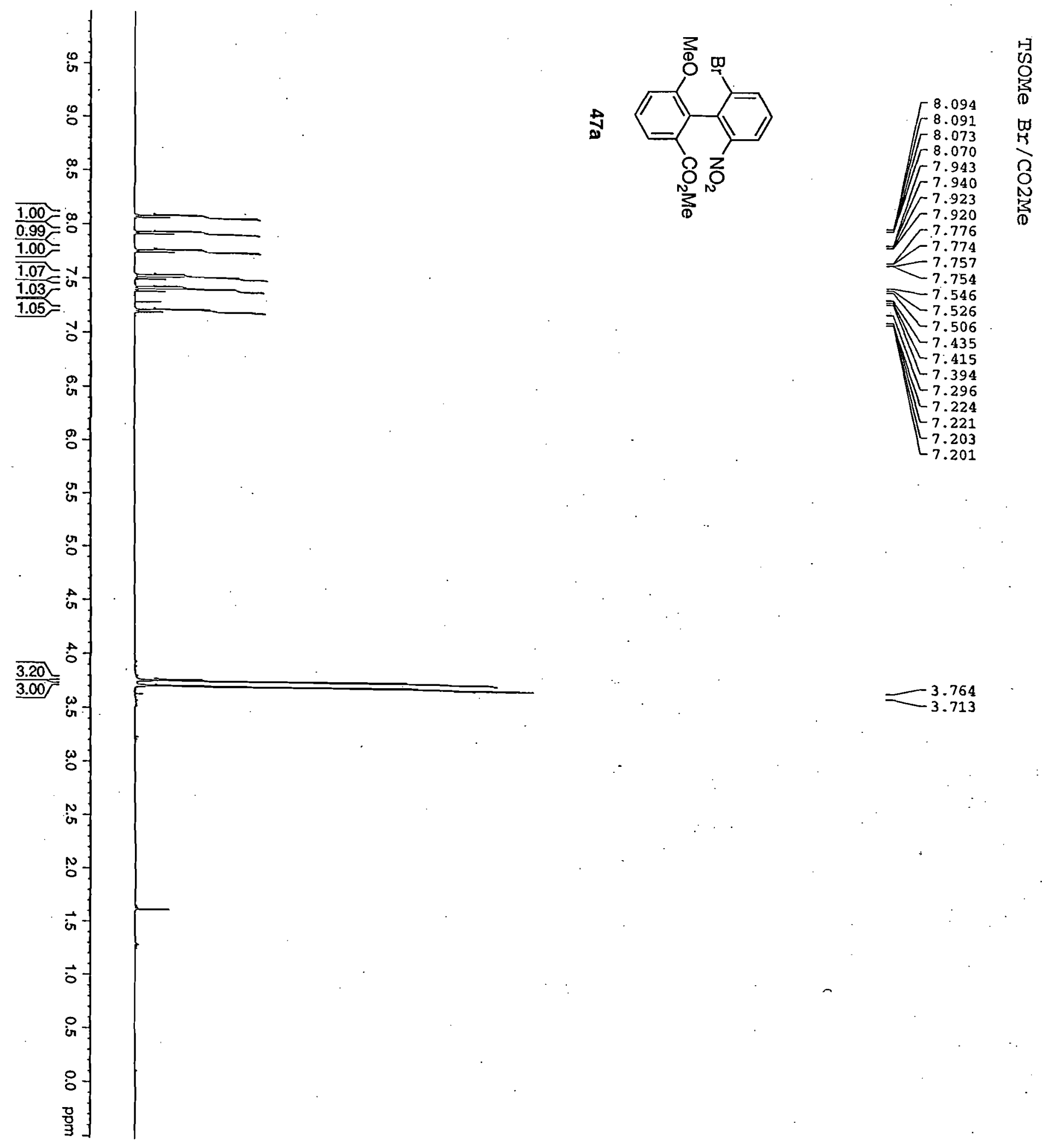

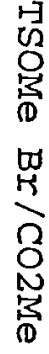

$-7.757$

$-7.546$

$-7.526$

-7.506

$-7.435$

$-7.415$

$[7.296$

7.224

7.221

$-7.203$

$-3.764$
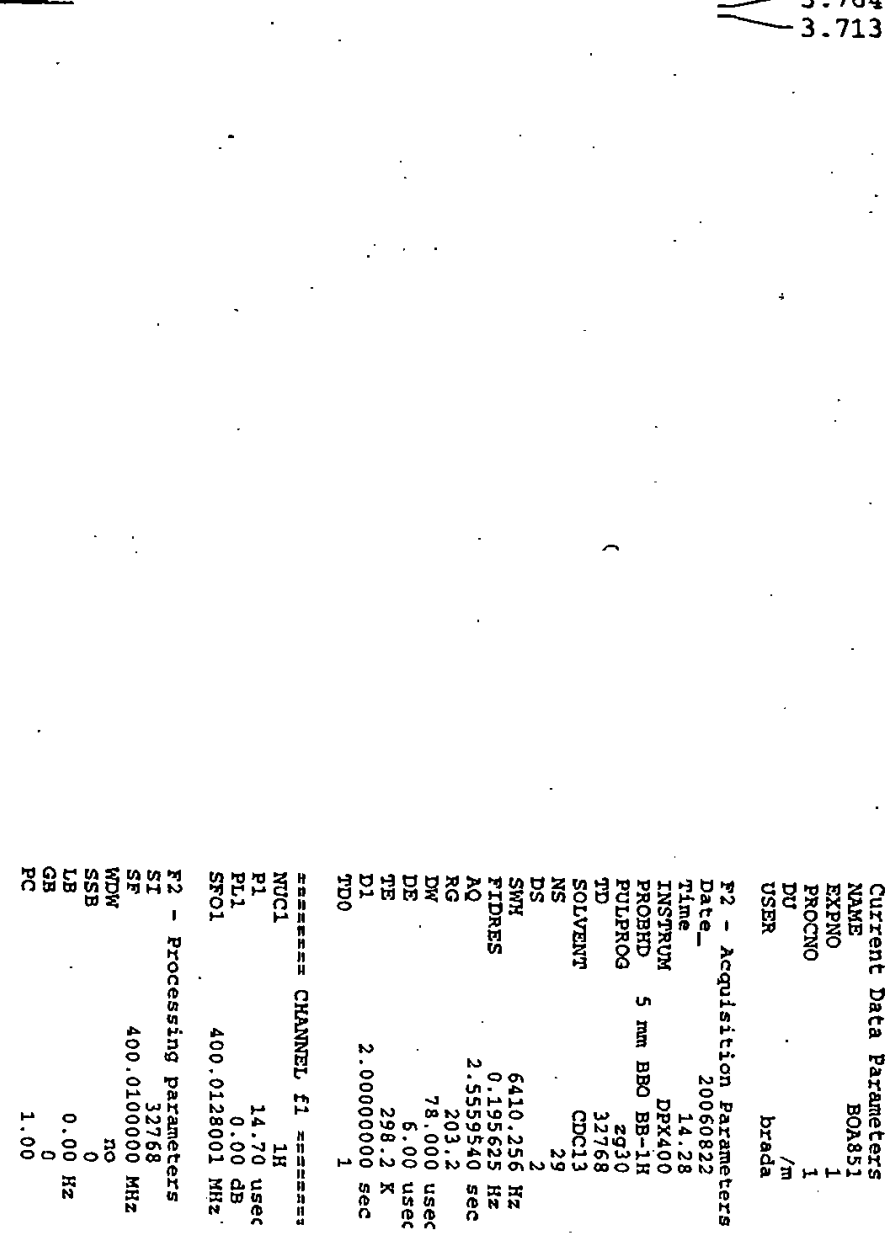


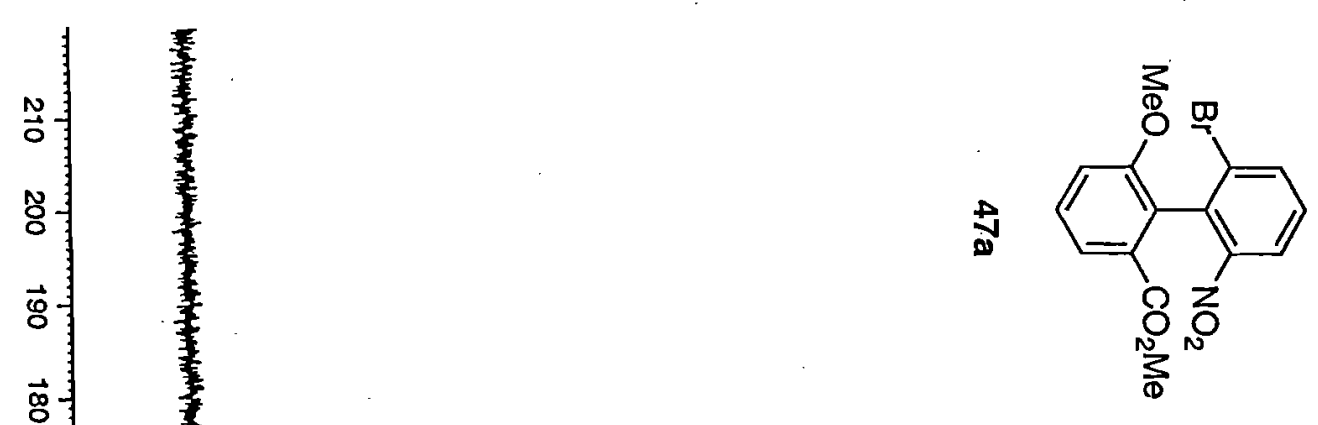

\section{古}

\section{.}

.

.

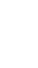

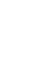



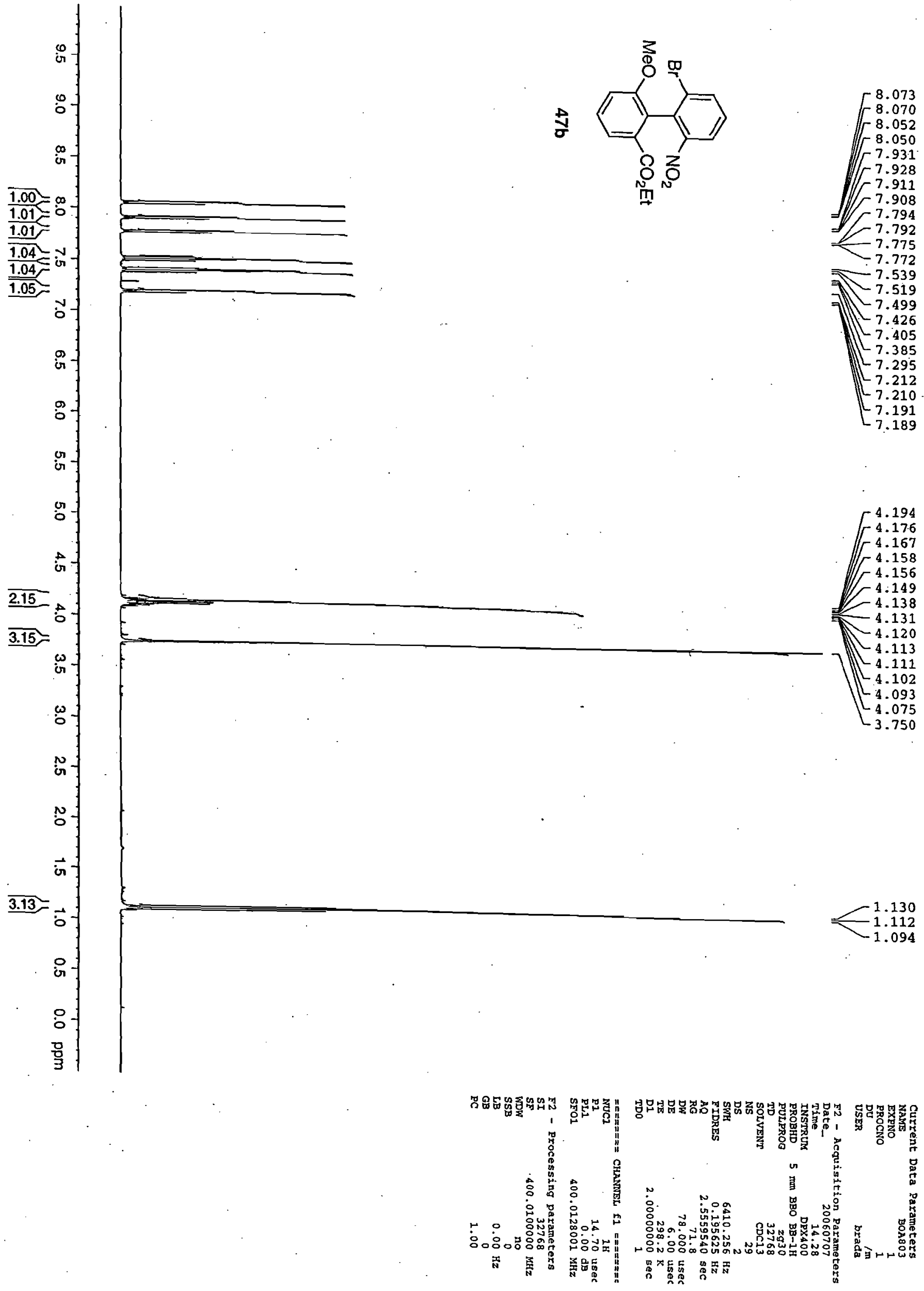

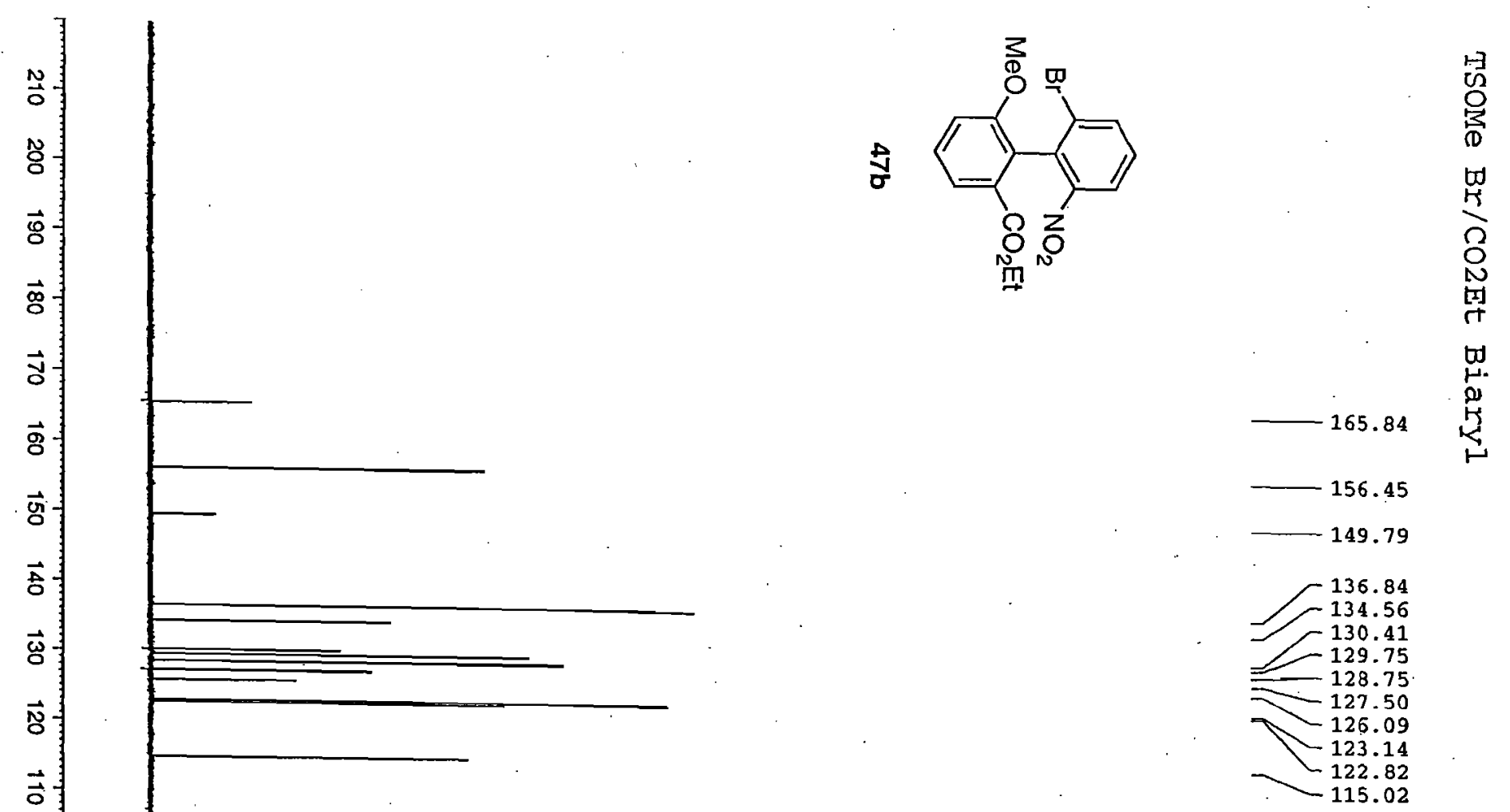

홍

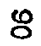

串

o

g

or

B

w

N

후

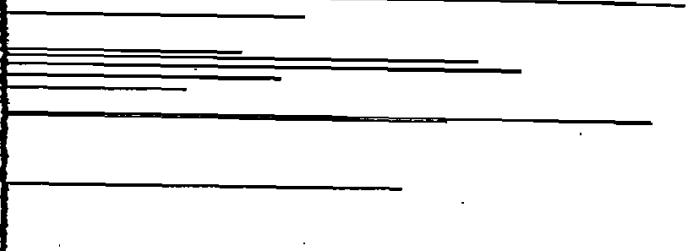

$\overrightarrow{\mathrm{s}}-$

$\overrightarrow{0}$

$\overrightarrow{\overrightarrow{0}}$

$+$

8

1

$\overrightarrow{1}$ 


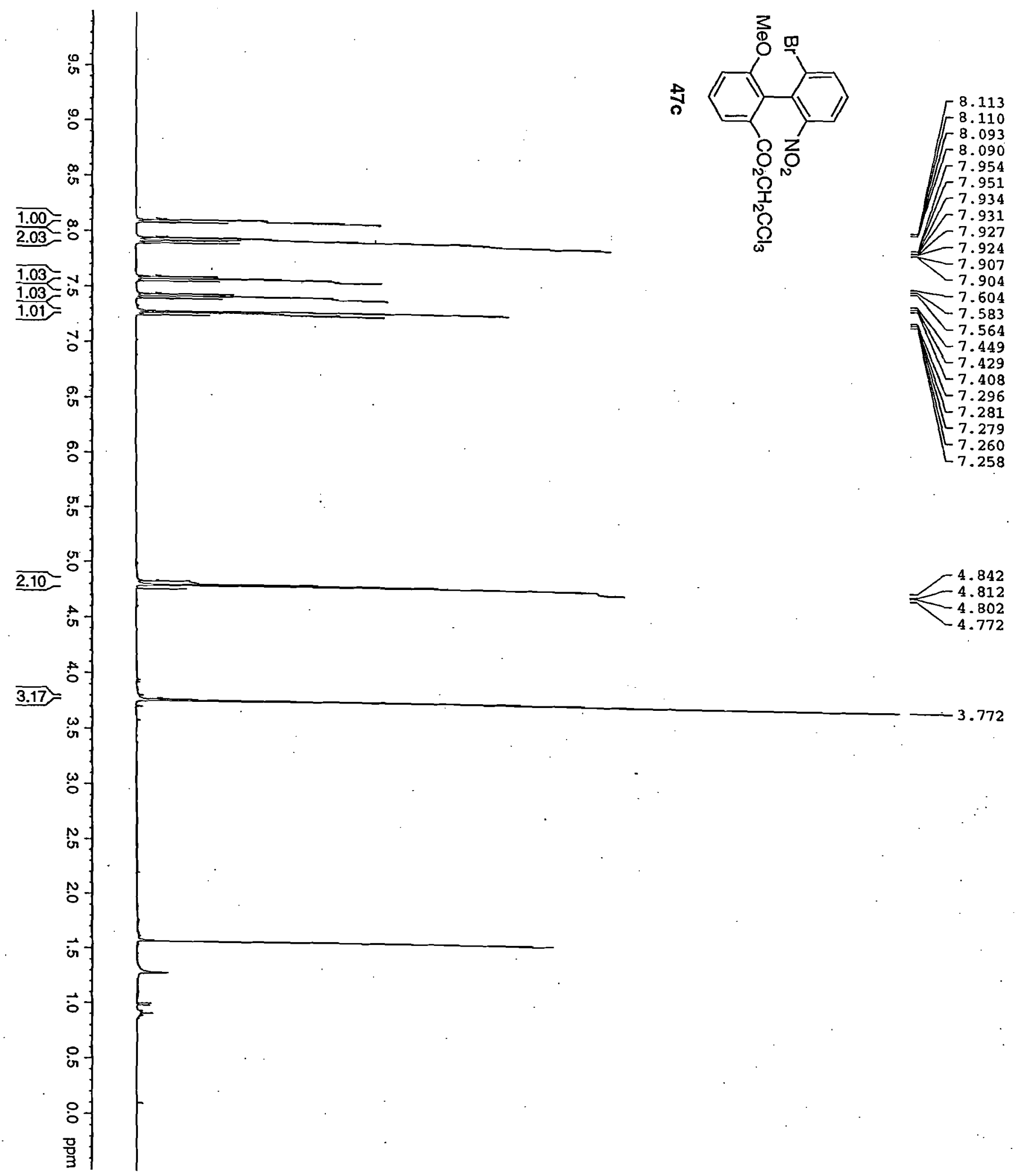

$\mid$

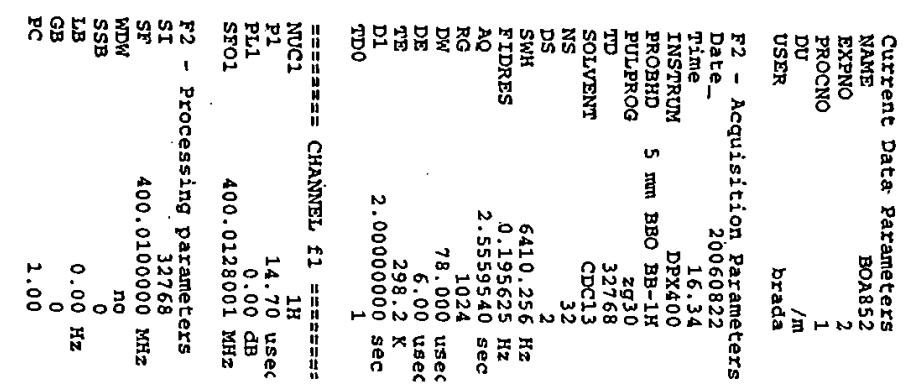




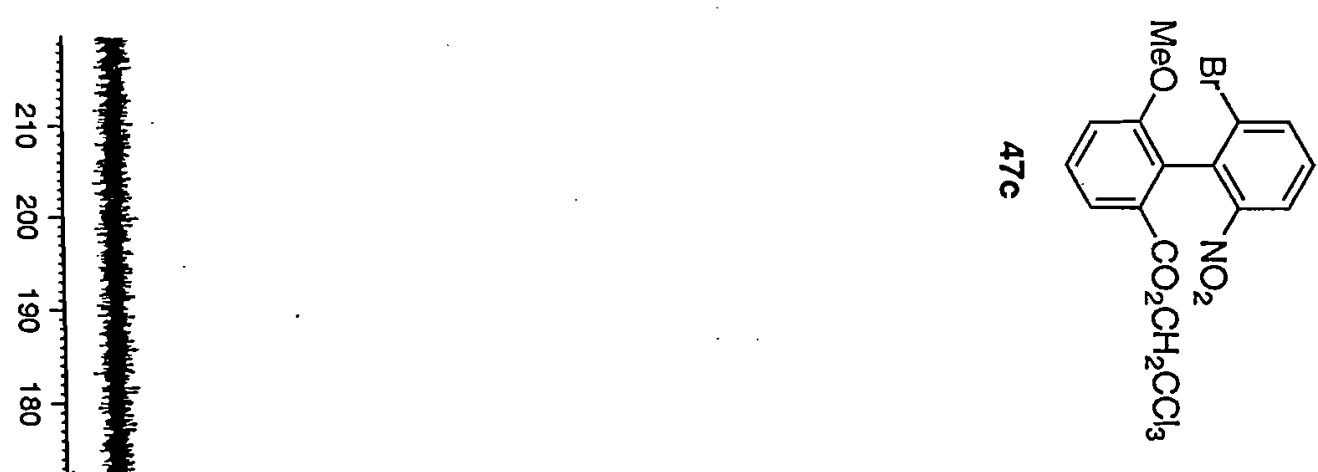

\section{¿}

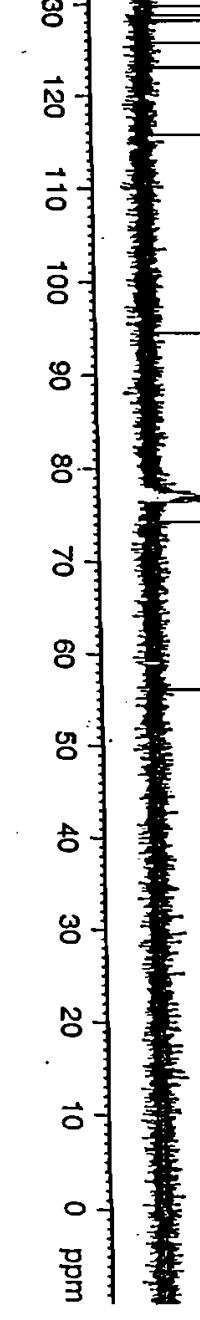




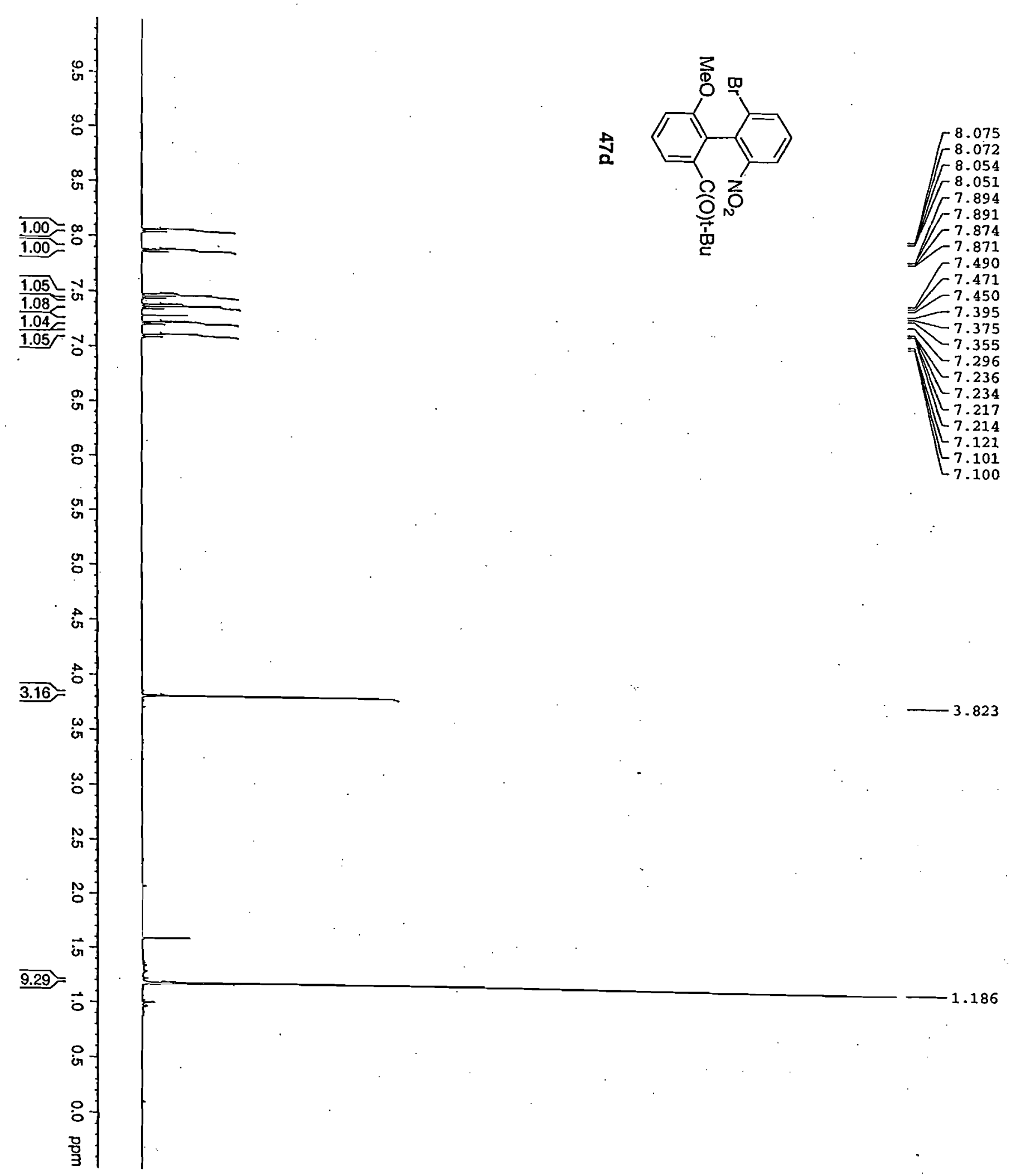

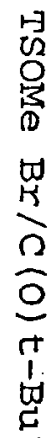

7.47

7.375

$-7.296$

7.21

7.101

.823

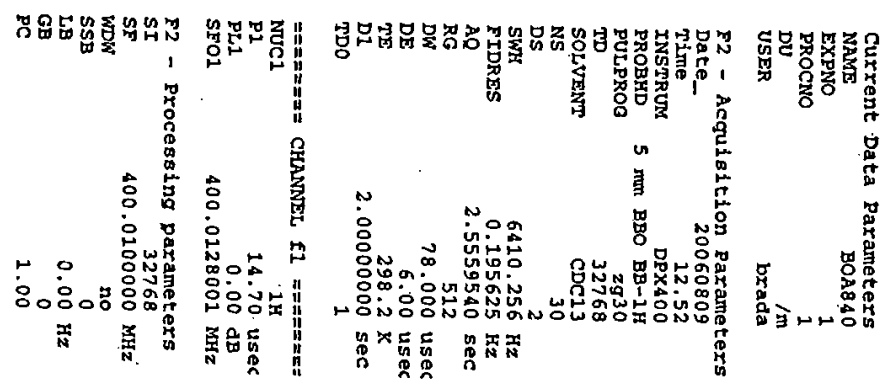




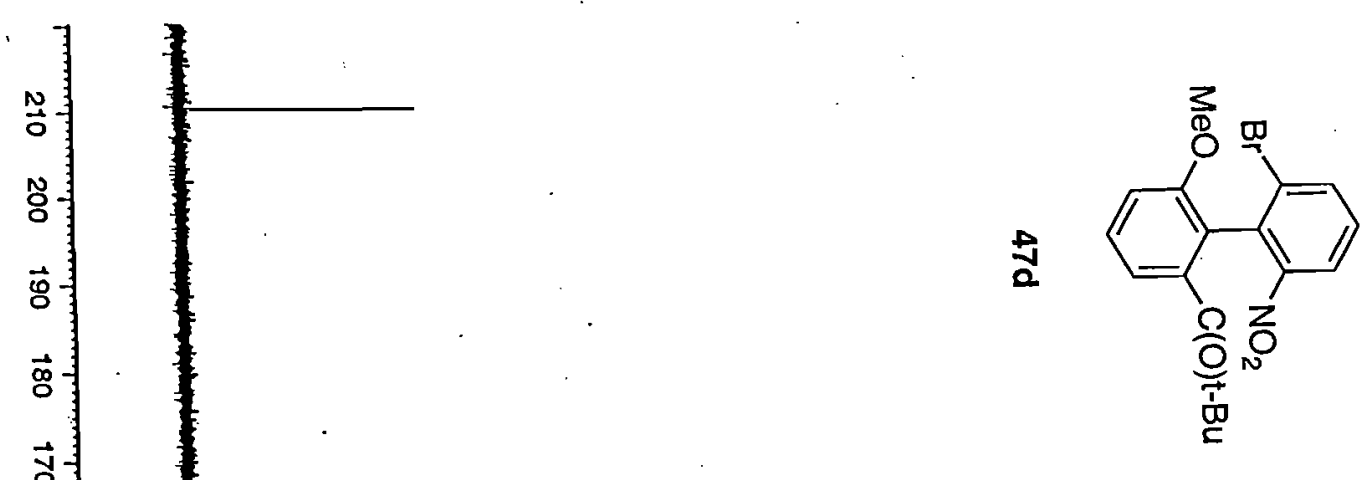

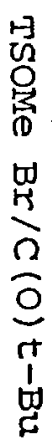

斊

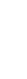

.

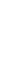

\section{\&}$$
\text { . }
$$

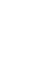

政

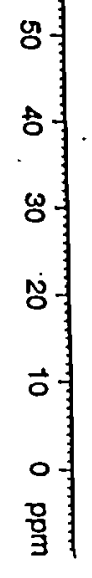

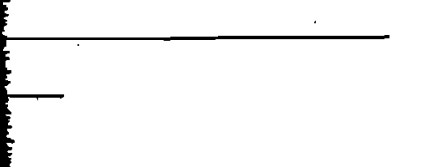



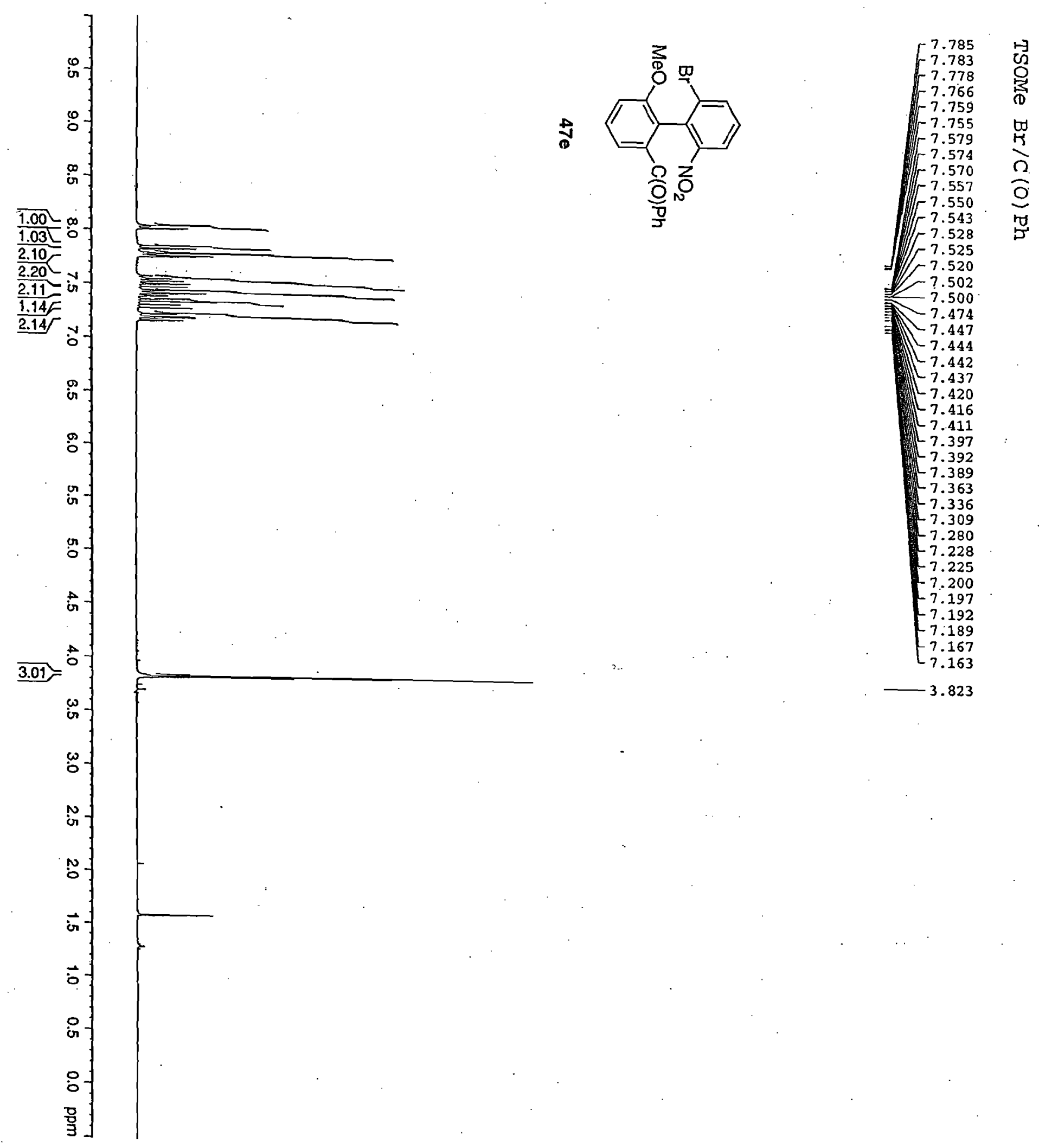

붕

$\frac{0}{0}$

7.525
7.520
7.502

7.502

7.500

7.474

7.444

7.442

7.437

7.420

7.416

7.411

7.397

7.392

7.389

7.363

7.336

7.309

7.280

7.228

$-7.225$

7.200

7.197

$-7.192$

7:189

7.167

7.163

3.823

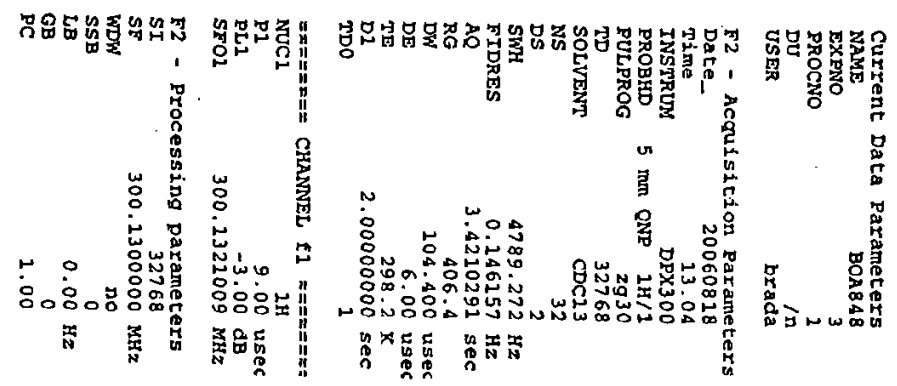




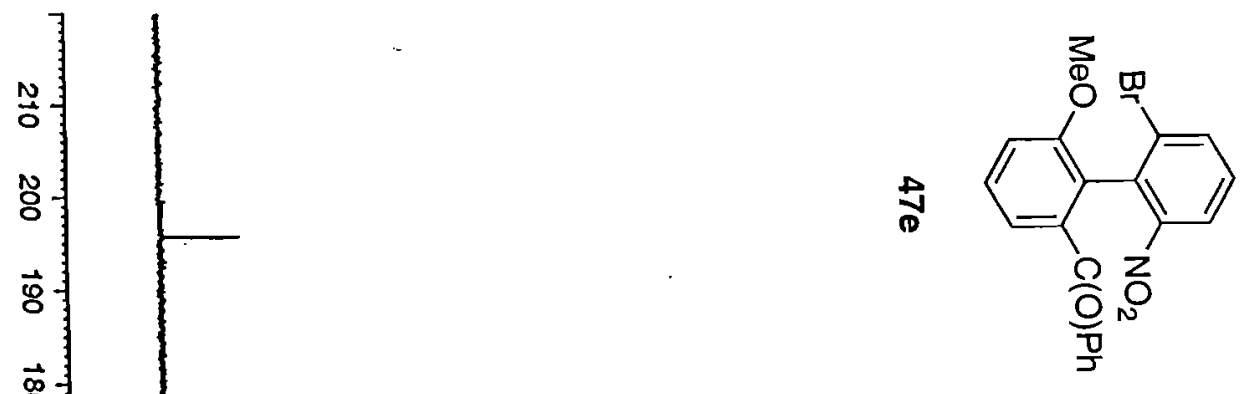

$\vec{\jmath}$

gㅇ

ज्ञ

t

ฝั

$\vec{N}$

a

홍 8

\section{8}

.

\&

요

o

묵
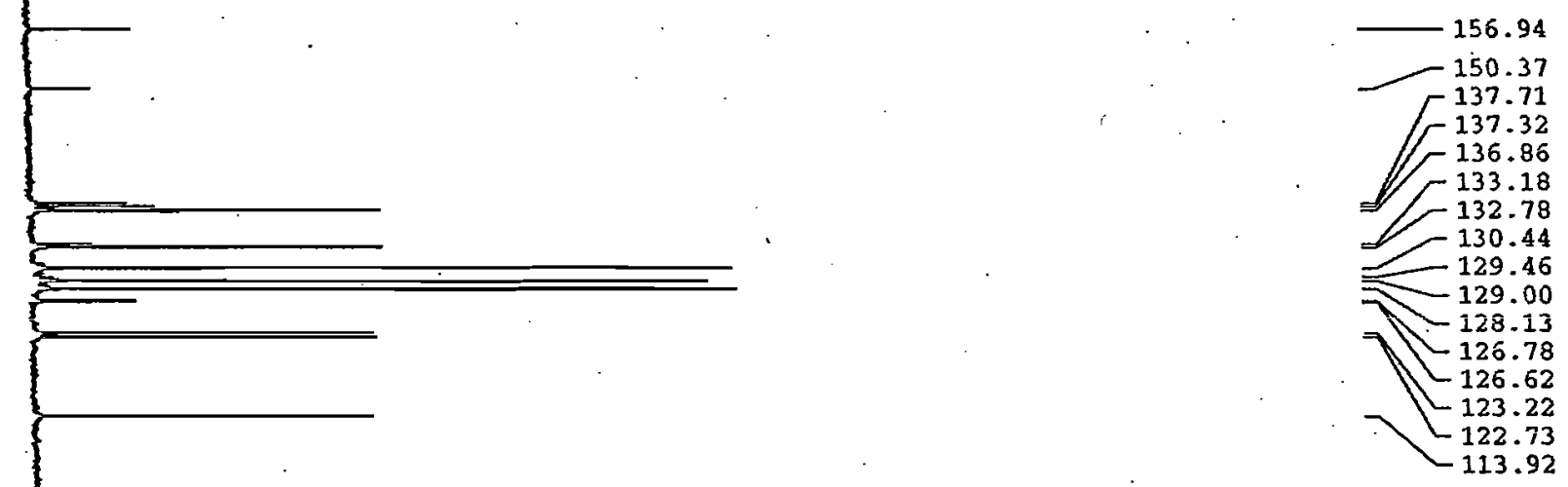

8

o

语要
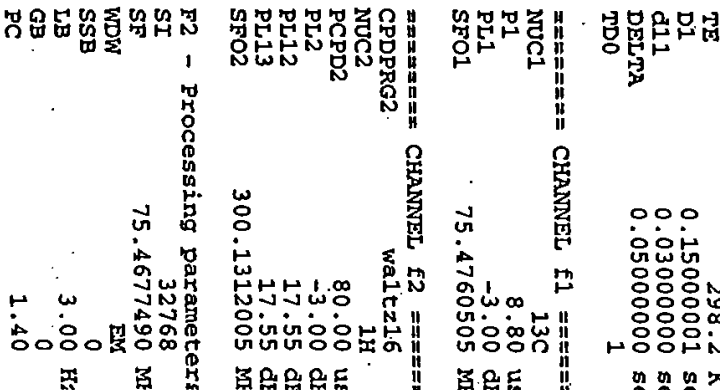

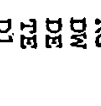



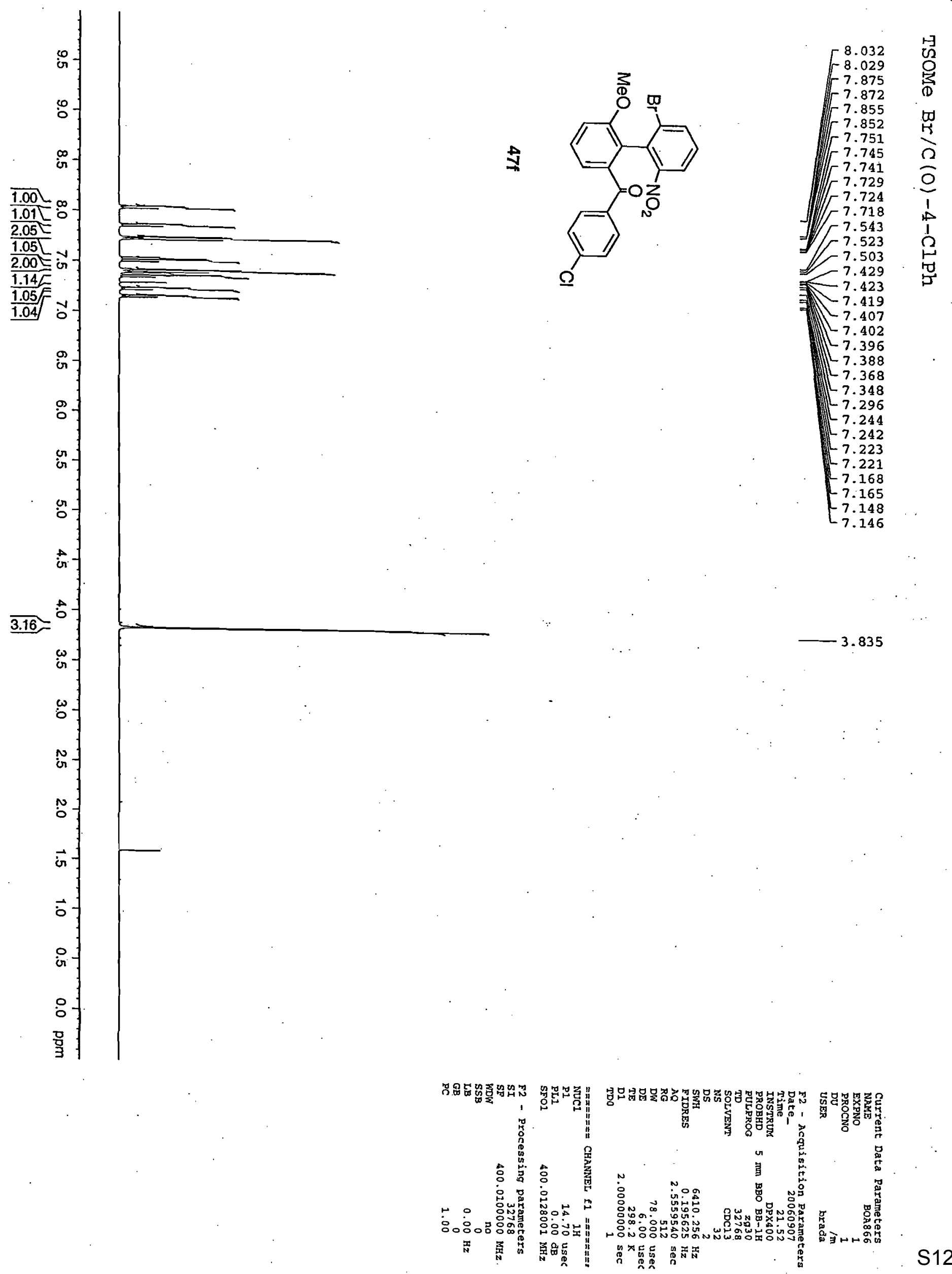


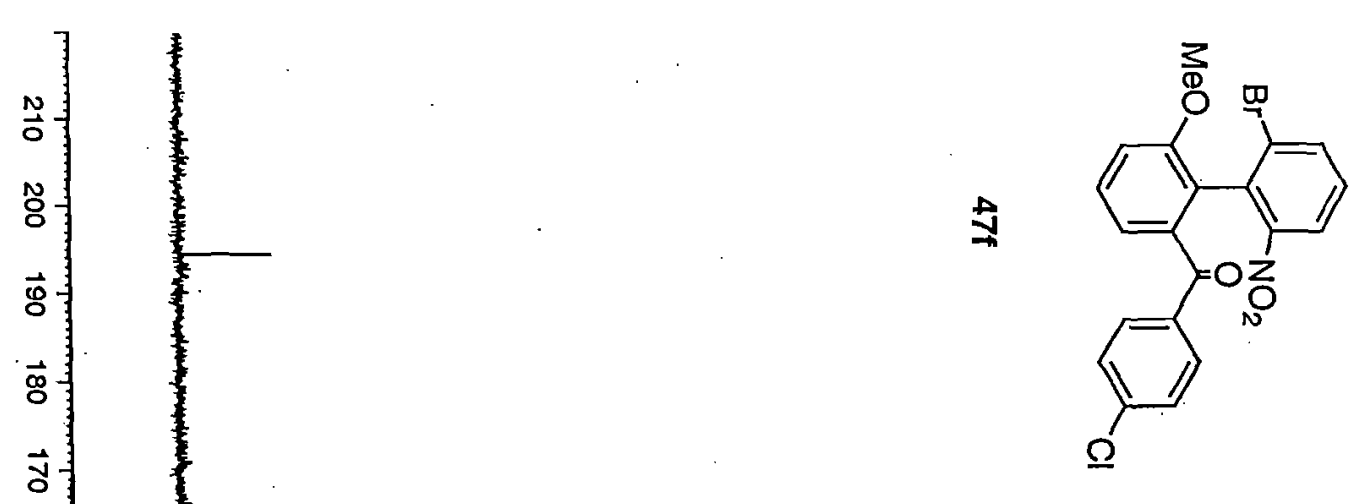

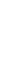

8

8
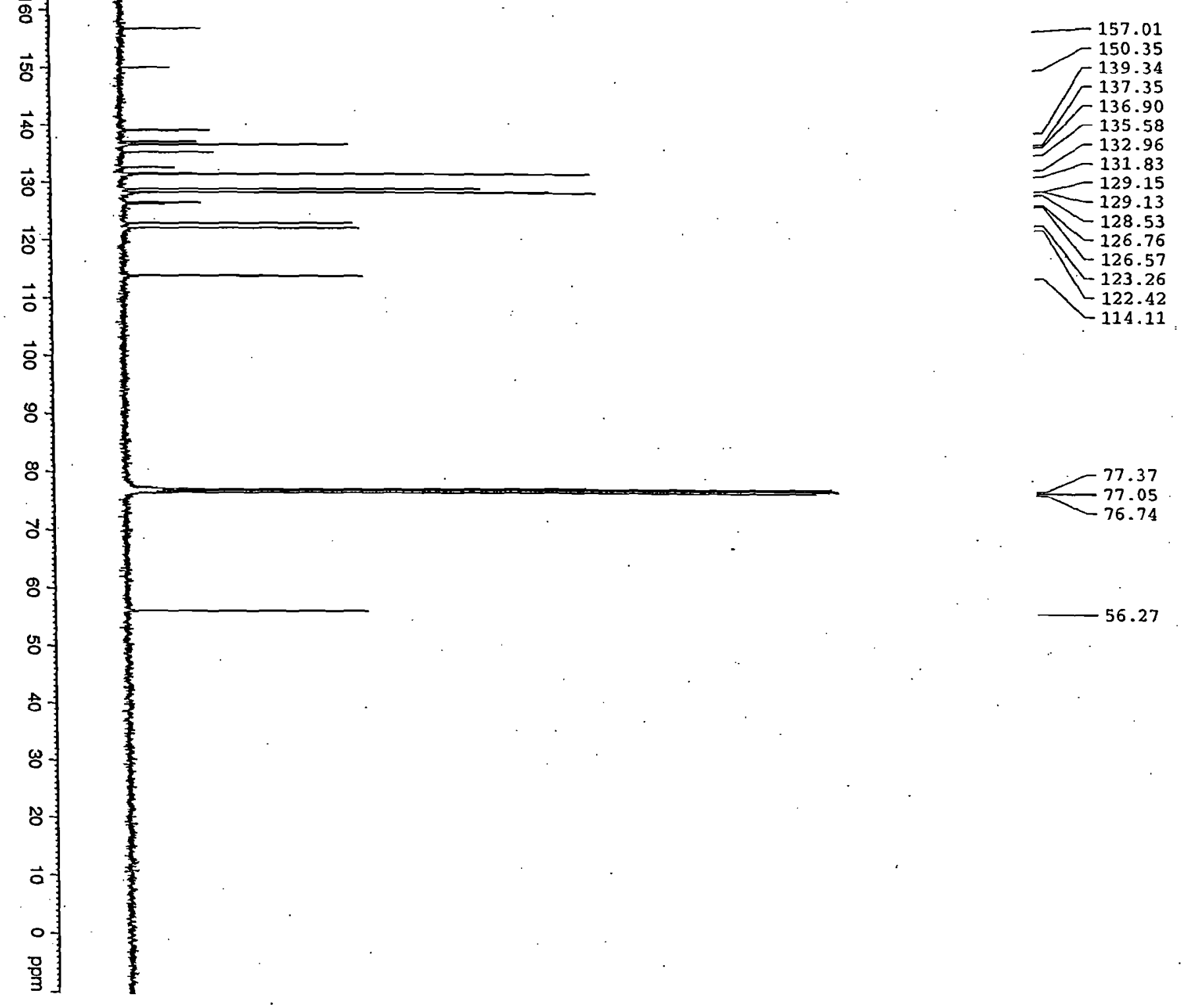

8

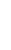



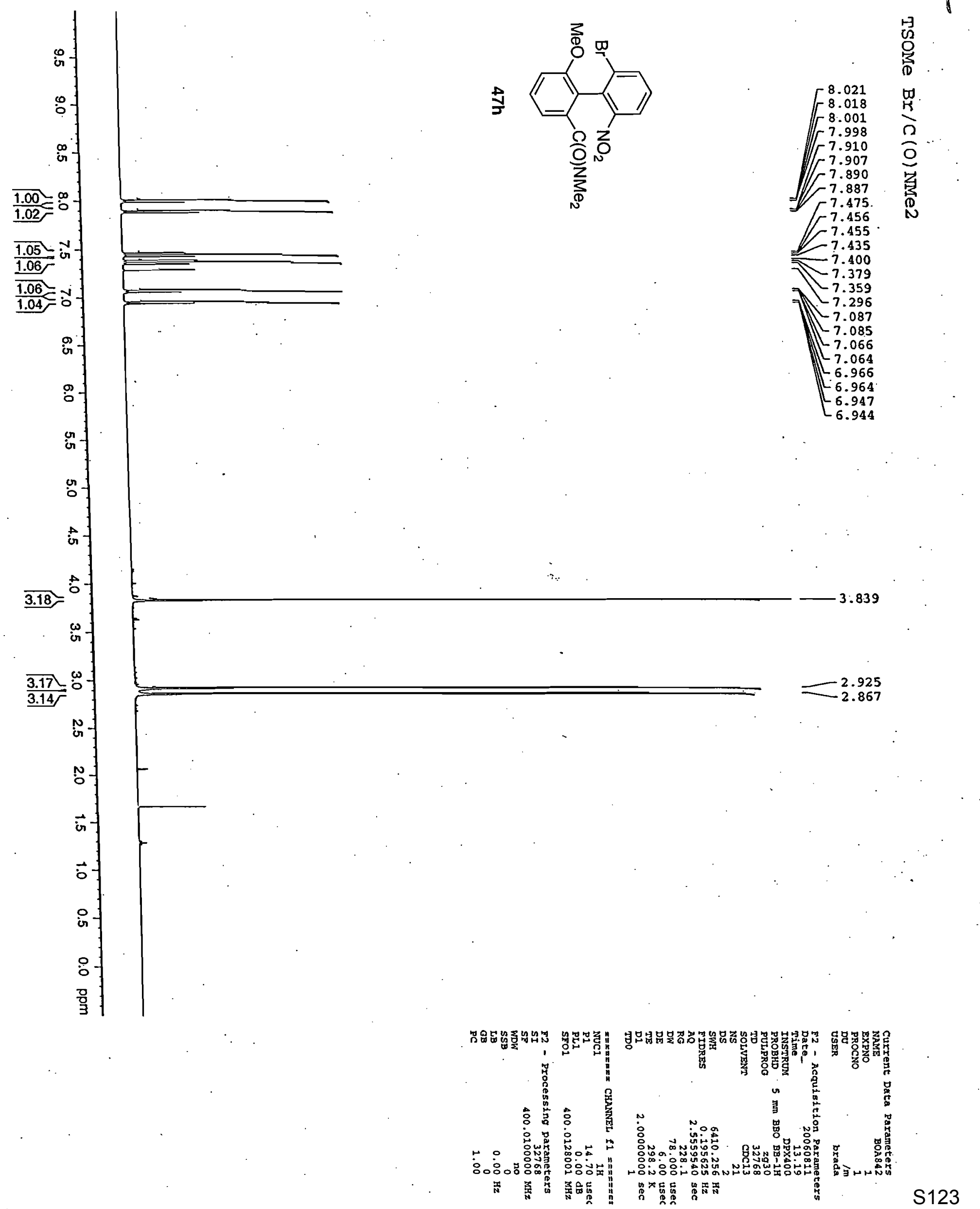


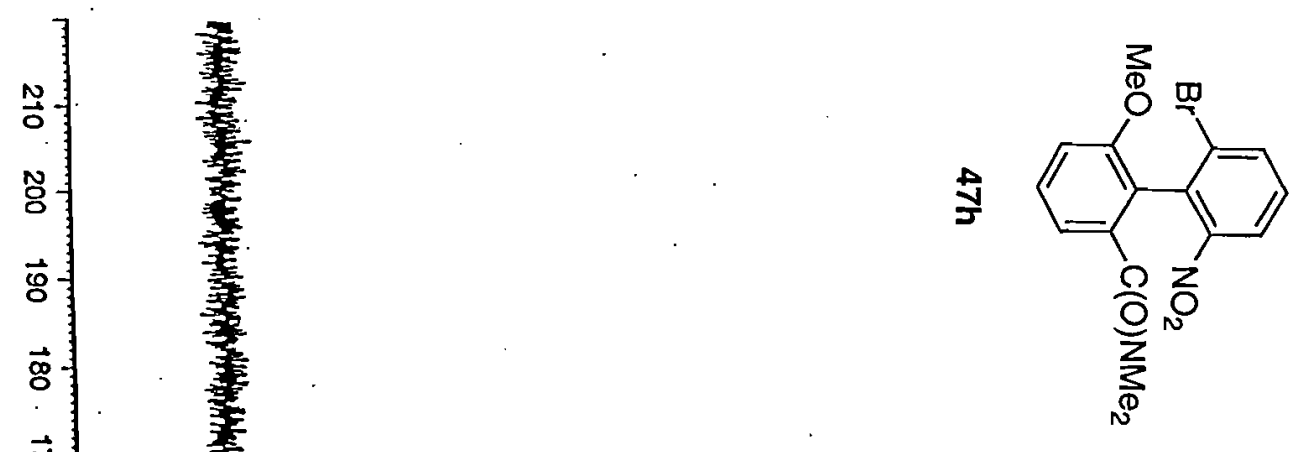

168.75

$\overrightarrow{8}$

ज़

宫

$\vec{\omega}$

총

\section{$\vec{t}$}

웅

$$
8
$$

西

(1)

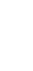

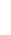
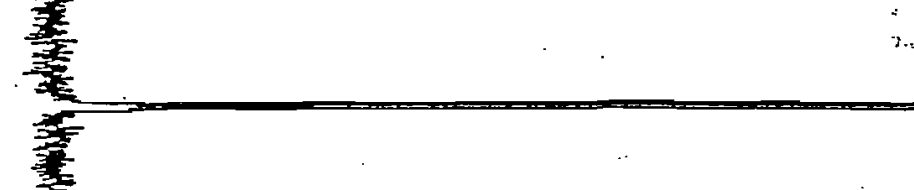

$$
2 .
$$$$
-157.42
$$
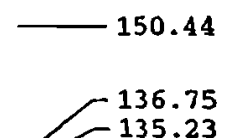

$-135.23$

132.76

129.27
-129.45

$-127.28$

Х 125.19

$-123.26$

119.01

$-111.57$

56.14

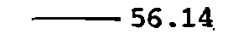

年

.
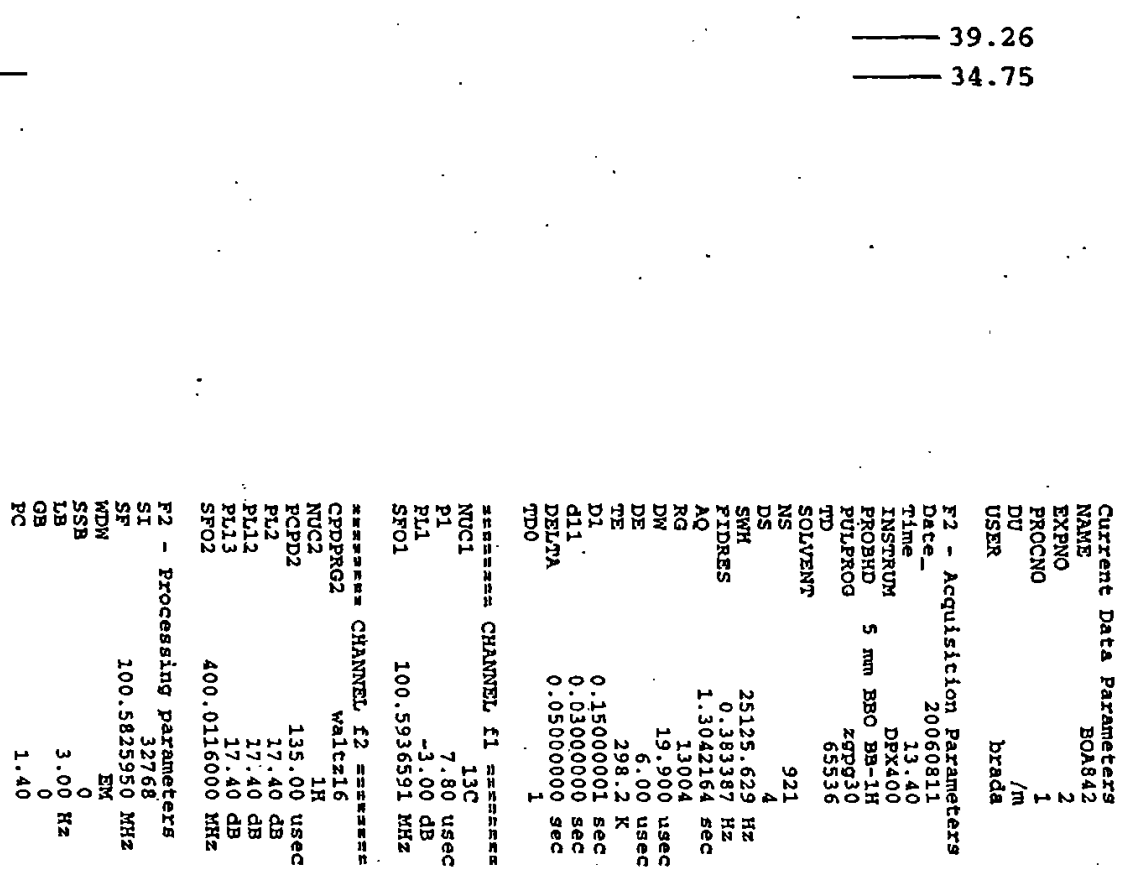

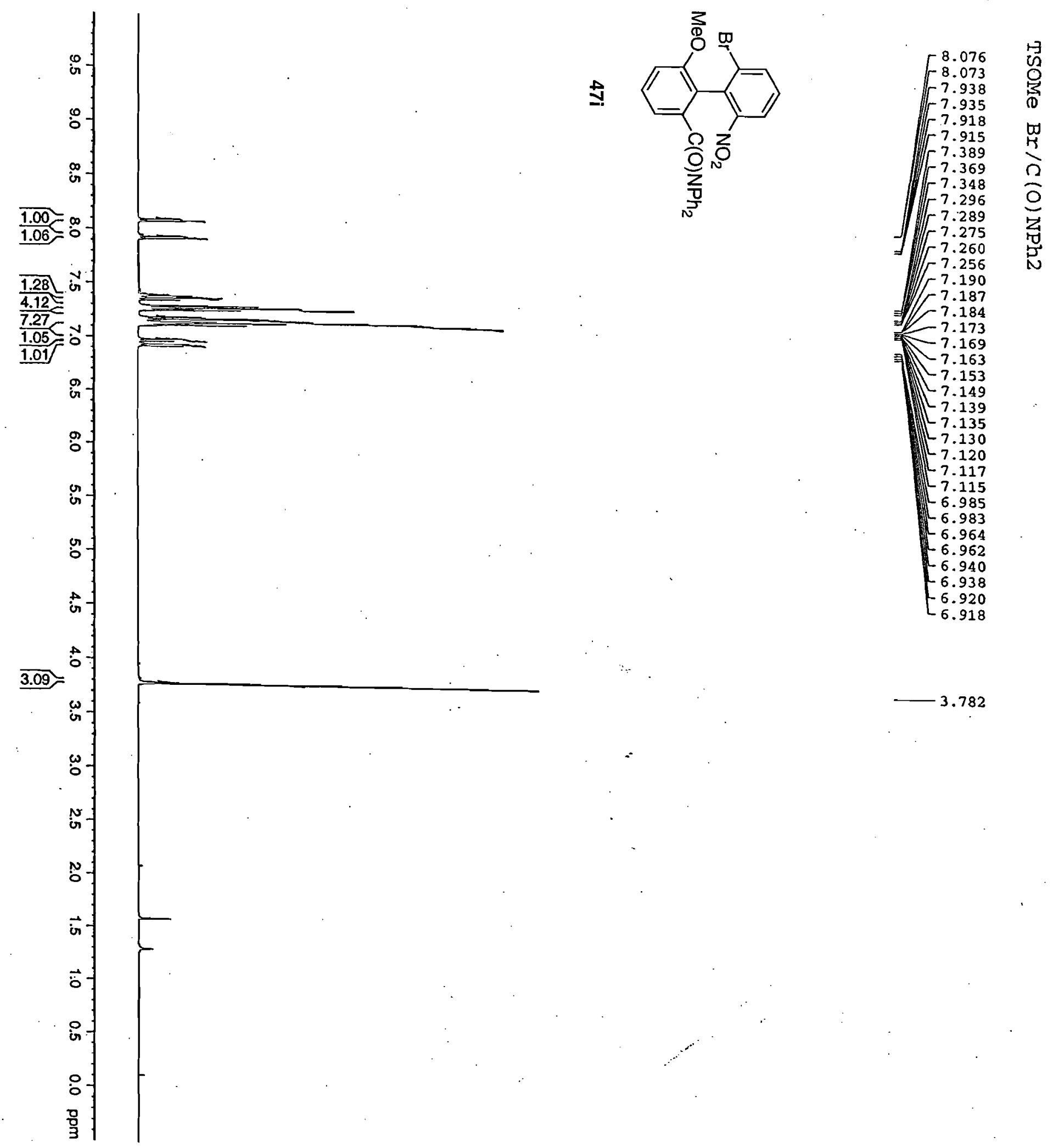

吕

7.190

7.187

7.184

7.173

$\Rightarrow \begin{array}{r}7.169 \\ -7.163\end{array}$

$-7.153$

$-7.149$

$-7.139$

7.135

$-7.130$

7.120

$-7.117$

$-7.115$

6.985

$-6.983$

- 6.964

$-6.962$

$-6.940$

$-6.938$

6.920

$-3.782$

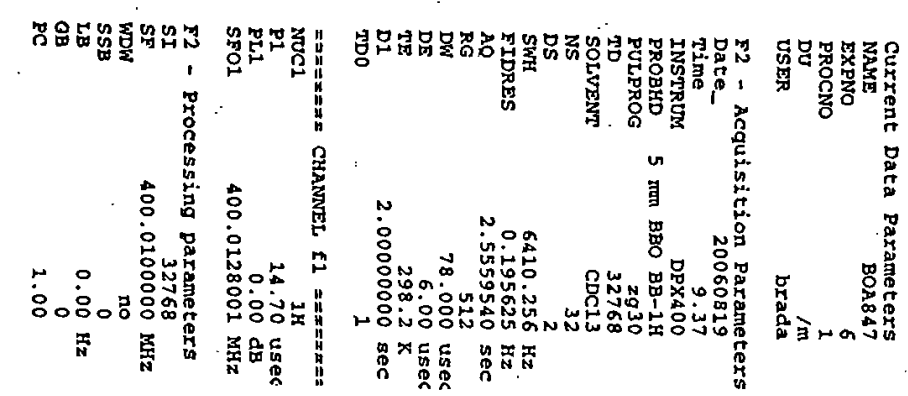




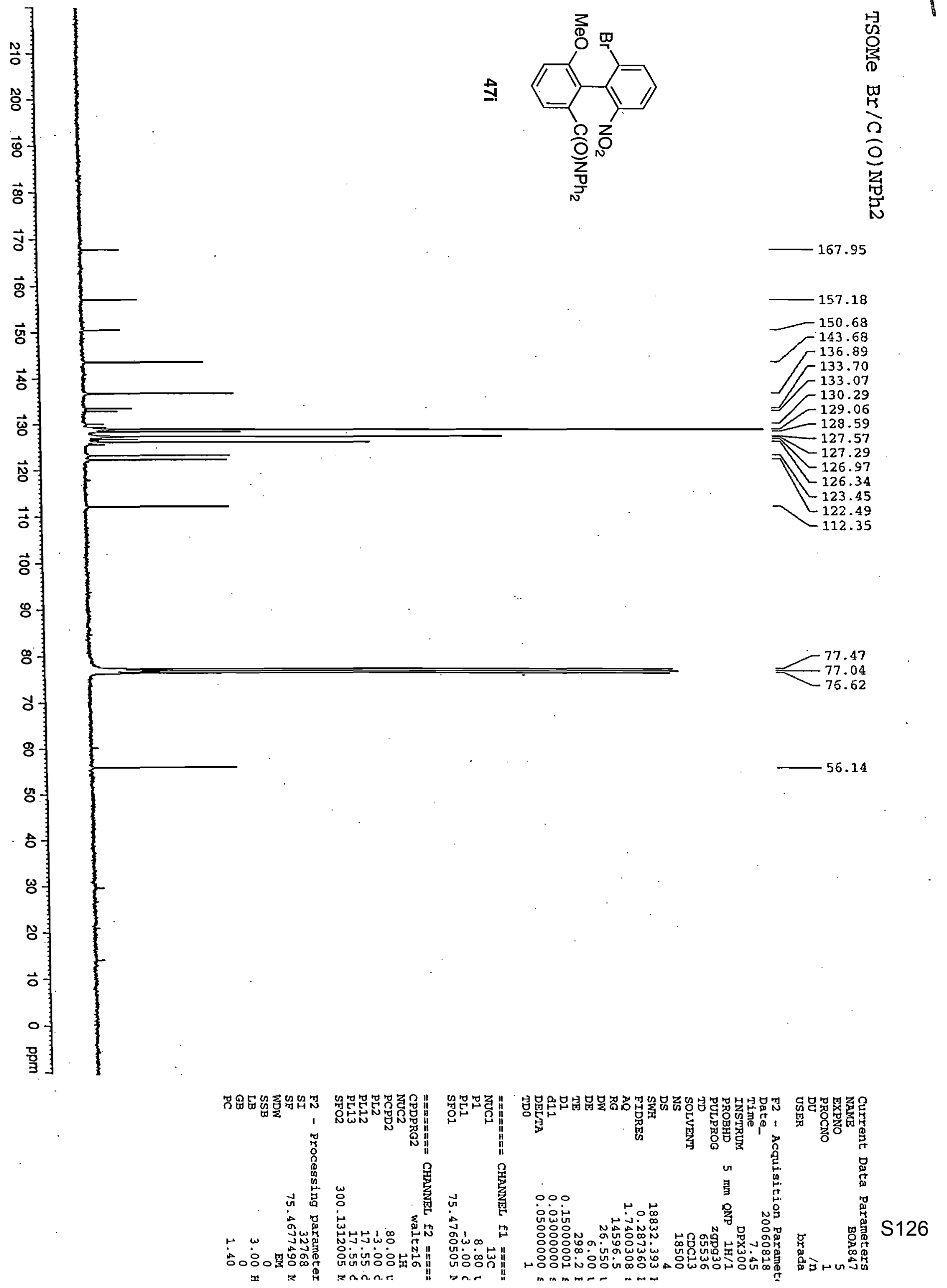




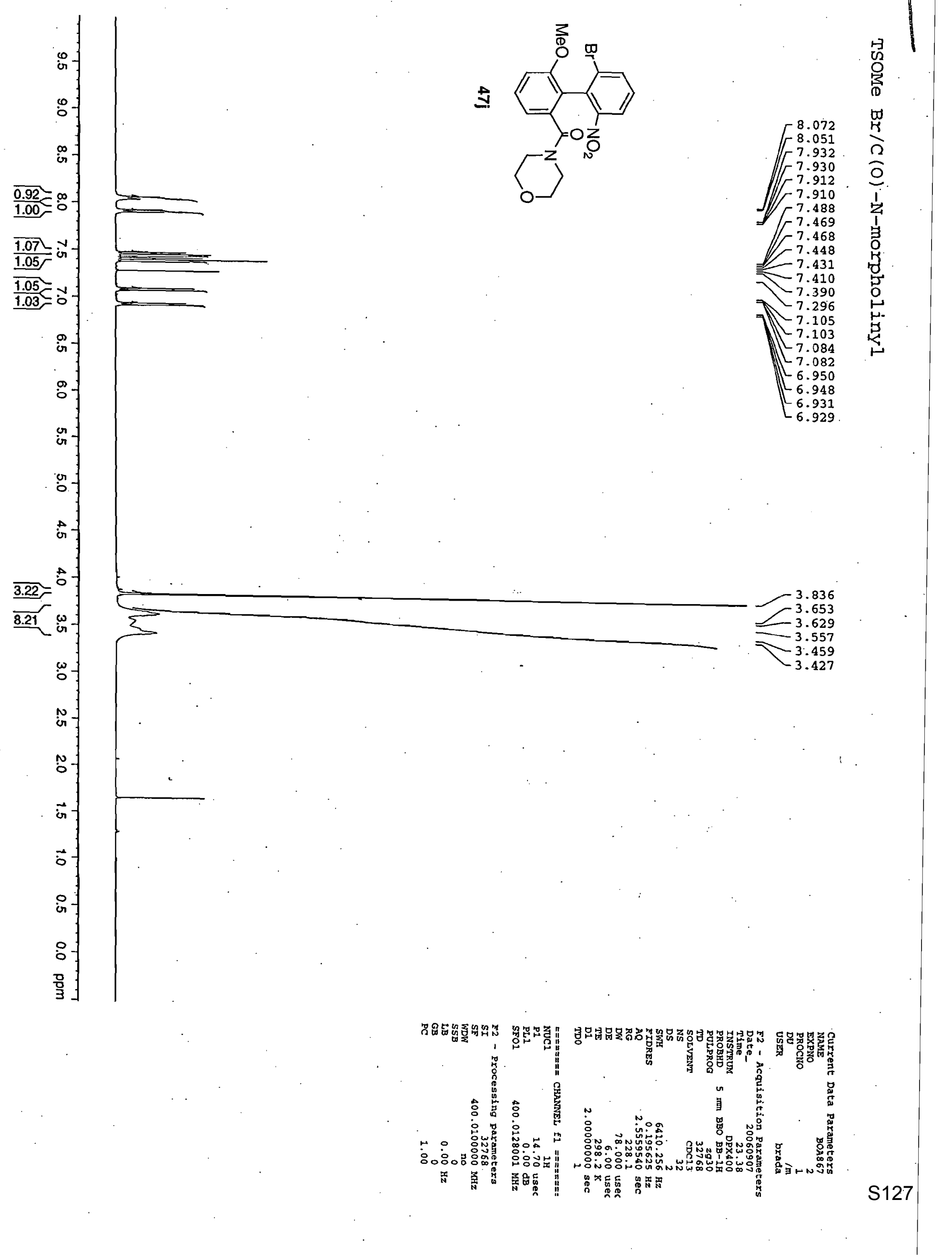



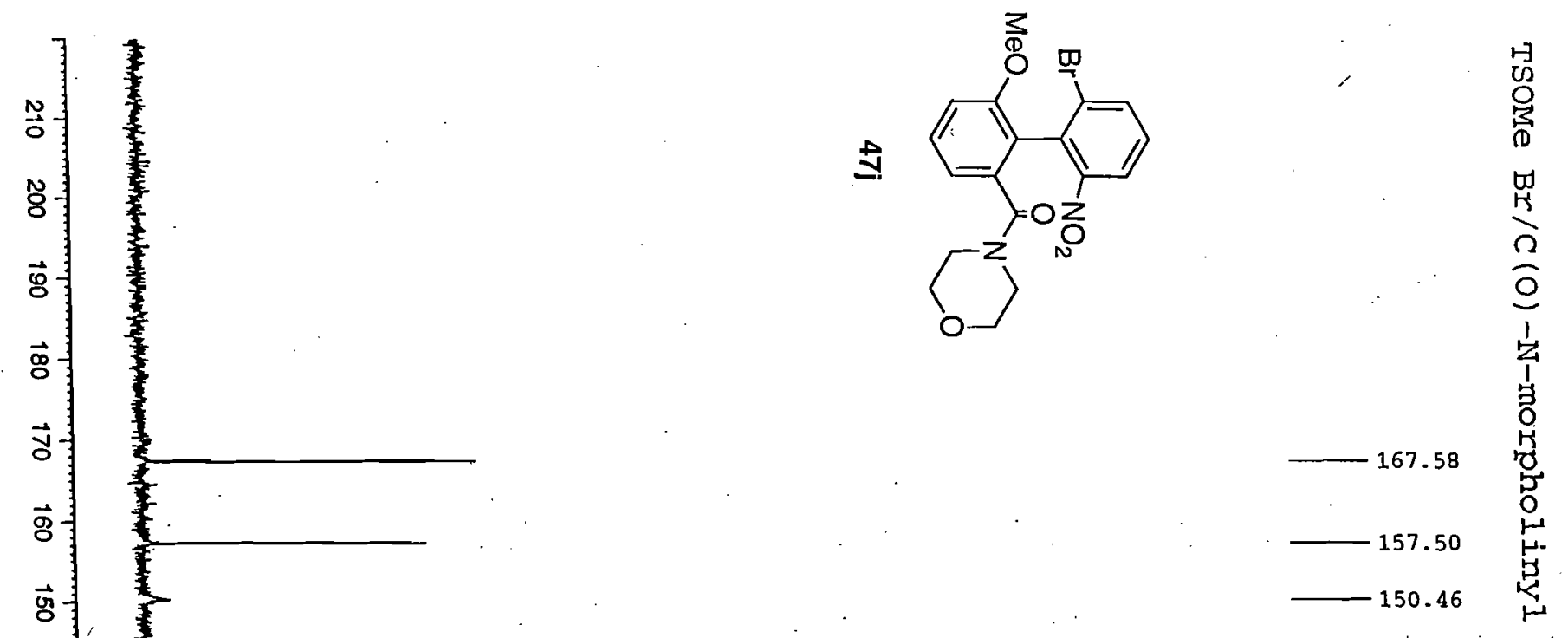

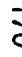

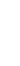

\section{.}

.

s 

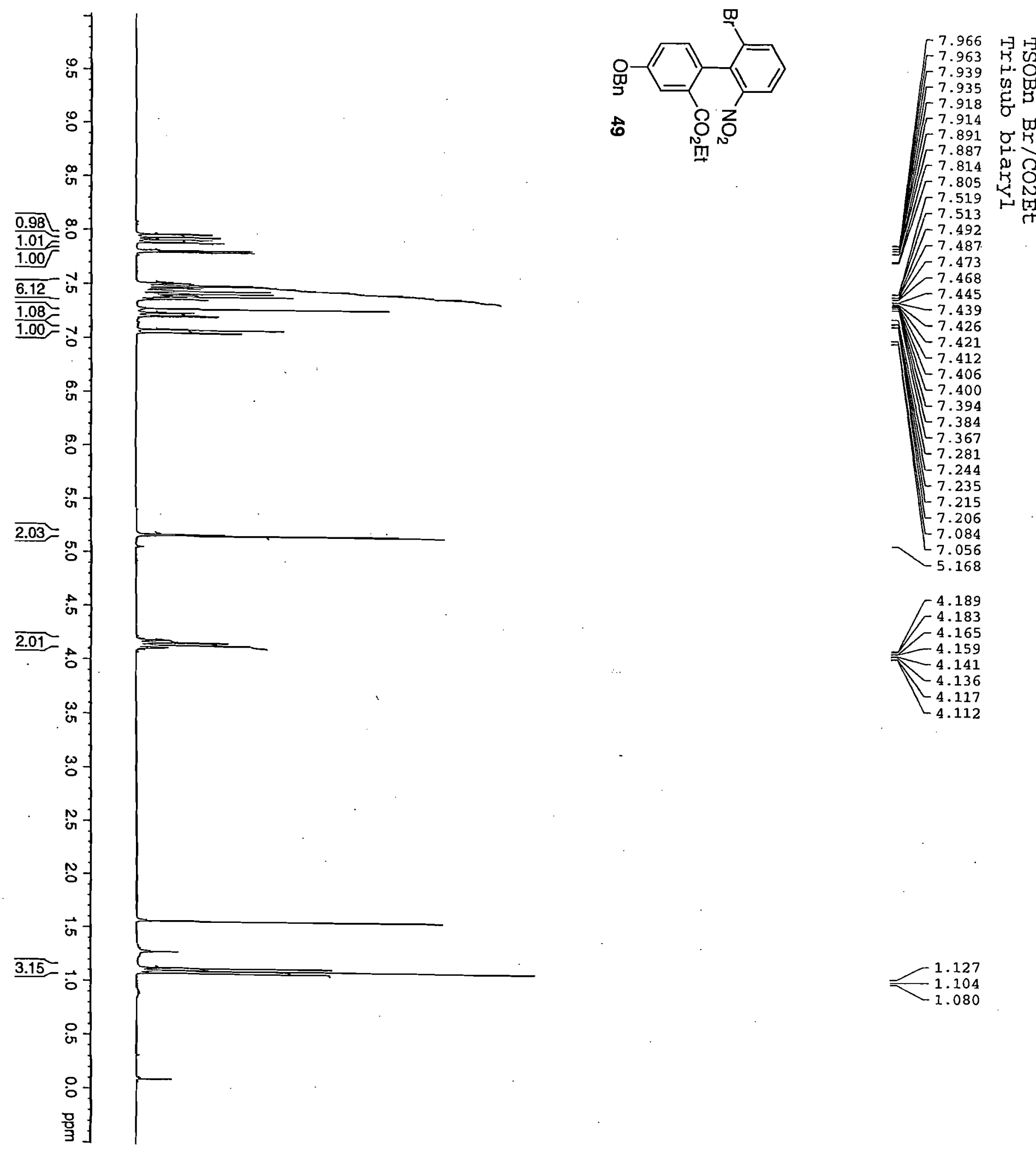

㩆

of

it

7.487

7.473

7.468

7.445

$-7.439$

$-7.426$

$-7.421$

7.406

7.400

$-7.394$

$-7.384$

$-7.367$

7.281

$-7.244$

[7.235

$-7.215$

$-7.206$

$-7.084$

7.056

$-5.168$

4.189

4.183

4.165

$-4.159$

$-4.136$

$-4.117$

$-4.112$

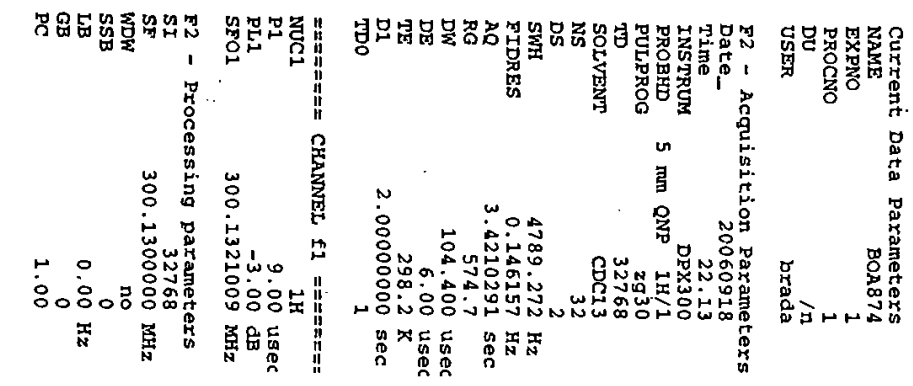



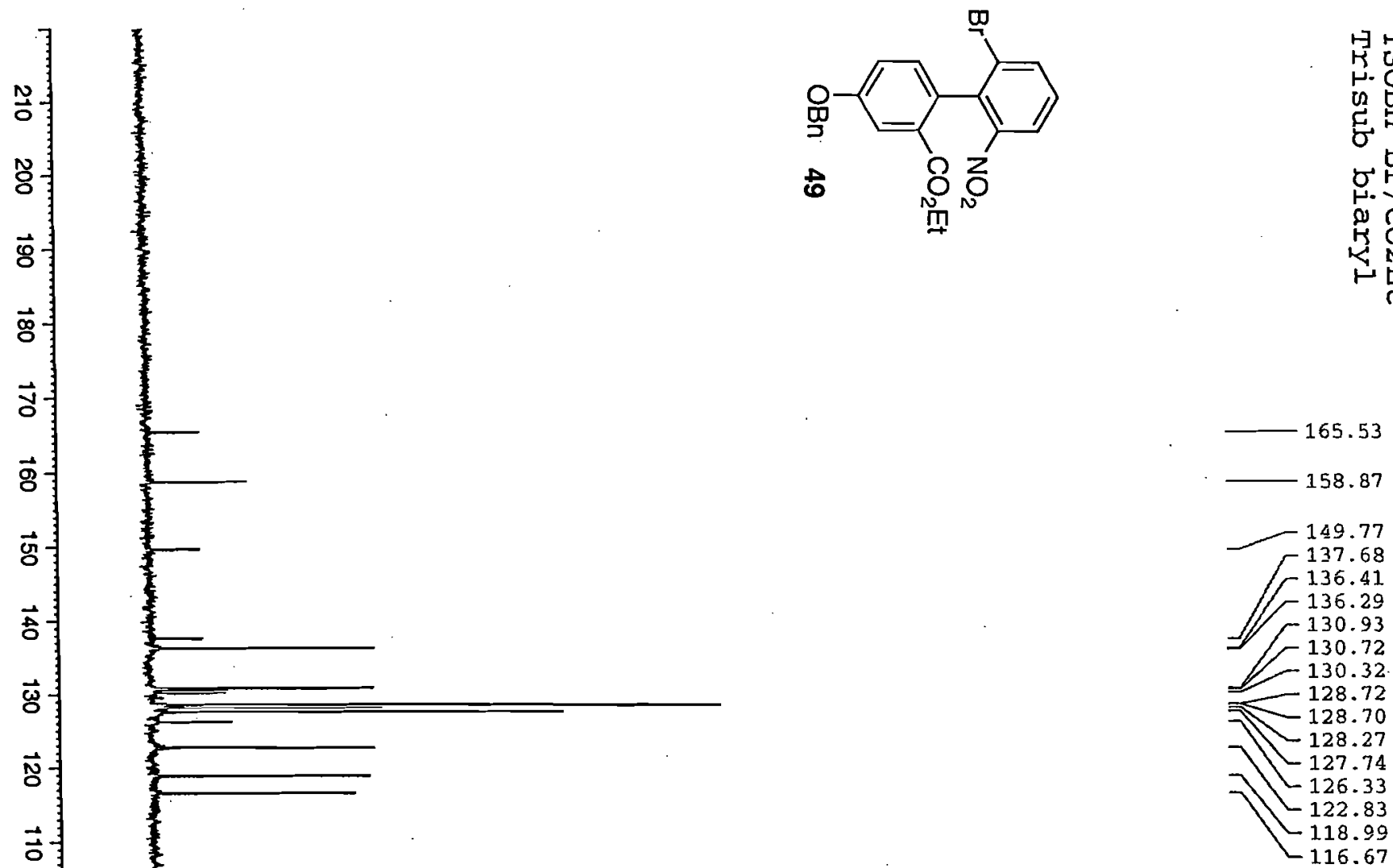

8

용

ㅇ

s

N

ㅎ

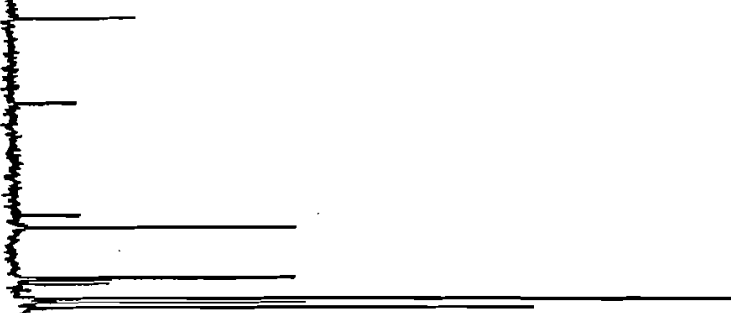

$\overrightarrow{\mathbb{O}}=$

$\vec{\sigma}$

용

8

\&

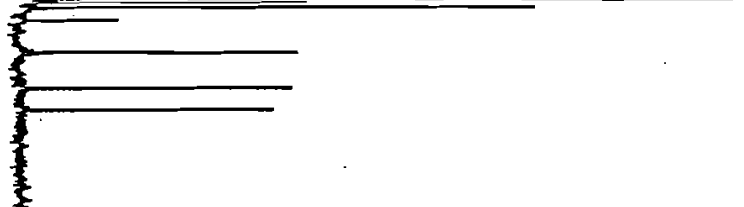

77.44

77.02

70.40

61.07

$-13.78$

묵

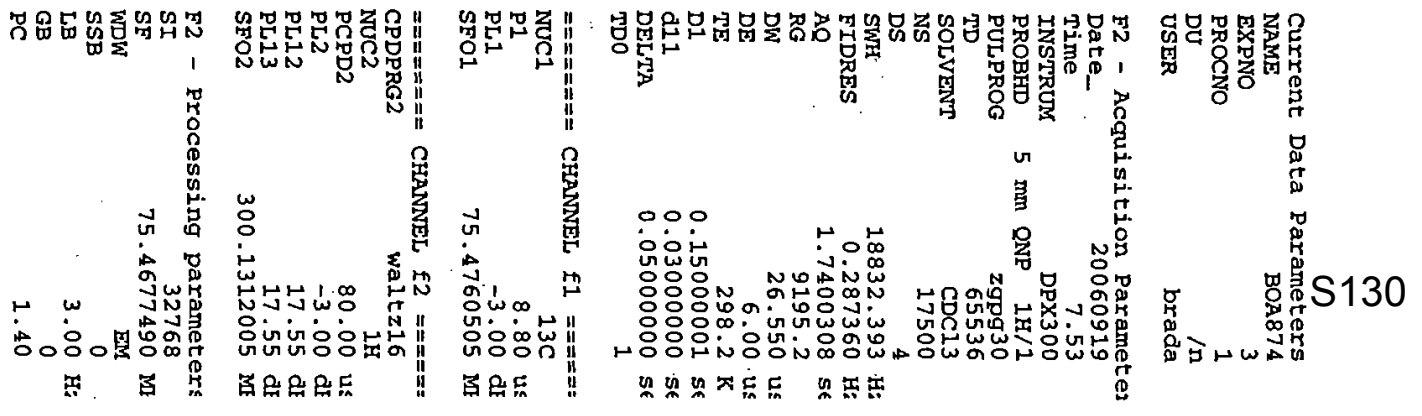



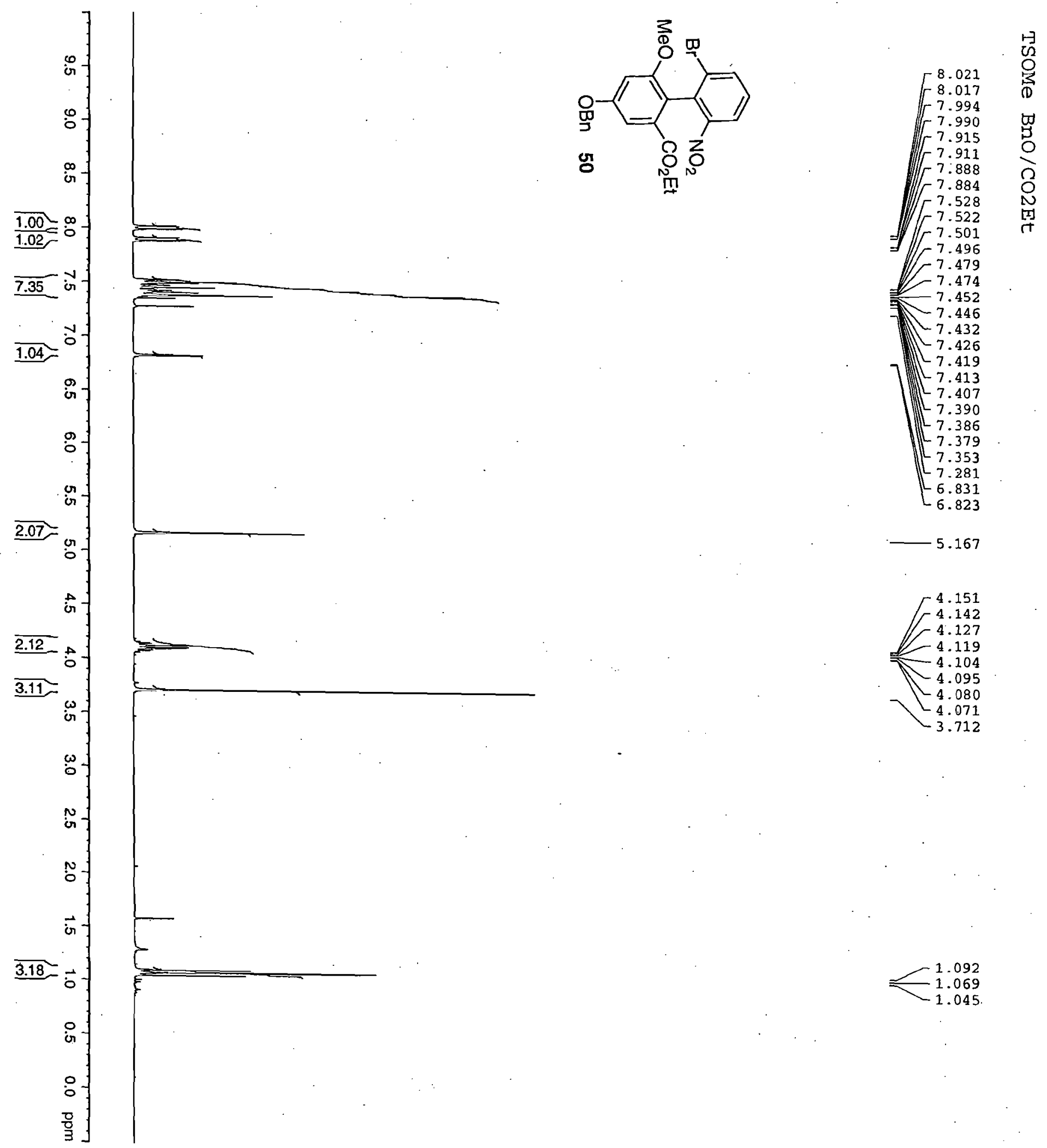

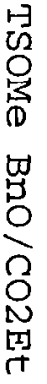

r 7.591 7.479
7.474

7.452
7.446
7.432

$-7.432$

$-7.426$

$-7.413$

-7.407

7.390

L 7.386

[7.389

7.353

7.281

$-6.831$

6.823

$-5.167$

Г.151

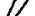

4.127
-4.119

$-4.104$

$-4.095$

$-4.080$

$-4.071$

$-3.712$

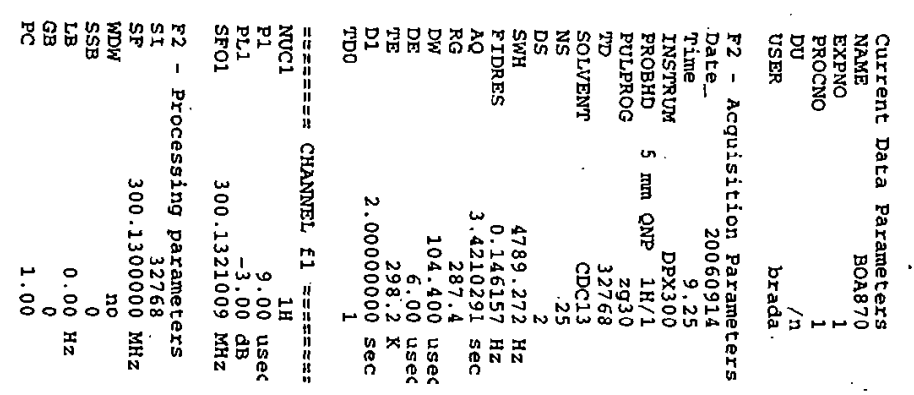



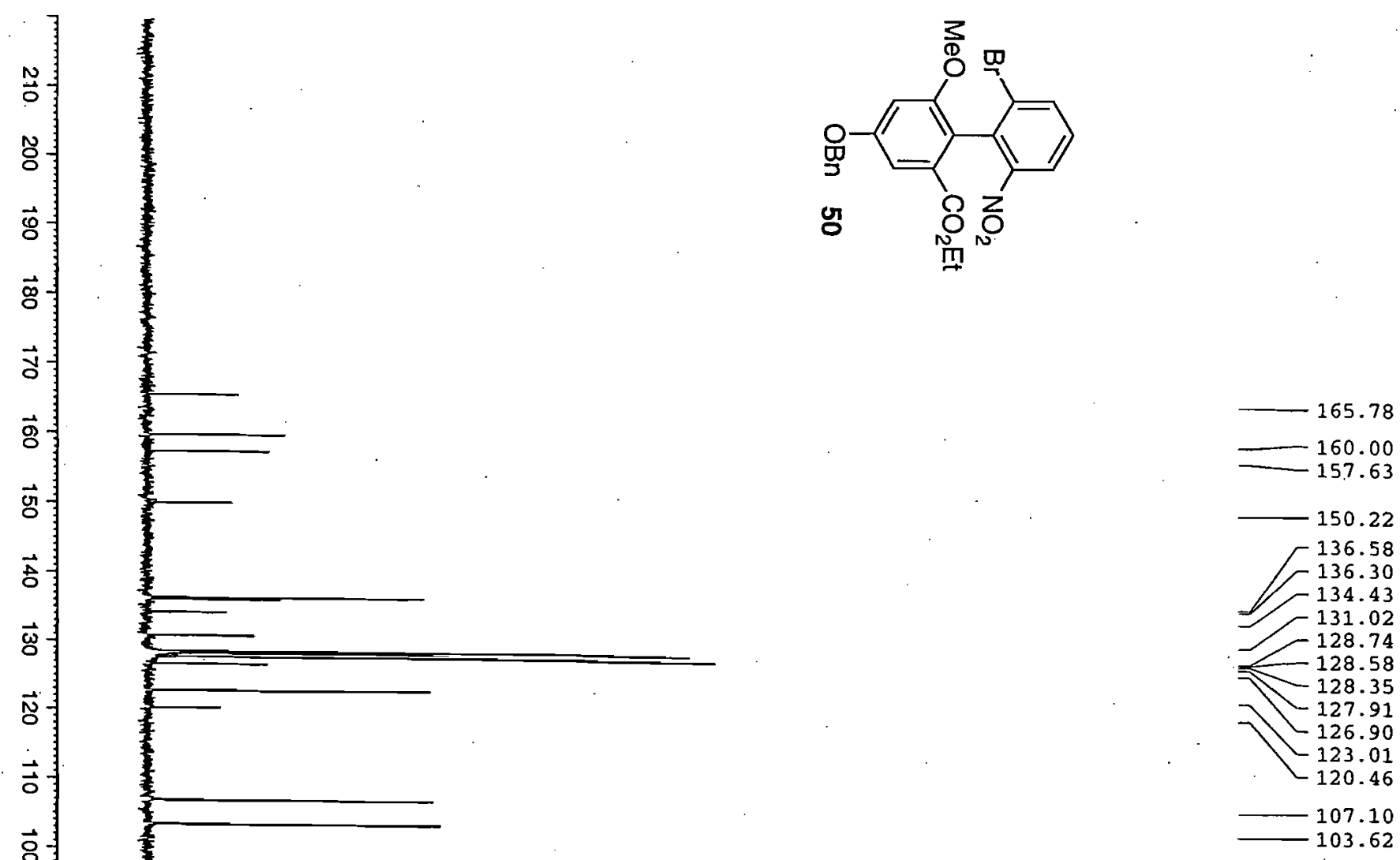

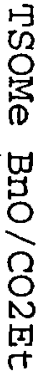

$\vec{\delta}$

8

뵹

$\vec{\Delta}$

$\vec{\omega}$

$\vec{\nabla}$

宁

$\overrightarrow{8}$

8

\&

ơ

8

on

음

w

N-

후

영
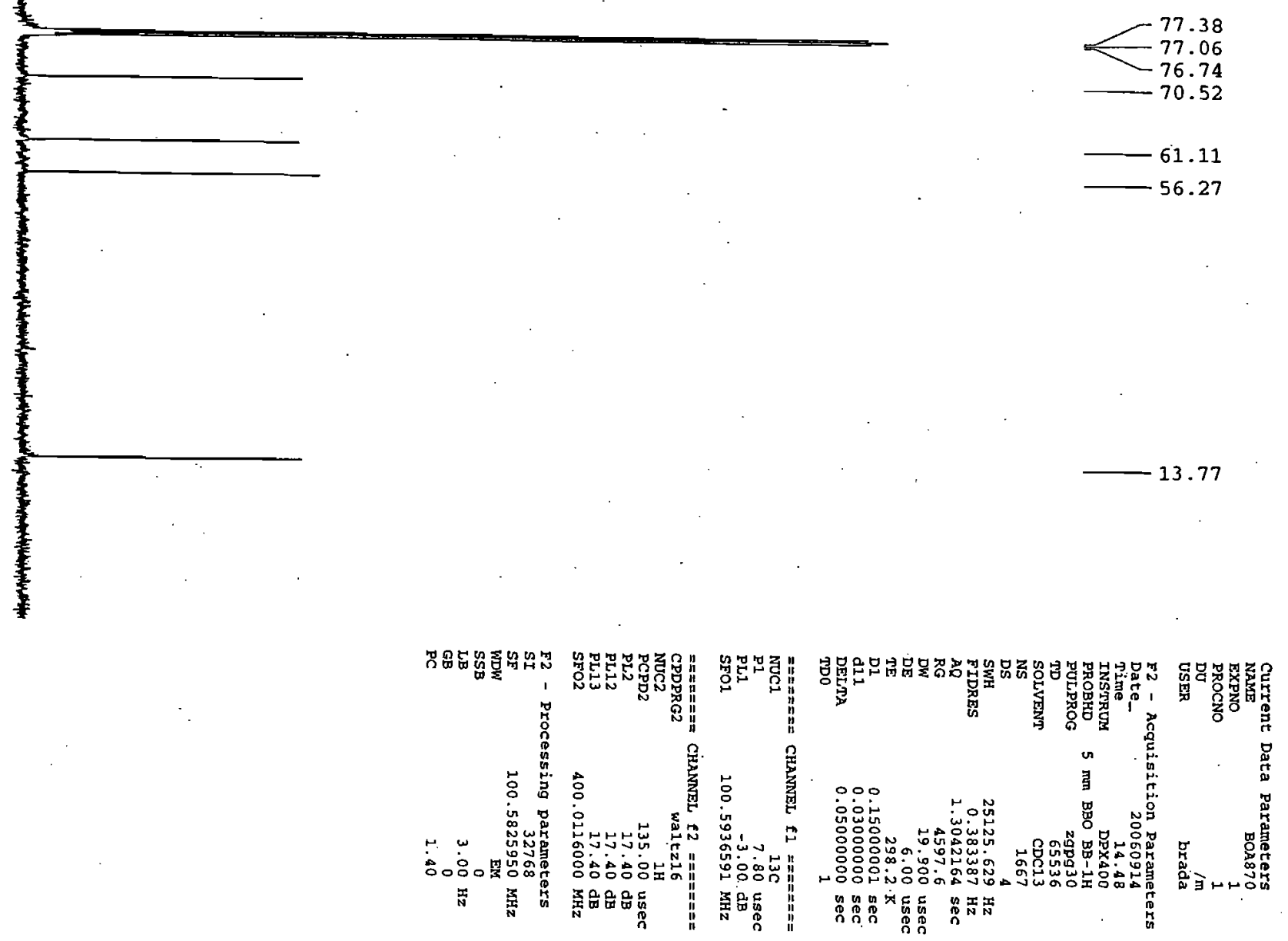

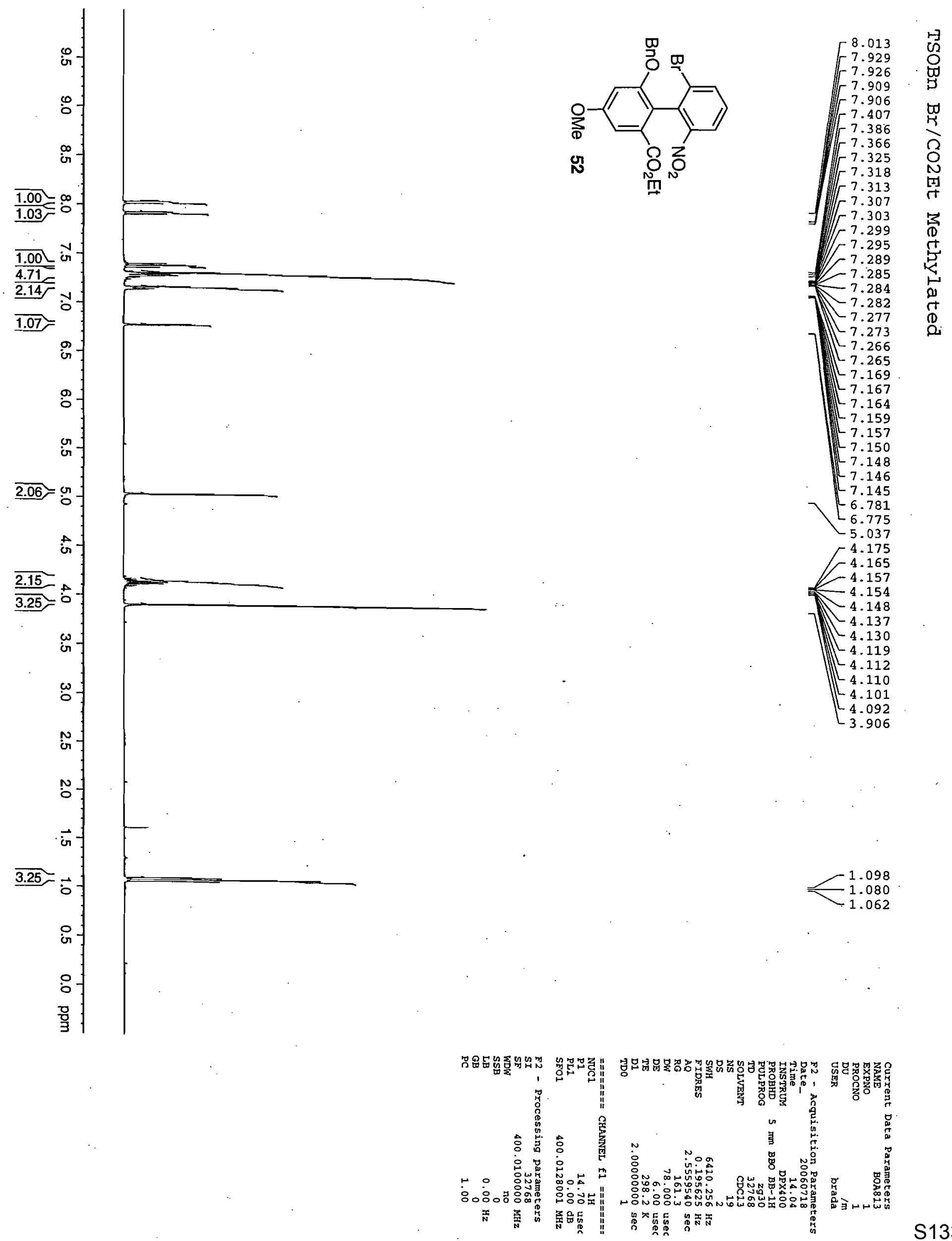

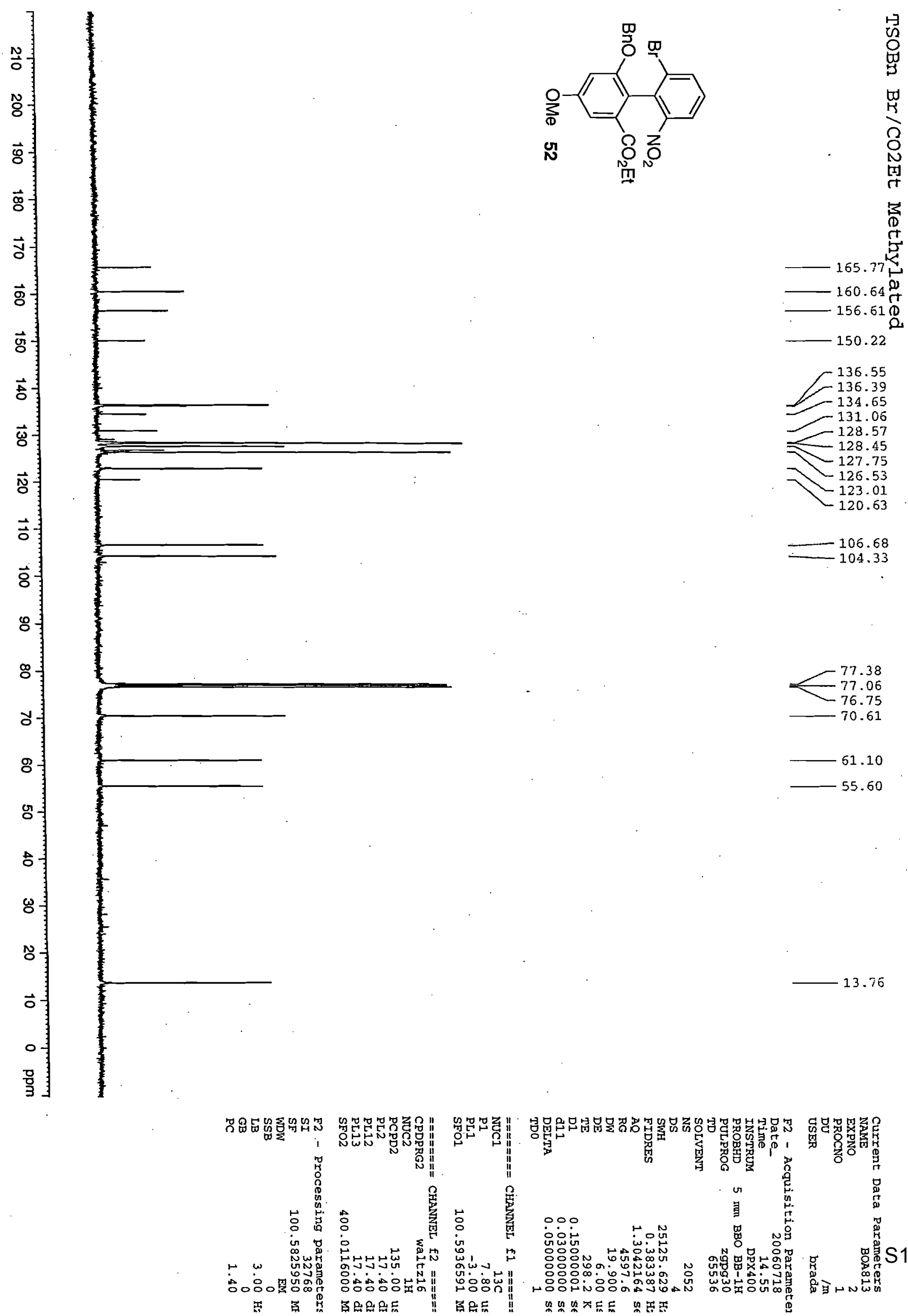

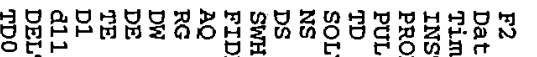

77.38

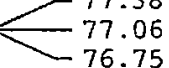

51.10

55.60

$-13.76$
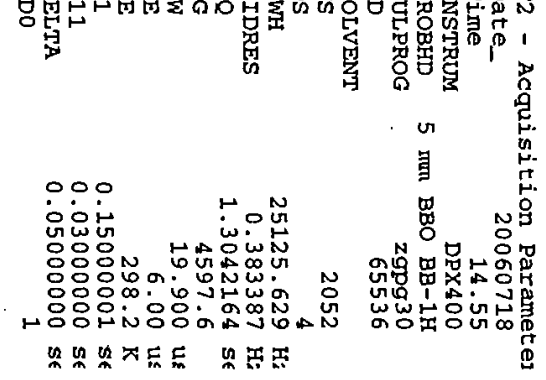

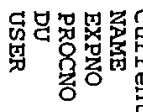

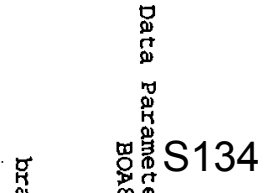

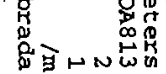




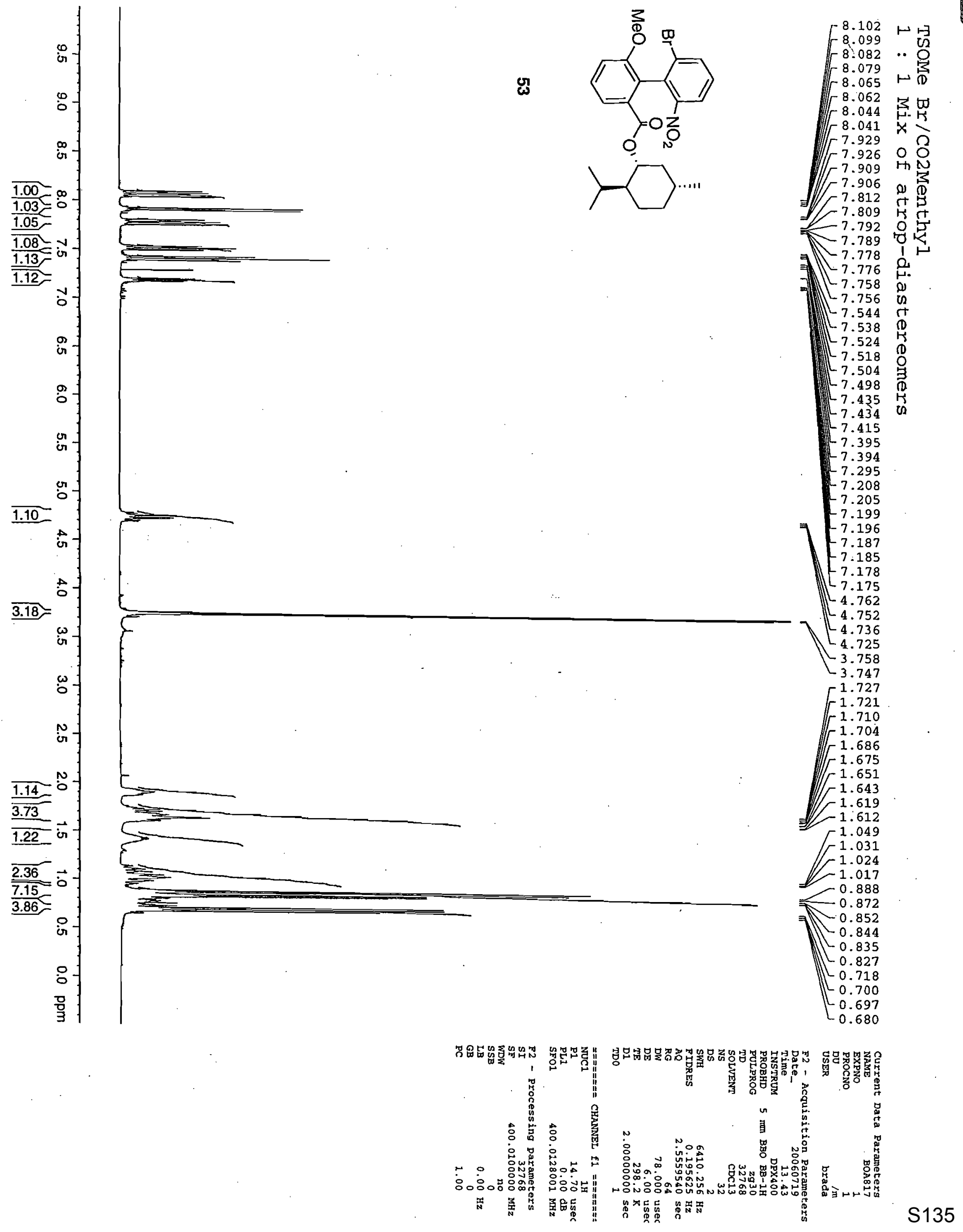




$$
E^{E}
$$




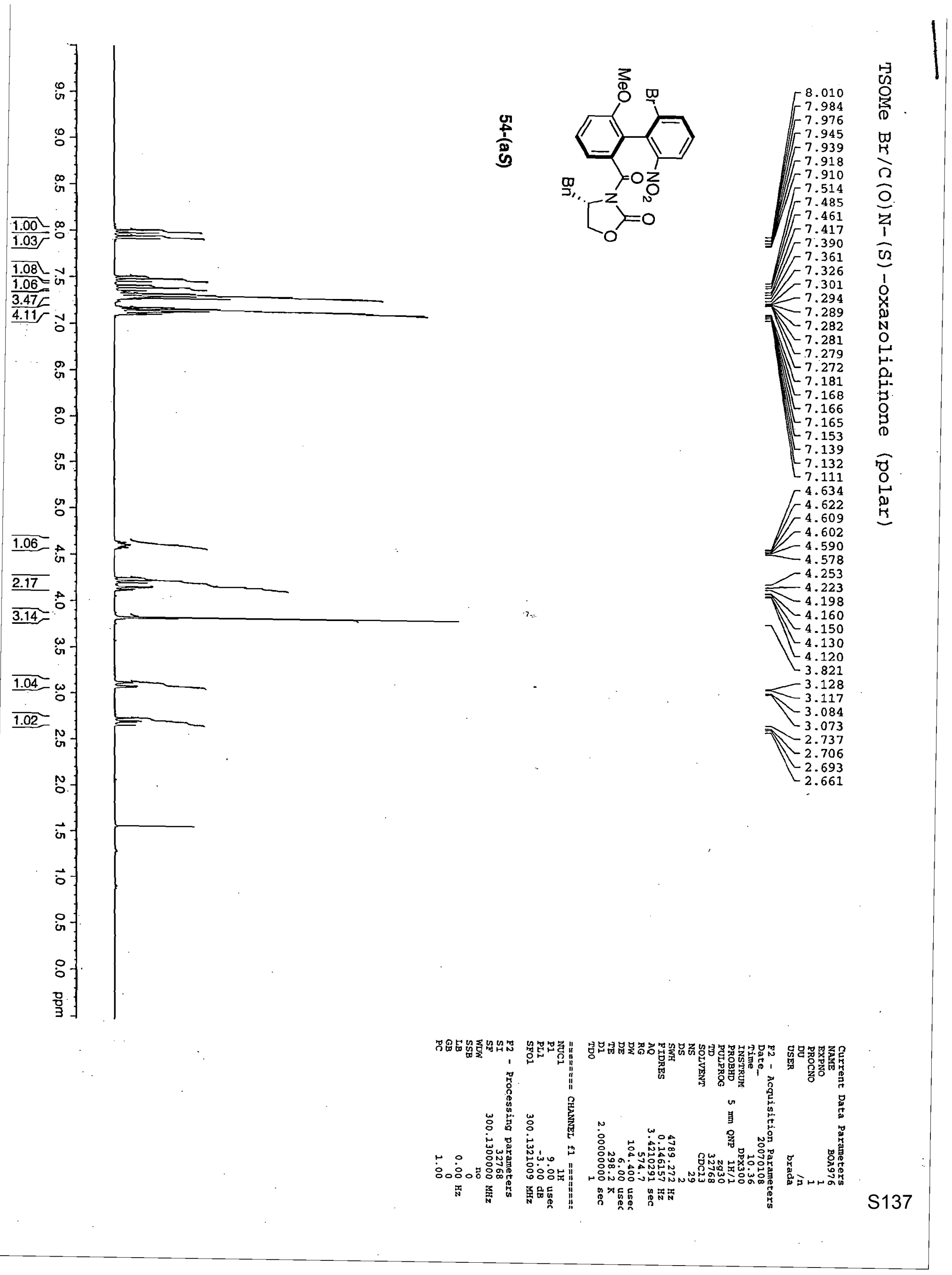



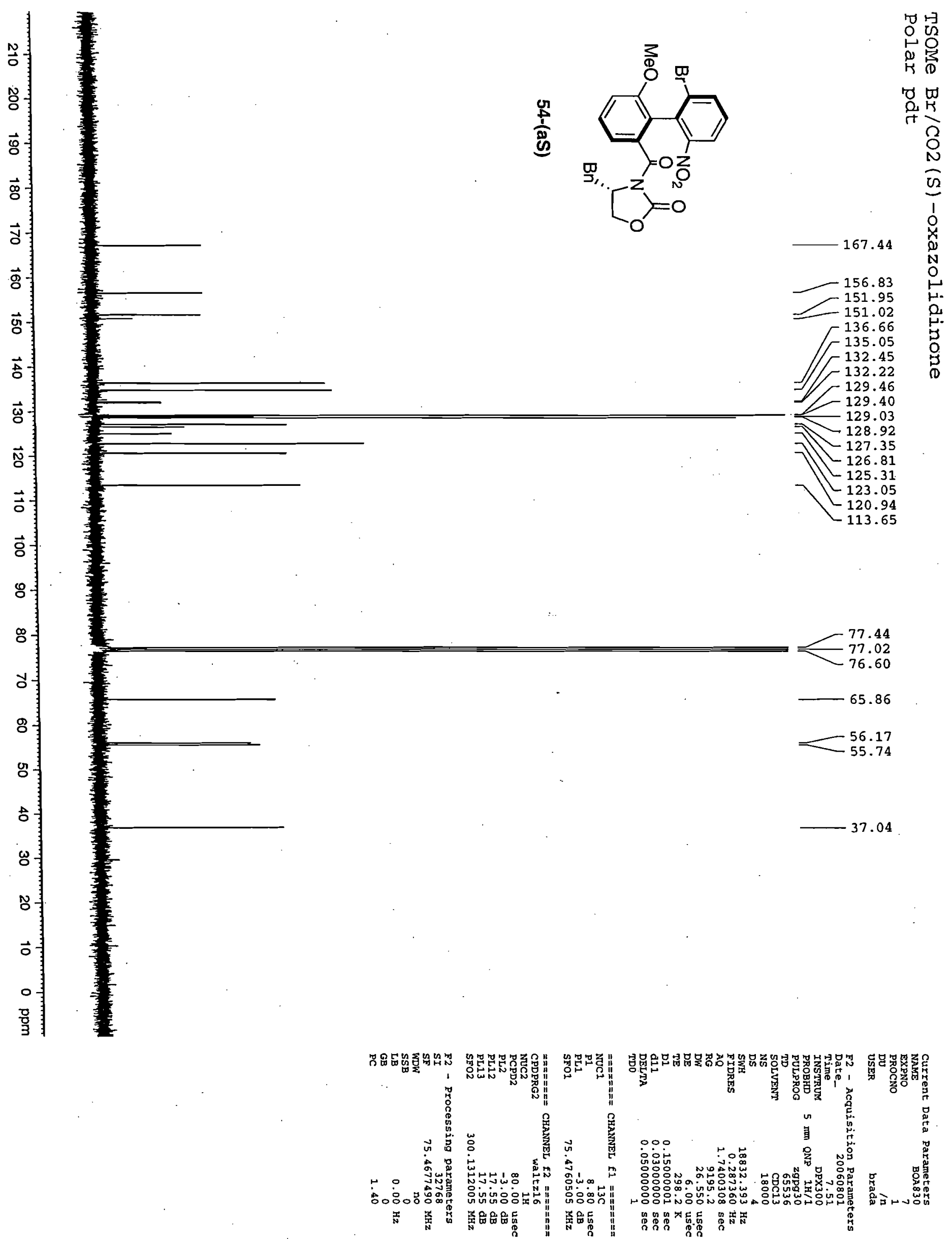


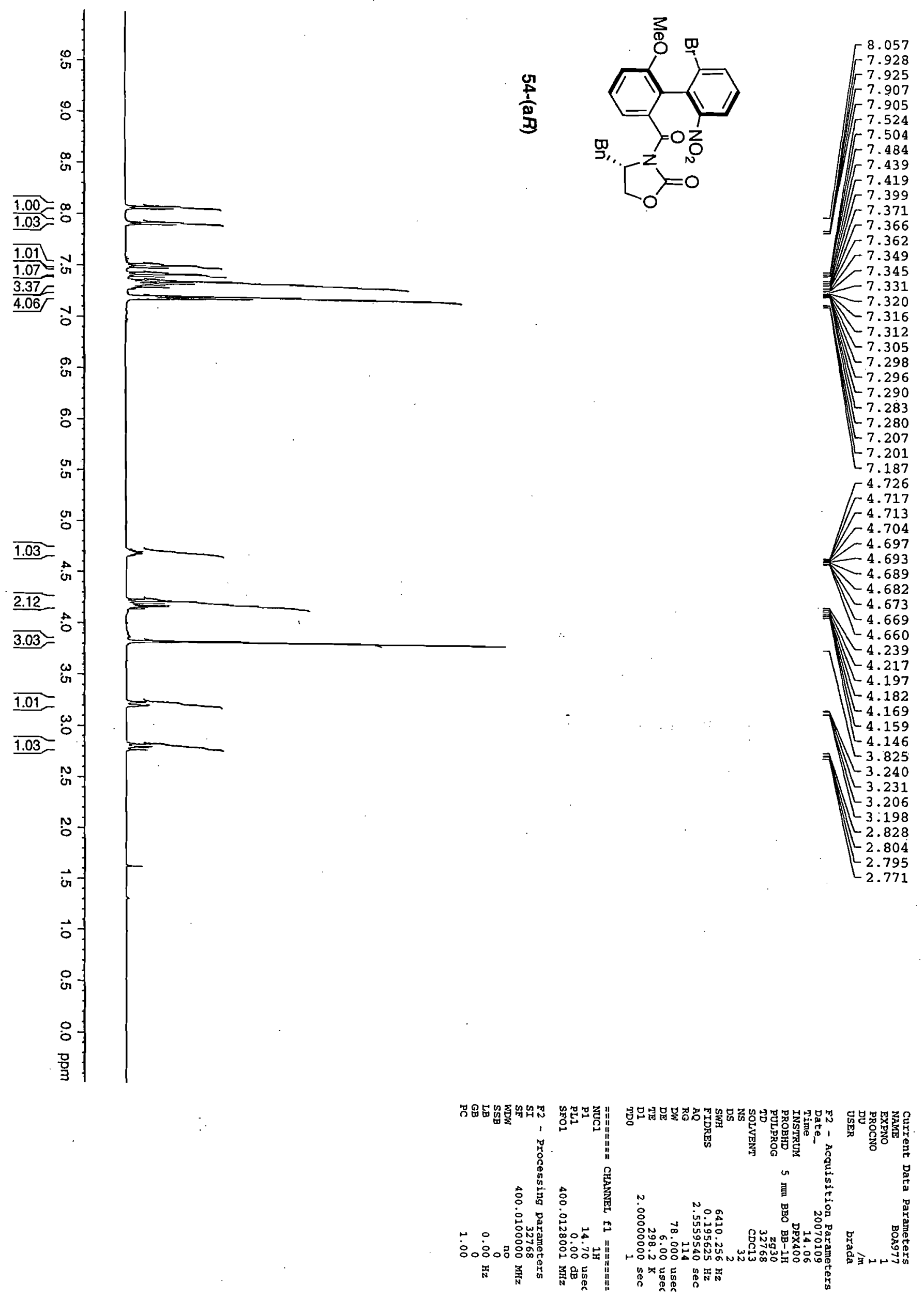

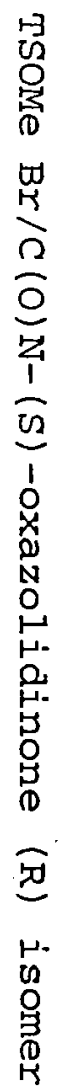



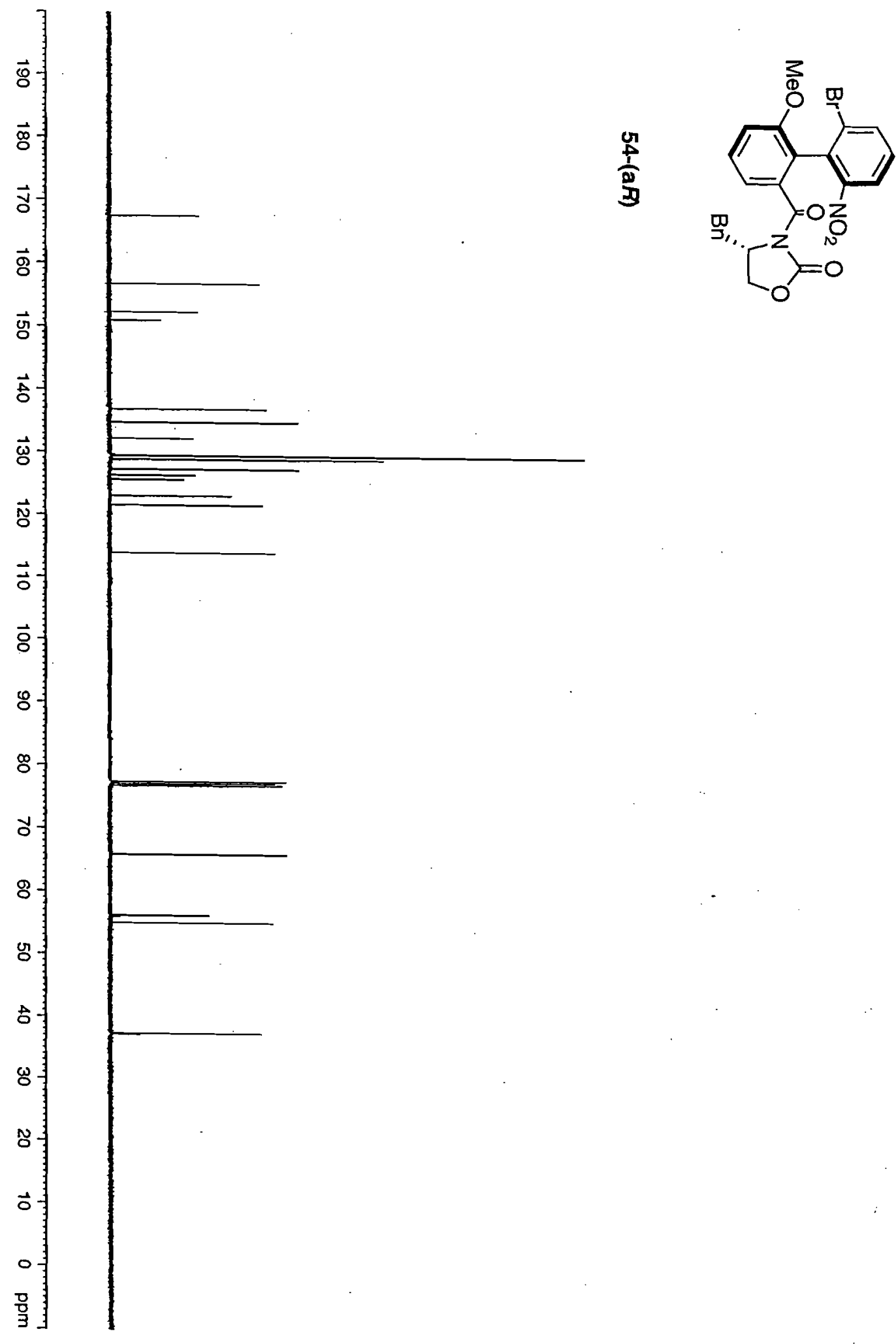

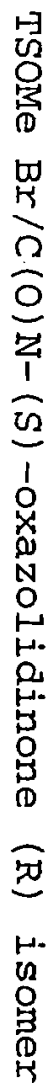

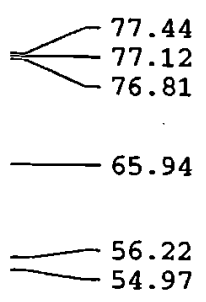

37.23

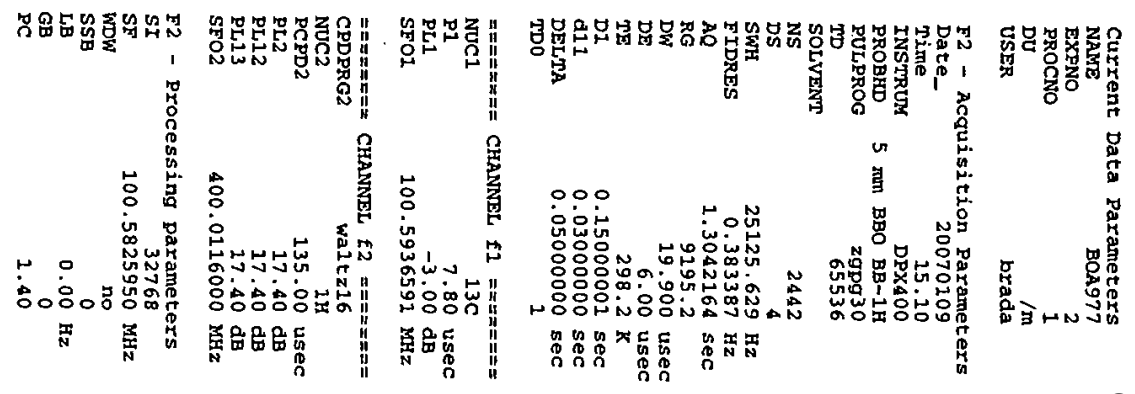



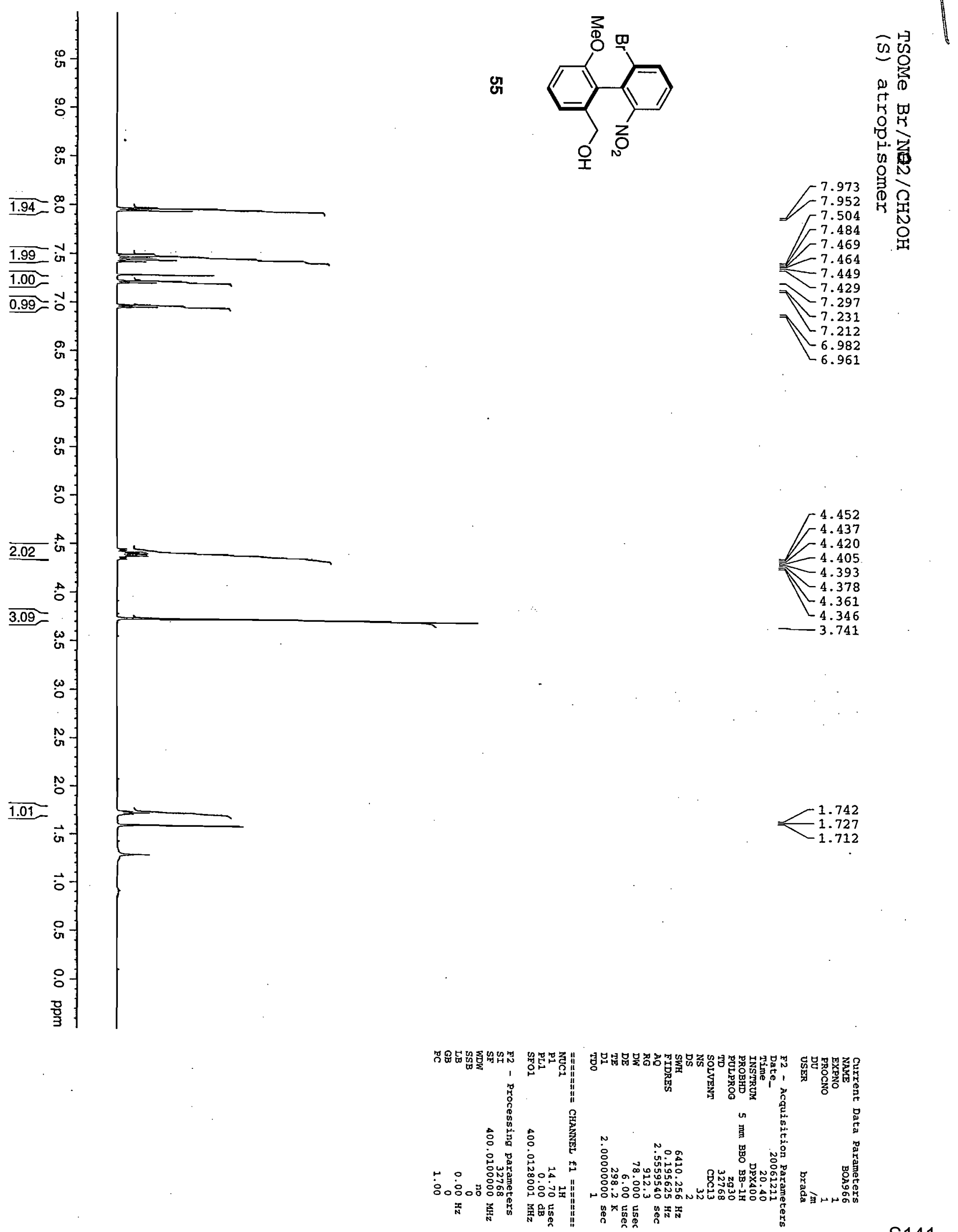


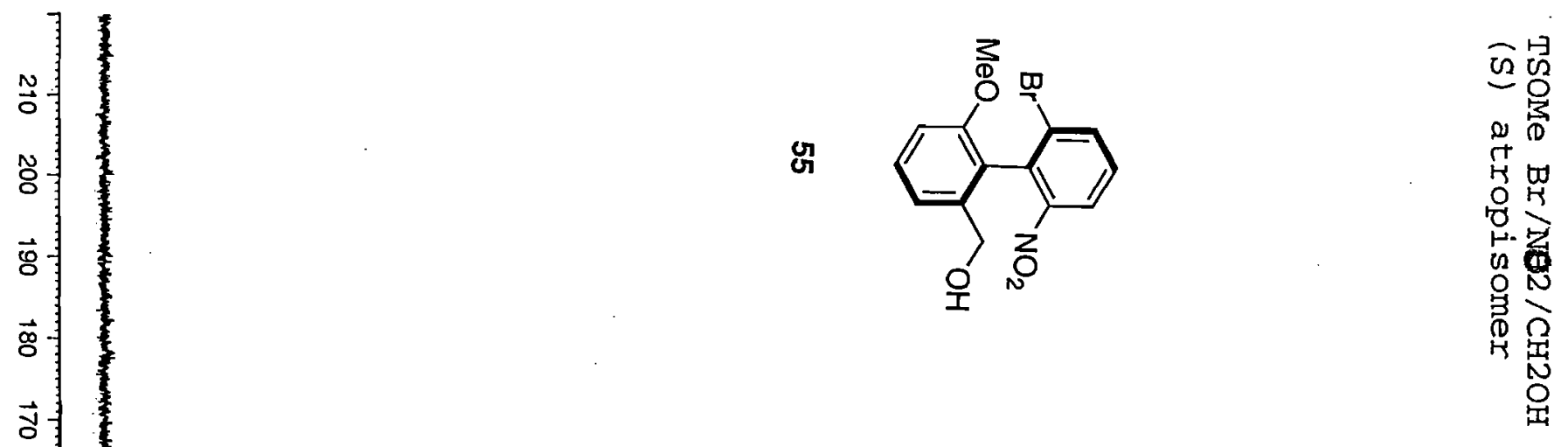

8

ச̆

$\vec{\Delta}$

$\vec{\omega}$

$\overrightarrow{0}$

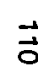

$\overrightarrow{8}$

8

\&

o

8

\%

\&

$\omega$

s

$\overrightarrow{0}$

역

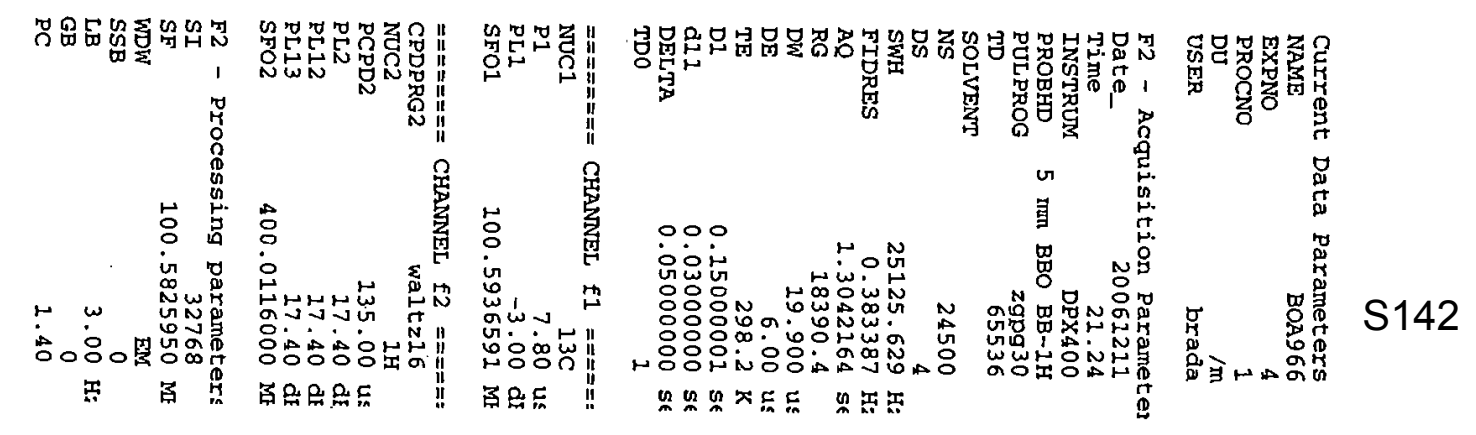




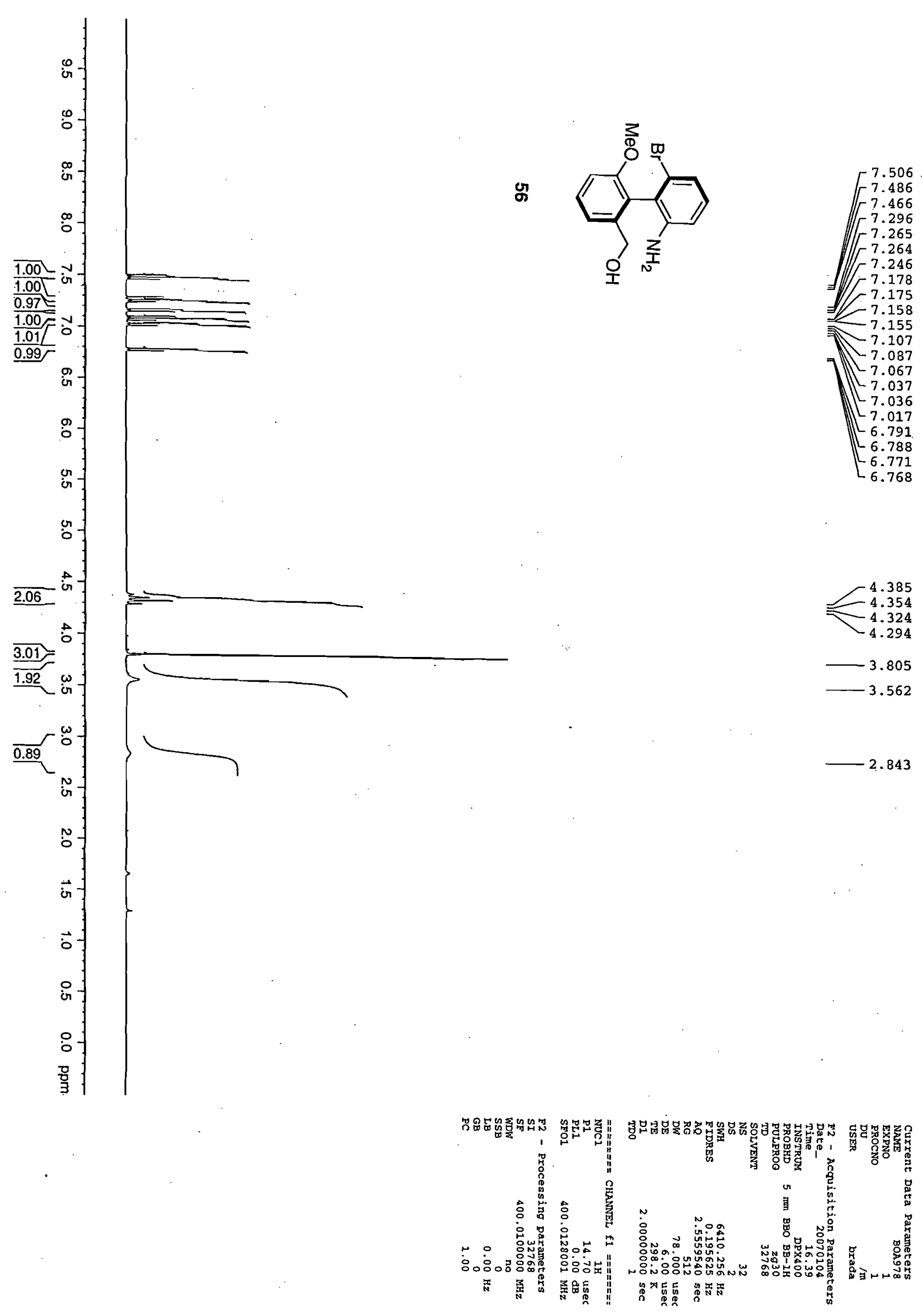

봉
点
D

思

蛋

웅

焉

菬

$\widehat{Q}$

N.

号

$H$

6.791

.

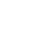

4.385

.805

.

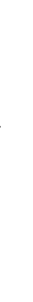

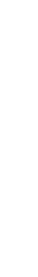




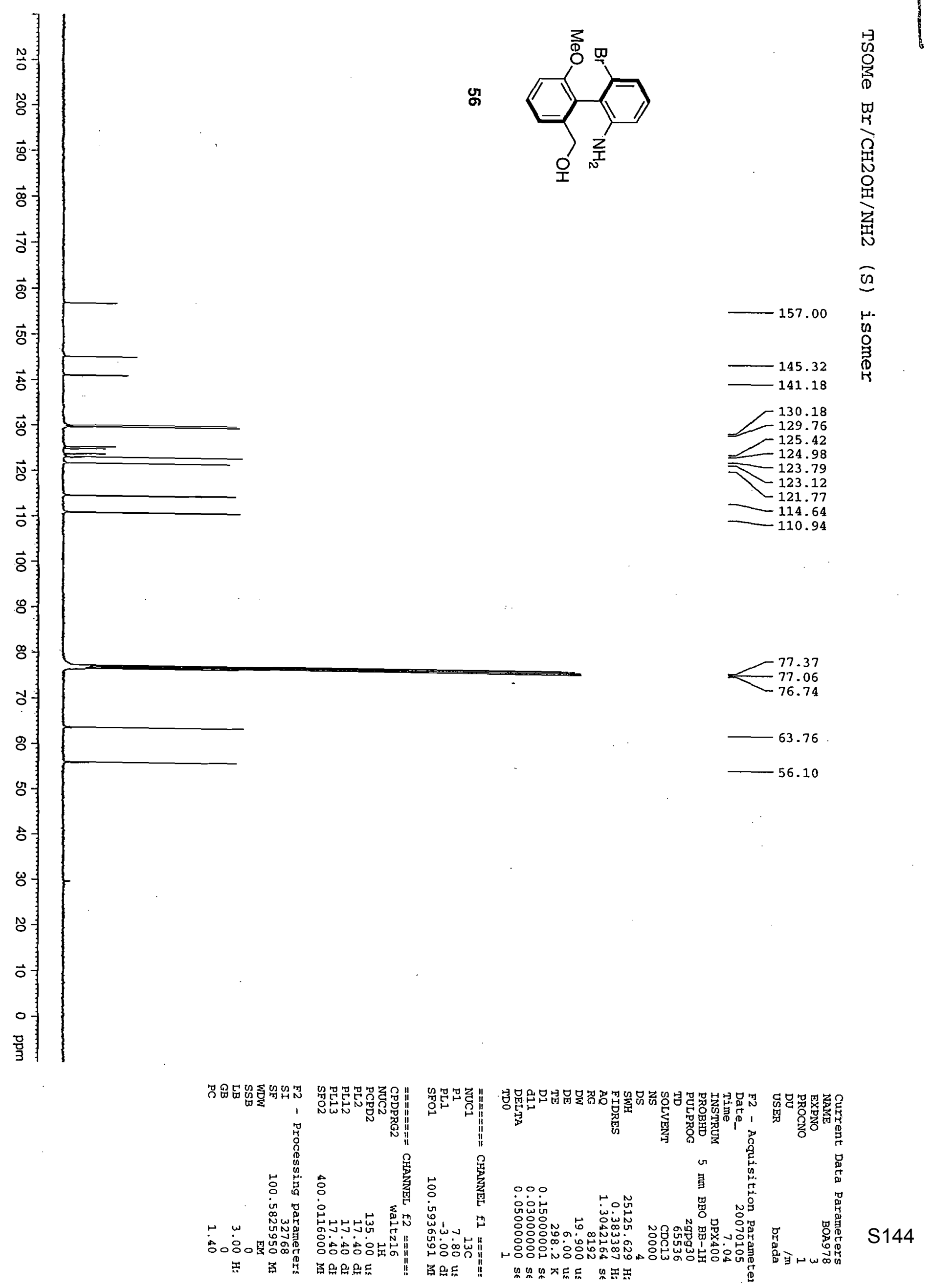



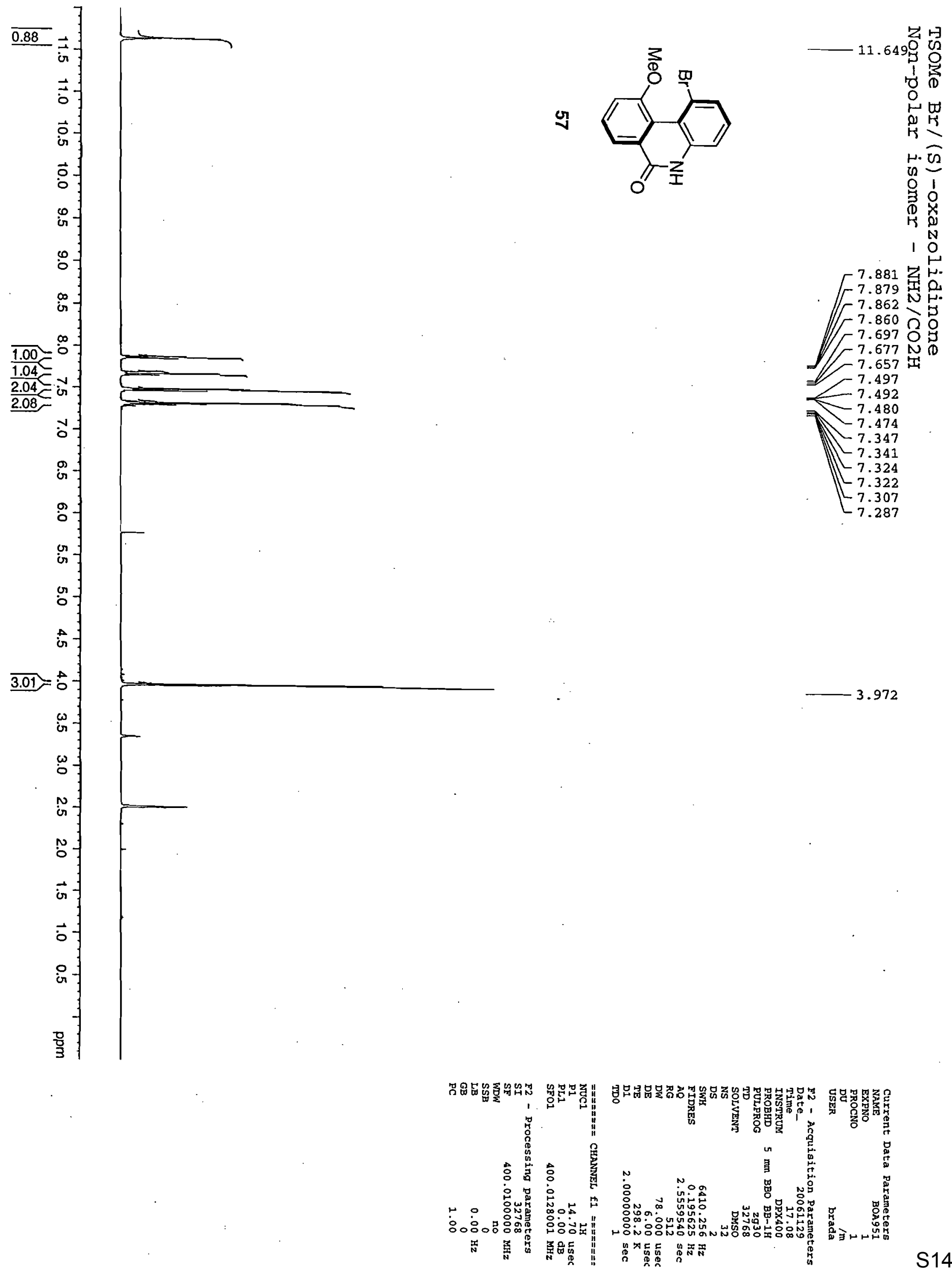
:
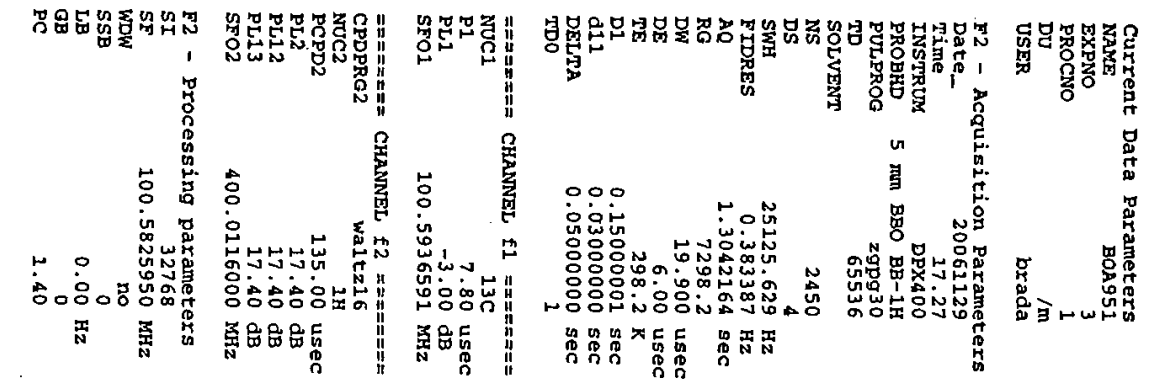

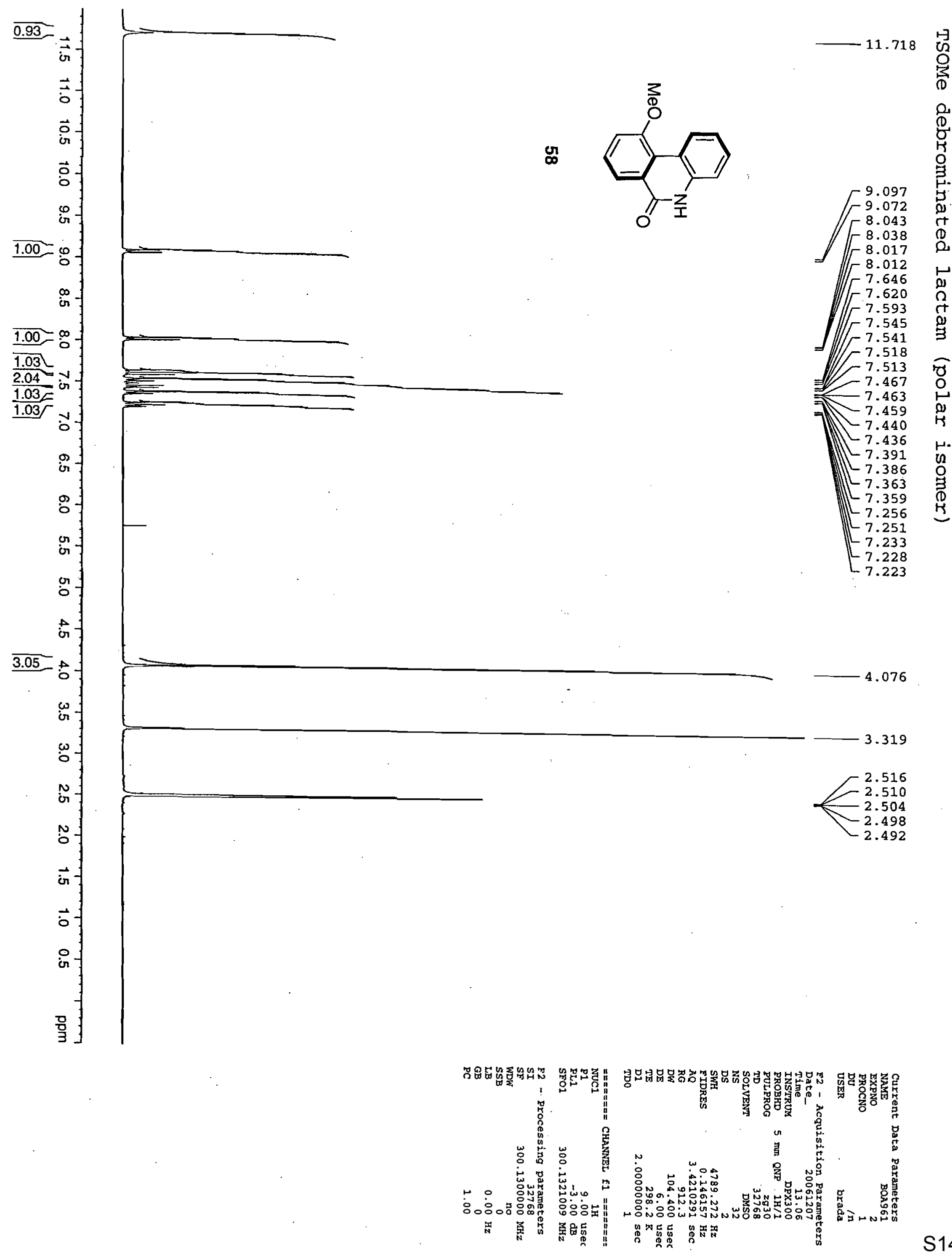

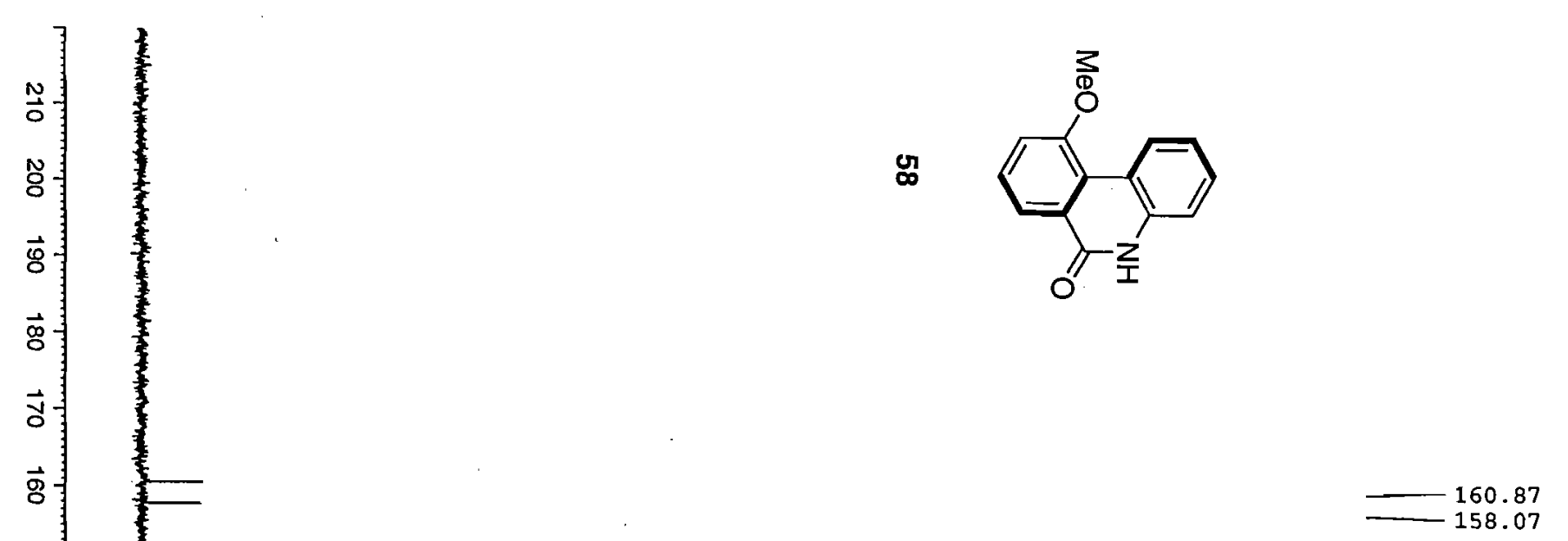

星

$\vec{\sigma}$

홍

공

흥

$\vec{\Phi}$

$\overrightarrow{0}$

홍

$\overrightarrow{8}$

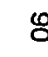

\&

ช

g

on

음

$\omega$

N

$\overrightarrow{0}$

묵

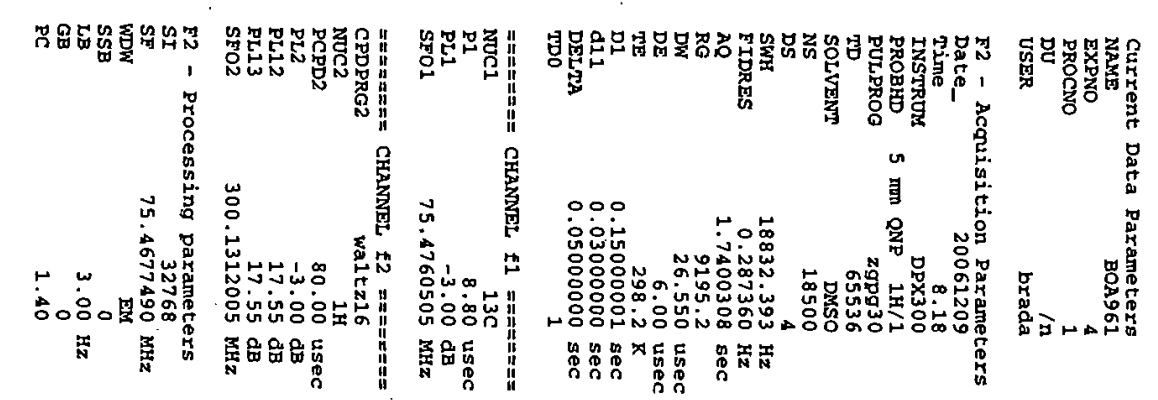

